\title{
A domestic solar/heat pump heating system incorporating latent and stratified thermal storage
}

\section{Christoph Trinkl}

PhD

2006 


\title{
A domestic solar/heat pump heating system incorporating latent and stratified thermal storage
}

\author{
Christoph Trinkl
}

\author{
A thesis submitted in partial fulfilment \\ of the requirements of De Montfort University \\ for the degree of Doctor of Philosophy (PhD)
}

December 2006

Institute of Energy and Sustainable Development

De Montfort University Leicester

Centre of Excellence for Solar Engineering Ingolstadt University of Applied Sciences 


\section{Abstract}

Both solar and heat pump heating systems are innovative technologies for sustaining ecological heat generation. They are gaining more and more importance due to the accelerating pace of climate change and the rising cost of limited fossil resources. Against this background, a heating system combining solar thermal collectors, heat pump, stratified thermal storage and water/ice latent heat storage has been investigated.

In order to investigate and optimise the heating system, a dynamic system simulation model was developed. On this basis, a fundamental control strategy was derived for the overall co-ordination of the heating system with particular regard to the performance of the two storage tanks. In a simulation study, a fundamental investigation of the heating system configuration was carried out and optimisation derived for the system control as well as the selection of components and their dimensioning. The influence of different parameters on the system performance was identified, where the collector area and the latent heat storage volume were found to be the predominant parameters for system dimensioning.

For a modern one-family house, a solar collector area of $30 \mathrm{~m}^{2}$ and a latent heat store volume of $12.5 \mathrm{~m}^{3}$ are proposed. In this configuration, the heating system reaches a seasonal performance factor of 4.6 , meaning that $78 \%$ of the building's and users' heat demand are delivered by solar energy. The results show that the solar / heat pump heating system can give an acceptable performance using up-to-date components in a state-ofthe-art building.

A novel but most significant component of the heating system is the latent heat store, working with water / ice as phase change material. For that reason, the store was developed in a systematic manner with special regard to the heat exchangers. Based on a detailed specification and a functional analysis, concept solutions were investigated and evaluated. A sheet matrix heat exchanger was eventually chosen as it fulfils the specialised requirements of the heating system. The heat exchanger's behaviour and its performance during phase change were analysed in laboratory tests. In addition, a storage tank design was developed and a preliminary storage dimensioning carried out for the heating system as defined by the simulations, showing that five polymer tanks with $3.3 \mathrm{~m}^{3}$ each and 14 sheet matrix heat exchangers in each tank are required. 


\section{Acknowledgements}

This research project was carried out at the Institute of Energy and Sustainable Development at De Montfort University Leicester working in cooperation with the Centre of Excellence for Solar Engineering at Ingolstadt University of Applied Sciences.

I would like to thank Prof. Vic Hanby, Dr. Simon Rees and Prof. Wilfried Zörner for the initiation of this research work, for their excellent support and guidance as well as for their revision of this thesis.

Moreover, I would like to give special thanks to the industrial project partner Ratiotherm, namely to Anton Fellner, Alfons Kruck and Alexander Weidinger for their project idea and their exceptional support during the work. Additionally, I would like to thank Wilfried Melang for enabling the project funding from the German Ministry of Economics and Technology and thereby making this research possible.

Furthermore, I am very grateful to the students and colleagues at the Centre of Excellence for Solar Engineering, especially to Achim Haller and Franz-Dominik Treikauskas, for their extraordinary and enduring assistance and for making university much more than just a place to work. Finally, I would like to thank my parents for their support both during my studies and during this research work, for their encouragement and for always believing in the success of this work.

I declare that the content of this submission is my own work. The contents of the work have not been submitted for any other academic or professional award. I acknowledge that this thesis is submitted according to the conditions laid down in the regulations. Furthermore, I declare that the work was carried out as part of the course for which I was registered. I draw attention to any relevant considerations of rights of third parties. 


\section{Table of Contents}

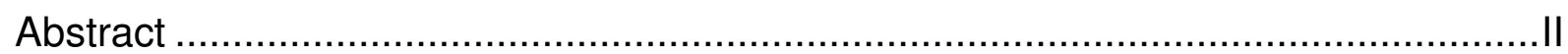

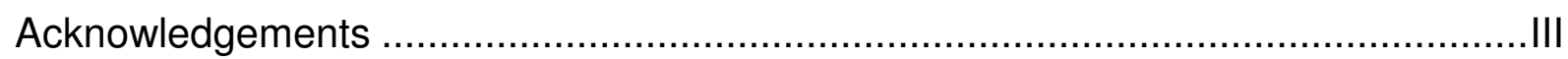

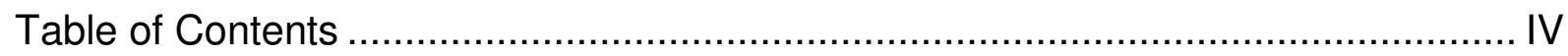

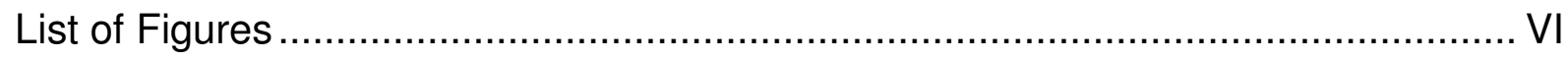

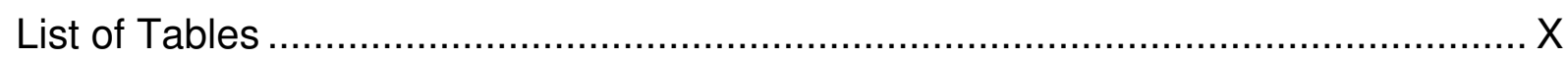

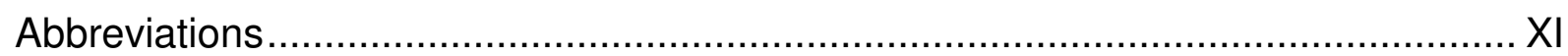

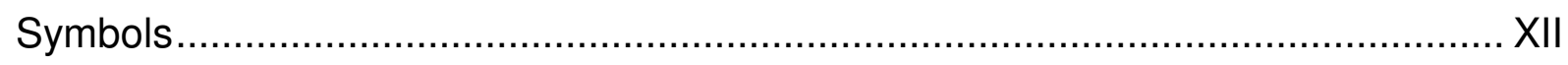

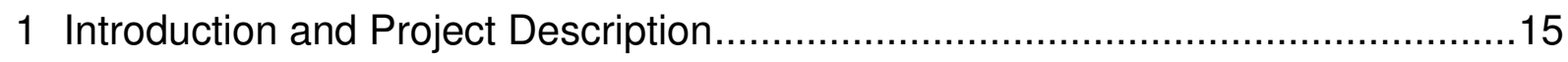

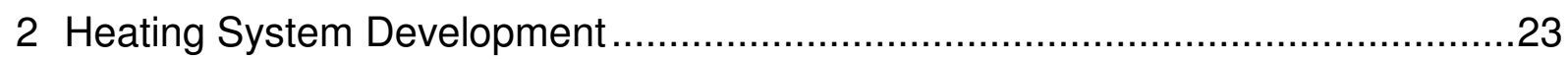

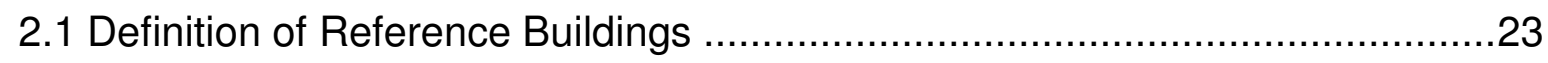

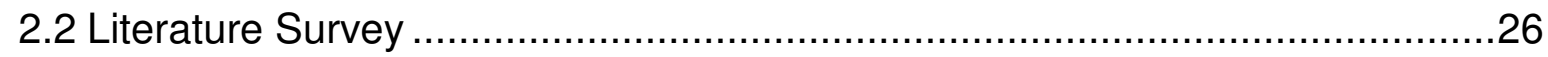

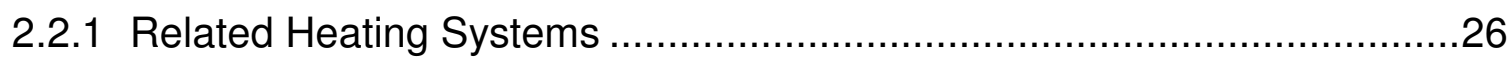

2.2.2 Performance of the Individual Components ............................................ 40

2.2.3 Evaluation of the System Configurations .................................................45

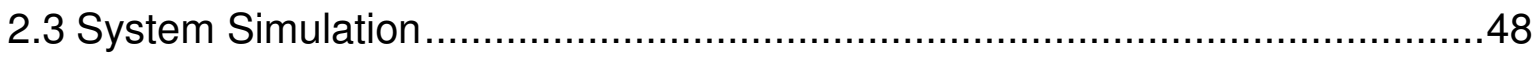

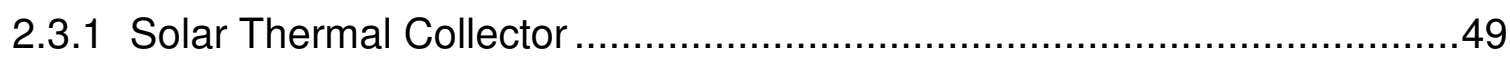

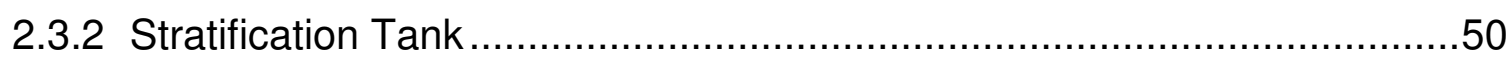

2.3.3 Heating Load and Hot Water Consumption .........................................51

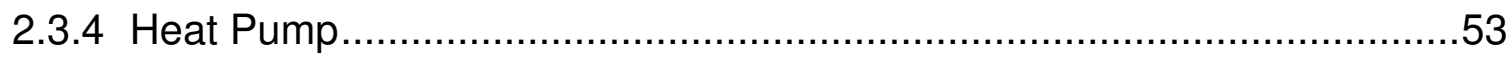

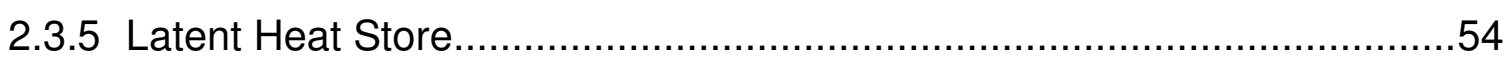

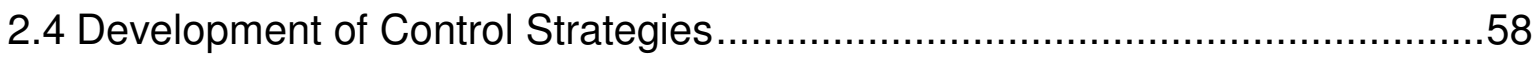

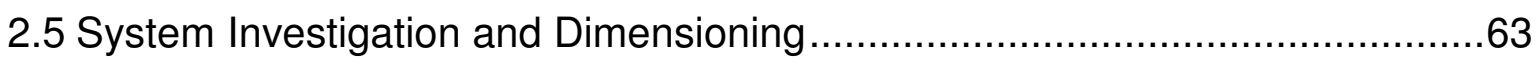

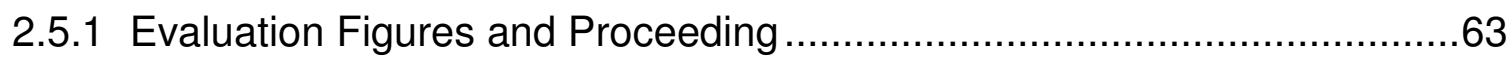

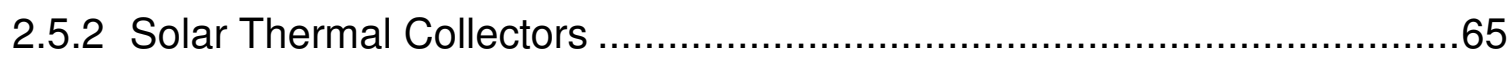

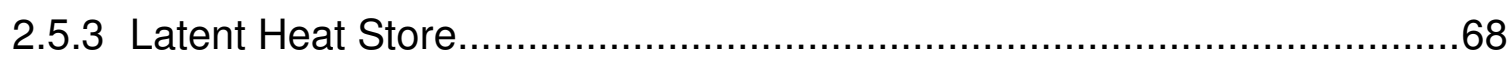

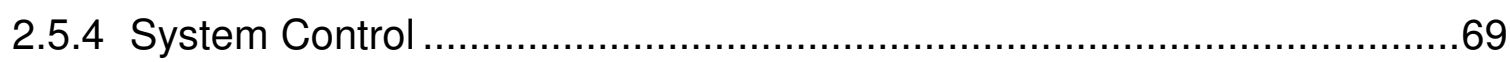

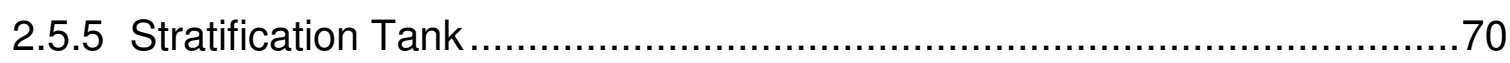

2.5.6 Parameter Influence on System Performance and Dimensioning.............72

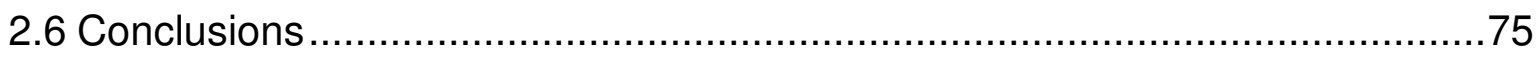




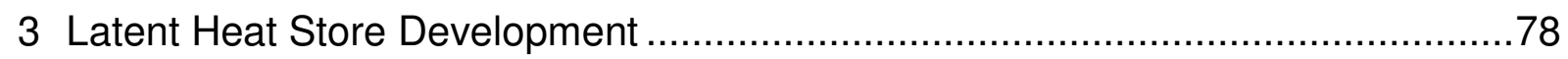

3.1 Latent Heat Materials and Problems linked with Phase Change .....................78

3.2 Literature Survey of Heat Exchanger Technology ................................... 82

3.2.1 Static Heat Exchanger Concepts ...................................................... 83

3.2.2 Dynamic Heat Exchanger Concepts ............................................. 91

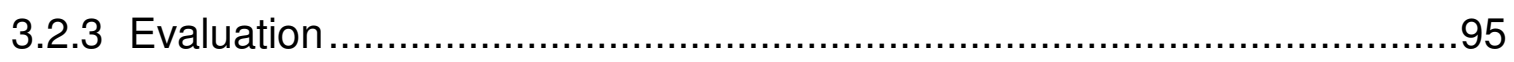

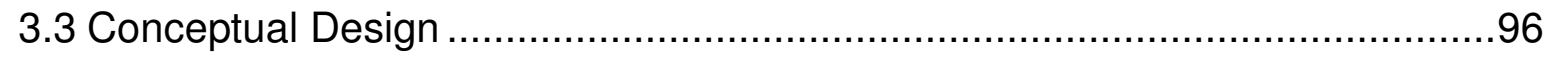

3.3.1 Definition of Design Specifications............................................. 96

3.3.2 Functional Analysis ................................................................. 100

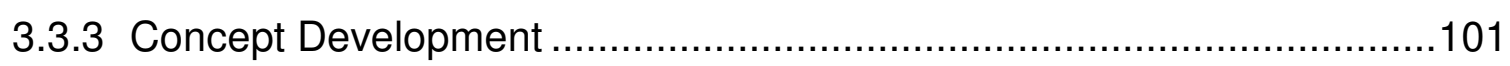

3.3.4 Concept Evaluation and Selection ............................................. 105

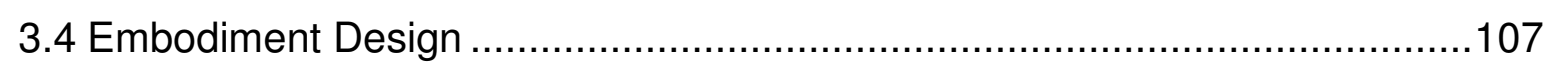

3.4.1 Design of the Heat Conduction Matrix ............................................. 107

3.4.2 Testing of the Sheet Matrix Heat Exchanger ...................................112

3.4.3 Latent Heat Store Design and Dimensioning .................................118

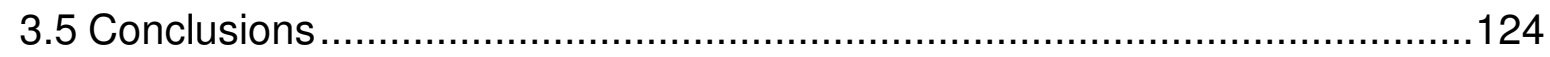

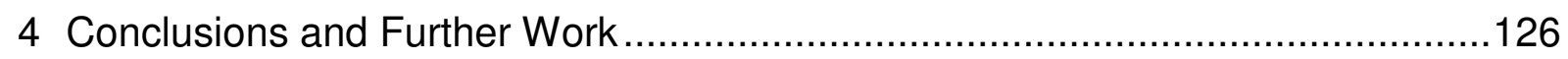

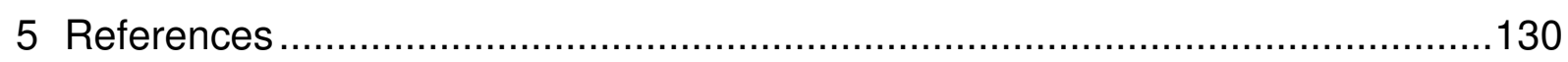

Appendix A: Simulation Parameters

Appendix B: Requirements List

Appendix C: Function Structure (Main Functions)

Appendix D: Test Stand

Appendix E: Publications 


\section{List of Figures}

Figure 1.1: Basic Configurations of Solar Thermal Collector and Heat Pump Incorporation for Domestic Heating Systems

Figure 1.2: Principle of the Proposed Solar Heating System 21

Figure 2.1: Specific Annual Space Heating Demand of Representative OneFamily Houses (OFH) after Redevelopment in Comparison to Typical Values without Redevelopment.

Figure 2.2: Classification of Solar Heat Pump Systems regarding Storage Characteristics in the Solar Collector/Evaporator Circuit.

Figure 2.3: Typical Compact Energy Absorber for Ambient Energy Usage [13] ..............28

Figure 2.4: Typical Example of a Roof-Integrated, Unglazed Solar Absorber [14]..........28

Figure 2.5: Cross Sections of Different Types of Solar Absorbers for Building Integration [15]....

Figure 2.6: A modular Plane Energy Absorber: Quick Step - SolarThermie [16]

Figure 2.7: Monthly Insolation on Collector Area, Dissipated Energy and Temperature in the Storage Tank in the Philips Experimental House [20]

Figure 2.8: Monthly Energy Balance of the Philips Experimental House [20] ..................32

Figure 2.9: Simplified Diagram of the Annual Cycle Energy System [25] ....

Figure 2.10: Diagram of the Heating System of the Experimental House of Lübeck University of Applied Sciences [28].

Figure 2.11: Interior View of Latent Heat Storage Tank of Lübeck University of Applied Sciences [28]. 36

Figure 2.12: Temperatures of Long-Term and Short-Term-Storage [29] 37

Figure 2.13: Schematic of the Heating System operated by W. Hesse in Bad Reichenhall (Germany) [31] 38

Figure 2.14: Heat Exchanger for Latent Heat Storage in a Cistern [34].....

Figure 2.15: Collector Efficiency of Combined Solar Heat Pump System Configurations as a Function of Collector Area (Seasonal Results, Climate: Trabzon, Turkey) [38]

Figure 2.16: Collector Efficiency of Series and Parallel Systems (Seasonal Results, Climate: Madison/Wisconsin, USA) [40].

Figure 2.17: Measured $C O P_{h p}$ Values of Different Solar Heat Pump Systems (Climate: Trabzon, Turkey) [39].

Figure 2.18: Heat Pump Frequency of Operation Distribution with and without Storage (Climate: Trabzon, Turkey) [38]

Figure 2.19: Influence of Storage Capacity on $S P F_{h p}$ (Climate: Hamburg,

Germany, PCM: Water) [42].... 43 
Figure 2.20: Influence of Storage Capacity on Auxiliary Heating Energy Required (Climate: Hamburg, Germany, PCM: Water) [42].

Figure 2.21: Collector Subsystem with Collector Calculation, Hydraulic Elements and Data Measurement.

Figure 2.22: Comparison of Measured and Simulated $C O P_{h p}$ for different Flow Temperatures (water/glycol $60 / 40 \%$ on source side; measurement values provided by manufacturer [57])

Figure 2.23: Exemplary Temperature Curve and Latent Heat of Fusion Extracted from Latent Heat Store.

Figure 2.24: Control Structure developed for the Direction of the two Storage Tanks

Figure 2.25: Insolation (top) and Storage Tank Charging (bottom) on a Typical

Day in September.

Figure 2.26: Important Parameters of the Heating System to be investigated in System Simulations.

Figure 2.27: Calculation Results with Trendlines regarding the

Variation of Collector Area

Figure 2.28: Calculation Results with Trendlines regarding the

Variation of Collector Quality....

Figure 2.29: Calculation Results with Trendlines regarding the

Variation of Latent Heat Store Volume....

Figure 2.30: Calculation Results with Trendlines regarding the

Variation of Control Parameters.

Figure 2.31: Calculation Results with Trendlines regarding the

Variation of Stratification Tank Volume .....

Figure 2.32: Variation of the Decisive Parameters $A_{c o l}$ and $V_{\text {lhst }}$ based on the Recommended System...

Figure 3.1: Specific Latent Heat of Fusion and Melting Point of Typical Phase Change Materials

Figure 3.2: Tube-type Heat Exchanger with Self-Insulating Layers of solid Material during Freezing [71].

Figure 3.3: Heat Exchanger Concepts for Latent Heat Storage. 82

Figure 3.4: Tube Coils of a Heat Exchanger in a Latent Heat Storage Tank [71] 83

Figure 3.5: Finned Tube Heat Exchanger [72] .................................................... 84

Figure 3.6: Finned Annulus Heat Exchanger [73] ................................................ 84

Figure 3.7: Extruded Aluminium Sheath Heat Exchanger [74].................................. 84

Figure 3.8: Latent Heat Store and Heat Exchanger with Copper Tubes and Heat Conduction Plates [76] 85

Figure 3.9: Latent Heat Store for Automotive Applications with Aluminium Matrix for Heat Transfer Enhancement [77] 
Figure 3.10: Thin Film Aluminium Matrix [80]

Figure 3.11: Heat Transfer Enhancement by the Use of Carbon Fibre Brushes [82]

Figure 3.12: Effective Thermal Conductivity of Different Paraffin/Enhancement

Material-Composites [83]

Figure 3.13: VSP25 (left) and VSP50 (right) as Enhancement Material [83]

Figure 3.14: VSP25 dispersed in the Storage Tank, surrounded by solid Paraffin [85] 88

Figure 3.15: Typical Spherical Nodule for Encapsulation of PCM [88] ... 90

Figure 3.16: Spherical Nodules containing PCM, poured in a Storage Tank [89] 90

Figure 3.17: Melting Process of Water within a Spherical Nodule [90] .... .90

Figure 3.18: Principle of Dynamic Ice Stores for Refrigeration Applications [71] .91

Figure 3.19: Principle of a Latent Heat Store working according to the Lindner-Process [92] .... 93

Figure 3.20: Principle of a Dynamic GALISOL-store [95] 94

Figure 3.21: Two Hydraulic Circuits with Separated Heat Exchangers..........................97

Figure 3.22: One Hydraulic Circuit with a Common Heat Exchanger ............................97

Figure 3.23: Principle Behaviour of a Double Heat Exchanger System ...........................99

Figure 3.24: Principle Behaviour of a Single Heat Exchanger System ............................99

Figure 3.25: Overall Function of the Latent Heat Storage Tank .................................100

Figure 3.26: Concept A - Encapsulation of PCM in Cylindrical

Polymer Containers 102

Figure 3.27: Concept B - Heat Exchanger System with Heat Conduction Matrix.........103

Figure 3.28: Conceptual Layout of the Lindner-process with

Change of Flow Direction 104

Figure 3.29: Conceptual Layout of the Lindner-process with Pumping of Water ...........104

Figure 3.30: Open Cell Aluminium Foam Samples................................................107

Figure 3.31: Steel Foam Sample (length: $110 \mathrm{~mm}$, diameter: $90 \mathrm{~mm}$ ) .......................108

Figure 3.32: Heat Exchanger with Expanded Graphite as Heat Conduction Matrix.......109

Figure 3.33: Heat Exchangers with Wire Netting as Heat Conduction Matrix................110

Figure 3.34: Conceptual Layout of a Sheet Matrix Structure Heat Exchanger ..............111

Figure 3.35: Design of a Plate Heat Exchanger with Fins ........................................111

Figure 3.36: Top View of the Heat Exchanger with Positioning of the Temperature Sensors

Figure 3.37: Behaviour of Sheet Matrix Heat Exchanger, during freezing (left) and completely frozen (right)....

Figure 3.38: Temperature Curves during the Freezing Process . 
Figure 3.39: Behaviour of Sheet Matrix Heat Exchanger during Melting 115

Figure 3.40: Temperature Curves during the Melting Process 116

Figure 3.41: Storage Tank Concepts: Rectangular Polymer Tank (left) Cylindrical Concrete Tank (right) ..... 120

Figure 3.42: Latent Heat Store for the Recommended Heating System. 122

Figure 3.43: Interior View on the Heat Exchanger Arrangement inside the Storage Tanks 122 


\section{List of Tables}

Table 2.1: Basic Characteristics of two Reference Buildings.......................................24

Table 2.2: Characteristics of Experimental Houses with Water Stores in the Collector Circuit....

Table 2.3: Characteristics of the Experimental House of Lübeck University of Applied Sciences [28][29][30].... 36

Table 2.4: Characteristics of the Heating System operated by W. Hesse in Bad Reichenhall (Germany) [31] 38

Table 2.5: Evaluation of Solar Heat Pump Concepts and Description of Problems 46

Table 2.6: Investigated Parameters and their Influence on the Evaluation Figures .72

Table 3.1: Characteristics of Typical Phase Change Materials (data from [2] [59] [64] [65] [66] [67])

Table 3.2: System Operating Behaviour concerning Different Hydraulic Designs .98

Table 3.3: Operating Modes of Components and Evaluation of their Behaviour and Influence on the System. 98

Table 3.4: Properties of the Concepts for Heat Exchangers 105

Table 3.5: Preliminary Latent Heat Store Dimensioning 121 


\section{Abbreviations}

ACES Annual Cycle Energy System

AHTF Additional Heat Transfer Fluid

BBC AG Brown, Boverie \& Cie AG

HTF Heat Transfer Fluid

OFH One-Family House

PCM Phase Change Material 


\section{Symbols}

\begin{tabular}{|c|c|c|}
\hline$A_{c o l}$ & Collector Area & {$\left[\mathrm{m}^{2}\right]$} \\
\hline$A_{\text {col_node }}$ & Surface of Collector Node & {$\left[\mathrm{m}^{2}\right]$} \\
\hline$A_{h x}$ & Surface Area of Heat Exchanger per Storage Node & {$\left[\mathrm{m}^{2}\right]$} \\
\hline$A_{\text {loss }}$ & Surface Area for Losses of one Storage Node & {$\left[\mathrm{m}^{2}\right]$} \\
\hline$C O P_{h p}$ & Heat Pump Coefficient of Performance & {$[-]$} \\
\hline$c_{c o l}$ & Heat Capacity of Collector per Area & {$\left[\mathrm{J} /\left(\mathrm{m}^{2} \mathrm{~K}\right)\right]$} \\
\hline$c_{h t f}$ & Heat Capacity of Heat Transfer Fluid & {$\left[\mathrm{J} /\left(\mathrm{kg}^{*} \mathrm{~K}\right)\right]$} \\
\hline$c_{\text {node }}$ & Node Heat Capacity & {$\left[\mathrm{J} /\left(\mathrm{kg}^{*} \mathrm{~K}\right)\right]$} \\
\hline$d h$ & Distance between two Nodes & {$[\mathrm{m}]$} \\
\hline DoS Ihst_max & Maximum Degree of Solidification of Latent Heat Store & [\%] \\
\hline$f_{\text {sol }}$ & Solar Fraction & {$[\%]$} \\
\hline$G$ & Incident Solar Radiation & {$\left[\mathrm{W} / \mathrm{m}^{2}\right]$} \\
\hline$G_{\min }$ & Minimum Incident Solar Radiation & {$\left[\mathrm{W} / \mathrm{m}^{2}\right]$} \\
\hline$K_{1}$ & Coefficient for Primary Inlet Temperature & {$[\mathrm{W} / \mathrm{K}]$} \\
\hline$K_{2}$ & Coefficient for Secondary Outlet Temperature & {$[\mathrm{W} / \mathrm{K}]$} \\
\hline$K_{3}$ & Temperature Independent Heating Power & {$[\mathrm{W}]$} \\
\hline$m_{\text {node }}$ & Node Mass & {$[\mathrm{kg}]$} \\
\hline$\dot{m}$ & Mass Flow Rate & {$[\mathrm{kg} / \mathrm{s}]$} \\
\hline$Q_{\text {aux_gain }}$ & Auxiliary Energy and Heat Gains & {$[\mathrm{kWh}]$} \\
\hline$Q_{\text {aux_loss }}$ & Auxiliary Energy and Heat Losses & {$[\mathrm{kWh}]$} \\
\hline$Q_{\text {heat_demand }}$ & Overall Heat Demand for Heating and Hot Water Preparation & {$[\mathrm{kWh}]$} \\
\hline$Q_{h p_{-} e l}$ & Electrical Energy Consumption of Heat Pump & {$[\mathrm{kWh}]$} \\
\hline$Q_{h p_{-} t h}$ & Thermal Energy delivered by the Heat Pump & {$[\mathrm{kWh}]$} \\
\hline$Q_{l h s t_{-} p c}$ & $\begin{array}{l}\text { Latent Heat of Fusion extracted from Latent Heat Store } \\
\text { during Phase Change }\end{array}$ & {$[\mathrm{kWh}]$} \\
\hline$Q_{l h s t_{-} p c_{-} \max }$ & Maximum Latent Heat of Fusion in Latent Heat Store (theoretical) & {$[\mathrm{kWh}]$} \\
\hline
\end{tabular}


$Q_{\text {sol }} \quad$ Thermal Energy delivered by Solar Installation

$[\mathrm{kWh}]$

$Q_{t h}$ in $\quad$ Incoming Thermal Energy

$[\mathrm{kWh}]$

$Q_{\text {th_out } \quad \text { Outgoing Thermal Energy }}$

[kWh]

$\dot{Q} \quad$ Heat Flow

$[\mathrm{W}]$

$\dot{Q}_{i n} \quad$ Heat Flows to / from Room Node

[W]

$\dot{Q}_{h p_{-} e l} \quad$ Electrical Power of Heat Pump

$[\mathrm{W}]$

$\dot{Q}_{h p_{-} t h} \quad$ Heat Pump Heating Power

$[\mathrm{W}]$

$\dot{Q}_{\text {sol }} \quad$ Solar Power per Area

$\left[\mathrm{W} / \mathrm{m}^{2}\right]$

$\dot{Q}_{\text {sol_use }} \quad$ Useful Power of a Solar Collector Installation

$S P F_{h p} \quad$ Heat Pump Seasonal Performance Factor

$S P F_{s y s} \quad$ Seasonal Performance Factor of the Heating System

$T_{a m b} \quad$ Ambient Temperature

$T_{c o l}$

Average Collector Temperature

$T_{\text {col_stag }} \quad$ Collector Stagnation Temperature

$T_{\text {ctr_diff }} \quad$ Temperature Difference for Storage Control

$T_{\text {flow }} \quad$ Flow Temperature

$T_{\text {hp_cold_in }} \quad$ Heat Pump Inlet Temperature of the Cold Branch

$T_{\text {hp_hot_in }} \quad$ Heat Pump Inlet Temperature of the Hot Branch

$T_{h x} \quad$ Heat Exchanger Temperature

$T_{\text {lhst }} \quad$ Temperature of Latent Heat Storage Tank

$T_{\text {lhst_max }} \quad$ Maximum Temperature of Latent Heat Storage Tank

$T_{\text {lhst_o }} \quad$ Bottom Temperature of Latent Heat Storage Tank

$T_{\text {node }}$ Node Temperature

$T_{\text {return }} \quad$ Return Temperature 
$T_{\text {strat_o.15 }}$ Stratification Tank Temperature (at 0.15 * store height)

$T_{10} \quad$ Temperature measured $10 \mathrm{~mm}$ distant from heat exchanger plate

$T_{25 a} \quad$ Temperature measured $25 \mathrm{~mm}$ distant from heat exchanger plate

$T_{25 b} \quad$ Temperature measured $25 \mathrm{~mm}$ distant from heat exchanger plate

$T_{55} \quad$ Temperature measured $55 \mathrm{~mm}$ distant from heat exchanger plate

$T_{75} \quad$ Temperature measured $75 \mathrm{~mm}$ distant from heat exchanger plate

$t \quad$ Time

$U_{h x} \quad$ Heat Transfer Coefficient of Heat Exchanger

$U_{\text {loss }}$ Heat Loss Coefficient

Radiative Heat Loss Coefficient

$U_{\text {wind }} \quad$ Wind Speed dependant Heat Loss Coefficient

$U_{1} \quad$ Linear Heat Loss Coefficient $\left[\mathrm{W} /\left((\mathrm{m} / \mathrm{s}) \mathrm{m}^{2} \mathrm{~K}\right)\right]$

$U_{2} \quad$ Quadratic Heat Loss Coefficient

Node Volume

Stratification Tank Volume

Wind Speed

Volume Flow

$\Delta V \quad$ Volume Change during Phase Change (from liquid to solid)

$\eta_{c o l} \quad$ Collector Efficiency

$\eta_{\text {col_min }} \quad$ Minimum Collector Efficiency

$\eta_{\text {col_strat }} \quad$ Collector Efficiency working in Stratification Tank Mode 


\section{Introduction and Project Description}

Given the finite nature of fossil fuel resources, the increasing pollutant emissions (particularly $\mathrm{CO}_{2}$ ) caused by their combustion and the change of the earth's climate, innovative technologies for sustaining ecological heat and power generation, especially in the field of solar heating, are gaining more and more importance. Supported by the increase in costs for fossil energy over the last few years, solar heating systems and the use of environmental thermal energy has become an interesting technology for heating applications.

Starting with technologically simple domestic hot water supply, solar space heating with larger collector areas and more complex storage units becomes increasingly popular. State-of-the-art solar heating systems, however, suffer from the necessity of an additional heat source, in most cases based on fossil fuel. The problem derives from the existing gap between solar radiation availability and thermal energy requirement (day/night and summer/winter shift). Solar-assisted heating systems are evaluated using the Solar Fraction $\left(f_{\text {sol }}\right)$ representing the fraction of an application's complete heat demand that is covered by solar sources [1]:

$$
f_{\text {sol }}=\frac{Q_{\text {sol }}}{Q_{\text {heat_demand }}} \cdot 100 \%
$$

with

$Q_{\text {sol }} \quad$ Thermal Energy delivered by Solar Installation

$Q_{\text {heat_demand }}$

Overall Heat Demand for Heating and Hot Water Preparation

One of the core components of a solar heating system, the solar thermal collector is evaluated using the collector efficiency [1]:

$$
\eta_{c o l}=\frac{\dot{Q}_{\text {sol_use }}}{A_{c o l} \cdot G}
$$

with

$\dot{Q}_{\text {sol_use }} \quad$ Useful Power of a Solar Collector Installation 
$A_{\text {col }} \quad$ Collector Area

G Incident Solar Radiation

$\left[\mathrm{W} / \mathrm{m}^{2}\right]$

Typical efficiency curves of solar thermal collectors are shown in Appendix $A$, where the dependency of collector efficiency on the collector's optical characteristics (glass, absorber coating) and its thermal losses to the ambience can be seen.

Combined heat pump heating systems have been a focus of researchers for several years. Furthermore, the heat pump market has grown steadily in Central Europe for many years. As heat pumps use mechanical energy to transfer ambient energy from a source at a low temperature $\left(0 \ldots+15^{\circ} \mathrm{C}\right)$ to a sink at a higher temperature $\left(+35 \ldots+50^{\circ} \mathrm{C}\right)$ they consume less primary energy than oil or gas fired systems provided appropriate application conditions and suitable dimensioning. Apart from the saving of primary energy, heat pumps have the advantage of independence from fossil fuels. For domestic heating systems the sources for a heat pump are mainly ambient air or the ground. The compressor is frequently driven by electrical energy. For the evaluation of heat pumps the Coefficient of Performance $\left(C O P_{h p}\right)$ is considered. The dimensionless figure represents the ratio of heating power and electrical power of the heat pump [2]:

$$
C O P_{h p}=\frac{\dot{Q}_{h p_{-} t h}}{\dot{Q}_{h p_{-} e l}}
$$

with

$\dot{Q}_{h p_{-} t h} \quad$ Heat Pump Heating Power

$\dot{Q}_{h p_{-} e l} \quad$ Electrical Power of Heat Pump

Apart from $\mathrm{COP}_{h p}$ that describes a present state in a working point, the Seasonal Performance Factor $\left(S P F_{h p}\right)$ is considered. This dimensionless figure indicates the long-term performance of the heat pump within the system as the thermal energy delivered to the sink in relation to the electrical energy consumption [2]: 


$$
S P F_{h p}=\frac{Q_{h p_{-} t h}}{Q_{h p_{-} e l}}
$$

with

$$
\begin{array}{ll}
Q_{h p_{-} t h} & \text { Thermal Energy delivered by the Heat Pump } \\
Q_{h p_{\_} e l} & \text { Electrical Energy Consumption of Heat Pump }
\end{array}
$$

The $C O P_{h p}$ and the $S P F_{h p}$ and thereby the fraction of ambient energy depends on the temperature difference between the source and the sink. Today these "thermodynamic heating systems" can use up to $75 \%$ of thermal energy for domestic heating from ambient sources, while $25 \%$ is electrical energy, which corresponds to a $S P F_{h p}$ of 4 . Mainly from an economic point of view an important objective in heat pump development and design is the possibility of monovalent operation. This means that the heat pump is the only heat source in the system covering the complete heat demand of the building. While ground source heat pumps are applicable for monovalent operation in modern domestic heating systems with low flow temperatures in Central Europe, air source heat pumps are often supplemented by an additional heat source (typically electric resistance heating or an oil/gas burner).

As both solar heating and heat pumps are sustainable and innovative technologies in the field of domestic heating their combination has often been subject to research in many countries. These so-called "solar heat pump systems" were examined theoretically as well as experimentally in several research laboratories and experimental houses. There are three basic configurations of solar thermal collector and heat pump incorporation for domestic heating purposes (Figure 1.1) [3]:

- The parallel solar heat pump incorporates solar collectors and a heat pump with an additional source (ambient air, ground,...). They work independently from each other and deliver thermal energy to the storage tank depending on solar insolation and heat demand. The advantage of this configuration is that $C O P_{h p}$ does not depend on the collector temperature; its disadvantage is the necessity of an additional heat source (e.g. a ground collector).

- In the series solar heat pump system solar energy is supplied to the heat pump evaporator by solar thermal collectors. The collectors are the only heat source for the 
heat pump, which delivers thermal energy to the heating system. In this system configuration $\mathrm{COP}_{h p}$ does highly depend on collector temperature (especially in configuration S1) and thereby on weather conditions. During low radiation periods, the heat pump works under unfavourable conditions. In contrast, during periods with high solar insolation when collector temperature is high, $C O P_{h p}$ is raised. To reduce the disadvantage of weather dependency a storage tank can be applied between the solar collector and heat pump evaporator (configuration S2). The series systems frequently operate with unglazed collectors to enhance the possibility of ambient energy usage (air, wind, rain,...). The major advantage of the direct connection of collectors and heat pump evaporator in the series system is the lower collector inlet temperature caused by the heat pump. As solar collector efficiency is highly temperature dependent (due to heat losses to the ambient), this configuration runs the collectors under favourable conditions.

- As a further possibility of solar collector and heat pump incorporation, combinations of parallel and series systems have to be taken into consideration. Combination $\mathrm{C} 1$ enables the use of solar collectors as heat source for the heat pump in the case of providing a higher temperature than the additional heat source. This configuration eliminates the problem of weather dependency of $C O P_{h p}$. However, it requires an additional heat source for the heat pump. Combination C2 allows the usage of solar heat for direct heating if the temperature of the collectors is sufficient for this purpose. Alternatively, usage of the collectors as a heat source for the heat pump is possible. Configuration C3 combines the possibility of direct solar heating with thermal energy storage between collectors and heat pump. Like combination C2, this system configuration allows the usage of the solar collectors over a wide range of collector temperatures and thereby improves their utilisation time. Additionally, the storage tank between collectors and heat pump evaporator compensates for periods with poor insolation.

Figure 1.1 shows the fundamental possibilities for a combination of solar collector utilisation and heat pump. As described before, parallel as well as series heat pump systems show basic disadvantages in their operation. For that reason, only a combination of both concepts promises an advantageous utilisation of a solar heat pump. 


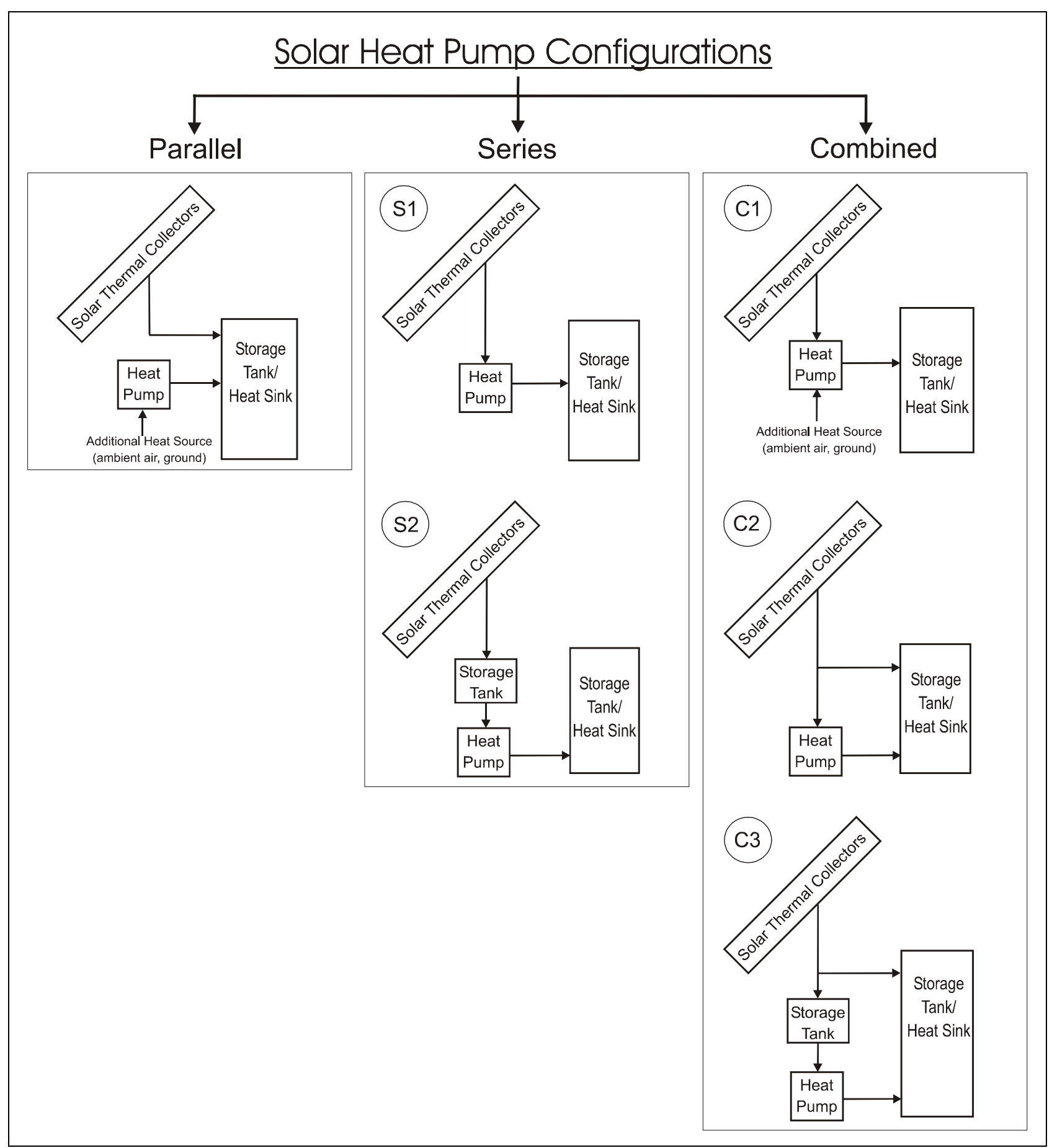

Figure 1.1: Basic Configurations of Solar Thermal Collector and Heat Pump Incorporation for Domestic Heating Systems

For this project combination $\mathrm{C} 3$ is chosen, as it provides the possibility of using different operating modes for varying boundary conditions (heat demand, solar insolation,...), hence offers advantages during most operating periods: 
- Direct solar energy utilisation is possible if the collector temperature is high enough. The heat pump is not necessary in this operating mode, which saves electrical energy.

- The storage tank between collector and heat pump allows the usage of solar energy even when the heat pump is out of operation. Furthermore, it bridges periods of low insolation. The $C O P_{h p}$ is less dependent on collector temperature.

- The collector works at low inlet temperatures, which raises its efficiency. The performance of a solar collector is highly temperature dependent due to its heat losses to the ambient. Thus, only a low collector inlet temperature (from the storage tank or the heat pump), and thereby a low average collector temperature maximises collector performance.

- The heat pump allows the usage of the collector even during low-temperature and low-radiation periods at low collector temperatures. The collector utilisation time of a solar installation principally depends on the temperature difference between the solar collector and the storage tank. Solar energy offered by the solar collectors can only be transferred into the storage tank when a minimum temperature drop of about $5 \mathrm{~K}$ exists between collector and storage tank. In comparison to a customary storage tank for solar installations working at $30^{\circ} \mathrm{C} \ldots 80^{\circ} \mathrm{C}$, the heat pump and its storage tank provide $-5^{\circ} \mathrm{C} \ldots+15^{\circ} \mathrm{C}$ for the collector during the low-temperature periods of the year.

In compliance with Figure 1.1 the proposed heating system consists of the following major components (Figure 1.2):

- Solar thermal collectors,

- Heat pump,

- Central storage tank (stratification tank),

- Latent heat thermal energy storage tank (low-temperature),

- Heat distributor,

- Central control unit.

Some of these components are proven and commercially available (e.g. solar collectors and stratification tank), but others have had to be developed (e.g. low-temperature latent heat storage tank and system control). 


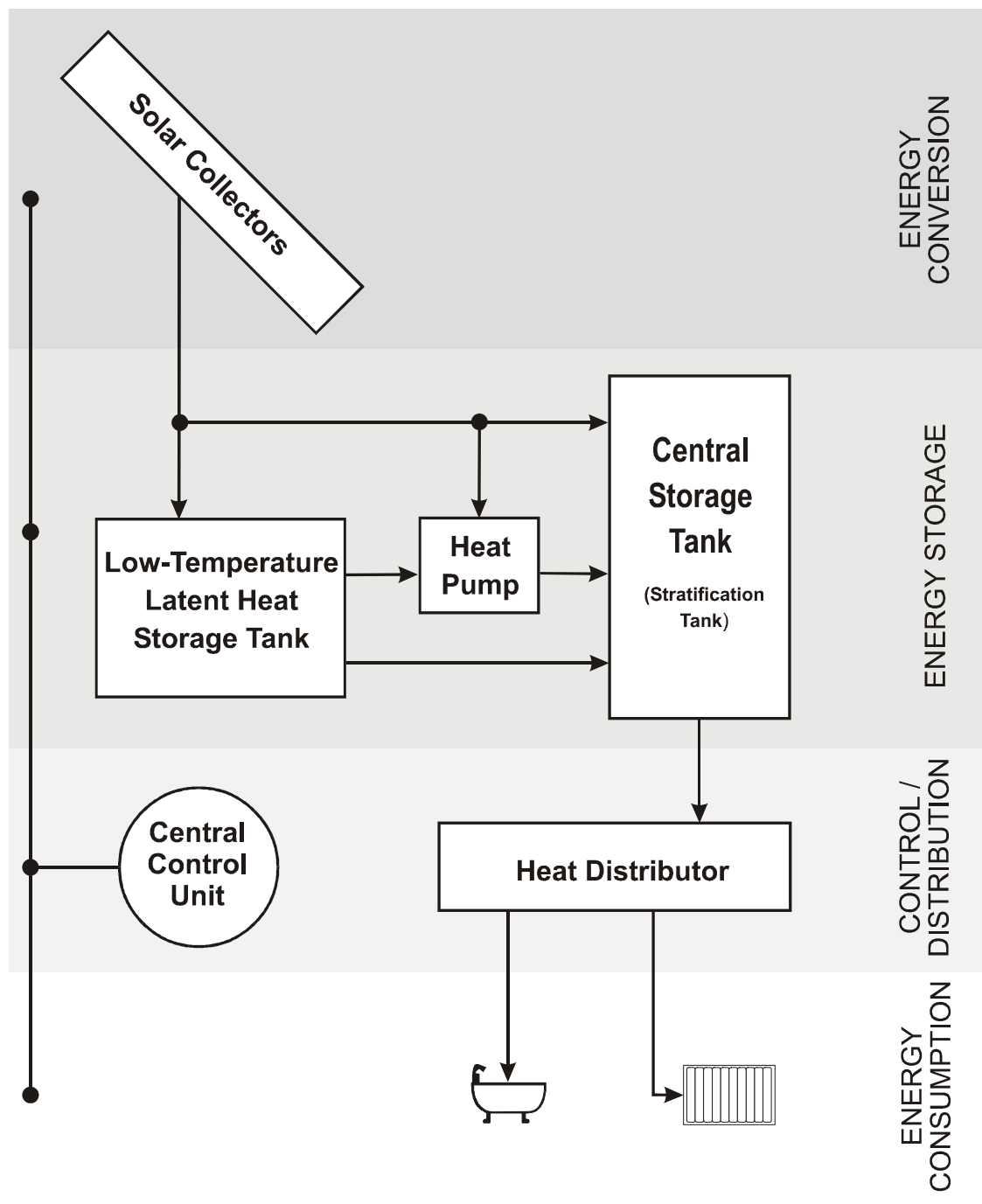

Figure 1.2: Principle of the Proposed Solar Heating System

Solar collectors only supply the system with thermal energy. During periods providing sufficient solar radiation, thermal energy is transferred into the latent heat storage tank (storage medium: water) by a heat exchanger and can be stored even at a low temperature level (down to $-5^{\circ} \mathrm{C}$ ) using the latent heat of fusion of water. In case of heat demand from the central heating, a heat pump transforms thermal energy (from the lowtemperature latent heat storage tank) to a usable temperature level $\left(+35^{\circ} \mathrm{C} \ldots+50^{\circ} \mathrm{C}\right)$ and thus supplies the central storage tank. This stratification storage tank compensates for temporary peaks of heat demand and distributes thermal energy by a directly connected heat distributor. In case of availability (adequate temperature level of solar collectors) and requirement (instantaneous heat demand) the central storage tank is directly heated by 
the solar collectors. A connection between collectors and heat pump is possible for direct utilisation of collectors without storage tank discharging. If the temperature of the latent heat storage tank is high enough, the central storage tank can be charged directly [4].

The principal objective of this investigation focuses on two issues:

- Heating system development (Chapter 2), which concentrates on the investigation and development of the proposed heating system with special regard to an optimised control strategy and the derivation of a system dimensioning for a reference building.

- Latent heat store development (Chapter 3), focusing on the systematic development and the testing of a water/ice store for the particular requirements of the heating system, eventually aiming at the exemplary store dimensioning for the system defined by the simulations. 


\section{Heating System Development}

In the course of heating system development reference buildings as preliminary targets for the dimensioning of reference systems and components are defined in a first step. Additionally, information research including a detailed literature survey is carried out to gather information on products as well as results of research projects concerning relevant heating systems.

\subsection{Definition of Reference Buildings}

The heating system promises adaptability to a wide range of buildings. It is applicable for small one-family houses with relatively low heat demand as well as for multifamily residential structures. The applicability principally depends on the dimensioning of the components (collector area, storage volume, heat pump capacity,...).

For the pre-dimensioning of a reference heating system and its components in the course of the heating system development and storage tank design, two reference buildings are defined. To cover a wide range of the targeted housing market, typical new and redeveloped family houses are selected.

Both reference buildings are typical detached family houses (4 persons) with a living area of $120 \mathrm{~m}^{2}$. For simulation purposes, Würzburg (Germany) is chosen as a reference location. Würzburg is widely used for certification and simulation purposes for its average ambient conditions and solar insolation. As a key value of the building characteristics, the specific annual heat demand for space heating is identified. The characteristics of both buildings are selected according to the German Energy Conservation Standard [5]. For new and existing buildings (in case of redevelopment), this standard prescribes the level of insulation for all relevant structural parts of the building depending on the heating system used.

Table 2.1 shows the buildings and their basic characteristics. In accordance to the level of insulation prescribed by the German Energy Conservation Standard, the "New Family House" is supposed to be a so-called "energy conservation building" with a maximum annual space heating demand of $43 \mathrm{kWh} /\left(\mathrm{m}^{2} \mathrm{a}\right)$. Examples of energy conservation buildings show that this is a representative value for such houses [6]. 
Table 2.1: Basic Characteristics of two Reference Buildings

\begin{tabular}{|c|c|c|}
\hline & “New Family House" & "Redeveloped Family House" \\
\hline $\begin{array}{l}\text { Specific Annual Space } \\
\text { Heating Demand }\end{array}$ & $\max .43 \mathrm{kWh} /\left(\mathrm{m}^{2} \mathrm{a}\right)$ & $\max .83 \mathrm{kWh} /\left(\mathrm{m}^{2} \mathrm{a}\right)$ \\
\hline $\begin{array}{l}\text { Max. Heat Transfer Coefficient } \\
\text { according to [5] for }\end{array}$ & & \\
\hline Outer Walls & \multicolumn{2}{|c|}{$0.45 \mathrm{~W} /\left(\mathrm{m}^{2} \mathrm{~K}\right)$} \\
\hline Windows & \multicolumn{2}{|c|}{$1.7 \mathrm{~W} /\left(\mathrm{m}^{2} \mathrm{~K}\right)$} \\
\hline Floor (against Ground) & \multicolumn{2}{|c|}{$0.5 \mathrm{~W} /\left(\mathrm{m}^{2} \mathrm{~K}\right)$} \\
\hline Roof & \multicolumn{2}{|c|}{$0.3 \mathrm{~W} /\left(\mathrm{m}^{2} \mathrm{~K}\right)$} \\
\hline $\begin{array}{l}\text { Specific Annual Heat Demand } \\
\text { for Hot Water }\end{array}$ & \multicolumn{2}{|c|}{$17 \mathrm{kWh} /\left(\mathrm{m}^{2} \mathrm{a}\right)$} \\
\hline $\begin{array}{l}\text { Supply Temperature for } \\
\text { Heating System }\end{array}$ & $\begin{array}{c}\max .35^{\circ} \mathrm{C} \\
\text { (Floor/Wall Heating) }\end{array}$ & $\begin{array}{c}\max .50^{\circ} \mathrm{C} \\
\text { (Radiator Heating) }\end{array}$ \\
\hline Living area for 4 Persons & \multicolumn{2}{|c|}{$120 \mathrm{~m}^{2}$} \\
\hline $\begin{array}{l}\text { Location } \\
\text { (for Simulation Purposes) }\end{array}$ & \multicolumn{2}{|c|}{ Würzburg (Germany) } \\
\hline
\end{tabular}

The "Redeveloped Family House" (Table 2.1) represents an existing building, redeveloped with several measures for the reduction of thermal energy consumption:

- Improved thermal insulation of roof,

- Improved thermal insulation of outer walls,

- Improved thermal insulation of cellar ceiling,

- Replacement of windows.

These measures are economically feasible and have to be carried out in coincidence with the German Energy Conservation Standard. Figure 2.1 shows investigations of representative buildings proving that most redeveloped family houses can reach an annual space heating demand of $83 \mathrm{kWh} /\left(\mathrm{m}^{2} \mathrm{a}\right)$.

In addition to the heat demand for space heating the heat demand for hot water preparation has to be defined for the reference buildings. According to the German Energy Conservation Standard a heat demand of $12.5 \mathrm{kWh} /\left(\mathrm{m}^{2} \mathrm{a}\right)$ can be presumed for calculations [5] [7]. This is equivalent to a hot water consumption of 23 litres per day per person (concerning 4 persons, $120 \mathrm{~m}^{2}, 50^{\circ} \mathrm{C}$ ). For the reference buildings 30 litres per day and 
per person as a more realistic value is selected. This leads to a specific annual heat demand of $17 \mathrm{kWh} /\left(\mathrm{m}^{2} \mathrm{a}\right)$ for hot water preparation.

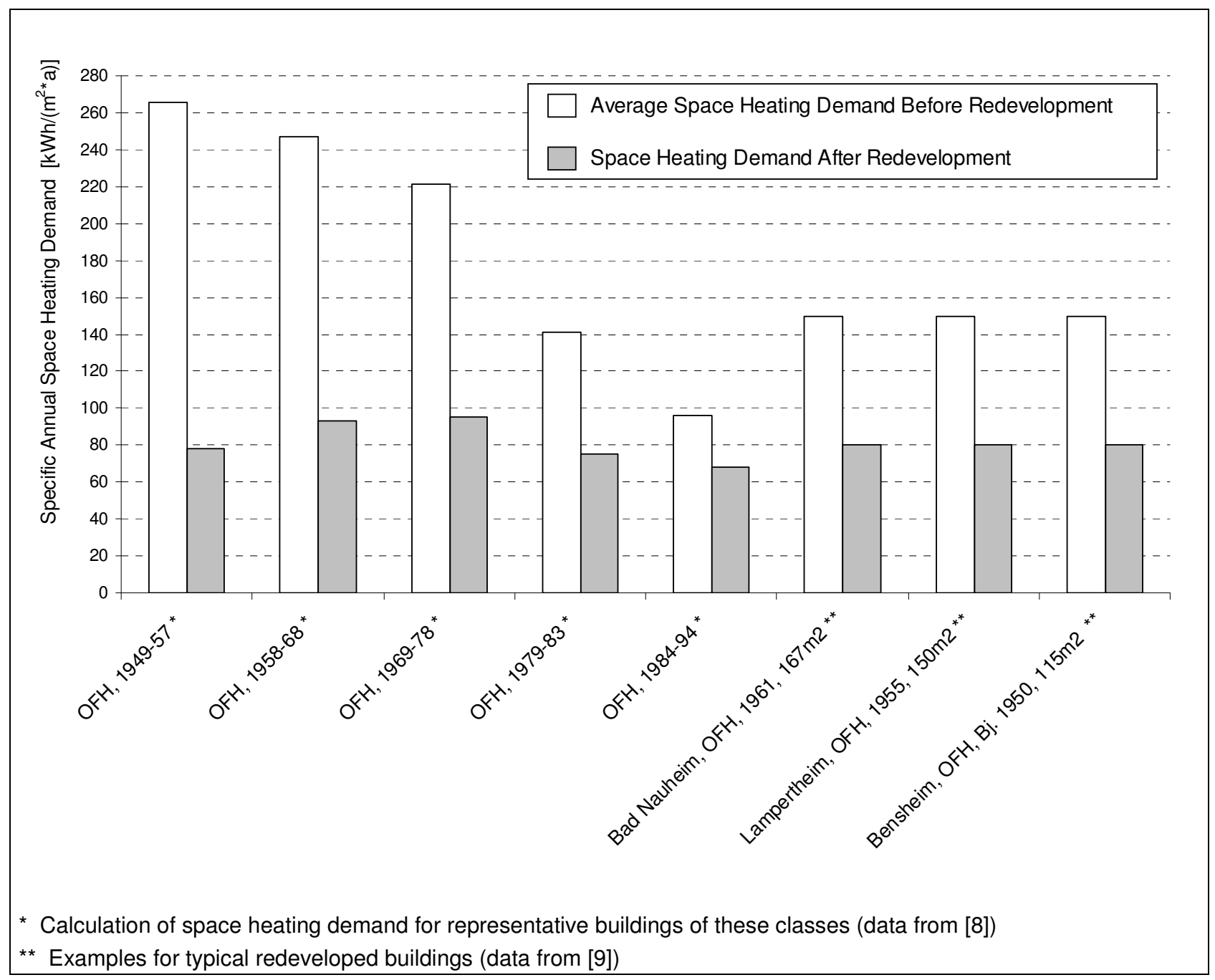

Figure 2.1: Specific Annual Space Heating Demand of Representative One-Family Houses (OFH) after Redevelopment in Comparison to Typical Values without Redevelopment.

A further requirement for the buildings is the supply temperature for the heat distribution system which chiefly depends on the type of heating elements (radiators, floor heating,...). For the new building, a supply temperature of $35^{\circ} \mathrm{C}$ is typical for floor or wall heating. For redeveloped houses in many cases $40 \ldots 50^{\circ} \mathrm{C}$ can be achieved by improving thermal insulation. Otherwise, the heat distribution system has to be modernised [10]. 


\subsection{Literature Survey}

\subsubsection{Related Heating Systems}

As Figure 1.1 shows there are several possibilities of solar collector and heat pump arrangement. The literature survey in this chapter concentrates on the series system as well as on the combinations of series and parallel systems because merely these systems promise relevant information for the heating system to be developed. An overview on relevant system approaches is also given in [3] and [11].

It is sensible to divide the different series and combination systems into subgroups. Figure 2.2 shows their classification regarding the type of storage tank between solar collector and heat pump evaporator.

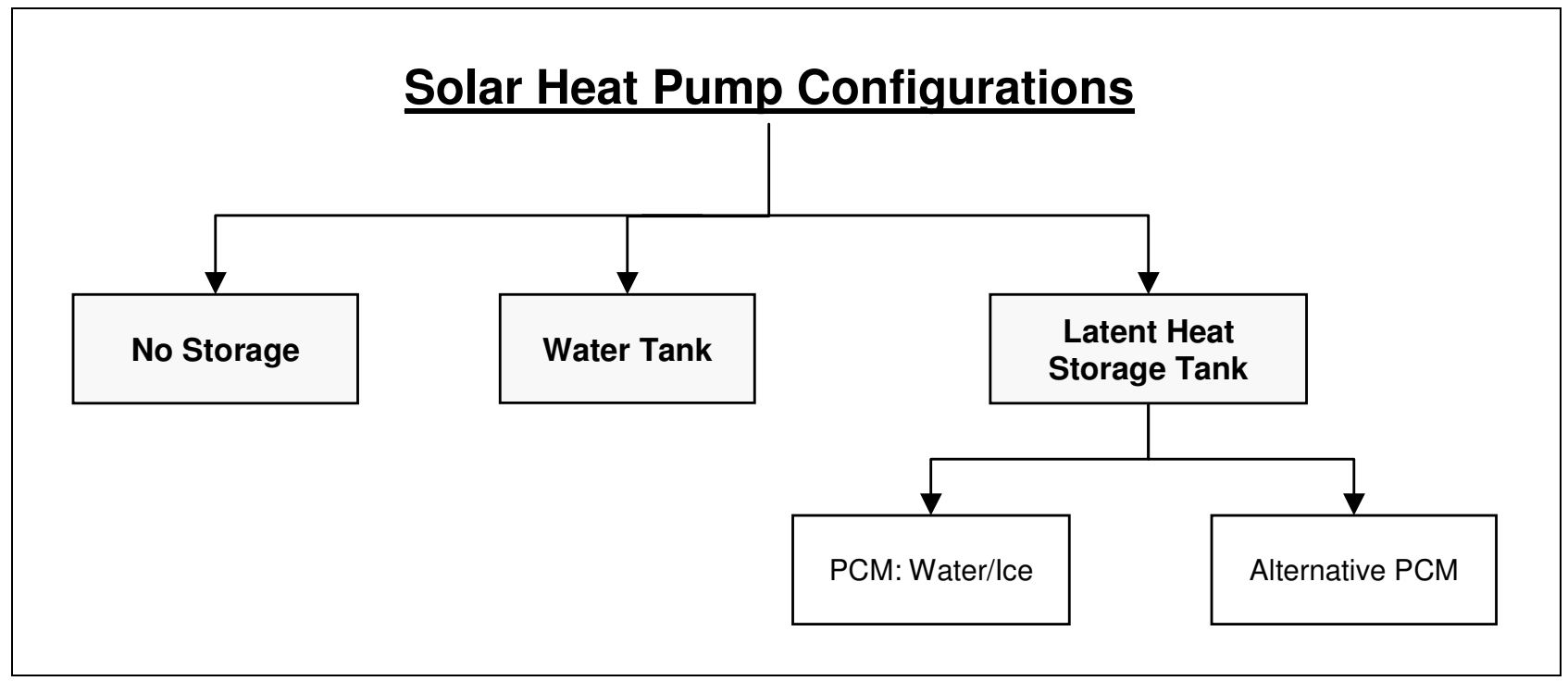

Figure 2.2: Classification of Solar Heat Pump Systems regarding Storage Characteristics in the Solar Collector/Evaporator Circuit

Non-storage systems are a straightforward option of solar energy utilisation by heat pump. The collector temperature restricts heat pump operation (switch off, if temperature is lower than $-10^{\circ} \mathrm{C}$ ), thus the systems usually require an additional heat source for periods with low solar insolation and low outdoor temperatures. Consequently, storage tanks for the compensation of these periods were applied in the evaporator circuit. A storage tank can compensate the relatively unsteady solar insolation and can thereby reduce the weather dependency of the heat pump operation times. 
Different storage technologies are possible in these systems. A water tank is a straightforward and often a low-cost alternative. In contrary, latent heat stores offer higher storage capacity per volume and lower collector inlet temperatures in case of an ice storage tank.

The non-storage collector systems are typical series solar heat pump combinations. In the course of heat pump development, several heat source options have been considered by various researchers. The most popular heat sources in Central Europe are ambient air and the ground, used by ground collectors. As $C O P_{h p}$ depends on the temperature of the heat source, the utilisation of solar radiation by absorbers, in addition to ambient air, is obvious. In this regard, two alternatives have been investigated:

- Compact Energy Absorbers are heat exchangers that abstract thermal energy from ambient air and precipitation without forced ventilation. Figure 2.3 shows the principle of a typical compact energy absorber.

- Plane Energy Absorbers or Solar Absorbers are designed for solar insolation absorption in addition to ambient air utilisation. They are available as so-called "energy roof" for roof mounting or as facade collectors. Due to their sun-oriented area, solar absorbers can supply the heat pump with temperatures higher than ambient temperature in case of solar insolation availability. The absorbers are usually designed as unglazed collectors. Figure 2.4 shows an example of a roof-integrated solar absorber.

Energy absorbers have been investigated in several research projects, where the feasibility of a direct combination of plane energy absorbers with a heat pump was shown, for instance by Dietrich et al [12]: The temperature of the evaporator can be increased by solar absorbers, but an additional heat source (oil or gas) is still required. The reason is that heat pump operation is limited to temperatures of the source above $-10^{\circ} \mathrm{C}$. Without a storage tank in the evaporator/collector circuit, the heat supply by the absorber is insufficient for example in cold nights especially when snow or hoar-frost insulates the absorber. 


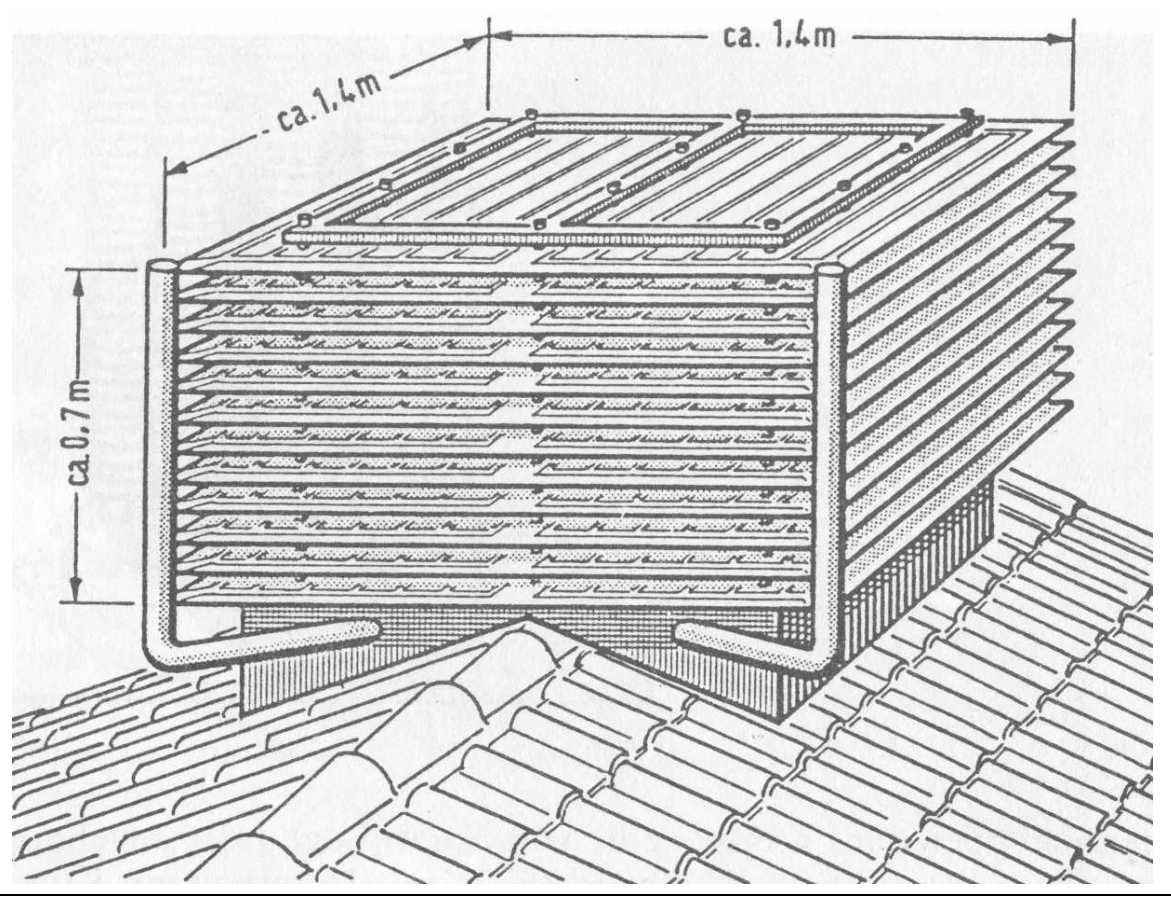

Figure 2.3: Typical Compact Energy Absorber for Ambient Energy Usage [13]

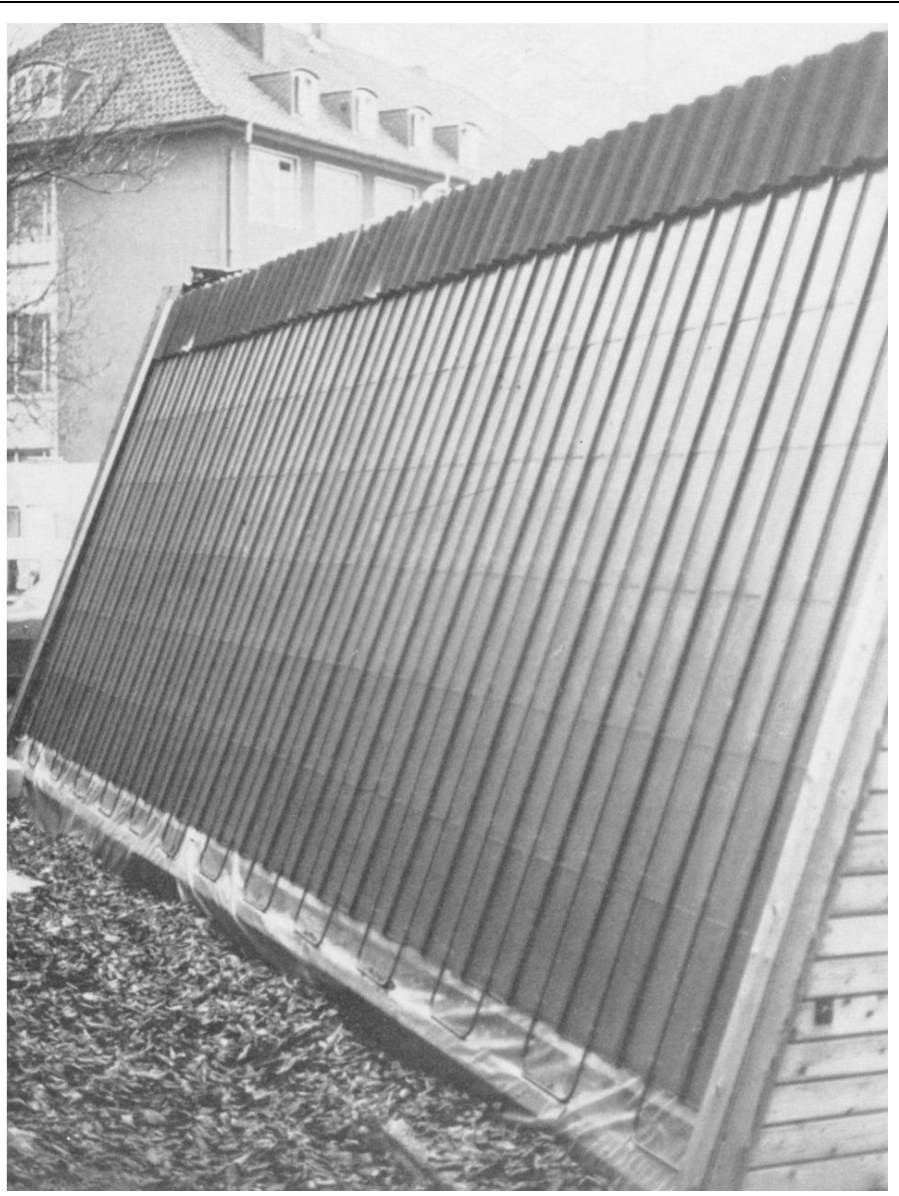

Figure 2.4: Typical Example of a Roof-Integrated, Unglazed Solar Absorber [14] 
Different kinds of solar absorbers for building integration were developed by Shinobu et al [15]. Figure 2.5 shows the collectors, made of black anodised extruded aluminium without back insulation and glass cover.

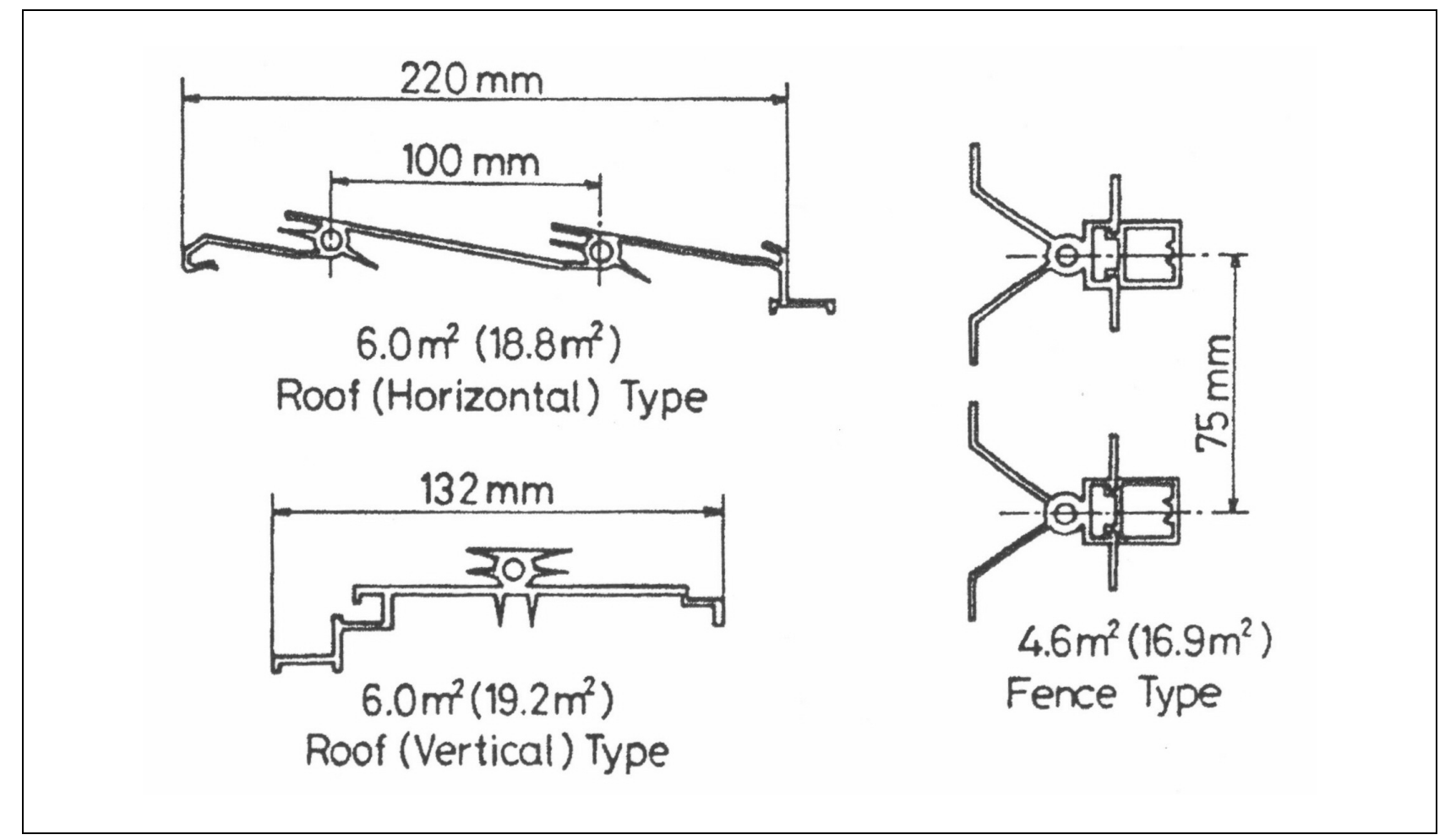

Figure 2.5: Cross Sections of Different Types of Solar Absorbers for Building Integration [15]

Rheinzink GmbH\&Co.KG, Datteln (Germany), a manufacturer of zinc sheet, developed a solar absorber for house heating purposes. Figure 2.6 illustrates the so-called "Quick Step - SolarThermie" module, which has recently been commercially available. It is mounted on the roof truss and takes over the function of a roof covering as well as the function of a solar thermal absorber. Tubes for fluid circulation and heat abstraction are fixed on the backside of the module. The single modules $\left(0,9 \mathrm{~m}^{2}\right)$ are connected to an aggregated fluid circuit. Rheinzink suggests a direct connection of the absorber to the heat pump evaporator circuit. Additionally a ground collector for storing surplus solar energy and bridging of periods with a low outdoor temperature (and thereby low absorber and evaporator temperature) is provided. The heating system is directly connected to the heat pump; a storage tank only exists for hot water supply. A simulation study showed a $S P F_{h p}$ of 4.5 for a one-family house [16]. 


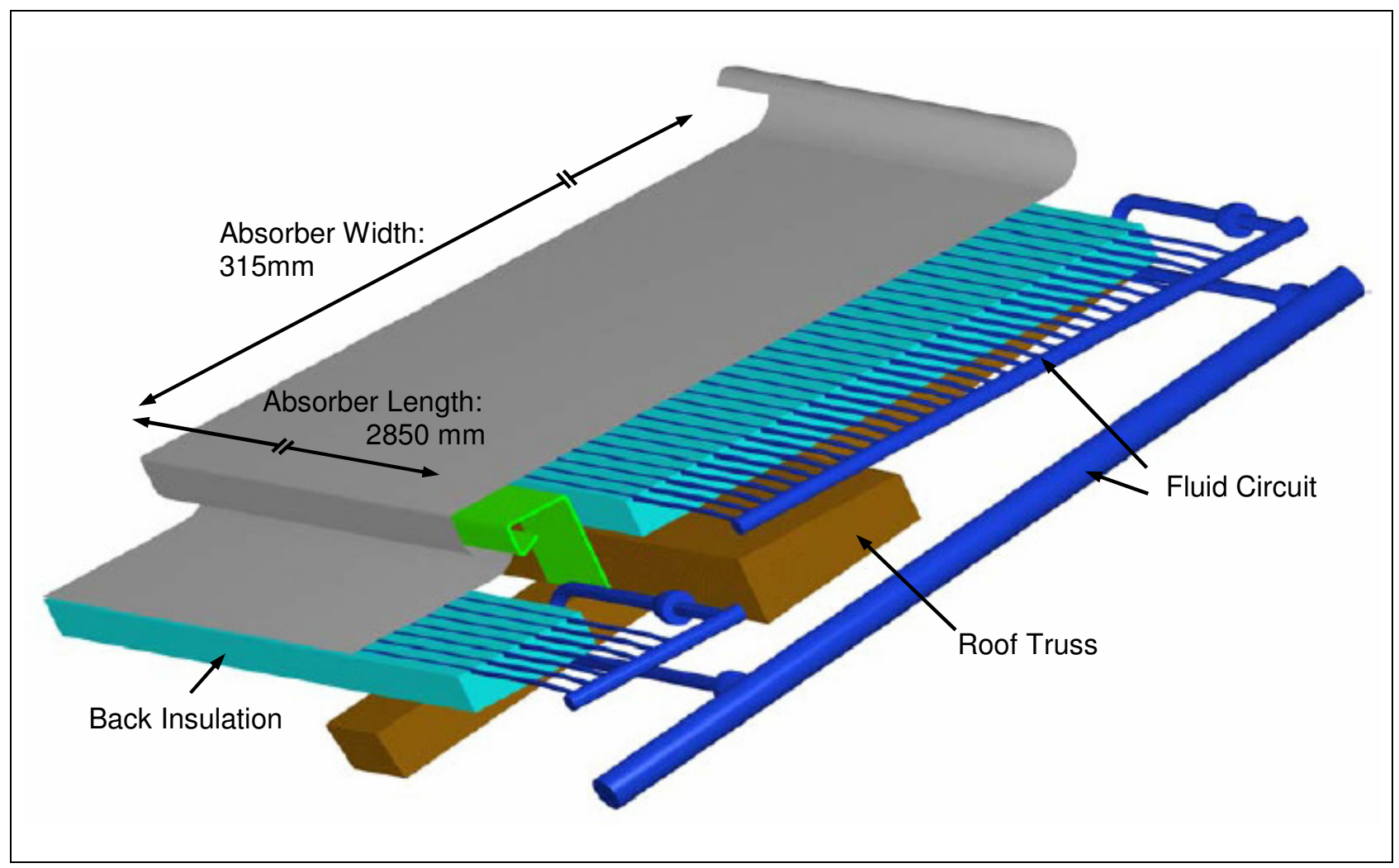

Figure 2.6: A modular Plane Energy Absorber: Quick Step - SolarThermie [16]

A laboratory-scale solar heat pump system with two types of collectors was investigated by Ito et al. One collector was an unglazed flat plate collector with tubes and insulation on the backside, a so-called radiative evaporator. The other collector, the convective evaporator, was made of a copper tube with thin aluminium fins. It was shown that using the two collectors in parallel raised $\mathrm{COP}_{h p}$ at low solar insolation [17].

Furthermore, Ito et al [18] analysed the performance of such a system with photovoltaic cells bonded on the surface of the thermal collectors by conductive silicone. It was found that the photovoltaic modules on the collectors did not influence the performance of the heat pump appreciably.

As described, there are several problems with non-storage systems as for example low collector temperatures during the night. For that reason, storage tanks between collector and heat pump evaporator have been applied. A very easy possibility of energy storage is the use of a water tank. Water as storage medium is favourable due to its physical properties (nontoxic, noncombustible, easy to handle,...) as well as its inexpensiveness. The store separates the collector and evaporator circuit hydraulically by a heat exchanger. 
Several studies on solar heat pumps with water stores have been carried out. Table 2.2 shows the characteristics of three experimental houses with solar heat pump systems and water tanks between collector and evaporator circuit.

Table 2.2: Characteristics of Experimental Houses with Water Stores in the Collector Circuit

\begin{tabular}{|c|c|c|c|c|}
\hline & & $\begin{array}{c}\text { Dornier/RWE } \\
\text { Solar House [19] }\end{array}$ & $\begin{array}{c}\text { Philips Experimental } \\
\text { House [20] }\end{array}$ & $\begin{array}{l}\text { BBC Solar } \\
\text { House [21] }\end{array}$ \\
\hline Location & & Essen (Germany) & Aachen (Germany) & Walldorf (Germany) \\
\hline Living Area & {$\left[\mathrm{m}^{2}\right]$} & 190 & 116 & 170 \\
\hline $\begin{array}{l}\text { Average Specific } \\
\text { Annual Heat De- } \\
\text { mand }\end{array}$ & $\begin{array}{l}{[\mathrm{kWh} /} \\
\left.\left(\mathrm{m}^{2 *} \mathrm{a}\right)\right]\end{array}$ & 127 & 71 & 82 \\
\hline Collector Area & {$\left[\mathrm{m}^{2}\right]$} & $\begin{array}{c}68 \\
\text { (flat-plate, } \\
\text { heat-pipe-absorber) }\end{array}$ & $\begin{array}{c}20.3 \\
\text { (evacuated tube, } \\
\text { non-concentrating) }\end{array}$ & $\begin{array}{c}71.5 \\
\text { (flat-plate, aluminium } \\
\text { roll-bond absorber) }\end{array}$ \\
\hline $\begin{array}{l}\text { Collector-side } \\
\text { Storage Volume }\end{array}$ & {$\left[\mathrm{m}^{3}\right]$} & $\begin{array}{c}7.2 \\
\text { (water tank) }\end{array}$ & $\begin{array}{c}42 \\
\text { (water tank) }\end{array}$ & $\begin{array}{c}8 \\
\text { (water tank) }\end{array}$ \\
\hline $\begin{array}{l}\text { Temperature } \\
\text { Range of Collec- } \\
\text { tor-Side Storage }\end{array}$ & {$\left[{ }^{\circ} \mathrm{C}\right]$} & $5 \ldots 35$ & $15 \ldots 70$ & $5 \ldots 90$ \\
\hline $\begin{array}{l}\text { Heat Pump Con- } \\
\text { nection Power }\end{array}$ & {$[\mathrm{kW}]$} & 2.8 & 1.8 & 1.9 \\
\hline$f_{\text {sol }}$ & [\%] & $\begin{array}{c}46 \\
(1979)\end{array}$ & $\begin{array}{c}72 \\
(1975 / 76)\end{array}$ & $\begin{array}{c}58 \\
\text { (1976/77, simulation) }\end{array}$ \\
\hline
\end{tabular}

All three houses were built and operated in the 1970s. They concordantly showed an improvement of insolated energy utilised by the solar collector of more than factor 2 (by higher efficiency on the one hand and extended operating time on the other hand) due to low storage temperatures [19] [22]. Especially the investigation of the Philips Experimental House showed that a Solar Fraction of $f_{s o l}=72 \%$ could be achieved by this collectorstorage-configuration. Figure 2.7 illustrates that the fraction of heat dissipated of the complete insolation on the collector area is relatively high in comparison to customary solar systems. 


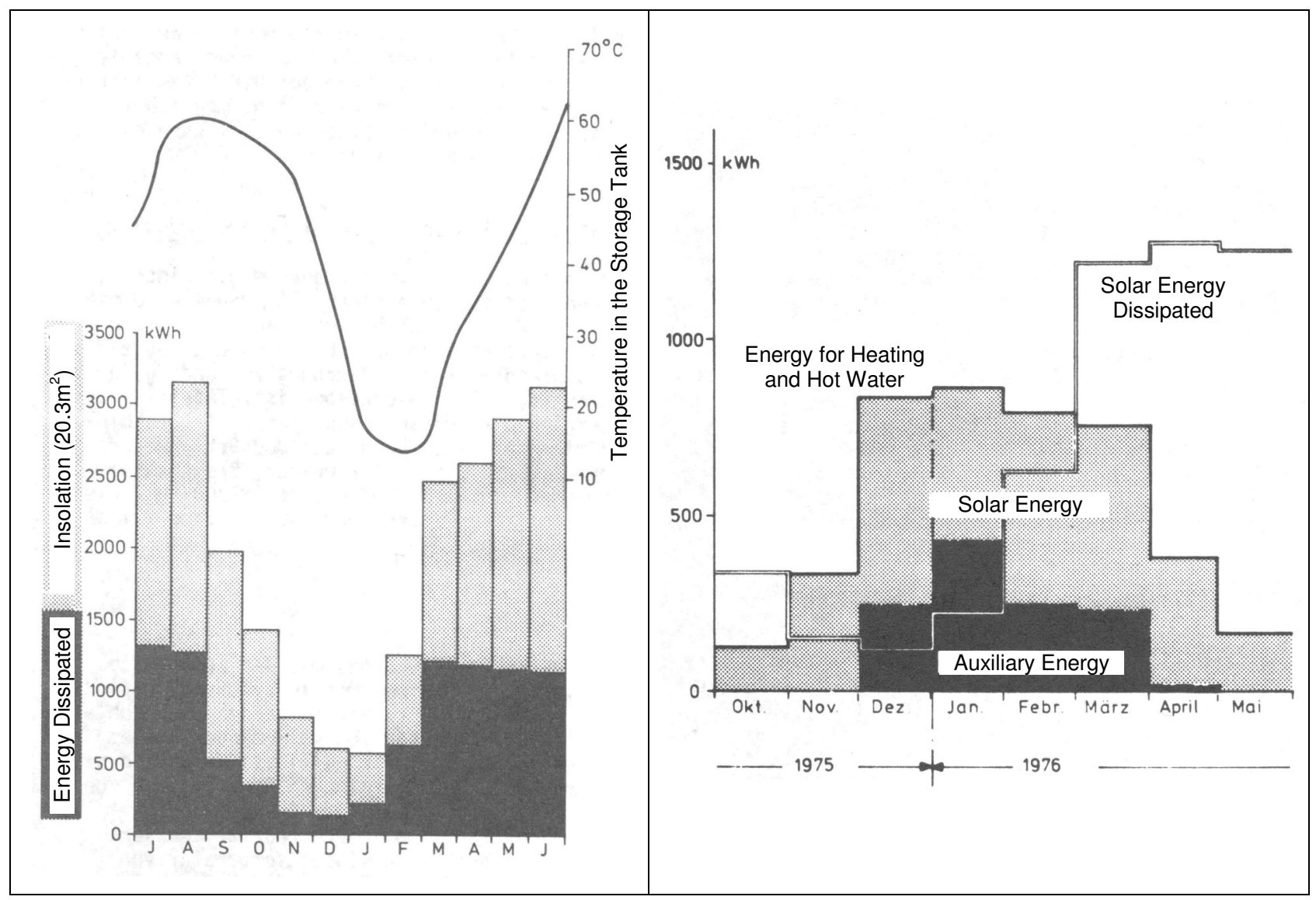

Figure 2.7: Monthly Insolation on Collector Area, Dissipated Energy and Temperature in the Storage Tank in the Philips Experi-

Figure 2.8: Monthly Energy Balance of the Philips Experimental House [20] mental House [20]

The highest monthly collector degree of utilisation was $50 \%$; its average value was $40 \%$. The curve of the storage temperature proves that solar energy is stored seasonally in this system. As can be seen in Figure 2.8, the storage tank is discharged until December, whereas it is charged from January onwards. From March, the solar energy extracted from the collectors is higher than the heat demand of the building. The auxiliary energy (28\% of the complete heat demand) is electrical energy for the heat pump (90\%) and heat extracted from a ground collector and a wastewater tank (10\%) by the heat pump [20].

Since the systems described have rather big heat stores, the Brown, Boverie \& Cie AG (BBC AG), Mannheim (Germany), investigated the use of a latent heat storage tank in its experimental house as an alternative to the water tank. 
In (water) tanks for sensible heat storage, heat can only be stored by increasing the temperature of the storage medium. As the performance of the collector-storage configuration decreases with increasing storage temperatures, the usage of latent heat materials with a low melting point is indicated.

In the Solar House of the $B B C A G$, the water store $\left(8 \mathrm{~m}^{3}\right)$ was replaced by a latent heat store $\left(2.1 \mathrm{~m}^{3}\right)$. As a heat storage medium, paraffin was investigated. It was found that the replacement of the storage tank had little influence on the system's performance. Water/ice as an alternative storage medium, however, increased the solar energy used by $15 \%$ due to the low melting point of water/ice [22].

At Karadeniz Technical University, Trabzon (Turkey) a solar-assisted heat pump system was operated. This experimental system incorporated a latent heat storage tank in combination with flat-plate collectors $\left(30 \mathrm{~m}^{2}\right.$, single-glazed, black board paint). As phase change material (PCM), a salt hydrate $(1,500 \mathrm{~kg}$ calcium chloride hexahydrate encapsulated in polyvinyl chloride containers) with a melting point of $28 \ldots 30^{\circ} \mathrm{C}$ was used. The system was designed for series, parallel and dual source (alternative source: ambient air) operation. Measurements over a day in the Black Sea region under comparable weather conditions showed a considerable improvement of the system's efficiency by the use of the latent heat store in a series system in comparison to non-storage series and parallel configurations. $C O P_{h p}$ was much more stable diurnally due to the storage tank. The collector efficiency was enhanced up to $90 \%$ in the series system with storage especially in the heating season. Furthermore, the application of the storage tank led to steady collector efficiency [23] [24].

The investigations described showed a beneficial influence of thermal energy storage between collector and heat pump on the short-term (e.g. Karadeniz Technical University) as well as on the long-term system efficiency (e.g. Philips Experimental House). Moreover, it is obvious that collector efficiency and thereby the efficiency of the whole system increases with decreasing storage temperatures. Hence, the incorporation of a latent heat storage tank with water as the PCM promises a favourable influence on the series solar heat pump system. The use of water with a low melting point has positive effect on the collector efficiency on the one hand. On the other hand, the usage of the latent heat 
of phase change helps reducing storage volumes. Nevertheless, only a few researchers and some companies have pursued this concept in the past.

The Oak Ridge National Laboratory, USA, developed a heat pump system with seasonal storage that provides heating, hot water and cooling. The system incorporates an insulated underground water tank being frozen during the heating season; the ice is stored for cooling in summer. Figure 2.9 shows a simplified diagram of the so-called Annual Cycle Energy System (ACES).

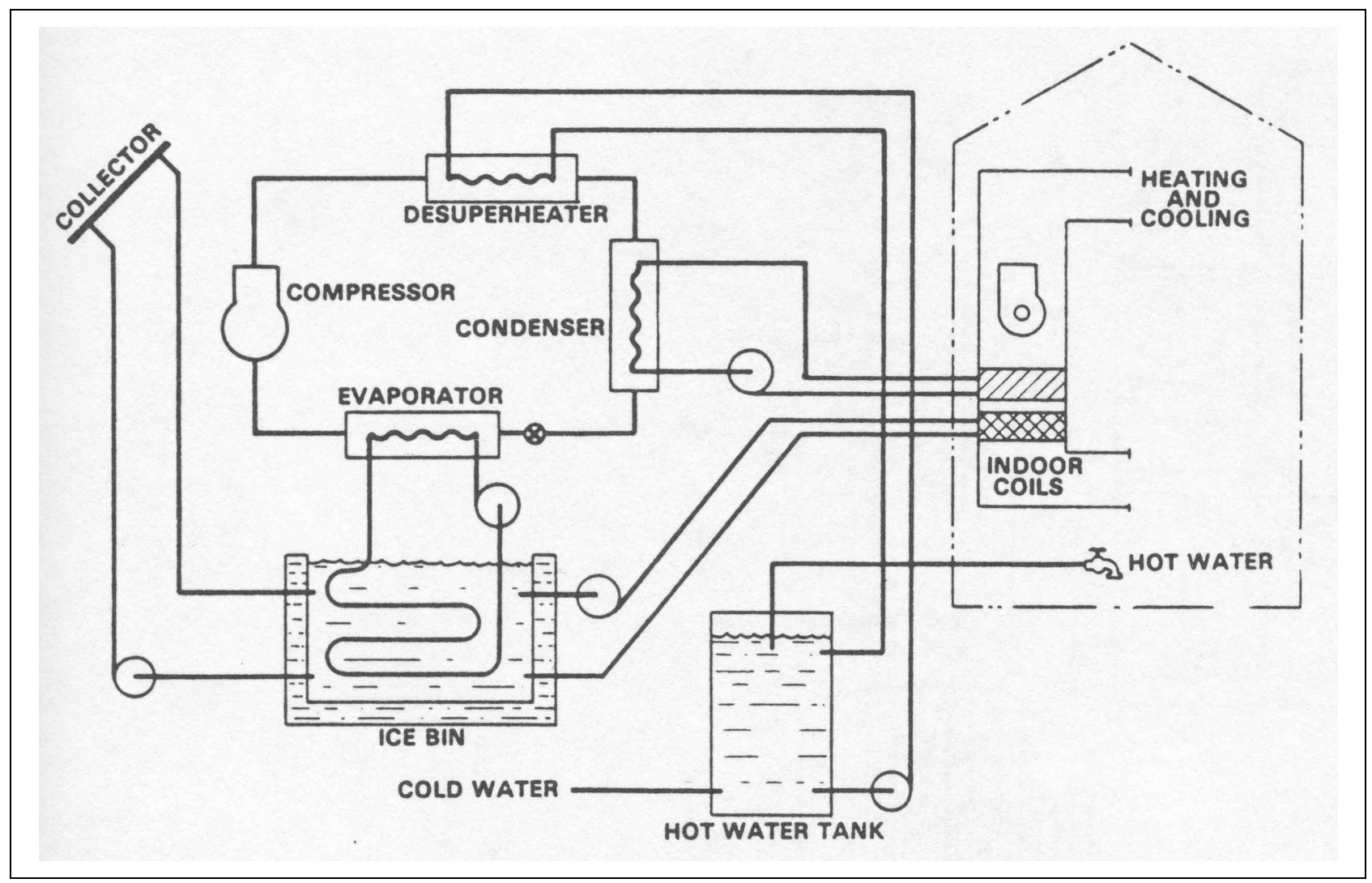

Figure 2.9: Simplified Diagram of the Annual Cycle Energy System [25]

The system is particularly advantageous in climatic zones with nearly equal heating and cooling loads. If the heating requirements exceed the cooling load, unglazed solar absorbers are used as an additional heat source. In an experimental installation, ice storage with an aluminium finned tube heat exchanger was employed. Experimental investigations showed an annual electricity saving of more than $50 \%$ in comparison to a system based on full electric energy supply [26] [27]. 
For several years, an experimental house with a solar assisted heat pump and a water/ice latent heat storage tank was investigated at Lübeck University of Applied Sciences (Germany). Figure 2.10 and Table 2.3 show the significant characteristics of the experimental system.

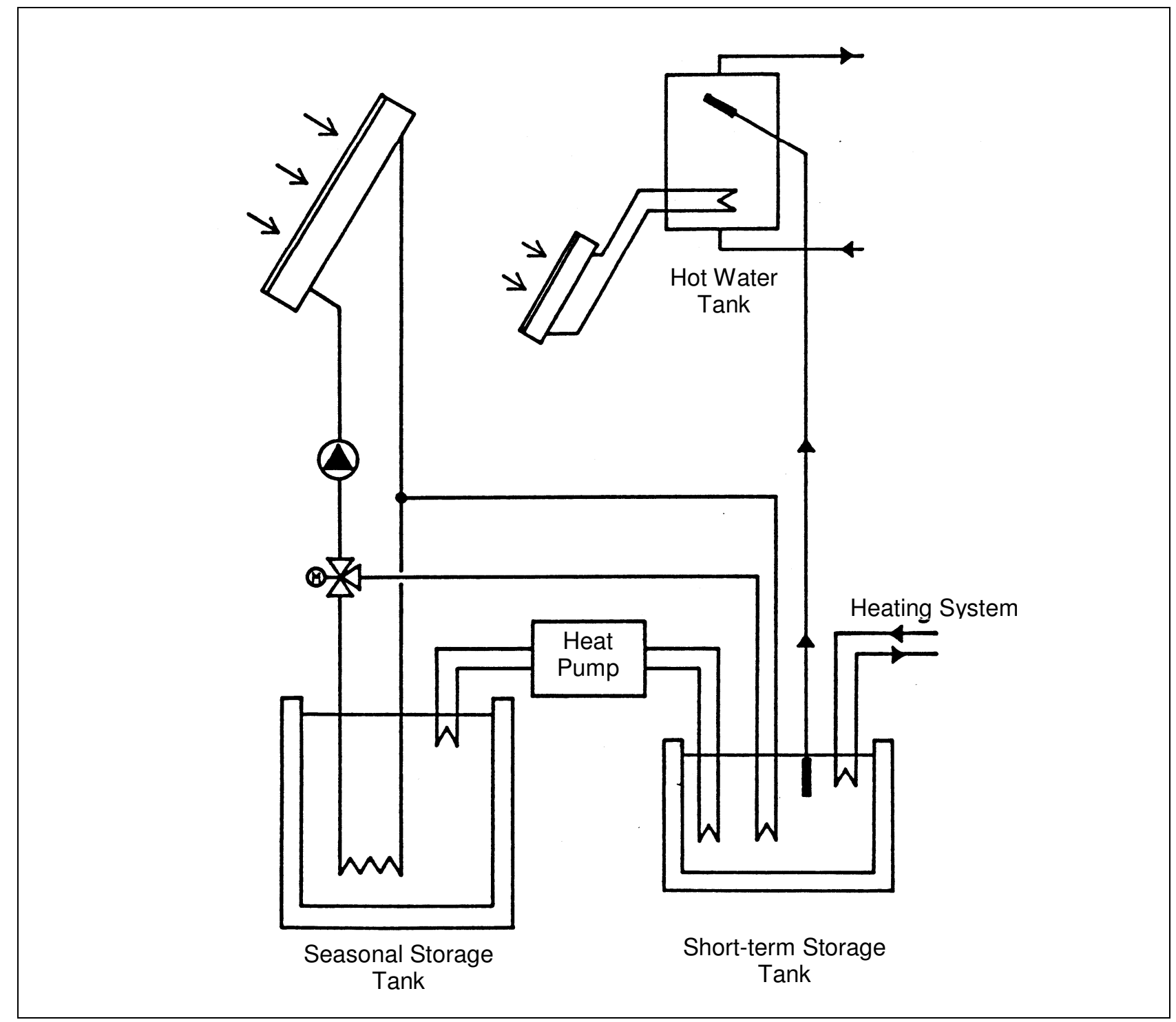

Figure 2.10: Diagram of the Heating System of the Experimental House of Lübeck University of Applied Sciences [28] 
Table 2.3: Characteristics of the Experimental House of Lübeck University of Applied Sciences [28][29][30]

\begin{tabular}{|c|c|c|c|}
\hline & & $1982-1987$ & $1987-1996$ \\
\hline Location & & \multicolumn{2}{|c|}{ Lübeck (Germany) } \\
\hline Living Area & {$\left[\mathrm{m}^{2}\right]$} & 130 & 190 (including winter garden) \\
\hline $\begin{array}{l}\text { Average Specific } \\
\text { Annual Space } \\
\text { Heating Demand }\end{array}$ & $\begin{array}{l}{[\mathrm{kWh} /} \\
\left.\left(\mathrm{m}^{2} \mathrm{a}\right)\right]\end{array}$ & 92 & 70 \\
\hline Collector Area & {$\left[\mathrm{m}^{2}\right]$} & $\begin{array}{c}17.5 \text { (flat-plate) } \\
11.5 \text { (flat-plate, heat-pipe-absorber) } \\
6 \text { (vacuum tube) }\end{array}$ & $\begin{array}{c}20 \\
\text { (flat-plate, transparent insulation) }\end{array}$ \\
\hline $\begin{array}{l}\text { Collector-Side } \\
\text { Seasonal Storage } \\
\text { Tank Volume }\end{array}$ & {$\left[\mathrm{m}^{3}\right]$} & $\begin{array}{c}18 \\
\text { (helical tube heat exchanger) }\end{array}$ & $\begin{array}{c}20 \\
\text { (helical tube heat exchanger) }\end{array}$ \\
\hline $\begin{array}{l}\text { Short-Term Stor- } \\
\text { age Tank Volume }\end{array}$ & {$\left[\mathrm{m}^{3}\right]$} & $\begin{array}{c}4 \\
\text { (water tank) }\end{array}$ & $\begin{array}{c}3 \\
\text { (water tank) }\end{array}$ \\
\hline $\begin{array}{l}\text { Temperature } \\
\text { Range of Collec- } \\
\text { tor-Side Storage }\end{array}$ & {$\left[{ }^{\circ} \mathrm{C}\right]$} & \multicolumn{2}{|c|}{$0 \ldots 80$} \\
\hline $\begin{array}{l}\text { Heat Pump Con- } \\
\text { nection Power }\end{array}$ & {$[\mathrm{kW}]$} & \multicolumn{2}{|c|}{2.1} \\
\hline$f_{\text {sol }}$ & [\%] & $\begin{array}{l}\text { 1985/86: } 57 \\
\text { 1986/87: } 62\end{array}$ & $\begin{array}{c}59 \\
\text { (average) }\end{array}$ \\
\hline
\end{tabular}

The system was equipped with a concrete storage tank for seasonal storage including phase change. Figure 2.11 shows the helical tube heat exchangers mounted in the tank.

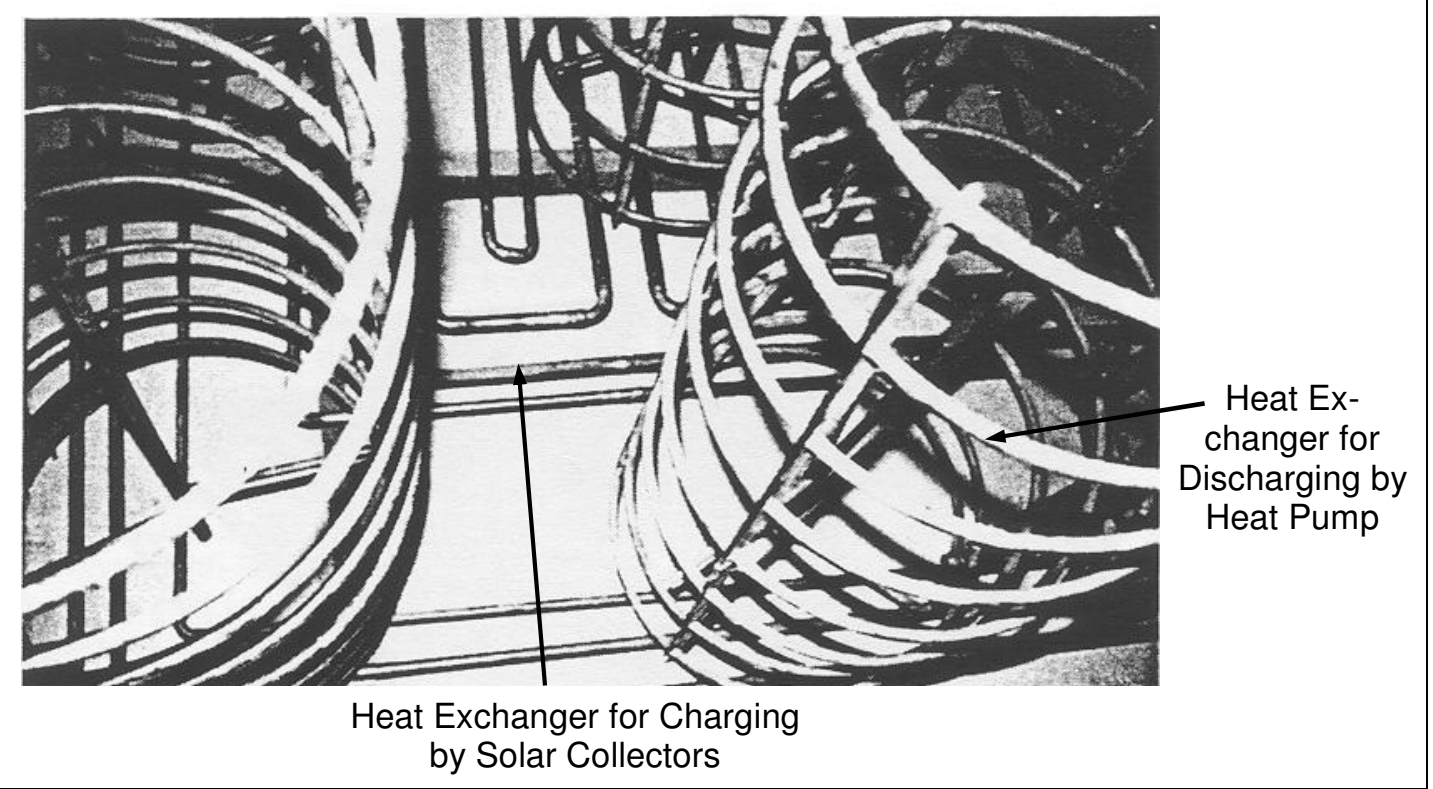

Figure 2.11: Interior View of Latent Heat Storage Tank of Lübeck University of Applied Sciences [28] 
Figure 2.12 illustrates the temperatures in the latent heat storage tank and in the shortterm storage tank in 1995 . The seasonal storage tank is heated up to approximately $80^{\circ} \mathrm{C}$ in summer. During the heating season it is cooled down by the heat pump to $0^{\circ} \mathrm{C}$. The phase transition is utilised. From June to November the thermal energy can be transferred directly into the short-term storage tank for hot water preparation and space heating. From December to May, the heat pump has to raise the temperature to a usable level. Beginning in April the seasonal store is heated up by the solar collectors, i.e. solar energy collected is higher than the heat demand. This corresponds well with the results obtained from the Philips Experimental House (Figure 2.7).

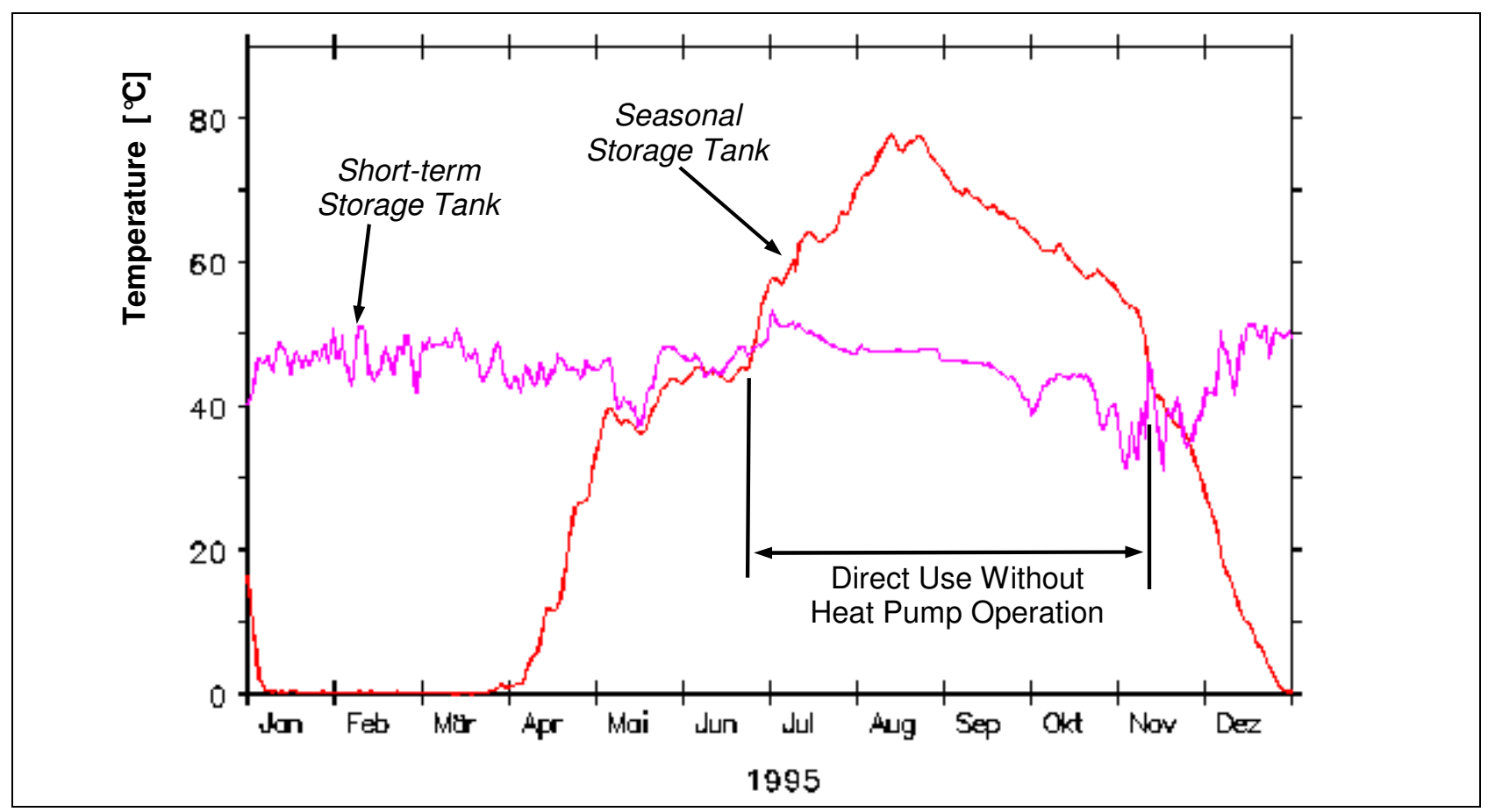

Figure 2.12: Temperatures of Long-Term and Short-Term-Storage [29]

As can be seen in Table 2.3, a Solar Fraction of up to $f_{\text {sol }}=62 \%$ was achieved in the Lübeck Solar House. This is significantly higher than the Solar Fraction a comparable solar installation without heat pump is able to achieve. The major problem of the experimental system is that the $S P F_{h p}$ is relatively low (2.1). The reason is that the performance of the tube type heat exchanger in the latent heat storage tank strongly decreases with a growing ice layer on the tubes. Consequently, the evaporator temperature and thereby $C O P_{h p}$ worsens. Furthermore, the storage medium can only be frozen to a degree of approximately $60 \%$ (vol.), due to insufficient heat exchanger performance. 
In a private initiative, a house with a solar heat pump is operated in Bad Reichenhall (Germany). W. Hesse planned and built the solar heating system, which is shown in Figure 2.13. Table 2.4 gives detailed information on the characteristics of the house and the heating system.

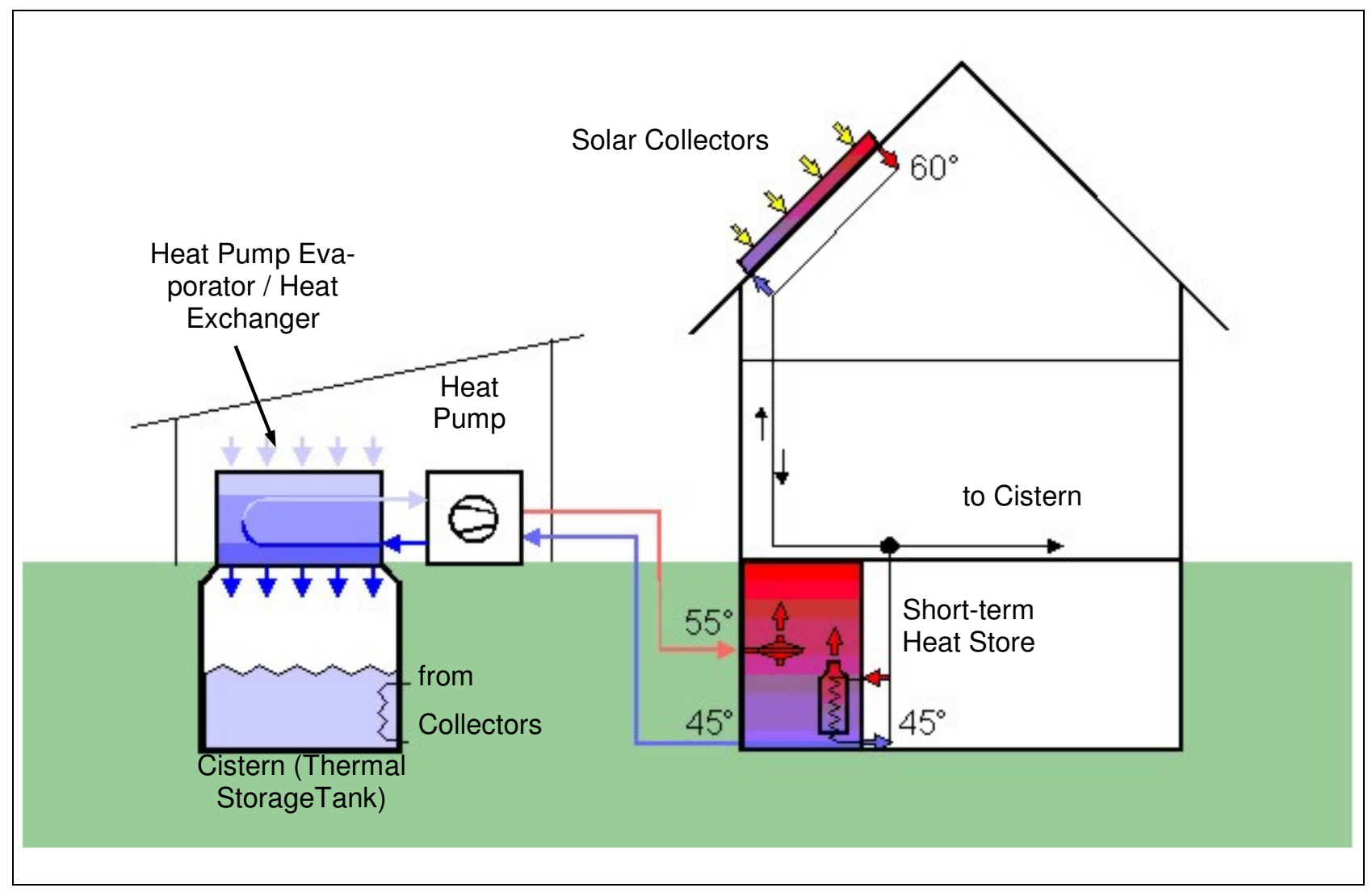

Figure 2.13: Schematic of the Heating System operated by W. Hesse in Bad Reichenhall (Germany) [31]

Table 2.4: Characteristics of the Heating System operated by W. Hesse in Bad Reichenhall (Germany) [31]

\begin{tabular}{|c|c|c|}
\hline Location & & Bad Reichenhall (Germany) \\
\hline Living Area & {$\left[\mathrm{m}^{2}\right]$} & 230 \\
\hline $\begin{array}{l}\text { Average Specific Annual Heat } \\
\text { Demand }\end{array}$ & $\begin{array}{l}{[\mathrm{kWh} /} \\
\left.\left(\mathrm{m}^{2} \mathrm{a}\right)\right]\end{array}$ & 130 \\
\hline Collector Area & {$\left[\mathrm{m}^{2}\right]$} & 16 (flat-plate) \\
\hline $\begin{array}{l}\text { Collector-Side Seasonal Stor- } \\
\text { age Tank Volume }\end{array}$ & {$\left[\mathrm{m}^{3}\right]$} & $\begin{array}{c}40 \\
\text { (cistern in the garden, } \\
\text { dynamic heat exchanger) }\end{array}$ \\
\hline $\begin{array}{l}\text { Short-Term Storage Tank Vol- } \\
\text { ume }\end{array}$ & {$\left[\mathrm{m}^{3}\right]$} & $\begin{array}{c}4 \\
\text { (water tank) }\end{array}$ \\
\hline $\begin{array}{l}\text { Temperature Range of Sea- } \\
\text { sonal Storage }\end{array}$ & {$\left[{ }^{\circ} \mathrm{C}\right]$} & $0 \ldots 30$ \\
\hline Heat Pump Connection Power & {$[\mathrm{kW}]$} & 2.47 \\
\hline
\end{tabular}


The speciality of this system is a cistern $\left(40 \mathrm{~m}^{3}\right)$ in the garden, which is used as a seasonal storage tank. The cistern is not insulated, thus makes use of thermal energy from the ground in winter times when the storage temperature is below the surrounding ground temperature. The latent heat of water is also utilised in this system by a so-called dynamic heat exchanger. The heat pump evaporator is mounted above the cistern. Water is poured over the heat exchanger plates; the ice is automatically removed after a certain period. The system operates satisfactorily and provides sufficiently for the building's heat demand. A direct connection between the heat pump and the collectors does not exist [32]. A technical analysis of this system is unfortunately not available.

A solar heat pump system with latent heat storage is commercially available from HitSolar21, Ramsau (Austria). The system incorporates an energy roof (collectors without insulation and glass cover), a heat pump and a cistern as latent heat store. The patented heat exchanger in the cistern is shown in Figure 2.14. The heat exchanger is mounted in the cistern and connected to the heat pump evaporator. The water freezes along the plates. Several systems have been installed in family houses in Germany and Austria [33]. Further information concerning the performance of the system is unfortunately not available.

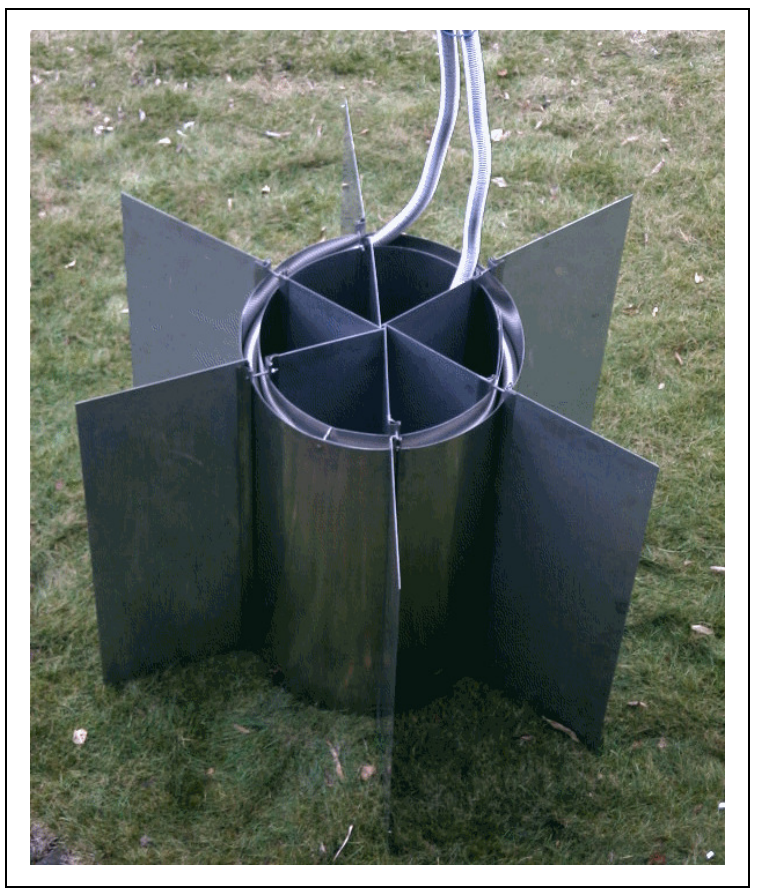

Figure 2.14: Heat Exchanger for Latent Heat Storage in a Cistern [34]

Engineering company Ecofys, Utrecht (The Netherlands) planned and operated a lowenergy one-family house in the Netherlands combining heat pump and solar thermal collectors $\left(10 \mathrm{~m}^{2}\right.$, flat-plate). An uninsulated garden cistern $\left(3 \mathrm{~m}^{3}\right)$ was equipped with smooth tube heat exchangers and a domestic wastewater tank for heat recovery. The system performance was partly monitored in the heating season 1998/99. A major problem with insufficient heat exchanger performance during phase change was identified [35]. The scientific monitoring of the project did not go beyond the preliminary investigation. 


\subsubsection{Performance of the Individual Components}

The efficiency of a solar thermal collector in general drops with increasing temperature difference between the collector and the ambient due to the collector's heat losses. Thus, a reduction of the temperature difference can improve the collector's energy output considerably [36] [37]. In the system proposed, the heat pump evaporator or the lowtemperature latent heat store supplies the collector inlet with low-temperature fluid and thereby reduces the collector temperature and the temperature difference to the ambient. A number of experimental and simulation studies show that the collector efficiency can be improved by the series connection with a heat pump.

The results of simulations at Karadeniz Technical University for example indicate that a high collector efficiency of $50 \ldots 90 \%$ can be realised with a series solar heat pump system. Figure 2.15 shows the collector efficiency of three different system configurations. The series solar heat pump system with storage is superior to the conventional solar system (without heat pump), the parallel solar heat pump system and the dual source series system (the source with higher temperature is chosen for the evaporator). Experimental investigations agree with these results [38] [39].

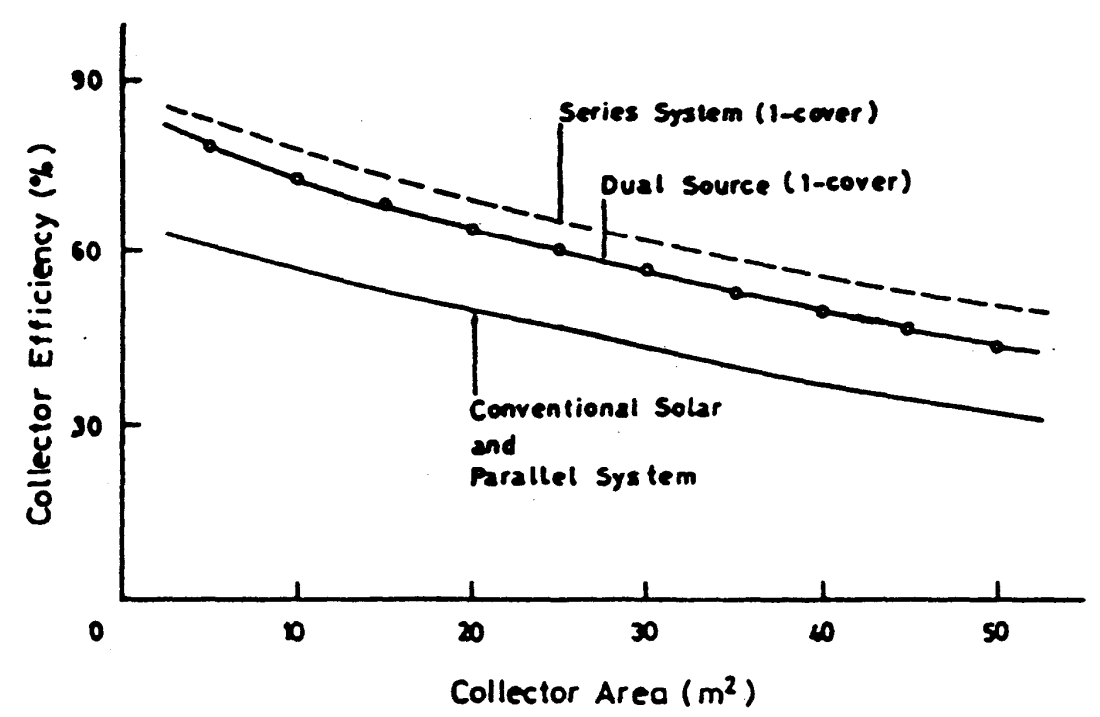

Figure 2.15: Collector Efficiency of Combined Solar Heat Pump System Configurations as a Function of Collector Area (Seasonal Results, Climate: Trabzon, Turkey) [38]

Complimentary to these investigations, Freeman et al [40] identified an increase of collector efficiency in series solar heat pump systems in a simulation study, as shown in Figure 2.16. 


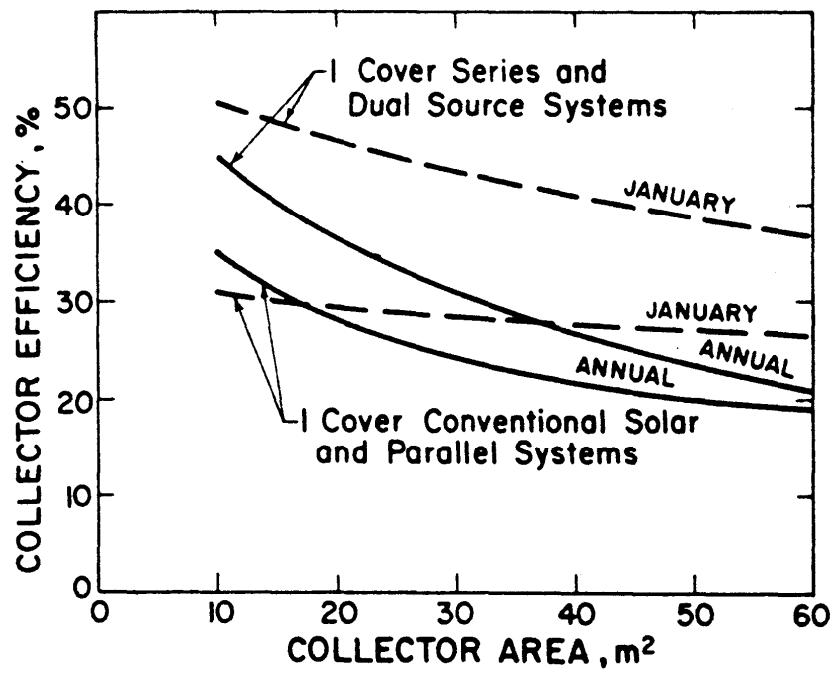

Figure 2.16: Collector Efficiency of Series and Parallel Systems (Seasonal Results, Climate: Madison/Wisconsin, USA) [40]

In addition to that, O'Dell et al [41] investigated the influence of the collector design and showed that the performance of uncovered collectors was much higher in series systems without storage compared to covered collectors. Since a high potential for covered collectors in series systems with storage was also found, the question of collector performance and quality required (especially regarding thermal insulation) needs further investigation.

As described before, Freeman et al [40] identified a high potential for series solar heat pump systems with storage in the collector circuit. Since the collector is the only heat source for the heat pump, night-time or low-insolation operation of the heat pump would lead to a low $C O P_{h p}$ in case of low outdoor temperatures. The storage tank can bridge these periods and thereby improve the $S P F_{h p}$.

In general, it is expected that the use of solar energy as a heat pump source raises $C O P_{h p}$ considerably by offering a higher temperature level. The influence of both the system configuration (series/parallel) and energy storage in the collector/evaporator circuit on $C O P_{h p}$ was experimentally analysed by Kaygusuz et al [38] [39]. Figure 2.17 shows that the series system with storage is superior to the series system as well as the parallel system without storage. In fact, the $\mathrm{COP}_{h p}$ of a non-storage system is higher in the beginning of the day. However, it strongly decreases when insolation becomes low. In contrary, the series system with storage can actually raise $C O P_{h p}$ overnight. In any case, the use of storage leads to a more stable $C O P_{h p}$. 


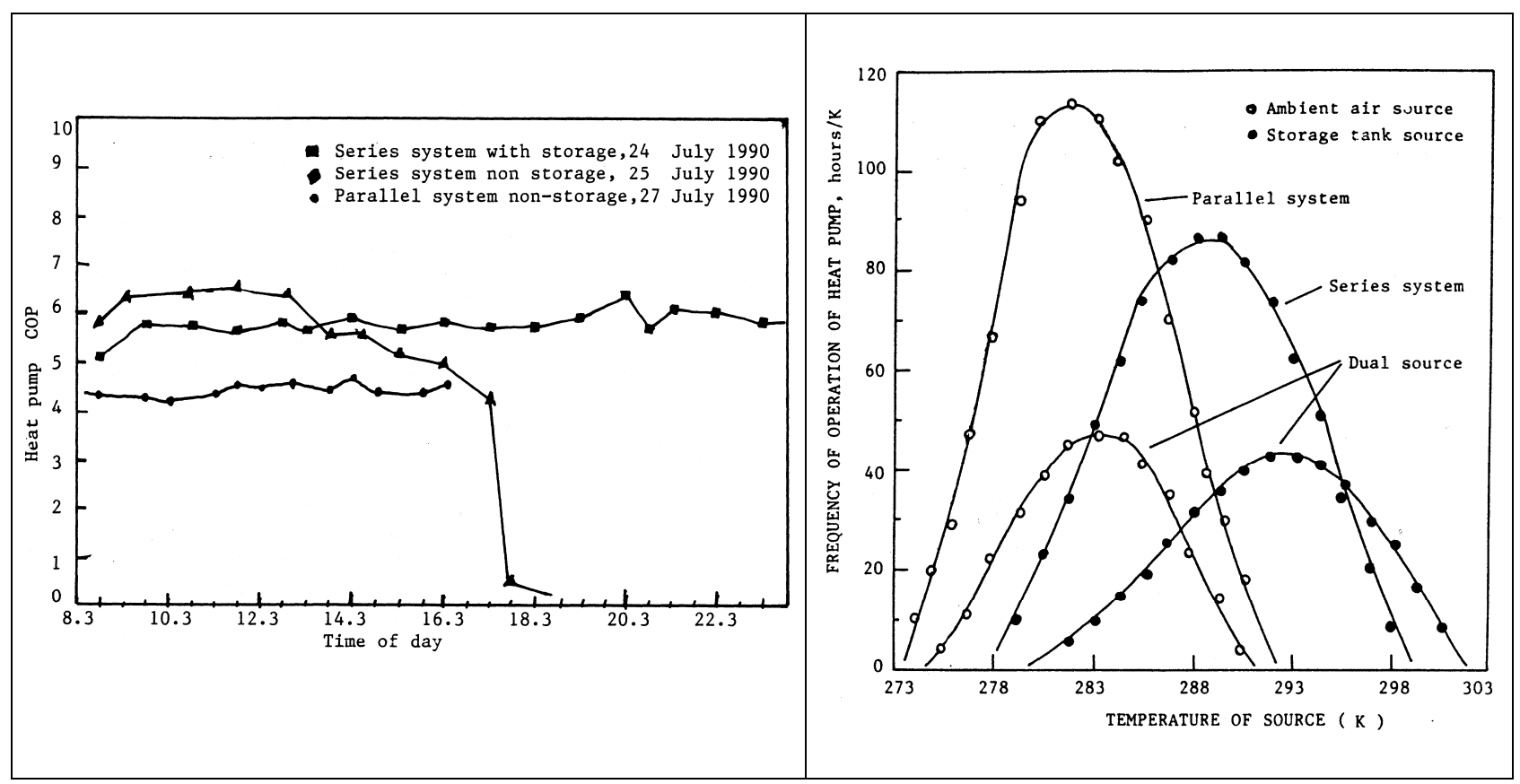

Figure 2.17: Measured $C O P_{h p}$ Values of Different Solar Figure 2.18: Heat Pump Frequency of Operation Heat Pump Systems (Climate: Trabzon, Turkey) [39] Distribution with and without Storage (Climate: Trabzon, Turkey) [38]

The improvement of $C O P_{h p}$ can be explained by more favourable source conditions for the heat pump for long periods. Figure 2.18 demonstrates a clear displacement of operation times of a series system to higher source temperatures.

Apart from the system configuration, the storage tank dimensioning has a decisive influence on the system performance, e.g. shown by Posorski [42]. A series solar heat pump system with water-ice storage in the collector circuit (uncovered solar absorbers) was simulated for northern German climates. As illustrated in Figure 2.19, the $S P F_{h p}$ can be improved noticeably by heat storage. Furthermore, it was shown that the incorporation of a latent heat storage tank reduces the auxiliary heating energy required to a minimum. Figure 2.20 demonstrates the influence of storage capacity on auxiliary energy requirement. It is concluded that a storage tank in the collector circuit reduces the heat pump power required for monovalent operation considerably. 


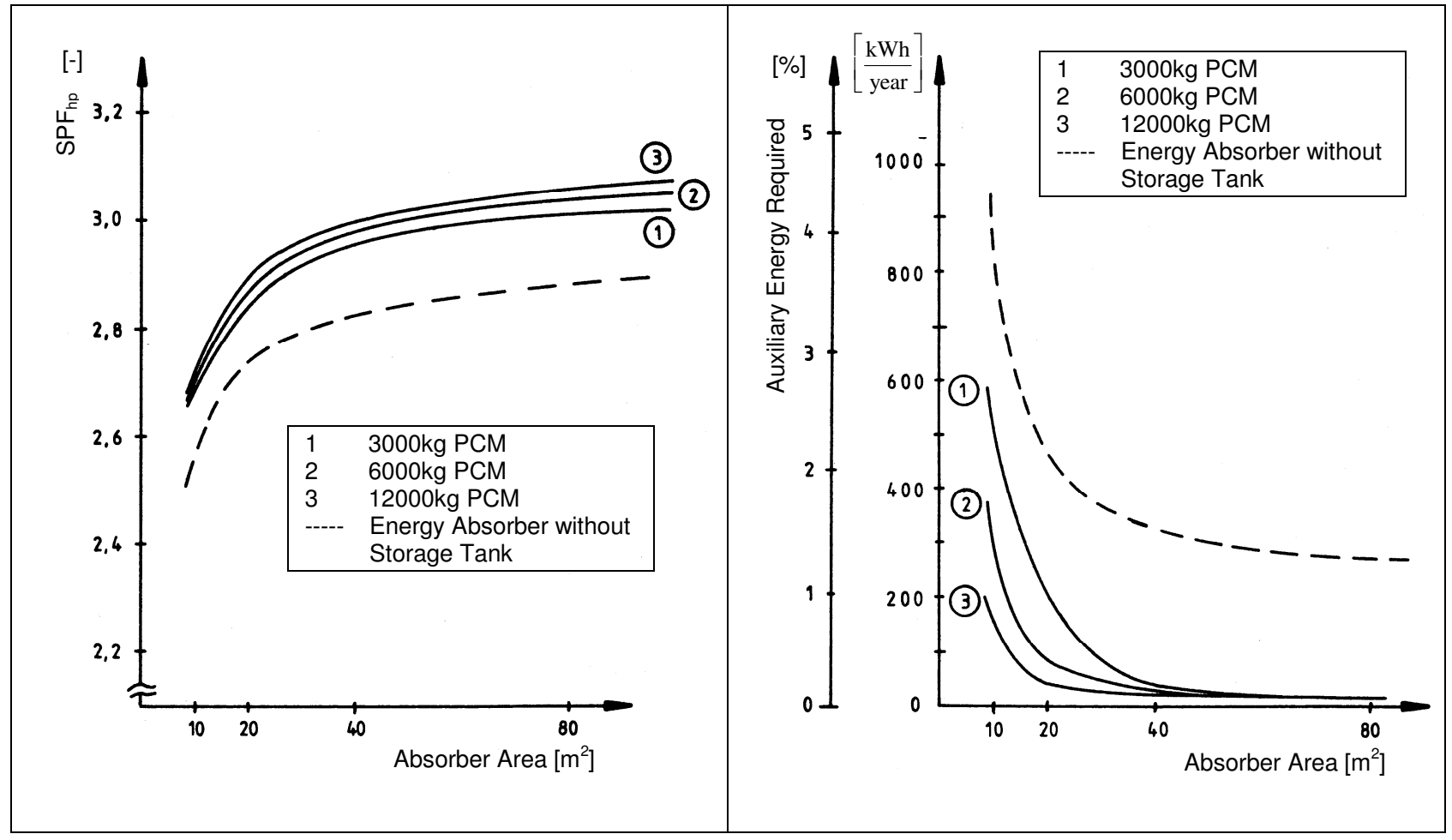

Figure 2.19: Influence of Storage Capacity on $S P F_{h p}$ Figure 2.20: Influence of Storage Capacity on Auxil(Climate: Hamburg, Germany, PCM: Water) [42] iary Heating Energy Required (Climate: Hamburg, Germany, PCM: Water) [42]

In the system proposed, the central store is a stratification tank. This type of storage tank has been taken into account for Central European heating systems for some years. Stratification tanks store water in layers of different temperature. Numerous techniques are commercially available to build up thermally stratified layers. Systems based on a self-acting build-up of layers in the tank by density differences are clearly advantageous over systems with externally actuated injectors. Electrically driven injectors, pumps and valves raise costs as well as failure probability [43].

Stratification tanks are normally incorporated as typical buffer tanks especially in solar systems. In general, their advantage is that on the one hand low collector inlet temperatures can be provided (from the cold layer in the bottom of the tank). On the other hand, solar energy is stored at a higher temperature level and can thus be used for heating/hot water purposes directly without further heating up by a heat generator, e.g. a gas burner. 
Within the system proposed the following advantages of the stratified tank are exploited:

- Basically, in this system the central storage tank is a short-term store for thermal energy delivered from the heat pump, the solar collectors or the latent heat storage tank (cf. Figure 1.2). It provides hot water and energy for space heating (on different temperature levels) to the heating system. Since the store holds thermal energy in readiness for users' demand, the number of heat pump starts and its operation time under unfavourable conditions (at night, low outdoor temperatures,...) can be reduced. Furthermore, the heat pump is able to operate at an expedient $C O P_{h p}$, because the temperature of the heat sink is divided into a higher temperature (approx. $45 \ldots 55^{\circ} \mathrm{C}$ for hot water / small volume) and lower temperature (approx. $35^{\circ} \mathrm{C}$ for space heating / big volume).

- Direct charging from the latent heat storage tank is possible if the temperature is sufficiently high. As for example in autumn when the latent heat tank is fully charged from the summer period the temperature is supposed to be high enough to directly provide thermal energy for the space heating layers of the stratification tank without heat pump operation.

- In case of sufficient solar insolation, the collectors are able to directly charge the stratification tank. The stratification is supposed to be beneficial for this purpose due to storing solar energy at a higher temperature for direct use without heat pump operation.

The incorporation of a stratification tank in a series solar heat pump system is novel. A comprehensive literature survey shows that this combination has not been investigated yet. Due to the advantages described above, the incorporation of a stratification tank promises to raise the system's efficiency further. In addition, this configuration provides a complete heating system for both hot water and space heating purposes. 


\subsubsection{Evaluation of the System Configurations}

It is evident from the preceding analysis that the system configurations have diverse advantages and disadvantages and are thus often applicable only in particular areas or buildings. Table 2.5 gives an overview on the system approaches presented, evaluates their characteristics especially concerning their applicability in Central European climate and buildings and describes the problems linked with the concepts [11]:

The parallel solar heat pump concepts with ground collector and air source are in principle good solutions for domestic heating especially in comparison to fossil fuel fired systems. However, major problems are the high space demand for the collector and the cost of its installation in the ground, which in general limit heat pump distribution especially in existing buildings [44] [45]. The air source heat pump clearly suffers from the long winter periods in Central Europe and the problems linked with it (e.g. hoar frost on the air heat exchanger).

The same problem occurs in non-storage solar heat pump systems with a direct heat pump-collector connection. Monovalent operation seems not to be feasible in Central European climates with long frost periods and for example snow lying on the absorber area, which means an additional heat source (e.g. a furnace) is required.

The water storage systems on the one hand have the disadvantage of large storage volumes and thereby high space demand. On the other hand, they use an easy to handle and cheap storage medium in contrast to the latent heat storage tanks working with paraffin or salt hydrate. These tanks also have the problem that the melting point of many PCMs is relatively high and that the heat exchanger design is complex.

The heat exchanger design is also a challenge for stores that use the water/ice transition. Nevertheless, a water/ice-latent heat storage tank has the most positive influence on the collector degree of utilisation due to the low melting point of water. As the collector efficiency and degree of utilisation increases, the $C O P_{h p}$ decreases; hence system development to achieve an acceptable $S P F_{h p}$ is necessary. Furthermore, the storage volume can be reduced in comparison to a sensible water store by the utilisation of the phase change. 
Christoph Trinkl

Table 2.5: Evaluation of Solar Heat Pump Concepts and Description of Problems

\begin{tabular}{|c|c|c|c|c|c|c|}
\hline & \multicolumn{2}{|c|}{ Parallel Solar Heat Pump } & \multicolumn{4}{|c|}{ Series Solar Heat Pump } \\
\hline & Ground Collector & Air Source & Non-Storage & Water Storage & Latent Heat Storage & Water/lce Storage \\
\hline Applicability in & -- & ++ & ++ & - & + & + \\
\hline Complexity & $\mathbf{0}$ & + & + & $\mathbf{0}$ & - & $\mathbf{0}$ \\
\hline $\begin{array}{l}\text { Applicability in Central } \\
\text { European Climate (re } \\
\text { monovalent operation) }\end{array}$ & ++ & - & - & ++ & ++ & ++ \\
\hline $\begin{array}{l}\text { Influence on Collector } \\
\text { Degree of Utilisation }\end{array}$ & $\mathbf{0}$ & $\mathbf{0}$ & + & + & + & ++ \\
\hline Influence on $S P F_{h p}$ & + & - & - & + & + & $+/ 0$ \\
\hline Problems & $\begin{array}{l}\text { High space de- } \\
\text { mand and installa- } \\
\text { tion effort for } \\
\text { ground collector. }\end{array}$ & $\begin{array}{l}\text { Comparably long } \\
\text { frost periods in Cen- } \\
\text { tral Europe. } \\
\text { Low air temperature } \\
\text { in winter reduces } \\
S P F_{h p} \text {. } \\
\text { Hair frost on air heat } \\
\text { exchanger requires } \\
\text { defrosting. }\end{array}$ & $\begin{array}{l}\text { Strong dependency } \\
\text { on solar insolation. } \\
\text { Additional heat } \\
\text { source (e.g. electric- } \\
\text { ity or fuel) required } \\
\text { for frost periods. } \\
\text { Hoar frost on collec- } \\
\text { tor reduces heat } \\
\text { exchange. }\end{array}$ & $\begin{array}{l}\text { High space de- } \\
\text { mand required due } \\
\text { to large storage } \\
\text { volume. } \\
\text { High storage tem- } \\
\text { peratures require } \\
\text { extensive insula- } \\
\text { tion }\end{array}$ & $\begin{array}{l}\text { Expensiveness of } \\
\text { PCM. } \\
\text { Melting point often } \\
\text { too high. } \\
\text { Heat exchanger de- } \\
\text { sign. }\end{array}$ & $\begin{array}{l}\text { Heat exchanger } \\
\text { design. }\end{array}$ \\
\hline $\begin{array}{l}\text { Examples } \\
\text { (Chapter 2.2.1) }\end{array}$ & & & Rheinzink & $\begin{array}{l}\text { Dornier/RWE } \\
\text { Solar House } \\
\text { Philips Experimen- } \\
\text { tal House } \\
\text { BBC Solar House }\end{array}$ & $\begin{array}{l}\text { BBC Solar House } \\
\text { Karadeniz Technical } \\
\text { University }\end{array}$ & $\begin{array}{l}\text { ACES } \\
\text { Lübeck University } \\
\text { Hesse } \\
\text { HitSolar21 } \\
\text { Ecofys }\end{array}$ \\
\hline
\end{tabular}

++ very positive + positive o acceptable/neutral - negative -- very negative 
As the evaluation of different solar collector / storage / heat pump configurations described above shows, the solar heat pump system proposed offers conceptual advantages for application in the reference buildings defined. The literature survey illustrates, that there have been a few investigations on comparable systems with promising results in the past. However, most projects obviously were initiated during the oil crisis during the 1970s, but not followed up after its end (e.g. Dornier/RWE, Philips, BBC). The activities of Lübeck University of Applied Sciences were cancelled in 1999, after project initiator Prof. H. Weik retired from University [46]. Recently built systems have not been analysed in the detail which would allow an evaluation and further development on a scientific level (W. Hesse, HitSolar21). As a result, fundamental experiences on the system's performance and the dimensioning with up-to-date components for modern state-of-the-art buildings are not available. In addition, a fundamental and comprehensive concept for the control of such systems has not been developed yet.

Therefore, the emphasis of this research project with regard to the system is placed on the development of a simulation model for the heating system including a fundamental control strategy. Based on annual system simulations, an investigation and evaluation of different parameters' influence on the system performance is carried out. Finally, the decisive parameters are identified and a recommended system design is derived. 


\subsection{System Simulation}

In order to evaluate and optimise the proposed heating system, a simulation model in the Matlab/Simulink environment [47] was developed. Matlab/Simulink has been established as a standard platform for researchers and industry in the field of dynamic simulations. While Matlab provides the basis for the handling of mathematical problems, Simulink is set up as a graphical environment in the form of a data-flow-editor, which has full access to all Matlab functions. System models are built up by combining blocks which contain the components' mathematical models and by defining block interactions, illustrated by the collector subsystem in Figure 2.21.

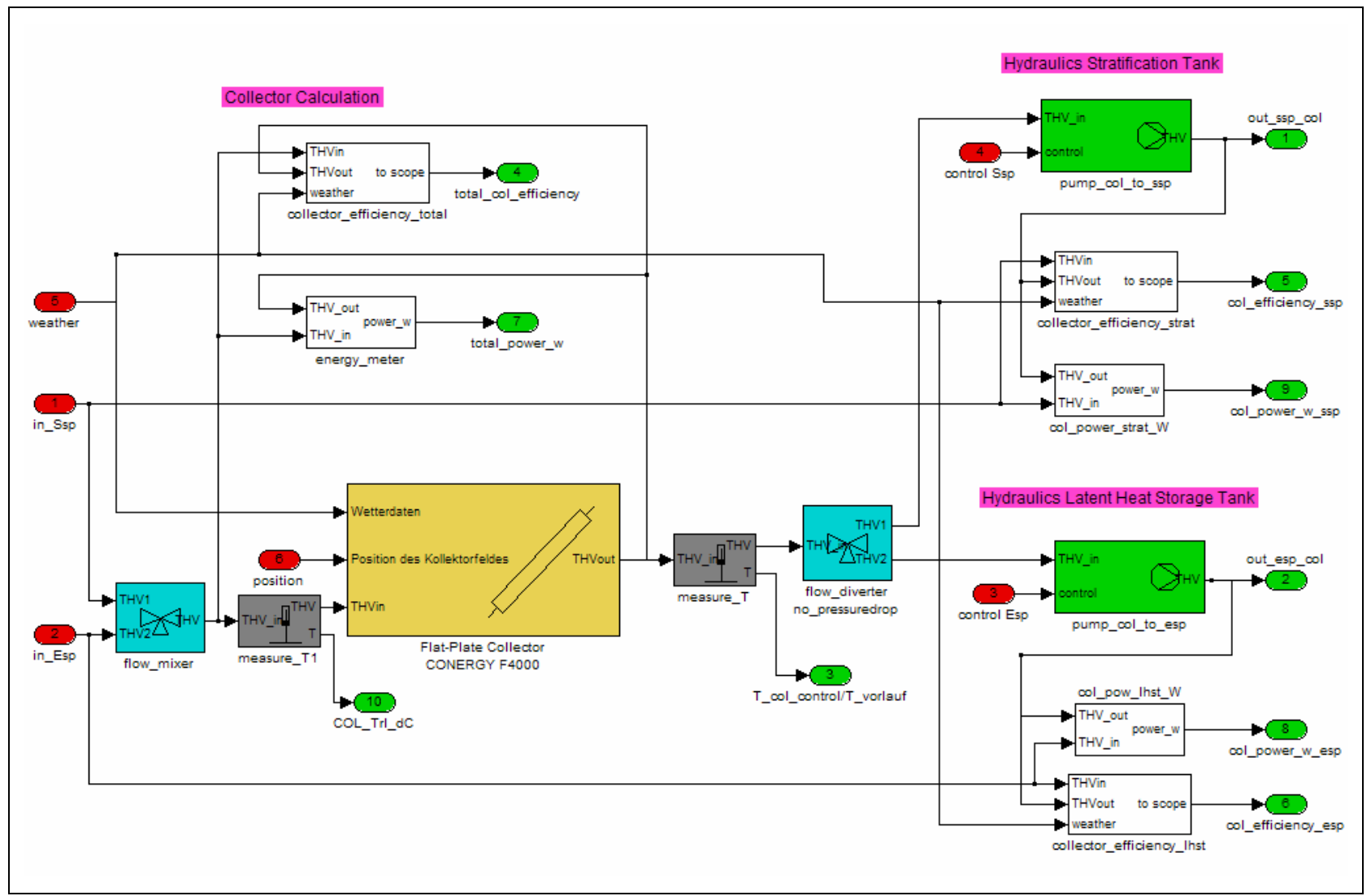

Figure 2.21: Collector Subsystem with Collector Calculation, Hydraulic Elements and Data Measurement

The Simulink-based CARNOT blockset (Conventional And Renewable eNergy systems Optimization Toolbox [48]) is a tool for the calculation and simulation of the thermal components of heating systems with regard to conventional and regenerative elements. It provides models for heat sources, storage systems, hydraulics and fundamental material calculation. The component models are connected by so-called thermohydraulic vectors, 
which transmit thermodynamic and hydraulic information between the blocks in every time-step. Extensions of the toolbox are enabled on the basis of modelling using Matlab/Simulink- or CARNOT-functions and its materials database. The investigated heating system was realised on the basis of the simulation environment described by the utilisation of the following components. The models used were validated by Hafner et al [48], except the latent heat store. A detailed overview of the parameters applied is given in Appendix A.

\subsubsection{Solar Thermal Collector}

The collector model is a one-dimensional multi-node approach for thermal flat-plate collectors according to the model proposed by Isakson [49]. It is based on parameters obtained from standardised measurements, i.e. collector test results. The heat transfer fluid is equally distributed among the risers of the absorber plate and the collector is cut into a variable number of nodes in flow direction. The following energy balance is calculated for every node [48] [50]:

$$
\begin{aligned}
c_{\text {col }} \frac{d T_{\text {node }}}{d t}= & \dot{Q}_{\text {sol }}+\frac{\dot{m} \cdot c_{\text {htf }}}{A_{\text {col_node }}} \cdot\left(T_{\text {lastnode }}-T_{\text {node }}\right) \\
& +U_{1} \cdot\left(T_{\text {amb }}-T_{\text {node }}\right)-U_{2} \cdot\left(T_{\text {amb }}-T_{\text {node }}\right)^{2} \\
& +U_{\text {wind }} \cdot v_{\text {wind }} \cdot\left(T_{\text {amb }}-T_{\text {node }}\right)+\mathrm{U}_{\text {sky }} \cdot\left(T_{\text {sky }}-T_{\text {node }}\right)
\end{aligned}
$$

with

$\begin{array}{llc}A_{\text {col_node }} & \text { Surface of Collector Node } & {\left[\mathrm{m}^{2}\right]} \\ c_{h f f} & \text { Heat Capacity of Heat Transfer Fluid } & {\left[\mathrm{J} /\left(\mathrm{kg}^{*} \mathrm{~K}\right)\right]} \\ c_{c o l} & \text { Heat Capacity of Collector per Area } & {\left[\mathrm{J} /\left(\mathrm{m}^{2} \mathrm{~K}\right)\right]} \\ \dot{m} & \text { Mass Flow Rate } & {[\mathrm{kg} / \mathrm{s}]} \\ \dot{Q}_{\text {sol }} & \text { Solar Power per Area } & {\left[\mathrm{W} / \mathrm{m}^{2}\right]} \\ T_{a m b} & \text { Ambient Temperature } & {[\mathrm{K}]} \\ T_{\text {node }} & \text { Node Temperature } & {[\mathrm{K}]} \\ T_{s k y} & \text { Sky Temperature } & {[\mathrm{K}]} \\ t & \text { Time } & {[\mathrm{s}]} \\ U_{l} & \text { Linear Heat Loss Coefficient } & {\left[\mathrm{W} /\left(\mathrm{m}^{2} \mathrm{~K}\right)\right]}\end{array}$




$\begin{array}{llc}U_{2} & \text { Quadratic Heat Loss Coefficient } & {\left[\mathrm{W} /\left(\mathrm{m}^{*} \mathrm{~K}\right)^{2}\right]} \\ U_{\text {wind }} & \text { Wind Speed dependant Heat Loss Coefficient } & {\left[\mathrm{W} /\left((\mathrm{m} / \mathrm{s}) \mathrm{m}^{2} \mathrm{~K}\right)\right]} \\ U_{\text {sky }} & \text { Radiative Heat Loss Coefficient } & {\left[\mathrm{W} /\left(\mathrm{m}^{2} \mathrm{~K}\right)\right]} \\ v_{\text {wind }} & \text { Wind Speed } & {[\mathrm{m} / \mathrm{s}]}\end{array}$

The radiation on the inclined surface of the collector is calculated from the horizontal insolation using the Hay-Davies sky model [1]. The incoming direct and diffuse radiation per unit area is transformed to absorbed radiation and thereby to solar power considering the collector's optical efficiency and the type of glass used as the collector cover (single glazing, extra white glass) [48] [50].

For the system under investigation, a collector tilt angle of $30^{\circ}$ facing south was used. As the collectors both supply the stratification tank and the latent heat storage tank depending on the system operating conditions, two hydraulic connections with separate pumps with a constant mass flow rate of $40 \mathrm{~kg} /\left(\mathrm{h}^{*} \mathrm{~m}^{2}\right)$ depending on the collector area were implemented. As heat transfer fluid a water-glycol-mixture with $40 \%$ glycol at 3 bar system pressure was applied in the collector circuits (Figure 2.21).

\subsubsection{Stratification Tank}

The basic concept of the stratification tank is a multi-port one-dimensional model that allows the integration of supplementary components like internal heat exchangers at userdefined positions with variable geometrical and thermodynamic properties. The storage tank characteristics are defined by parameters from standardised measurements (heat loss coefficients, effective axial conductivity). The store is divided into a variable number of slices. For these nodes, the following energy balance applies [48] [50]:

$$
\begin{aligned}
\rho c \frac{d T_{\text {node }}}{d t}= & \frac{(U A)_{\text {loss }}}{V_{\text {node }}} \cdot\left(T_{\text {amb }}-T_{\text {node }}\right)+\frac{\lambda_{\text {eff }}}{d h^{2}} \cdot\left(T_{\text {node_above }}+T_{\text {node_below }}-2 T_{\text {node }}\right) \\
& +\frac{\dot{m}_{u p} \cdot c_{\text {node }}}{V_{\text {node }}} \cdot\left(T_{\text {node_below }}-T_{\text {node }}\right)+\frac{\dot{m}_{\text {down }} \cdot c_{\text {node }}}{V_{\text {node }}} \cdot\left(T_{\text {node_above }}-T_{\text {node }}\right) \\
& +\frac{(U A)_{h x}}{V_{\text {node }}} \cdot\left(T_{h x}-T_{\text {node }}\right)
\end{aligned}
$$


with

$\begin{array}{llc}A_{\text {loss }} & \text { Surface Area for Losses of one Storage Node } & {\left[\mathrm{m}^{2}\right]} \\ A_{h x} & \text { Surface Area of Heat Exchanger per Storage Node } & {\left[\mathrm{m}^{2}\right]} \\ c_{n o d e} & \text { Node Heat Capacity } & {\left[\mathrm{J} /\left(\mathrm{kg}{ }^{\star} \mathrm{K}\right)\right]} \\ d h & \text { Distance between two Nodes } & {[\mathrm{m}]} \\ \dot{m} & \text { Mass Flow Rate } & {[\mathrm{kg} / \mathrm{s}]} \\ T_{n o d e} & \text { Node Temperature } & {[\mathrm{K}]} \\ T_{a m b} & \text { Ambient Temperature } & {[\mathrm{K}]} \\ T_{h x} & \text { Heat Exchanger Temperature } & {[\mathrm{K}]} \\ t & \text { Time } & {[\mathrm{s}]} \\ U_{l o s s} & \text { Heat Loss Coefficient } & {\left[\mathrm{W} /\left(\mathrm{m}^{2} \mathrm{~K}\right)\right]} \\ U_{h x} & \text { Heat Transfer Coefficient of Heat Exchanger } & {\left[\mathrm{W} /\left(\mathrm{m}^{2} \mathrm{~K}\right)\right]} \\ V_{n o d e} & \text { Node Volume } & {\left[\mathrm{m}^{3}\right]} \\ \lambda_{\text {eff }} & \text { Effective Axial Thermal Conductivity } & {\left[\mathrm{W} /\left(\mathrm{m}^{*} \mathrm{~K}\right)\right]} \\ \rho & \text { Density } & {\left[\mathrm{kg} / \mathrm{m}^{3}\right]}\end{array}$

To model a typical stratification tank for solar heating systems, the following charge and discharge devices were applied to the store [51]: Heat pump charging was enabled by two stratified charging pipe connections at different heights for hot water preparation (charging $100 \ldots 66 \%$ of store height) and room heating (50...30\%). Solar collector charging and direct energy transfer from the latent heat store were realised by two stratified charging smooth tube heat exchangers. For supplying room heating and hot water from the storage tank, stratified charging pipe connections were integrated.

\subsubsection{Heating Load and Hot Water Consumption}

The system's heating load is represented by a south-oriented building with a living area of $120 \mathrm{~m}^{2}$. As the room model is of secondary importance for the heating system investigation, a single zone approach was chosen using a room model provided by the CARNOT blockset [48]: In the centre of the zone a room node represents the zone's air volume. It incorporates radiative and convective heat flows as well as air-, humidity- and $\mathrm{CO}_{2}$-mass flows and is enhanced by transfer functions with a time constant of $100 \mathrm{~s}$. This room node is surrounded by separate elements (walls, windows, floor, ceiling) interacting 
and exchanging heat flows with the room node. In the room node, the room temperature is calculated by the following energy balance:

$$
\frac{d T_{\text {node }}}{d t}=\frac{\dot{Q}_{\text {in }}}{m_{\text {node }} \cdot c_{\text {node }}}
$$

with

$\begin{array}{ll}c_{\text {node }} & \text { Node Heat Capacity } \\ m_{\text {node }} & \text { Node Mass } \\ \dot{Q}_{\text {in }} & \text { Heat Flows to / from Room Node } \\ T_{\text {node }} & \text { Node Temperature } \\ t & \text { Time }\end{array}$

$\left[\mathrm{J} /\left(\mathrm{kg}^{*} \mathrm{~K}\right)\right]$

[kg]

[W]

$[\mathrm{K}]$

$[\mathrm{s}]$

Thereby, $\dot{Q}_{\text {in }}$ represents the sum of all heat flows between the room node and the surrounding walls, windows, ceiling and thermally activated floor. These heat flows are calculated in separate elements, where the outward-facing components are subject to absorption of short-wave solar radiation, radiative and convective heat transfer and heat conduction. The latter is calculated according to the Beuken-model assuming onedimensional heat flow in multiple, heat storing layers as proposed by Feist [52]. The beneath and above laying room are modelled as virtual zones with a fixed temperature. The room model was validated by Hafner et al [48] with calculated and measured data given by Feist [52] and Balters et al [53].

For the components interacting with the ambient heat loss coefficients prescribed by the German Energy Conservation Standard [5] are used, so that a specific annual heat demand of $43 \mathrm{kWh} /\left(\mathrm{m}^{2} \mathrm{a}\right)$ is represented as defined in Chapter 2.1. The room's floor heating system is supplied with a flow temperature of $35^{\circ} \mathrm{C}$ at $1,000 \mathrm{~kg} / \mathrm{h}$. The hot water consumption was implemented as a three-period draw-off from the stratification tank of $120 \mathrm{l} / \mathrm{d}$, distributed over the day. This represents an energy consumption of $17 \mathrm{kWh} /\left(\mathrm{m}^{2} \mathrm{a}\right)$. As a location for the reference building, Würzburg (Germany) was chosen, as it is widely used for certification and simulation purposes due to its average ambient conditions and solar insolation. The average annual weather data are derived from the Meteonorm database on an hourly basis [54]. 


\subsubsection{Heat Pump}

The behaviour of the heat pump was calculated using an empirical model derived by Schwamberger [55]. The basis is the static heat pump characteristics according to the German standard DIN 8900 that gives the heating power for different temperatures in the primary and secondary cycle [56]. The heating power is approximated by the following linear equation [48]:

$\dot{Q}_{h p_{-} t h}=K_{1} \cdot T_{h p_{-} \text {cold_in }}+K_{2} \cdot T_{h p_{-} h o t_{-} i n}+K_{3}$

with

$K_{1} \quad$ Coefficient for Primary Inlet Temperature

$[\mathrm{W} / \mathrm{K}]$

$K_{2} \quad$ Coefficient for Secondary Outlet Temperature

$[\mathrm{W} / \mathrm{K}]$

$K_{3} \quad$ Temperature Independent Heating Power

$T_{\text {hp_hot_in }} \quad$ Heat Pump Inlet Temperature of the Hot Branch

$T_{h p \_c o l d}$ in $\quad$ Heat Pump Inlet Temperature of the Cold Branch

Based on this approximation, the outlet temperature of the hot circuit is calculated by an energy balance. The temperature in the cold branch is then determined from the energy balance of cooling power, heating power and electrical power, neglecting thermal losses. The electric power consumption is derived from characteristic lines depending on the temperature spread of the cold and hot medium. The model is enhanced by two transfer functions to consider the heat capacity of evaporator and condenser. The time constant of the transport delay is approximately 120 s according to Schwamberger [55]. To take the fluid volume in the heat pump into account, a transport delay is added where the delay time is the mass of fluid divided by the mass flow rate in the pipe [48].

For the investigation of the solar heat pump heating system, the characteristics of a commercially available unit were applied to the model (brine/water-heat pump WPF5 of German manufacturer Stiebel Eltron, Holzminden [57]) using a least square method to determine the values for $K_{1}, K_{2}$ and $K_{3}$. The simulation shows satisfactory correlation with measured values, as illustrated in Figure 2.22. Even so, the model contains limitations especially when it is applied to a non-customary system, as the performance data are obtained by the manufacturer under specific conditions only. This means that the behav- 
iour of the heat pump's internal components is partly neglected for extraordinary operating conditions. Nevertheless, the model is considered to be satisfying for this investigation on the system level.

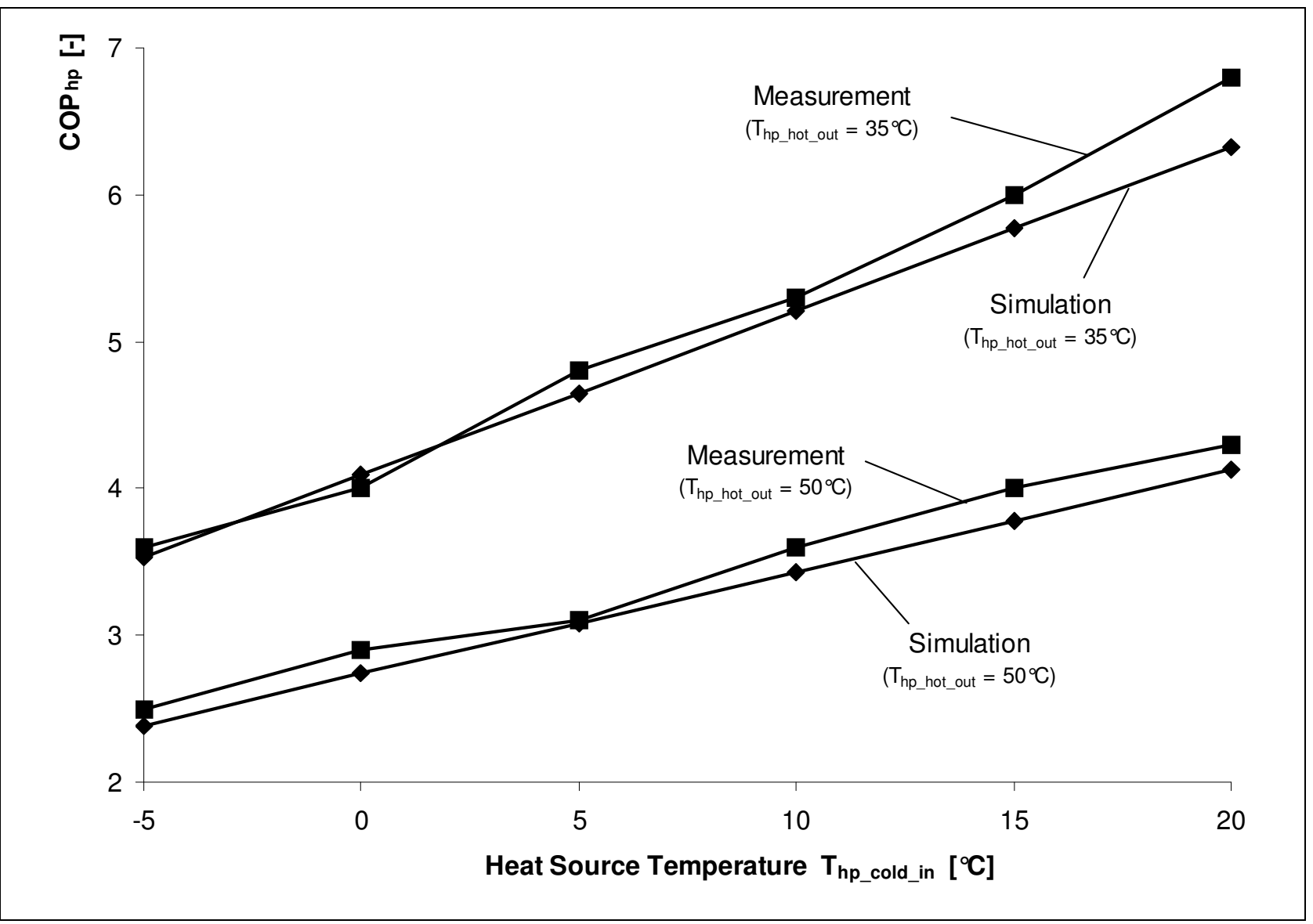

Figure 2.22: Comparison of Measured and Simulated $\mathrm{COP}_{h p}$ for different Flow Temperatures (water/glycol 60/40\% on source side; measurement values provided by manufacturer [57])

The heat pump evaporator side is hydraulically connected to the latent heat storage tank; the mass flow rate is set to $1,400 \mathrm{~kg} / \mathrm{h}$ according to manufacturer's recommendations. The condenser side supplies the stratification tank at a mass flow rate of $500 \mathrm{~kg} / \mathrm{h}$.

\subsubsection{Latent Heat Store}

The model of the latent heat store distinguishes two operating conditions:

- The use of sensible heat of water and

- The latent heat of fusion during the phase change between water and ice. 
During the sensible heat storage phase, heat transfer and storage behaviour is modelled for a mixed water store using the multi-port store model. It includes two smooth tube heat exchangers for discharging by the heat pump and charging by the solar collectors (nonstratifying). Heat loss coefficients of a $10 \mathrm{~cm}$ polystyrene insulation are used for circular store geometry with variable volume and diameter. As constant ambient temperature $5^{\circ} \mathrm{C}$ was chosen, to account for the possibility that the storage tank is mounted for instance in a cold cellar room.

When it comes to the phase change, the detailed analysis of these so-called moving boundary problems is in general rather complex. The solid-liquid boundary moves during solidification and melting depending on the heat absorbed at the boundary. The speed of the moving boundary is not known a priori but forms part of the solution. Although there are a lot of approaches on latent heat transfer modelling for storage applications, for example reviewed by Dincer et al [58] or Zalba et al [59], even complex analytical solutions to the problem are not generally applicable, but refer to very specific conditions of application (heat exchanger geometry, materials, boundary conditions,...). Considering this system investigation, an accurate description of the physical phenomena in the store is not required. On the other hand, the model should contain the typical characteristics of a latent heat store operating in the system and enable acceptable simulation time, hence contain a mathematically simple model.

When the store temperature reaches $0^{\circ} \mathrm{C}$ it is assumed that ice formation occurs in the store, so that the model works in the phase change mode. Considering the store as a black box, it is assumed that the store temperature stays at phase change temperature without sub-cooling, hence the flow temperature to the heat pump and the solar collectors is set to $0^{\circ} \mathrm{C}$, presuming sufficient heat exchanger performance. During phase change, the transported heat is calculated, taking into consideration heat extracted by the heat pump and heat delivered by the collectors. Thereby, the mass of ice produced is assessed for every time-step which also represents the discharging state of the store.

The following assumptions are made in the latent heat store model:

- Ideal phase change at $0^{\circ} \mathrm{C}$ without sub-cooling of the phase change material.

- Sufficient heat exchanger performance under all conditions. 
- No three-dimensional distribution of ice formation in the store, i.e. partial liquid regions at heat exchanger surfaces are not considered.

- No heat gains from the ambient during phase change.

- Utilisation of sensible heat in solid medium is not considered, so that further discharging beyond phase change is not possible.

Figure 2.23 shows the behaviour of the latent heat store working in the system. Compared with measurement data available from Lübeck University collected in a comparable system in 1995 (cf. Chapter 2.2.1), the temperature curve shows very good qualitative congruence (cf. Figure 2.12): The maximum temperature is at approximately $80^{\circ} \mathrm{C}$ in August, the solidification phase lasts from December/January to March and the temperature curve shows a similar characteristic. The annual system simulation is started in May to consider long-/medium-term storage effects in the system. The initial temperature of $35^{\circ} \mathrm{C}$ in the latent heat storage tank is chosen based on the experimental experiences in the Lübeck system.

For the system investigation the performance of the latent heat store model is considered to be satisfactory, as it represents the typical characteristics of a latent heat store within a heating system. The store performance tends towards underestimation due to the assumptions chosen, particularly in the solidification phase. 

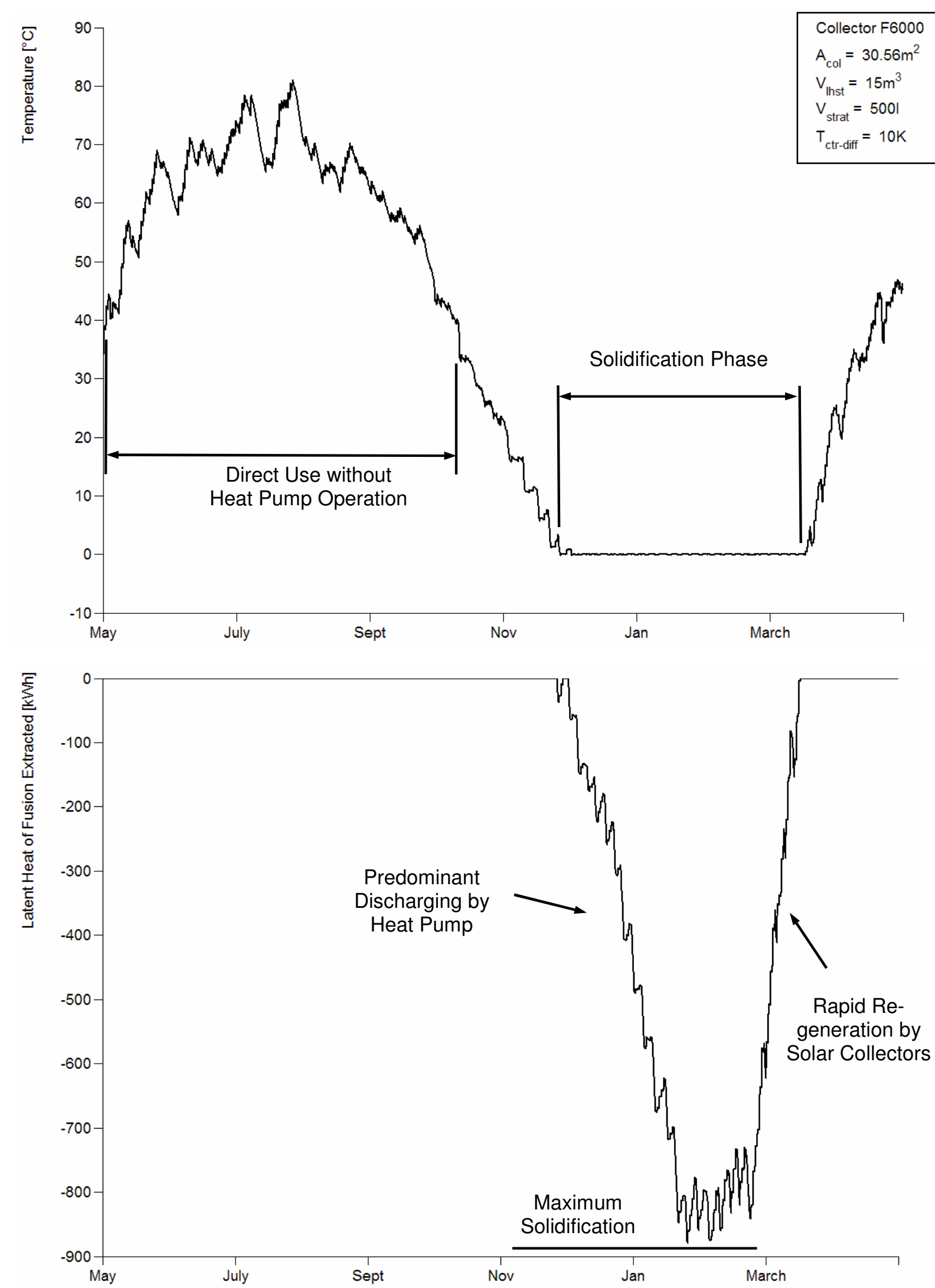

Figure 2.23: Exemplary Temperature Curve and Latent Heat of Fusion Extracted from Latent Heat Store 


\subsection{Development of Control Strategies}

As the proposed heating system consists of several components, the system control plays an important role considering the system's functionality, users' comfort and maximised utilisation of solar energy. For the single components of the system, controllers and control strategies are partly available. Therefore, the development of control strategies in this chapter concentrates on the interaction of components and on the control of the complete system. The following requirements have to be fulfilled by the system control:

- Control of heat pump (on/off including hysteresis, temperature control for supply of stratification tank).

- Control of solar collector circuit (on/off including hysteresis, maximum temperature control).

- Co-ordination of latent heat storage tank and central storage tank (direct energy transfer without heat pump, charging co-ordination of collectors).

- Adaptation of the system to the users' requirements (hot water preparation, temperature set points of the building).

The heat pump control is realised as a temperature difference hysteresis controller which keeps the stratification tank at $45^{\circ} \mathrm{C}$ on the top for hot water preparation and at $35^{\circ} \mathrm{C}$ on the bottom for room heating. Therefore, temperatures are measured in the stratification tank at different heights (33\% / 66\% of store height) and taken into consideration.

In case that the temperature of the latent heat store is higher than the temperature required by the stratification tank, the latter can directly be charged by the latent heat store without heat pump operation. For this functionality, the control compares the temperature of both stores and decides whether heat pump operation is necessary.

The reference building has a heat demand depending on heat losses through walls and windows and solar insolation into the building. As a desired room temperature, $20^{\circ} \mathrm{C}$ is set. The floor heating system is directed by a temperature difference hysteresis controller comparing the room model's zone temperature with the desired room temperature. 
The co-ordination of the latent heat storage tank and the stratification tank is the most important, but most challenging task regarding control development. A clear strategy for alternate charging of the tanks is the basis for the minimisation of electrical energy consumption. This means that solar energy has to be used directly, for example for hot water preparation in the stratification tank, when possible as the heat pump is not required for this purpose. On the other hand, solar heat is necessary in the latent heat storage tank to keep the temperature on an acceptable level and ensure heat pump operation under favourable conditions. Apart from that, the ice volume produced has to be limited by solar charging in winter times. The collector outlet temperature cannot be used as a control parameter in this system, as it strongly depends on the current consumer.

Comparable systems have followed different approaches. For instance in the system investigated by Posorski [42] (cf. Chapter 2.2.2), the temperature of an idle absorber element is used as control parameter instead of the absorber temperature. The control of the Lübeck laboratory installation (cf. Chapter 2.2.1) is divided into seasonal strategies: During summer times, the store with lower temperature is preferred regarding charging. During winter times, the seasonal storage tank is charged except when solar insolation exceeds $600 \mathrm{~W} / \mathrm{m}^{2}$. In the beginning and in the end of the heating season, the short-term storage tank is preferred [28].

Figure 2.24 shows the control structure developed in this project for the direction of the two storage tanks. It contains the following functions [60]:

- Two solar controllers (blocks Control Col-Lat and Control Col-Strat), which are temperature difference controllers with enhanced functionality. For collector on/off-control the storage temperature and the collector temperature are compared; the pump is activated / deactivated considering a hysteresis defined in the blocks. In case that a maximum storage or collector temperature (stagnation with steam in collector circuit) is reached, termination conditions with hysteresis are implemented.

- A condition considering sufficient solar insolation to avoid collector operation during night-time $\left(G \geq G_{\min }\right)$.

- Calculation of the collector stagnation temperature $T_{\text {col_stag }}$ (theoretical idle running temperature; block Calc. $T_{\text {col_stag) }}$ which is required to evaluate the possibility of charg- 
ing the stratification tank when the collector operates on a low temperature level in the latent heat store circuit.

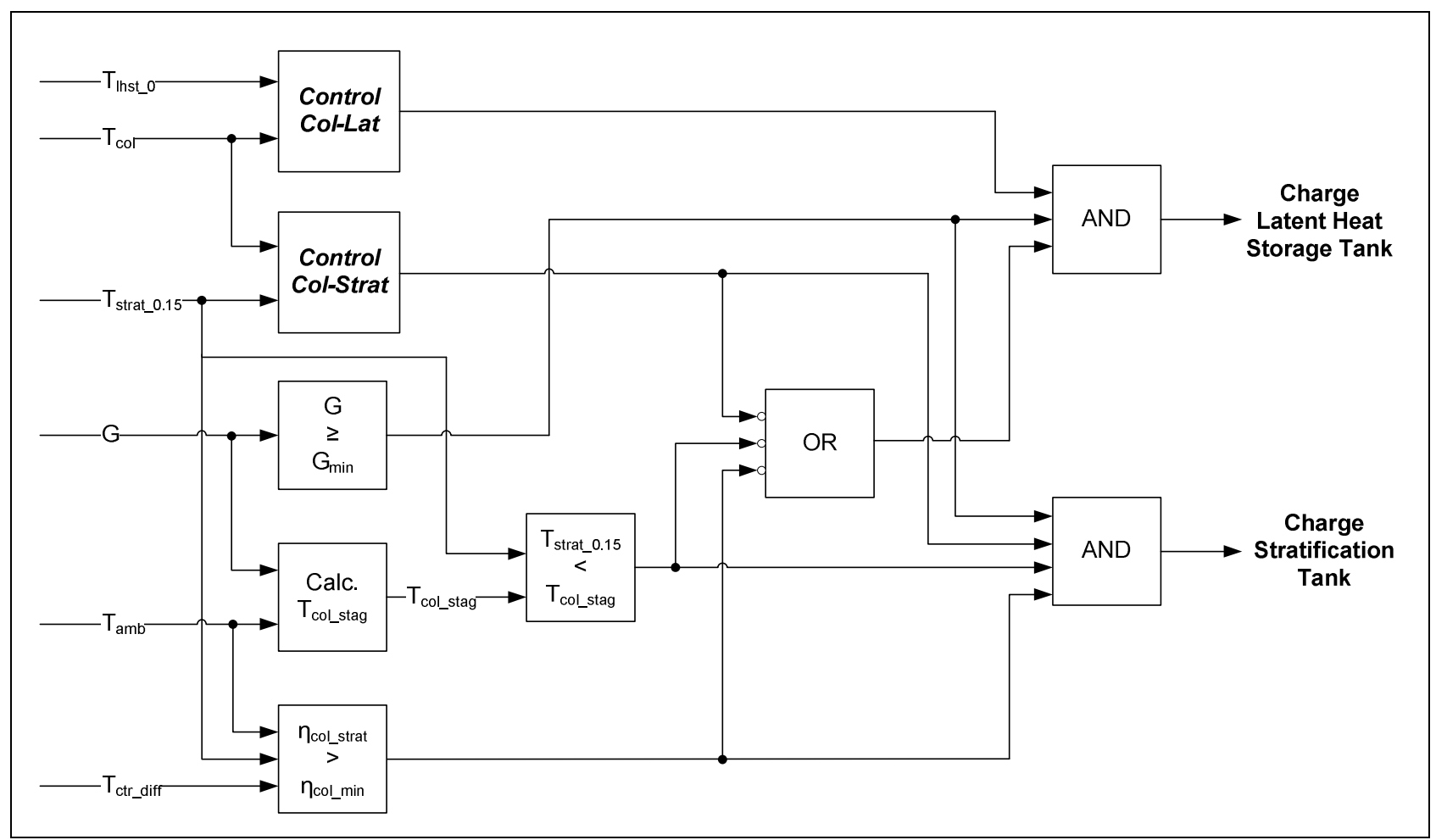

Figure 2.24: Control Structure developed for the Direction of the two Storage Tanks

- Evaluation of the (theoretical) collector efficiency $\eta_{\text {col_strat }}$ referred to the stratification tank operation mode, and a minimum collector efficiency $\eta_{c o l}$ min. For this purpose, the collector efficiency $\eta_{c o l}$ strat is traced back to the temperature difference between stratification tank and ambient, as it is mainly influenced by the heat losses from the collector to the ambient. The stratification tank temperature in the bottom equals the return temperature to the collector and thereby represents the collector temperature. The minimum temperature difference $T_{\text {ctr_diff }}$ is defined as a control parameter, representing the minimum collector efficiency $\eta_{c o l}$ min. Depending on this efficiency evaluation, the collectors work in the stratification tank circuit if the collector efficiency is high enough in this operating mode $\left(\eta_{\text {col_strat }} \geq \eta_{\text {col_min }}\right.$ meaning $\left.T_{\text {ctr_diff }} \geq T_{\text {strat_0.15 }}-T_{\text {amb }}\right)$. Otherwise they work in the latent heat store circuit at a lower temperature level to increase the collector efficiency $\left(\eta_{\text {col_strat }}<\eta_{\text {col_min }}\right.$ meaning $\left.T_{\text {ctr_diff }}<T_{\text {strat_0.15 }}-T_{\text {amb }}\right)$. Figure 2.25 shows the behaviour of the collectors alternately working on both stores in turn on a typical day in September. 
Considering the annual simulations, the system control works as intended. During summer times with sufficient insolation, hot water preparation is realised by the solar collectors. Surplus energy heats the latent heat store. When it comes to winter times, primarily the ice in the latent heat store is melted by the solar collectors. This limits the degree of solidification and thereby the required storage volume. In this regard, the parameter $T_{\text {ctr_diff }}$ represents the prioritisation of the two storage tanks in the system and thereby is the main system control parameter. $T_{\text {ctr_diff }}$ has a direct influence on the dimensioning of the latent heat store as it limits solar energy delivery for the regeneration of the store.

In the system model, pipe heat losses and direct utilisation of collectors by the heat pump are not considered. Although several assumptions are made in the system and component models, it is considered to be satisfactory for a system investigation and optimisation, especially as a trade-off between accuracy and simulation time is required. The comparison with measured data of laboratory systems (cf. Chapter 2.2.1) shows similar annual performance and qualitative characteristics. Unfortunately, the system investigations have very specialised configurations (e.g. regarding (ice-) storage design or dimensioning), so that only a qualitative comparison is possible. 

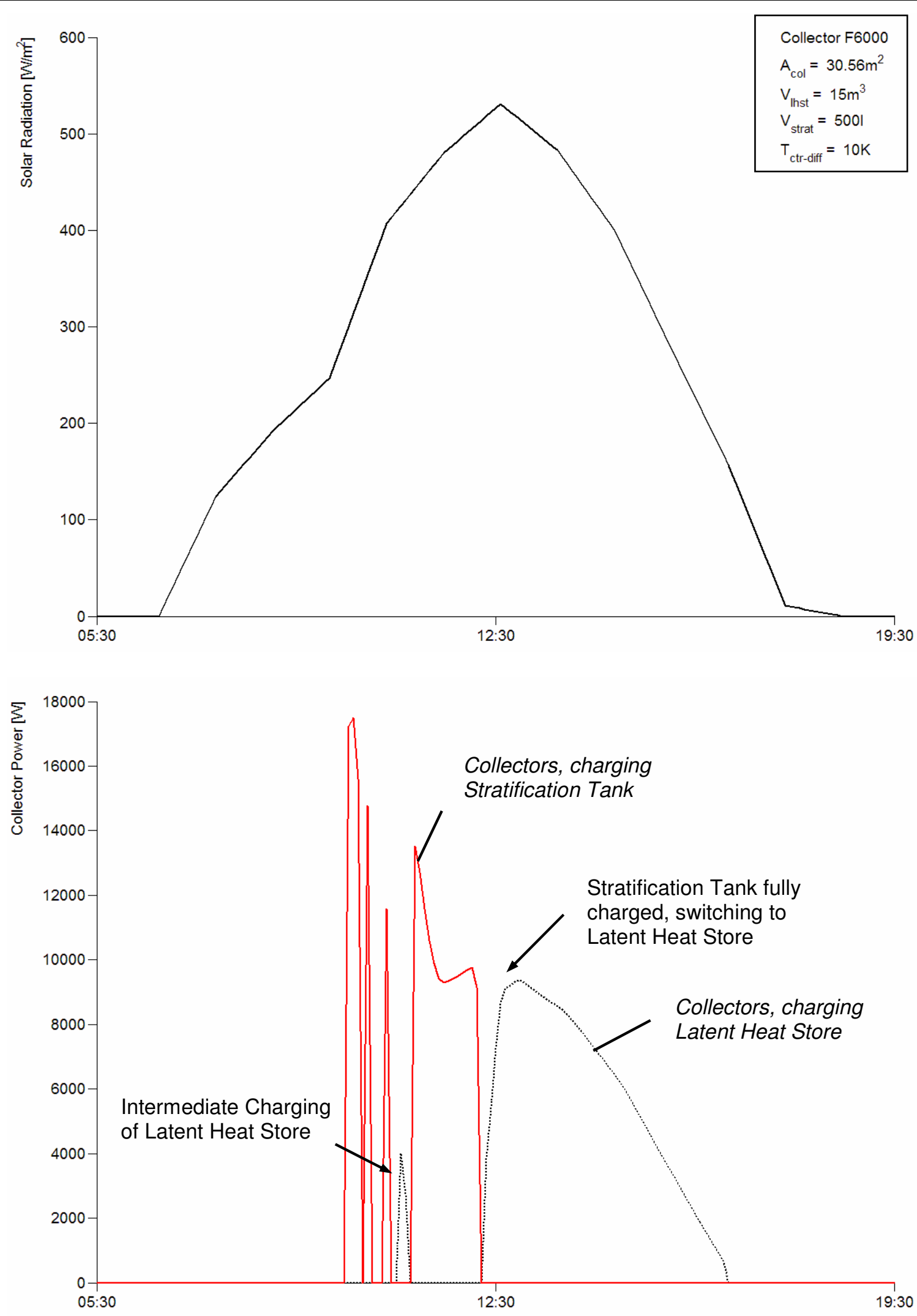

Figure 2.25: Insolation (top) and Storage Tank Charging (bottom) on a Typical Day in September 


\subsection{System Investigation and Dimensioning}

The investigation and optimisation of the proposed heating system configuration is focussed on the reference building "New Family House" (Chapter 2.1) as implemented in the system model. It is carried out considering the following objectives:

- Determination of parameters' influence on system behaviour and performance.

- Determination of systems with reasonable collector area and latent heat store volume for a one-family house.

- Minimisation of electrical energy consumption, which corresponds to the maximisation of solar energy utilisation.

\subsubsection{Evaluation Figures and Proceeding}

For the system evaluation, the Seasonal Performance Factor at the heat pump level $\left(S P F_{h p}\right)$ is considered (cf. equation (4) in Chapter 1). Apart from that, the Seasonal Performance Factor of the complete heating system (SPF sys $)$ is chosen. The dimensionless figure represents the electrical energy consumption for the heat pump operation in relation to the complete heat demand for heating and hot water preparation; hence it also considers the direct utilisation of solar energy without heat pump operation. It is defined as

$$
S P F_{s y s}=\frac{Q_{\text {heat_demand }}}{Q_{h p_{-} e l}}
$$

with

$Q_{\text {heat_demand }} \quad$ Overall Heat Demand for Heating and Hot Water Preparation [kWh]

$Q_{h p_{-} e l} \quad$ Electrical Energy Consumption of Heat Pump 
Apart from that, the Maximum Degree of Solidification (DoS Ihst_max $_{\text {) }}$ of the latent heat storage tank is considered. It is defined as

$$
D o S_{l h s t_{-} \max }=\frac{Q_{l h s t_{-} p c}}{Q_{l h s t_{-} p c_{-} \max }} \cdot 100 \%
$$

with

$Q_{l h s t_{-} p c} \quad$ Latent Heat of Fusion extracted from Latent Heat Store during Phase Change

$Q_{l h s t_{-} p c_{-} \max } \quad$ Maximum Latent Heat of Fusion in Latent Heat Store (theoretical) [kWh]

This figure is the decisive parameter with regard to latent heat storage tank dimensioning. As illustrated in Figure 2.23, the latent heat of fusion extracted from the latent heat store reaches a maximum during winter times. The limitation of the latent heat of fusion extracted to a level beneath its maximum theoretical value, i.e. the limitation of the Degree of Solidification to maximum $100 \%$, is an important boundary condition in heating system dimensioning. However, in the following simulation results, the Maximum DoS is partly above $100 \%$ which would not be valid in reality, nevertheless indicates the influence of the investigated parameters.

To evaluate the components' and parameters' influence on the system performance regarding the optimisation objectives, a variation of the systems' most important parameters is carried out as follows:

1 Definition of a preliminary system configuration based on results of previous investigations from literature.

2 Variation of single parameters influencing the system performance (Figure 2.26).

3 Evaluation of the parameters' influence on system performance and identification of the decisive parameters.

4 Definition of a recommended system design and variation of the decisive parameters. 
Figure 2.26 shows the system's most important parameters. Their influence is analysed by a variation of single parameters in annual system calculations and is illustrated subsequently.

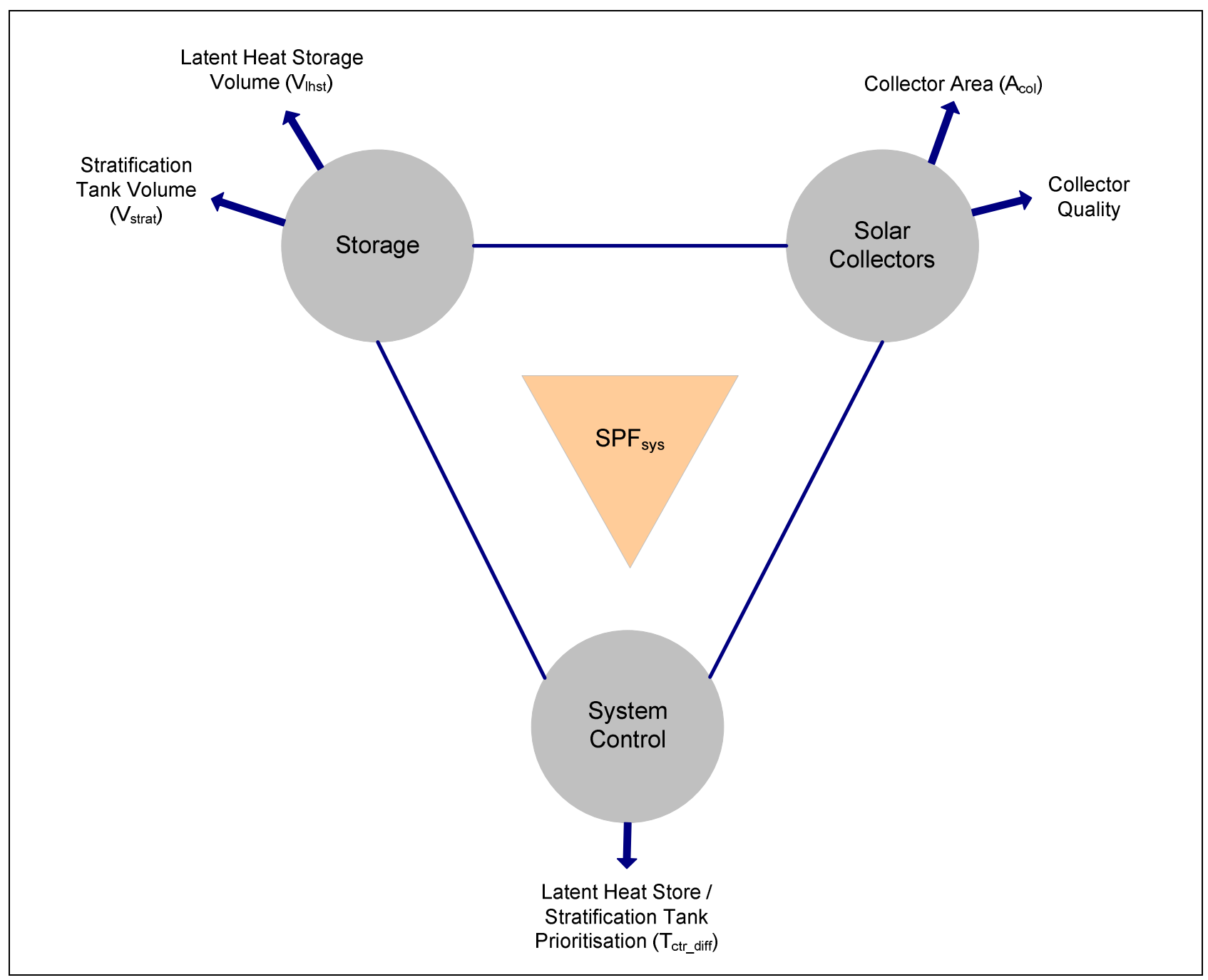

Figure 2.26: Important Parameters of the Heating System to be investigated in System Simulations

The recommended system design defined in step 4 as well as the derived calculation data (required volume and heat transfer performance, volume flow,...) form the basis for the dimensioning of the latent heat storage tank (Chapter 3.4.3). 


\subsubsection{Solar Thermal Collectors}

With regard to the collectors, the influence of collector area and the collector quality are investigated. Figure 2.27 shows the simulation results of the relevant parameters over the collector area for a preliminary system dimensioning. Increasing the collector area improves both $S P F_{s y s}$ and $S P F_{h p}$. On the one hand, more solar energy can be directly used in the stratification tank, which enhances $S P F_{s y s}$. On the other hand, also the operating conditions for the heat pump become more favourable (increasing $S P F_{h p}$ ), because the temperature of the latent heat storage tank is higher with increasing collector area (indicated by the maximum temperature of the latent heat storage tank $T_{\text {Ihst_max }}$ ). As more solar energy is brought into the latent heat store with a larger collector area, ice production is limited and the Maximum Degree of Solidification decreases.

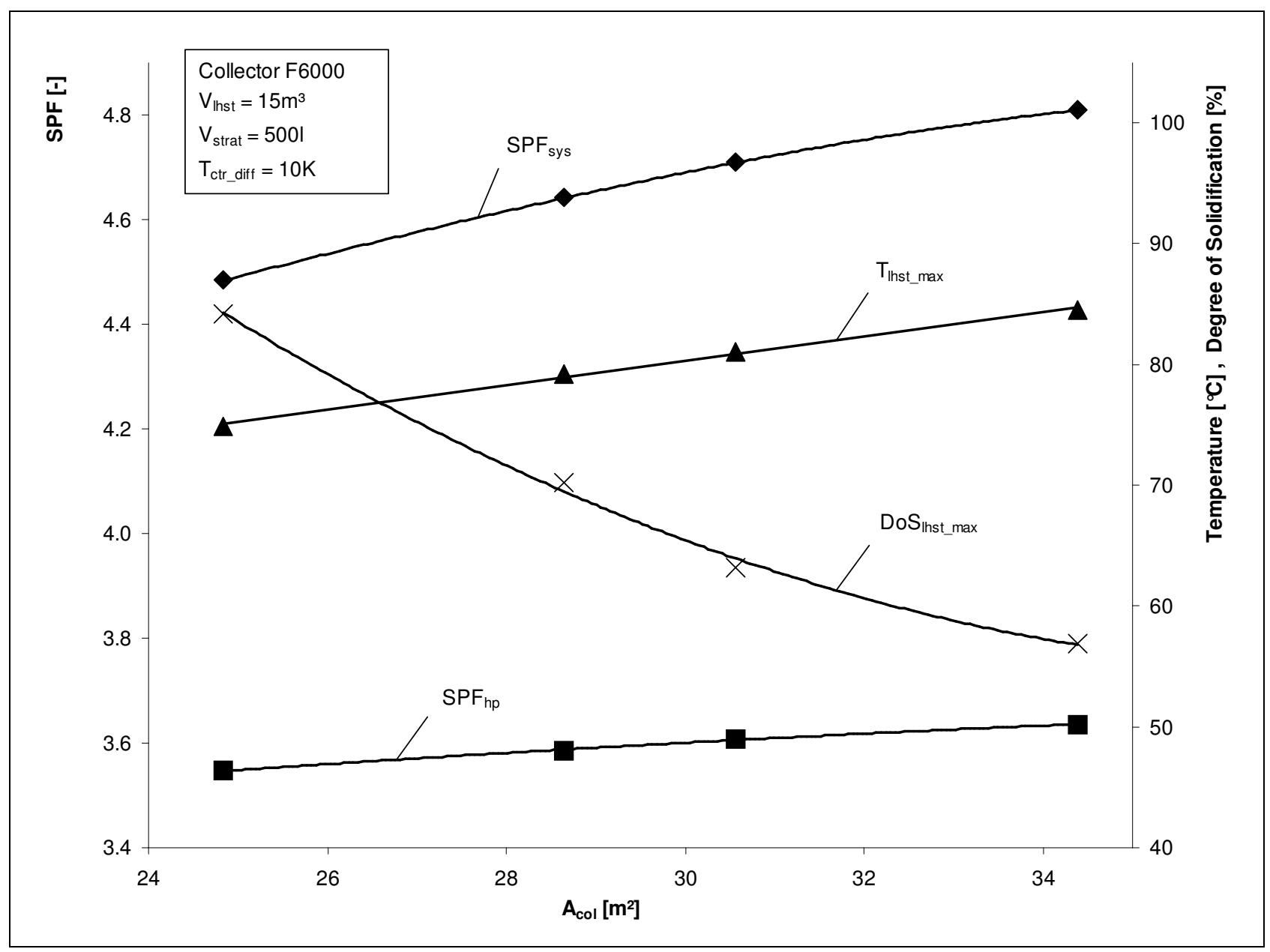

Figure 2.27: Calculation Results with Trendlines regarding the Variation of Collector Area 
Next to the collector area, the influence of the collector quality on the system performance is of major interest, because the collectors work under unusual conditions in this system, e.g. low flow temperatures in winter times. Hence, three commercially available collector types, representing different classes of thermodynamic collector quality are calculated and compared. The collectors are (cp. Appendix A):

- Conergy F6000 is a high quality collector with enhanced insulation and non-reflecting glass. Its target applications originally are solar process heat and solar driven cooling systems [61].

- Conergy F4000 is a medium quality collector for customary solar hot water and space heating systems. It represents a typical collector class used in domestic applications [62].

- Thermosolar TS300N is a low-level collector for simple solar hot water systems [63].

Figure 2.28 shows the simulation results of the three collector types. As was anticipated, $S P F_{s y s}$ is increased by improved collector quality. However, the increase between $F 4000$ and $F 6000$ is almost negligible $\left(S P F_{\text {sys }}:+0.8 \%\right)$. Otherwise, a higher collector quality leads to less solidification in the latent heat storage tank, especially considering TS30ON and $F 4000$ (DoS Ihst_max : -13\%). Since a higher collector quality is usually linked to a higher insulation level of the collector, more solar energy is available to regenerate the store especially during periods with low ambient temperature.

As the simulations show, a minimum collector quality is required even in this low temperature system. Nevertheless, the use of a high quality collector is not reasonable, as the further improvement, especially in SPF, is almost negligible. Considering the economic point of view, a medium quality collector, e.g. F4000 or a comparable product, can be recommended. 


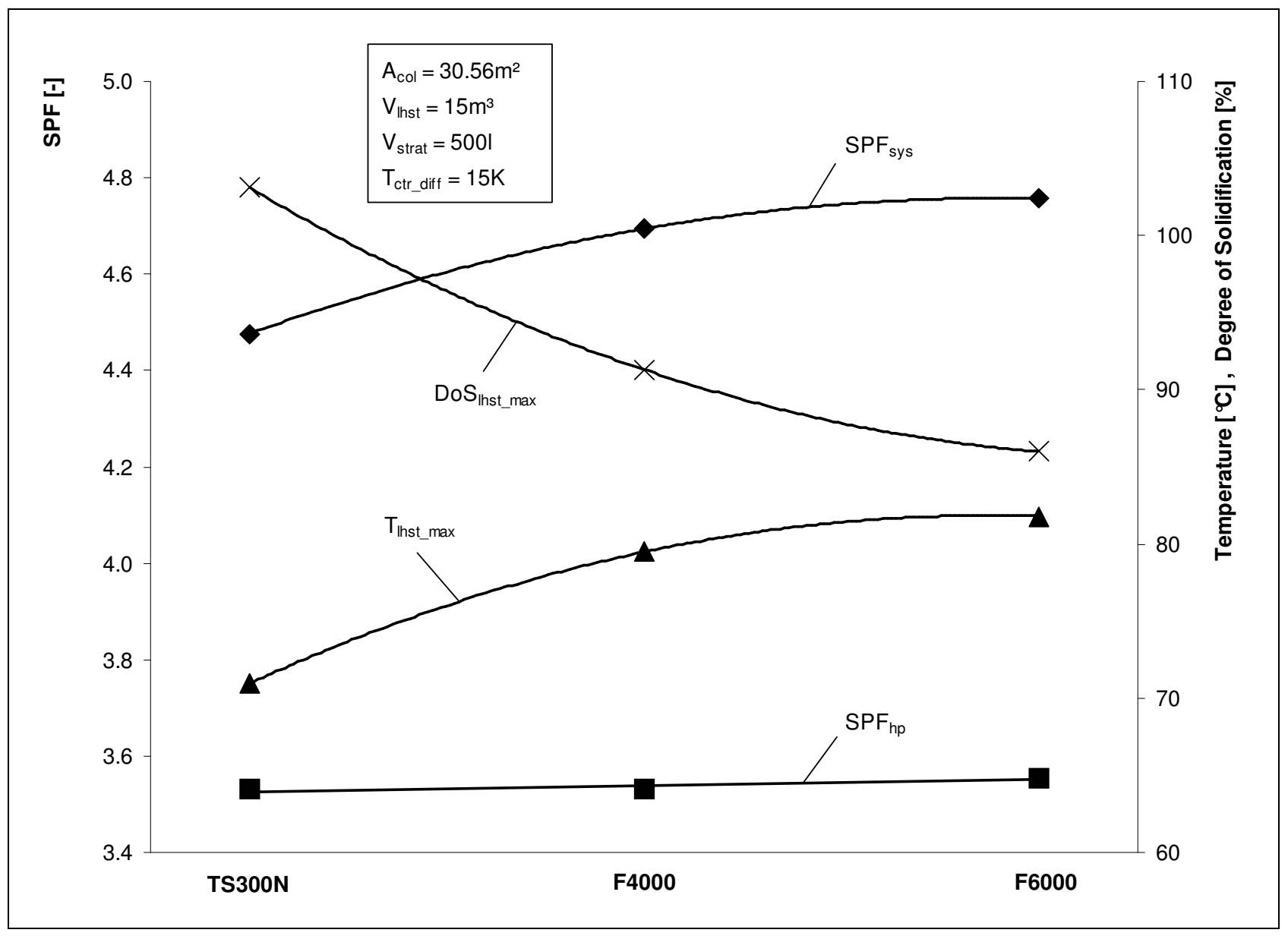

Figure 2.28: Calculation Results with Trendlines regarding the Variation of Collector Quality

\subsubsection{Latent Heat Store}

Figure 2.29 shows the variation of the latent heat storage tank volume. As was expected, the increase of latent heat storage volume reduces the Maximum Degree of Solidification significantly because the usable volume for phase change is enlarged. But then, the influence on $S P F_{s y s}$ and $S P F_{h p}$ is almost negligible $( \pm 1.2 \%$ and $\pm 0.65 \%)$. The reason is considered to be that the duration of solidification is almost the same in all simulated systems (110...120 days per year). Apart from that, in a smaller latent heat storage tank, the temperature level is higher during summer times, which leads to more direct energy transfer from the latent heat store to the stratification tank without heat pump operation. 


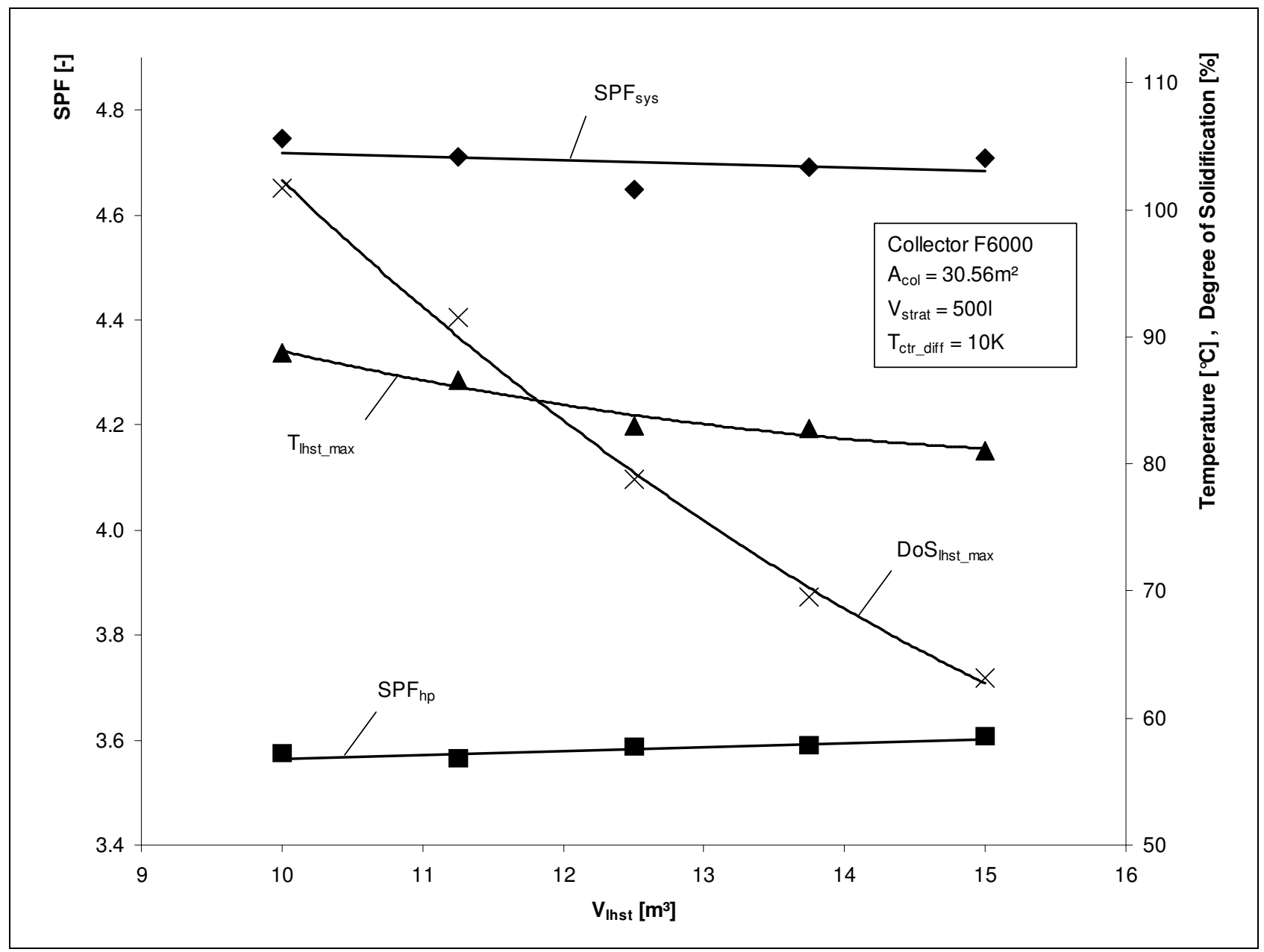

Figure 2.29: Calculation Results with Trendlines regarding the Variation of Latent Heat Store Volume

\subsubsection{System Control}

As a further decisive parameter for the system behaviour, the control of both stores is identified. The parameter $T_{\text {ctr_diff }}$ indirectly represents the collector efficiency at which the latent heat store is preferred, being a rate for the prioritisation of the stores. As shown in Figure 2.30, especially the influence on the Maximum Degree of Solidification is remarkable. A decrease of $T_{\text {ctr_diff }}$ means that the latent heat store is more often in operation, even at high ambient temperature. On the contrary, an increase of $T_{\text {ctr_diff }}$ leads to a preference of the stratification tank. As a result of increasing $T_{c t r d i f f}$, the DoS goes up, because the regeneration of the ice volume is not sufficient anymore. On the opposite side, below approximately $T_{\text {ctr_diff }}=7.5 \mathrm{~K}$ the influence on the DoS is negligible, as solar energy delivered to the latent heat store from the collectors cannot be increased anymore. The influence of the parameter variation on $T_{\text {Ihst_max }}, S P F_{s y s}$ and $S P F_{h p}$ is compa- 
rably small. $S P F_{\text {sys }}$ tends to increase with rising $T_{\text {ctr_diff }}$ since the collectors more often work directly for the stratification tank. As a trade-off between maximum $S P F_{s y s}$ and minimum Degree of Solidification, $T_{\text {ctr_diff }}=7.5 \mathrm{~K}$ is suggested.

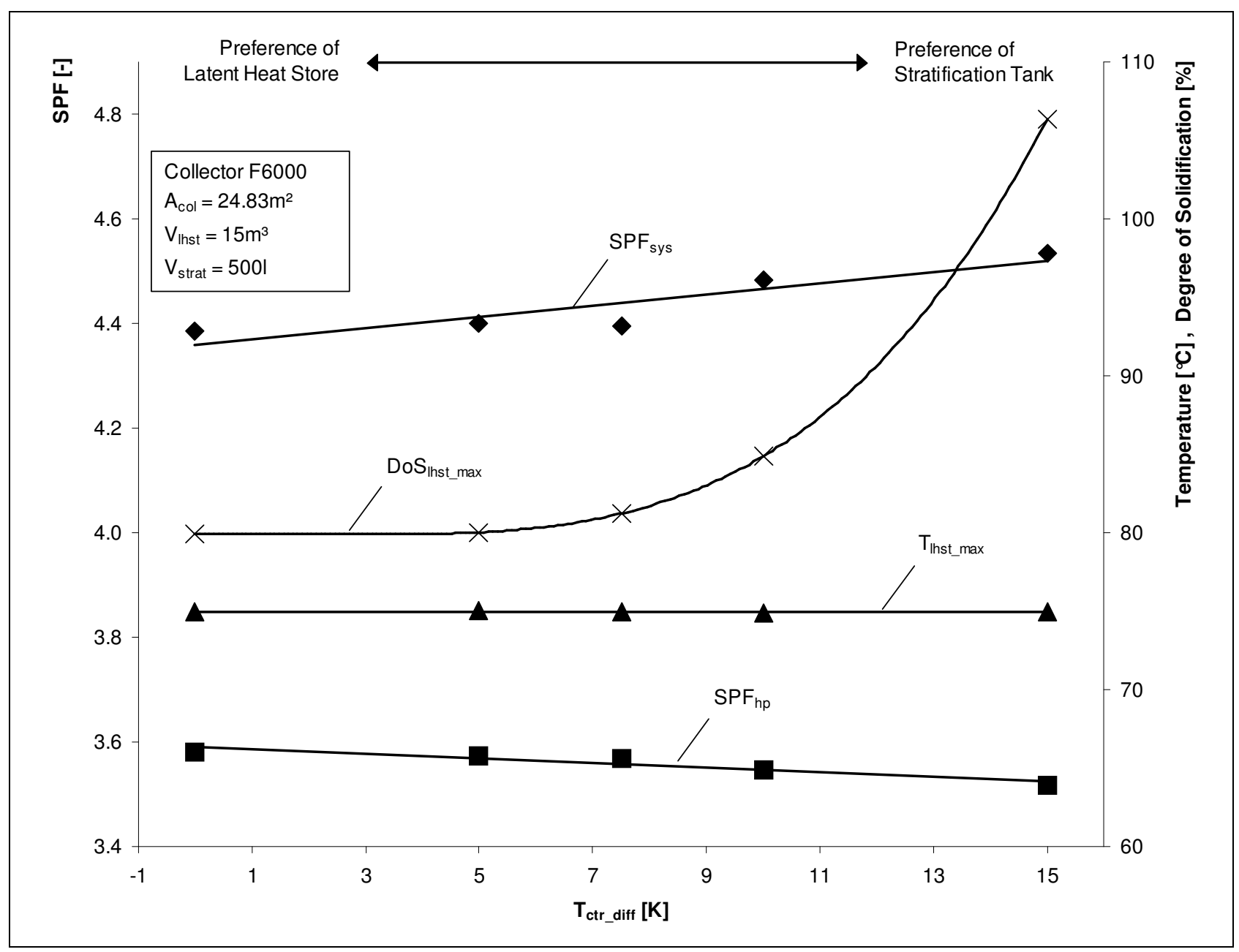

Figure 2.30: Calculation Results with Trendlines regarding the Variation of Control Parameters

\subsubsection{Stratification Tank}

A variation of the stratification tank volume from 300 l up to 1,000 (Figure 2.31) shows neither significant influence on $S P F_{s y s}( \pm 1 \%)$ and $S P F_{h p}( \pm 1.3 \%)$, nor on the DoS $( \pm 1.1 \%)$. Considering the need to secure sufficient hot water performance for a onefamily house and the optimum from an economic side of view, a 500 l stratification tank is recommended in this system. 


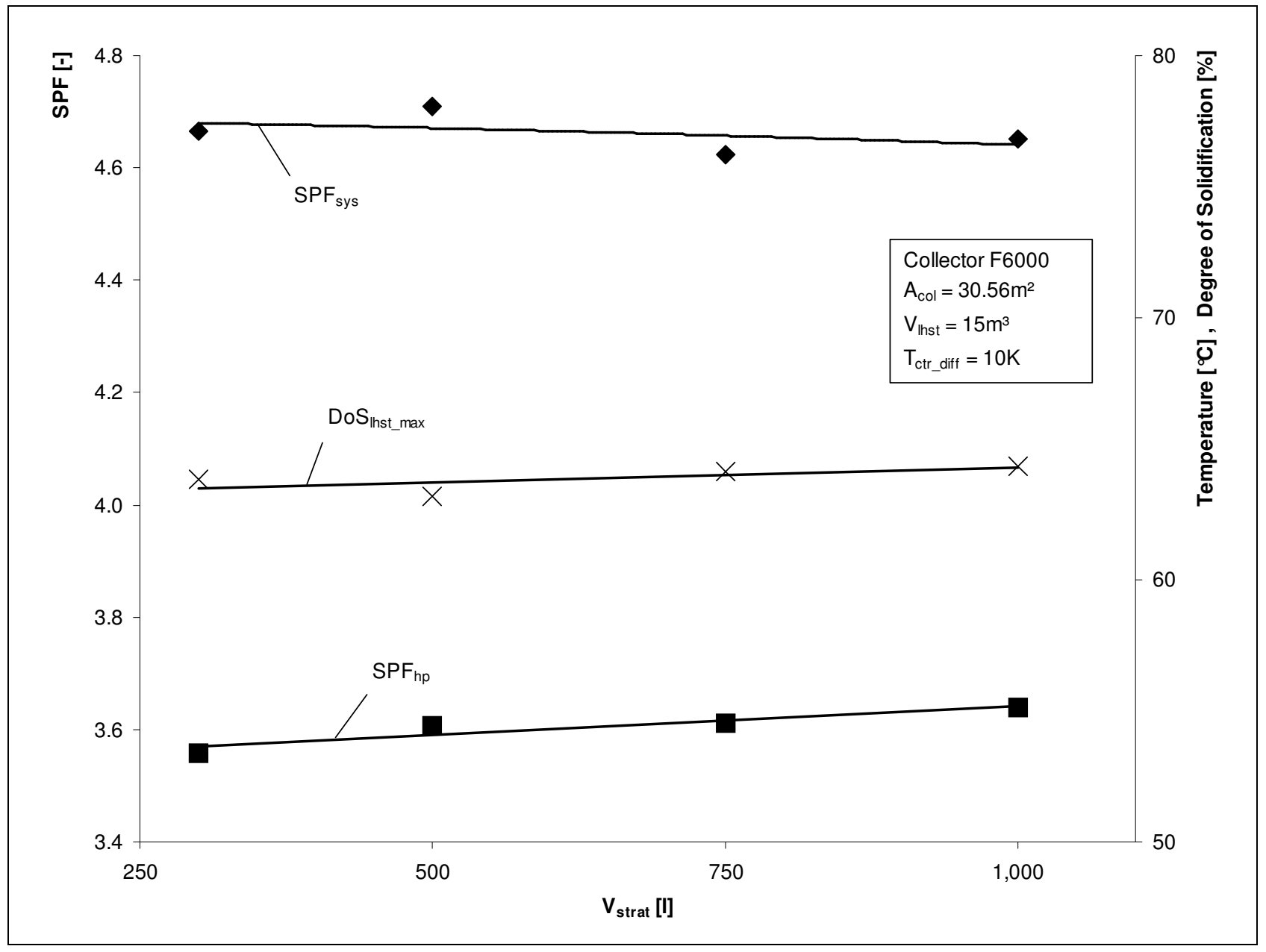

Figure 2.31: Calculation Results with Trendlines regarding the Variation of Stratification Tank Volume 


\subsubsection{Parameter Influence on System Performance and Dimensioning}

In Table 2.6 the investigated parameters and their influence on the evaluation figures are summarised. While the stratification tank volume $V_{\text {strat }}$ is completely neutral and can be fixed at 500 l for a system dimensioning, the other parameters partly show a significant influence on the system performance. However, the control parameter $T_{\text {ctr_diff }}$ can be generally set to $7.5 \mathrm{~K}$ in dimensioning as a trade-off between maximum system performance and minimum Degree of Solidification, as it was shown above. With regard to collectors, a medium quality type as for example the Conergy F4000 can be recommended for all systems. As for these parameters optimum values were figured out, the collector area $A_{c o l}$ and the latent heat storage volume $V_{\text {lhst }}$ are the remaining decisive parameters for an individual system dimensioning.

Table 2.6: Investigated Parameters and their Influence on the Evaluation Figures

\begin{tabular}{|l|c|c|c|c|c|}
\hline \multirow{2}{*}{$\begin{array}{l}\text { Parameters' } \\
\text { Influence on }\end{array}$} & $\boldsymbol{A}_{\text {col }} \uparrow$ & $\boldsymbol{V}_{\text {lhst }} \uparrow$ & Coll. Quality $\uparrow$ & $\boldsymbol{V}_{\text {strat }} \uparrow$ & $T_{\text {ctr_diff }} \uparrow$ \\
\cline { 2 - 6 } SPF $_{\text {sys }}$ & $\uparrow \uparrow$ & 0 & $\uparrow$ & 0 & $\uparrow$ \\
SPF $_{\text {hp }}$ & $\uparrow$ & 0 & 0 & 0 & $\downarrow$ \\
DoS $_{\text {Ihst_max }}$ & $\downarrow \downarrow$ & $\downarrow \downarrow$ & $\downarrow$ & 0 & $\uparrow \uparrow$ \\
\hline $\begin{array}{l}\text { Recommended } \\
\text { Value/Component }\end{array}$ & $\begin{array}{c}30.56 m^{2} \\
(\text { variable) }\end{array}$ & $\begin{array}{c}12.5 m^{3} \\
(\text { variable) }\end{array}$ & $\begin{array}{c}\text { medium } \\
\text { (fixed) }\end{array}$ & $\begin{array}{c}500 l \\
\text { (fixed) }\end{array}$ & $\begin{array}{c}7.5 \mathrm{~K} \\
\text { (fixed) }\end{array}$ \\
\hline
\end{tabular}

$\uparrow \uparrow$ strong enhancement $\uparrow$ enhancement o neutral $\downarrow$ reduction $\quad \downarrow \downarrow$ strong reduction

For the reference building defined in Chapter 2.1, a collector area of $A_{c o l}=30.56 \mathrm{~m}^{2}$ (which is equivalent to 16 collectors of type F4000) and a latent heat storage volume of $V_{\text {lhst }}=12.5 \mathrm{~m}^{3}$ are suggested. In order to investigate the influence of the two decisive parameters on the system performance, variations of both parameters are calculated (Figure 2.32). The yellow bar shows the recommended system with $A_{c o l}=30.56 \mathrm{~m}^{2}$, $V_{\text {lhst }}=12.5 \mathrm{~m}^{3}$ and a system based Seasonal Performance Factor of 4.6, which corresponds to a Solar Fraction of approximately $f_{\text {sol }}=78 \%$. 
An increase of the latent heat storage volume doesn't show any influence on the system performance, the system based Seasonal Performance Factor $S P F_{s y s}$ stays at 4.6. An increase of collector area to $A_{c o l}=34.38 \mathrm{~m}^{2}$ (18 collectors) slightly enhances the $S P F_{s y s}$ to 4.7. As the Maximum Degree of Solidification is decreasing, the latent heat storage volume can be reduced to $11 \mathrm{~m}^{3}$ in this system with constant $S P F_{\text {sys. }}$. The system with $A_{c o l}=24.83 \mathrm{~m}^{2}$ (13 collectors) and $V_{\text {lhst }}=15 \mathrm{~m}^{3}$ shows the lowest $S P F_{\text {sys }}$ (4.3), but would be applicable in a building with limited space on the roof for collectors [60].

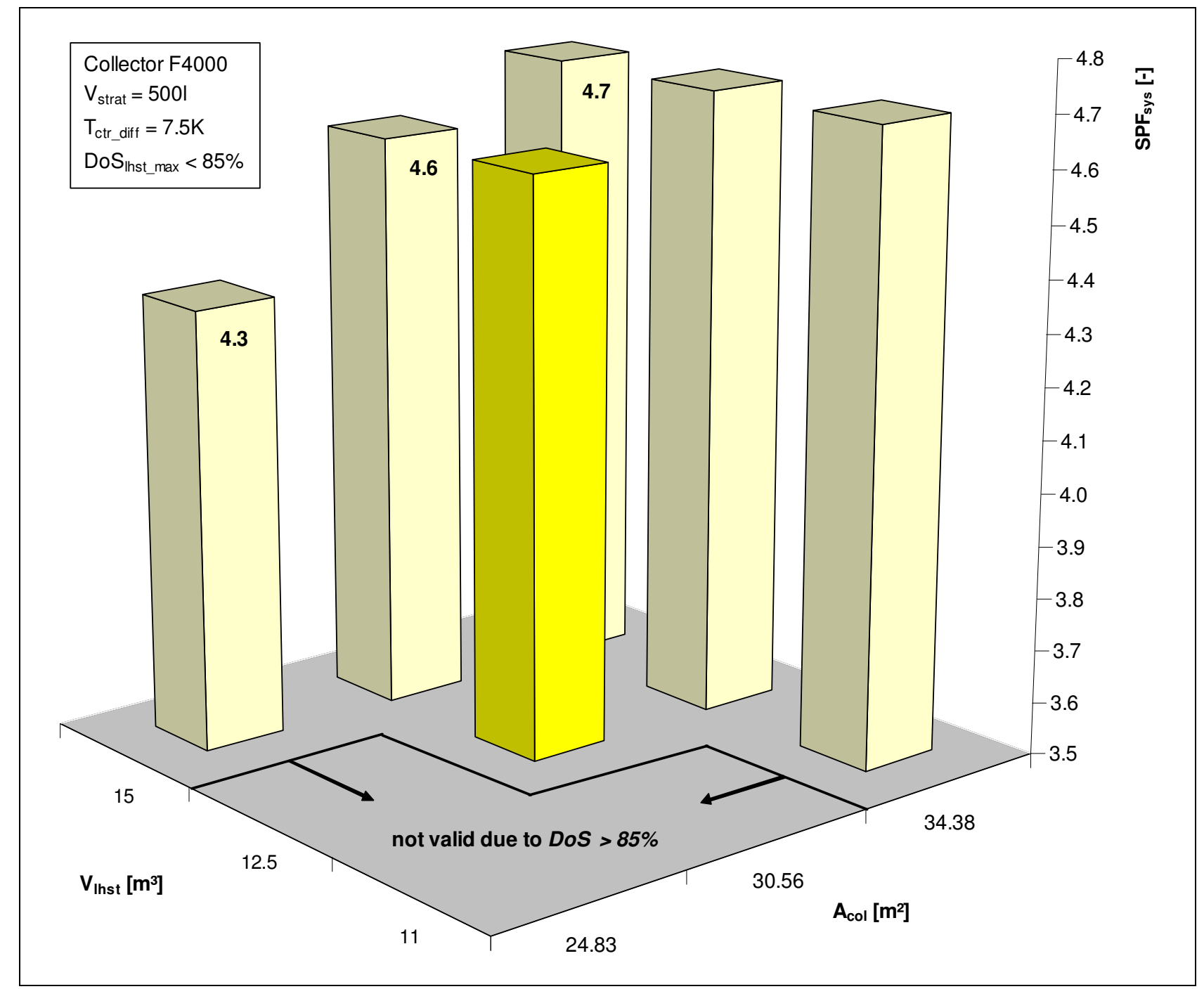

Figure 2.32: Variation of the Decisive Parameters $A_{c o l}$ and $V_{\text {lhst }}$ based on the Recommended System

In these calculations, the Maximum Degree of Solidification is set to $85 \%$, considering the assumptions made in the latent heat store model during phase change and in the heat pump model regarding source side cooling power. Thus, several collector/storage combinations exceeding that maximum value are not valid as indicated in Figure 2.32. 
The smaller the latent heat storage tank is dimensioned, the more importance gains the limitation of ice production in winter by a prioritisation of the latent heat storage tank charging in collector control. Nevertheless, this prioritisation restricts a further improvement of the $S P F_{s y s}$, which would be possible by more direct use of collectors for hot water and space heating in the stratification tank without heat pump operation. One promising possibility to optimise the system performance will thus be a more targeting control strategy regarding ice melting in the latent heat store. Figure 2.23 clearly demonstrates that the mass of ice produced strongly declines (beginning in March) after having reached a maximum in winter (February). The reason is that the solar yields are strongly increasing when coming to spring in contrary to the decreasing heat demand. A seasonal control strategy taking into account the point of time during the year, the Degree of Solidification, the ambient temperature and the heat demand could lead to a longer duration of the solidification phase, but also to more direct solar use without heat pump operation. Considering these possibilities, especially further development of the control strategy promises improvement of the system performance. 


\subsection{Conclusions}

In the course of heating system development, performance data with innovative heating system configurations were collected in the simulation study. They clearly show that the system can work satisfactorily with up-to-date components in a state-of-the-art building as a target application. The collector area and the latent heat store volume are the decisive parameters for system dimensioning, having reasonable values for the application in a one-family house, so that the main target of the system development could be achieved.

The promising annual simulation results of the heating system offer very good prospects for a further application of both heat pump and solar thermal systems in Central Europe. With the solar/heat pump heating system proposed, horizontal or vertical ground heat exchangers for the heat pump can be avoided. Due to their disadvantages (high space required, subject to authorisation, cost intensive, problematic application in existing buildings) they presently constrict the heat pump market in particular.

The simulation model provides relevant calculation results and thereby forms the basis for further investigation of the heating system. A fundamental control strategy for the complex heating system was developed, so that a solution to the problem of the two storage tanks (the major task in the system control) has been achieved. The realisation of the system control has proved to be a challenging task, which is not solvable by known and common approaches from conventional heating systems. On the one hand, the system combines numerous components with various system operational modes. On the other hand, control decisions often cannot be based on the current system state but also have to be made considering the annual context. For that, the control strategy should be extended by a more seasonal strategy to enhance the system performance and allow a further optimisation of the components' dimensioning. Particularly in the field of system control further development has a considerable potential for the optimisation of the system. Next to such refinement of the system control, further deepening of the investigation especially in the simulation is recommended in the following fields:

- The model of the latent heat storage tank contains some simplifications, especially in the solidification phase. A more precise model, particularly representing the three- 
dimensional distribution of solid and liquid medium in the store would enable the consideration of in-between solar collector charging effects with partial liquid regions in the store. These will occur when the collectors melt an ice layer around the heat exchangers while the rest of the store is still solidified.

- The heat pump model is based on measured static heat pump characteristics. Though the simulation shows satisfying correlation with the measured manufacturer's data, the applied model contains limitations. The application of a more detailed, internal component based model would both allow an in depth analysis of the heat pump and show the prospects of heat pump development in this system. Additionally, the direct solar collector utilisation by the heat pump could be realised and investigated.

Although the investigation presented shows promising results, it is limited to a single system configuration and to the reference building defined. While the results are transferable to similar buildings with varying heat demand (as for example the reference building "Redeveloped Family House"), they allow only limited conclusions for conceptually different system configurations. Therefore, a broadening of the investigation with an analysis of further system configurations requiring different control strategies and dimensioning is recommended:

- An interesting option is provided by the application of a ground-coupled uninsulated latent heat store interacting with the surrounding ground as storage mass. As this approach forms a low-temperature system, the combination with unglazed solar absorbers or simple low-cost collectors (including ambient energy utilisation) seems to be favourable. Also a combination of these inexpensive absorbers (for low-temperature heating) and more sophisticated glazed solar collectors (for high-temperature hot water preparation) in one system seems to be a promising alternative.

- As more and more modern family houses are equipped with waste-air-utilisation, such systems could be used as a further heat source next to solar collectors.

- A further extension of the investigation is recommended for alternative buildings: as well as redeveloped multi-family houses, modern industrial office and production buildings offer attractive target applications.

- Apart from Central Europe, alternative locations should be taken into consideration. More solar insolation on the one hand and less building heat demand on the other 
hand make Southern Europe interesting for instance. This would certainly lead to a smaller latent heat storage volume, a smaller collector area and to a higher seasonal performance factor of the system, as significantly less electrical energy is required.

- Both southern locations and modern industrial buildings lead to a conceptual extension of the system by a space cooling option. The utilisation of ice melting in summer for cooling purposes offers considerable potential as the required collector area decreases and the economic efficiency simultaneously increases as one system is used for two functions.

In addition to the recommended deepening and broadening of the investigation, monitored field tests with the solar/heat pump heating system should be carried out in different buildings as a next step to gather practical experience with the system's and components' behaviour. 


\section{Latent Heat Store Development}

In the course of latent heat storage tank development, initially a literature survey on both products and developments was carried out. Then, the design requirements for the store are defined and the function structure of the store worked out. Based on this analysis, suitable working principles are combined with concepts, which are compared concerning their suitability in terms of the requirements defined. The most promising heat exchanger concept was investigated in laboratory tests, ending up with a preliminary store design based on the dimensions defined by the system simulation.

\subsection{Latent Heat Materials and Problems linked with Phase Change}

Latent heat of fusion is used for several energy storage applications. In any application the selection of a phase change material (PCM) mainly depends on the material's melting point. For space applications PCMs with a melting point up to $800^{\circ} \mathrm{C}$ are considered. In contrary, for domestic heating systems as well as for industrial cooling a melting point between $-5^{\circ} \mathrm{C}$ and $100^{\circ} \mathrm{C}$ is required. Table 3.1 shows some typical PCMs for heating systems and water as a reference material. Mainly salt hydrates and paraffins are considered for these purposes due to their inertance (paraffins) and their relatively high latent heat of fusion (salt hydrates).

The salt hydrates have relatively high latent heat of fusion but they suffer from various problems in handling as a PCM:

- Most salt hydrates have an incongruent melting point, meaning that the material separates into a saturated aqueous phase and a solid phase when temperature increases beyond the melting point. Due to density differences, the solid phase settles out and collects at the bottom of the container [64]. This effect, called phase separation, leads to a degradation of the storage capacity with repeated cycling [1].

- Salt hydrates tend to supercooling: The melt does not solidify at its thermodynamic melting point but at a temperature beneath. As this phenomenon reduces the advantages of these materials for phase change applications, attempts have been made to reduce supercooling by using nucleating additives [58]. 
- Barium Hydroxide Octahydrate for example is highly toxic and corrosive [65], hence demands complex and costly containers.

Table 3.1: Characteristics of Typical Phase Change Materials (data from [2] [59] [64] [65] [66] [67])

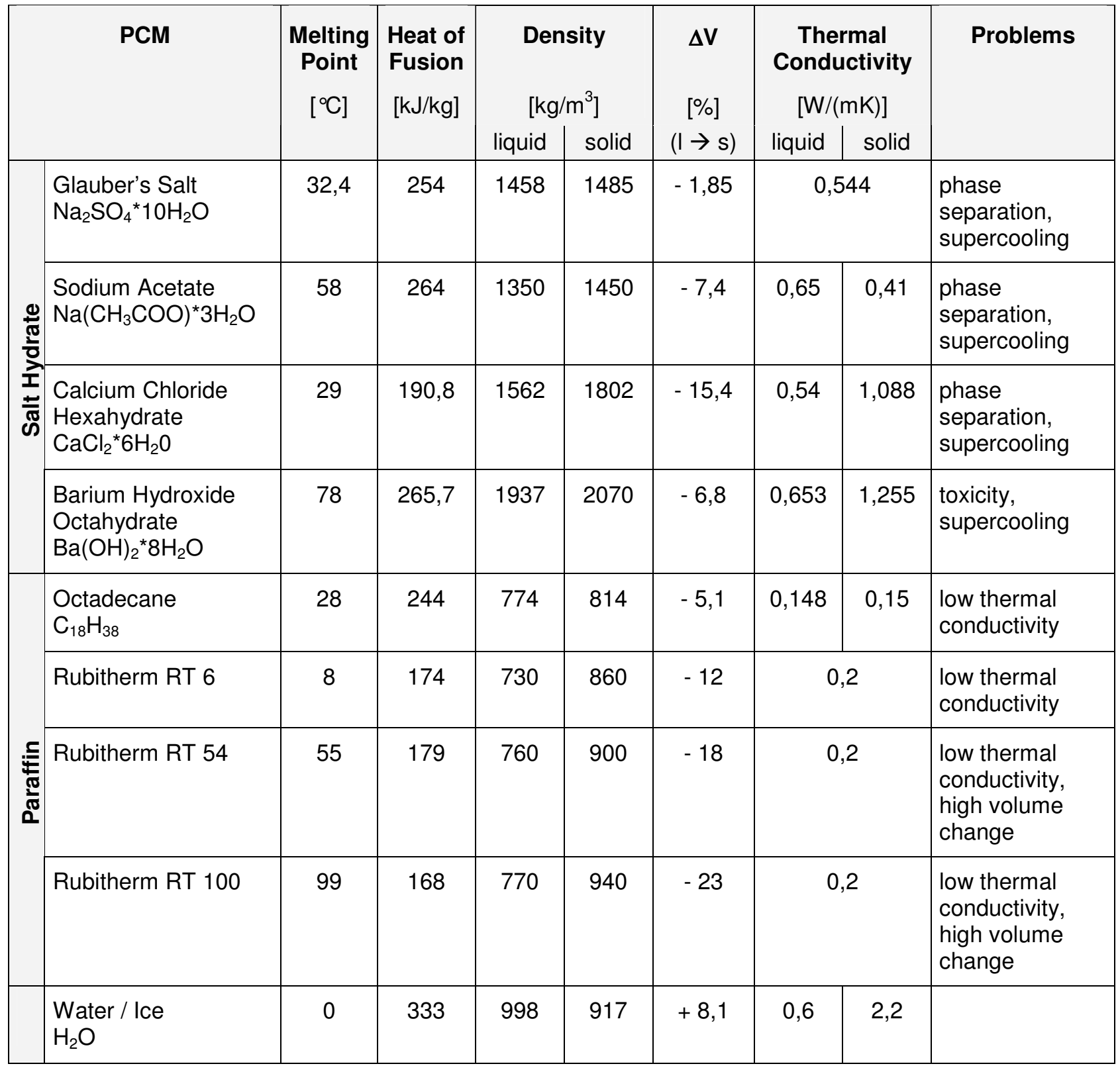

Paraffin is commercially available with melting points from $-3^{\circ} \mathrm{C}$ to $+100^{\circ} \mathrm{C}$, depending on the material's number of $\mathrm{C}$-atoms [68]. Paraffin in general suffers from very poor thermal conductivity $(\approx 1 / 4$ of the thermal conductivity of water), which is critical for charge and discharge and requires complex heat exchangers with large heat transfer surfaces. Furthermore, some technical grade paraffins have a considerable volume change. But the most striking disadvantage of paraffin as a PCM is its relatively low latent heat of fusion. Figure 3.1 illustrates the melting point and the latent heat of fusion of some PCMs. An 
overview on PCMs, the scientific background from a chemical point of view and the PCM selection criteria for latent heat stores are described in detail by Lane [69] [70].

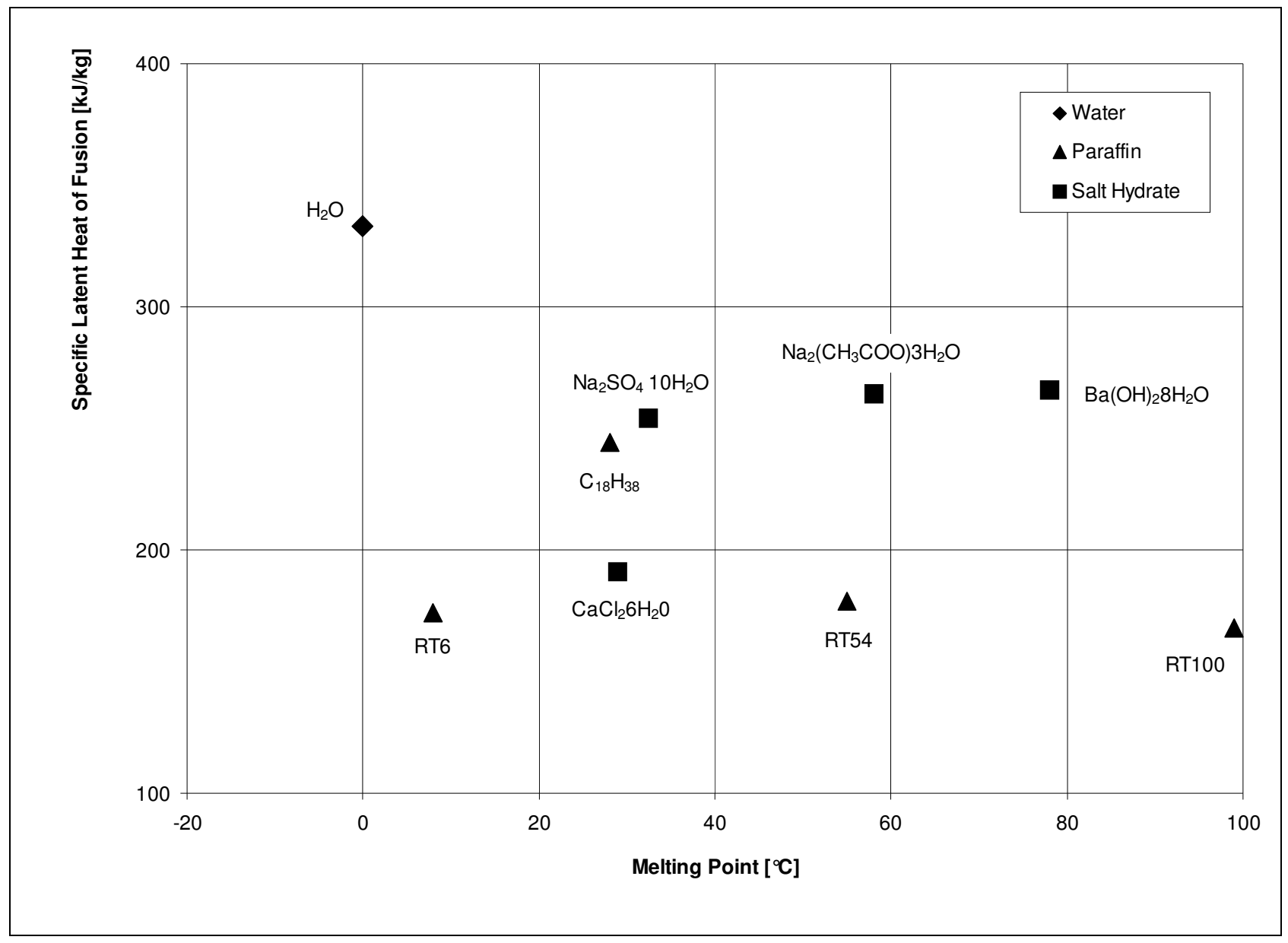

Figure 3.1: Specific Latent Heat of Fusion and Melting Point of Typical Phase Change Materials

When considering the materials' characteristics, the general problems connected with a phase change energy store can be derived. The physical properties of the materials vary considerably with phase change:

- The change in density leads to a volume change. The volume of all materials shown in Table 3.1 except water reduces when freezing. This is not problematical for the tank and the heat exchanger because the liquid medium can flow into the emerging hollow space. When liquefying, the expanding liquid medium is displaced. The volume of water, however, expands during freezing. This can cause mechanical stress on the heat exchanger and the tank. When melting, hollow spaces can emerge in the solid material and reduce thermal conduction. 
- Thermal conductivity of all the materials is relatively low, which particularly forms a problem as natural convection cannot occur in the solid state. Thus, conduction is the only heat transfer mechanism during freezing, which generally decreases the heat transfer in comparison to the melting process. This effect is called self-insulation of the heat exchanger, meaning that solid material sticks to the heat exchanger when the PCM is freezing. The solid-liquid interface moves away from the heat exchanger surface, hence the thermal resistance rises with the growing layer of solid PCM. Figure 3.2 shows a typical tube-type heat exchanger with layers of solid material around the tubes.

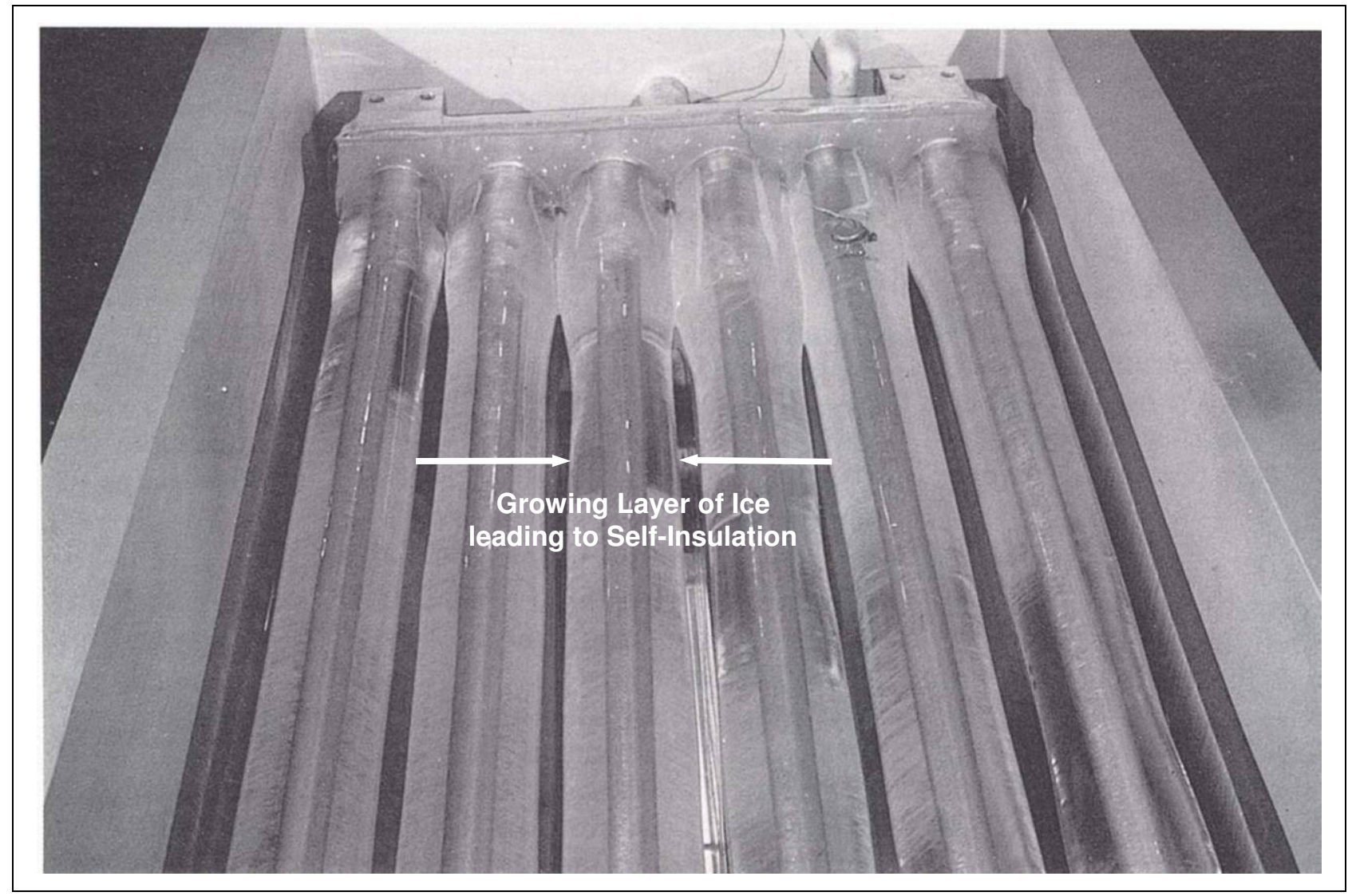

Figure 3.2: Tube-type Heat Exchanger with Self-Insulating Layers of solid Material during Freezing [71] 


\subsection{Literature Survey of Heat Exchanger Technology}

Numerous different conceptual heat exchange solutions have been investigated for latent heat stores in the past. Figure 3.3 shows a classification of heat exchanger concepts.

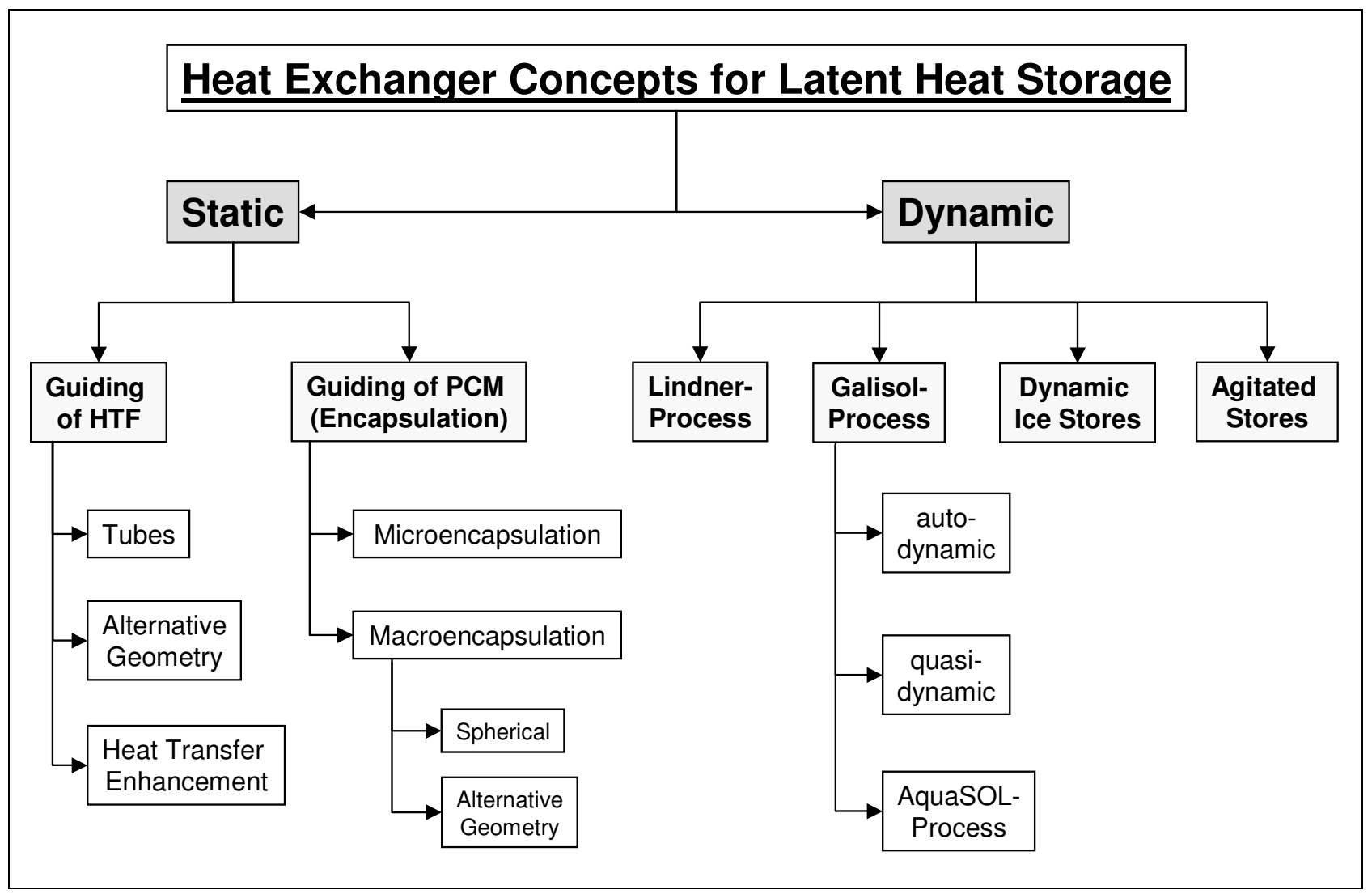

Figure 3.3: Heat Exchanger Concepts for Latent Heat Storage

Static (or passive) heat exchanger concepts operate without movement of the PCM in the tank, i.e. without agitating, pumping, etc. There are two conceptual options for the realisation of this concept: Guiding the heat transfer fluid (HTF: brine in the collector/heat pump circuit) in a defined geometry (e.g. in tubes) through the PCM lying in the tank. The second option is keeping the PCM in a defined geometry in the tank (e.g. in spherical nodules) with the HTF flowing through the tank freely.

In contrary, in a store with dynamic (or active) heat exchange the PCM is in motion during operation. This can be realised by agitating the PCM or by the application of an additional, immiscible HTF for direct contact with the PCM. 


\subsubsection{Static Heat Exchanger Concepts}

A straightforward and well-known possibility for guiding the HTF through the storage tank is the integration of a tube system in a tank. Figure 3.4 shows a typical heat exchanger with tube coils for a latent heat storage tank. In case of heat removal, the PCM (often water for refrigeration processes) freezes around the tubes.

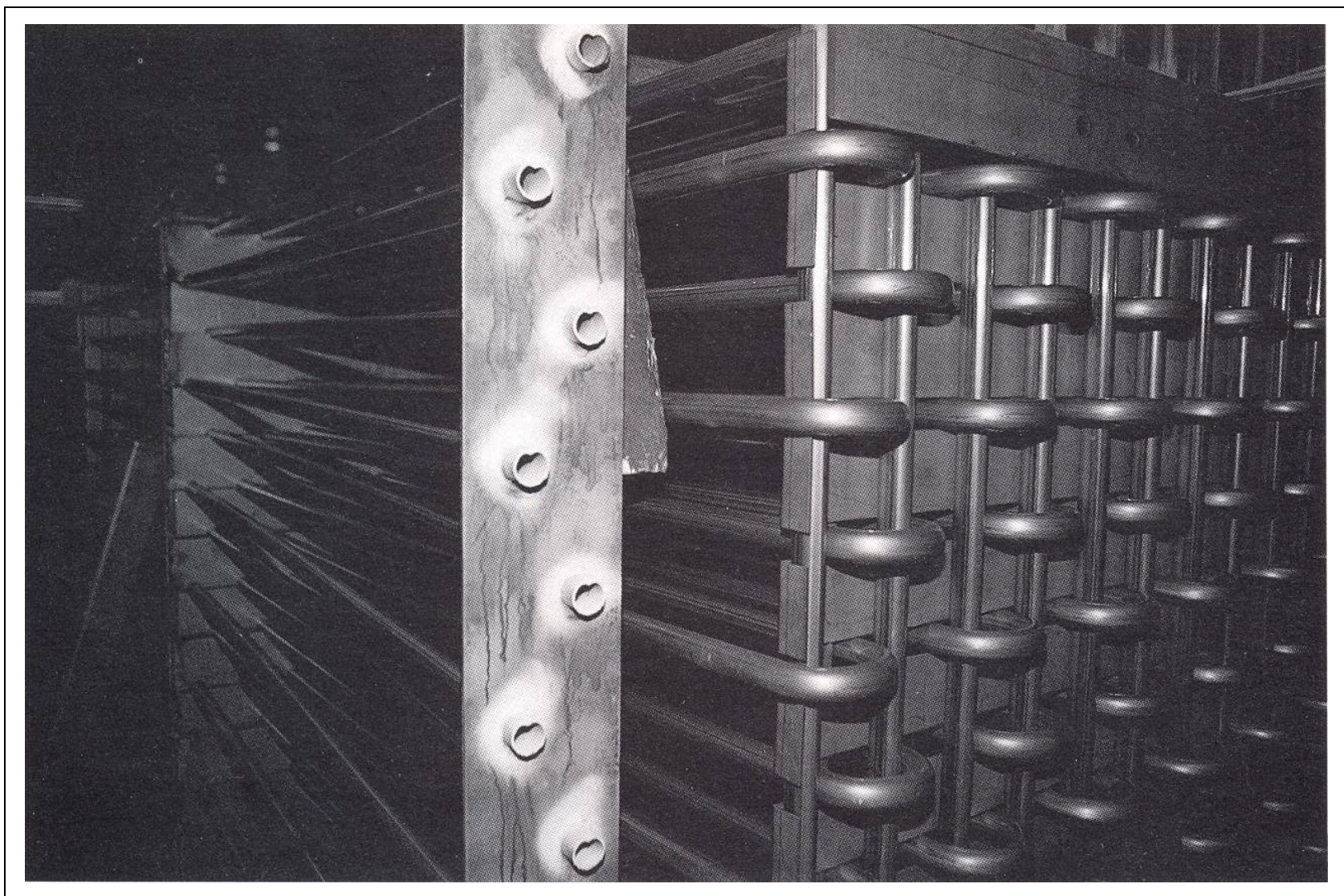

Figure 3.4: Tube Coils of a Heat Exchanger in a Latent Heat Storage Tank [71]

Otherwise, warm fluid circulates through the tubes, melts the solid medium and builds a liquid layer between the tube and the solid PCM. For an adjustment of the heat exchanger performance, the number of tubes is raised. As illustrated in Figure 3.2, the problem of self-insulation occurs in these systems and leads to a decrease in charge and discharge performance with increasing layer of solid PCM. The tube-type heat exchangers are commercially available from different companies mainly for refrigeration purposes in an industrial scale (e.g. Baltimore Aircoil Comp., Baltimore (USA), Calmac Manufacturing Co., Englewood (USA) or Tankki Oy, Ähtäri (Finland)). Apart from that, such a system 
was investigated by Lübeck University of Applied Sciences in a solar heat pump system (cf. Figure 2.11).

As the tube-type heat exchangers have the problem of decrease in performance, in the course of further development, alternative geometrical elements for guiding the HTF through the tank have been investigated. Finned tubes are one possibility to increase the heat transfer surface in the store, investigated for example by de Jong et al [72] (Figure 3.5). Tubes with chambers for PCM, shown in Figure 3.6 and Figure 3.7, were proposed and analysed in simulation

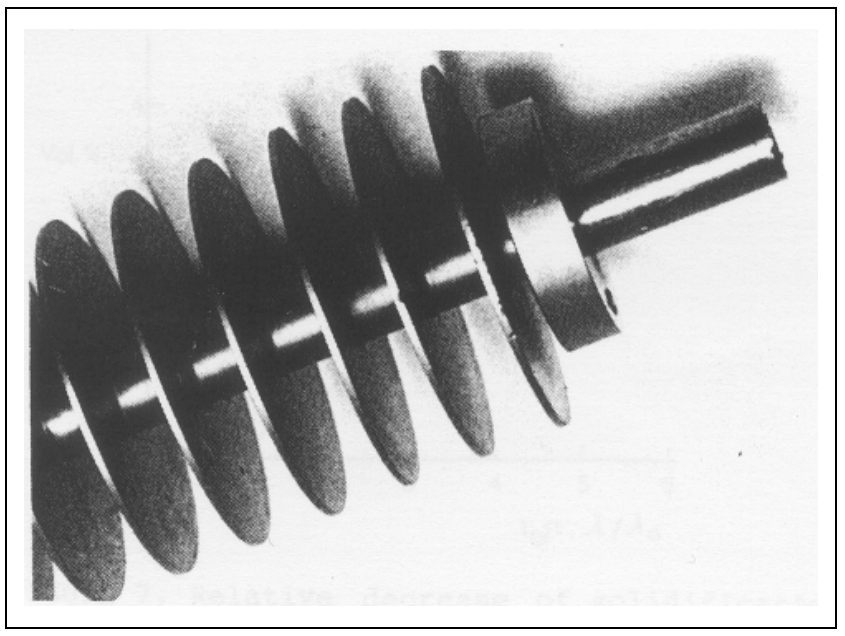

Figure 3.5: Finned Tube Heat Exchanger [72] and experimental studies by Abhat [73] and Bostel [74]. The major target of these developments is to enlarge the heat transfer surface in the storage tank and to advance the penetration of the heat exchanger in the PCM.

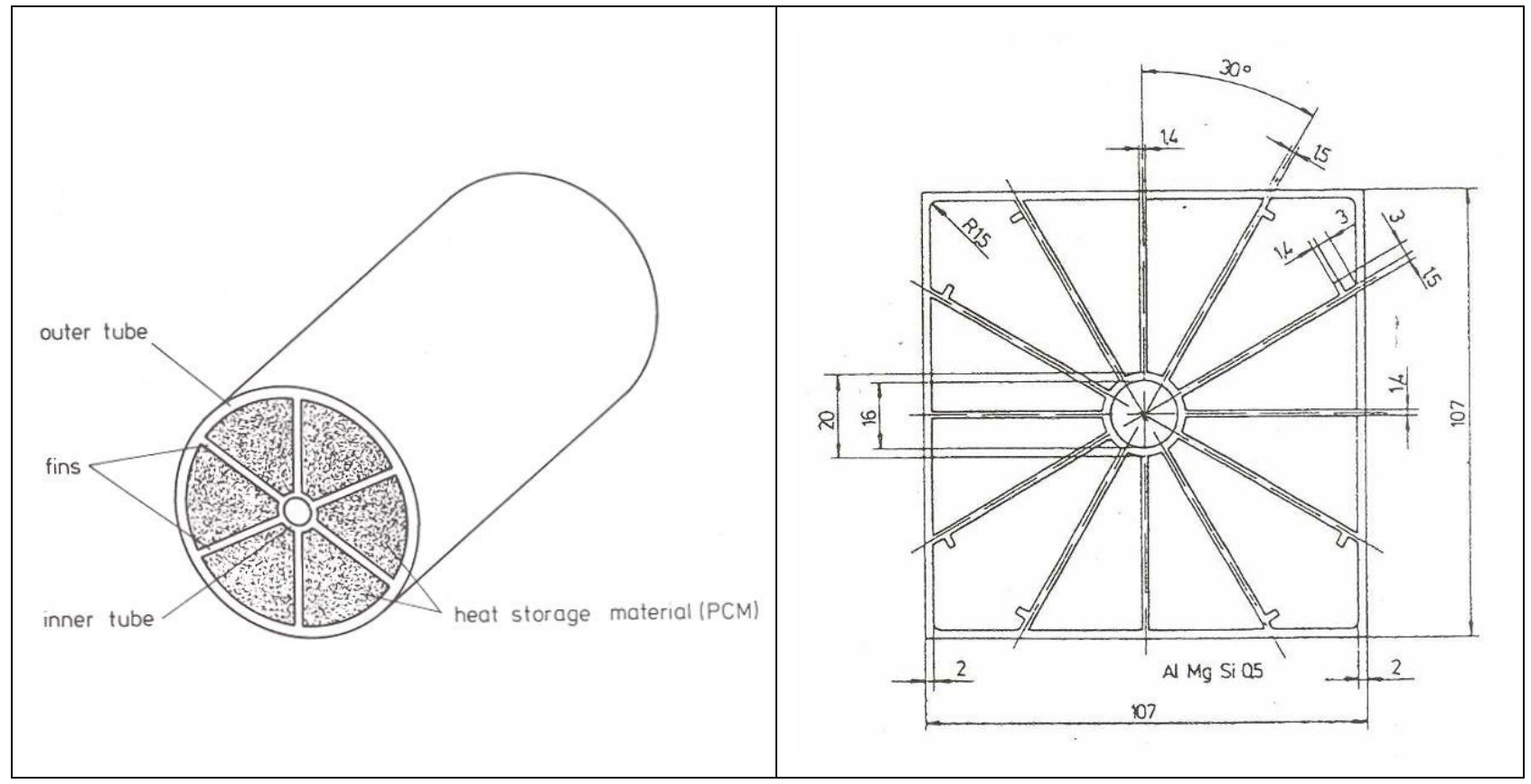

Figure 3.6: Finned Annulus Heat Exchanger [73]

Figure 3.7: Extruded Aluminium Sheath Heat Exchanger [74] 
A latent heat storage tank for domestic heating is provided by Alfred Schneider $\mathrm{GmbH}$, Lahr (Germany). The heat exchanger consists of vertically mounted heat conduction plates spaced from another. The plates are soldered to copper tubes containing the HTF. The plates are in contact with the PCM (salt hydrate) and have sharp edges and spikes to minimise supercooling of the salt hydrate (Figure 3.8). The system is extensively protected by European patents [75].

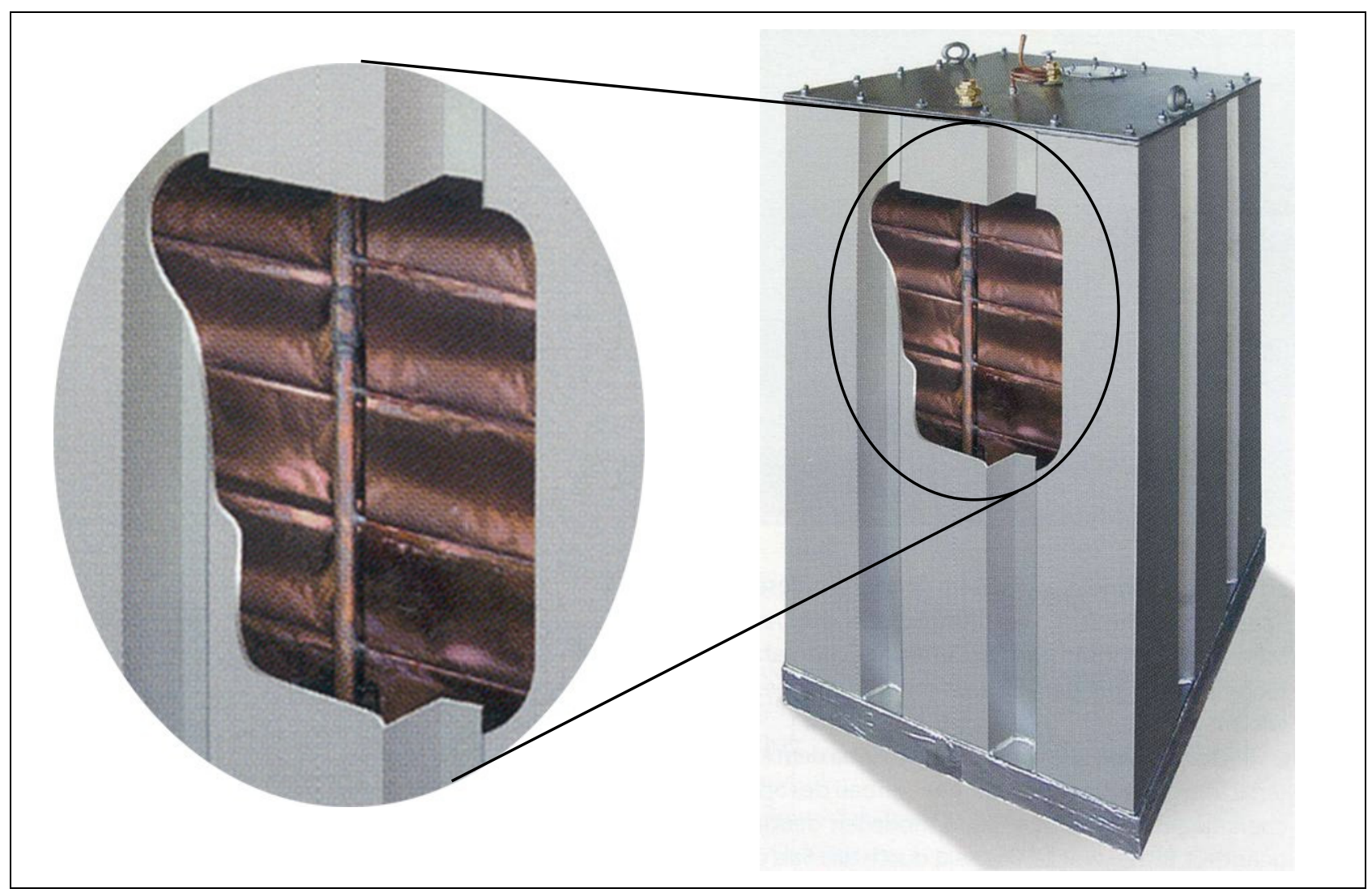

Figure 3.8: Latent Heat Store and Heat Exchanger with Copper Tubes and Heat Conduction Plates [76]

Conceptually, the application of fins and heat conduction plates leads to a further approach named heat transfer enhancement. As described, a major problem of latent heat storage systems is the low thermal conductivity of the PCMs especially in the solid phase and self-insulation restricting the heat exchangers' performance. Consequently, it has been tried to enhance heat transfer within the tank by design measures, such as extended heat exchanger geometry, inserts mounted in the tank or pouring adequate material into the PCM. In general, the target of these developments is to enhance the heat exchanger performance during phase change. Along with this, the volume occupied by the additional material in some cases significantly reducing the storage capacity has to 
be taken into consideration on the one hand. On the other hand, the increase in complexity and costs must not be neglected.

A typical example for inserts in the tank has been developed by Modine/Längerer\&Reich, Filderstadt (Germany), for automotive applications (storage of engine waste heat for cold start). The storage tank has a volume of 12 litres and contains a eutectic salt (melting point: $70^{\circ} \mathrm{C}$ ). The engine coolant directly flows through the store. For heat transfer enhancement an aluminium matrix is inserted between the coolant ducts as illustrated in Figure 3.9.

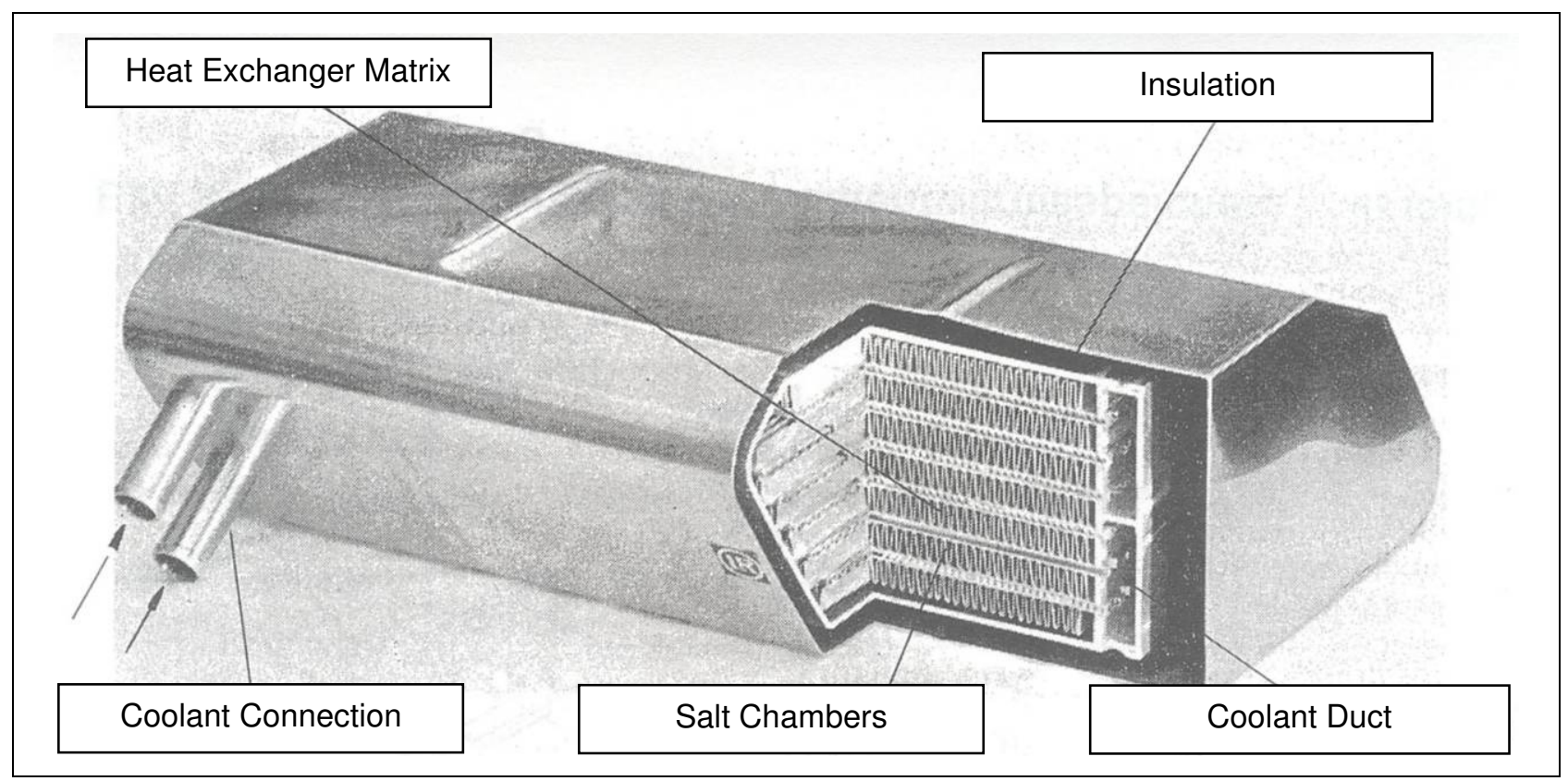

Figure 3.9: Latent Heat Store for Automotive Applications with Aluminium Matrix for Heat Transfer Enhancement [77]

The system has a storage capacity of $600 \mathrm{Wh}\left(90 \ldots 50^{\circ} \mathrm{C}\right)$; the discharge performance temporarily reaches $30 \mathrm{~kW}$, which is remarkably high. However, the volume fraction of PCM is no more than approx. $36.5 \%$ [78]. The system is protected by international patents [79].

Embedding a metal matrix in the PCM was proposed by de Jong et al [72] and Hoogendoorn et al [80], using aluminium thin-strip-matrices (Figure 3.10) with a thickness of $0.05 \mathrm{~mm}$ and width of the strips of $2 \mathrm{~mm}$ in a paraffin latent heat store for solar systems. The metal matrix is connected to the heat exchanger wall for good thermal contact. It was 
found that a metal volume fraction of only $1.6 \%$ could enhance the effective thermal conductivity of the metal-paraffin configuration by a factor of 4 in comparison to pure paraffin.

The use of carbon fibres with high thermal conductivity of $220 \mathrm{~W} /(\mathrm{mK})$ as an enhancement material in paraffin was investigated by Fukai et al [81]. In an experimental investigation, randomly oriented fibres as well as fibre brushes were packed in a cylindrical capsule (volume fraction of fibres: $<2 \%$ ). Comparing the two experiments, it was found that the effective thermal conductivity of the composite was approximately enhanced by a factor of 5 (random-type) and a factor of 20 (brush-type) to the thermal conductivity of pure PCM.

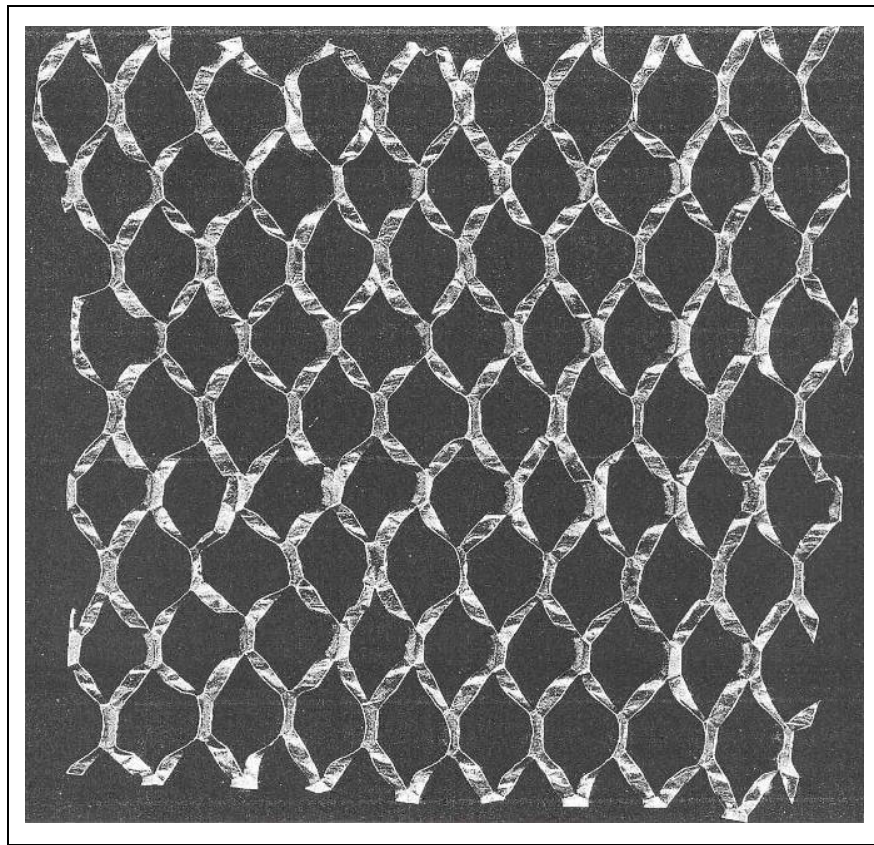

Figure 3.10: Thin Film Aluminium Matrix [80]

Figure 3.11 shows the proposed application of fibre brushes in a latent heat storage tank with a tube-type heat exchanger.

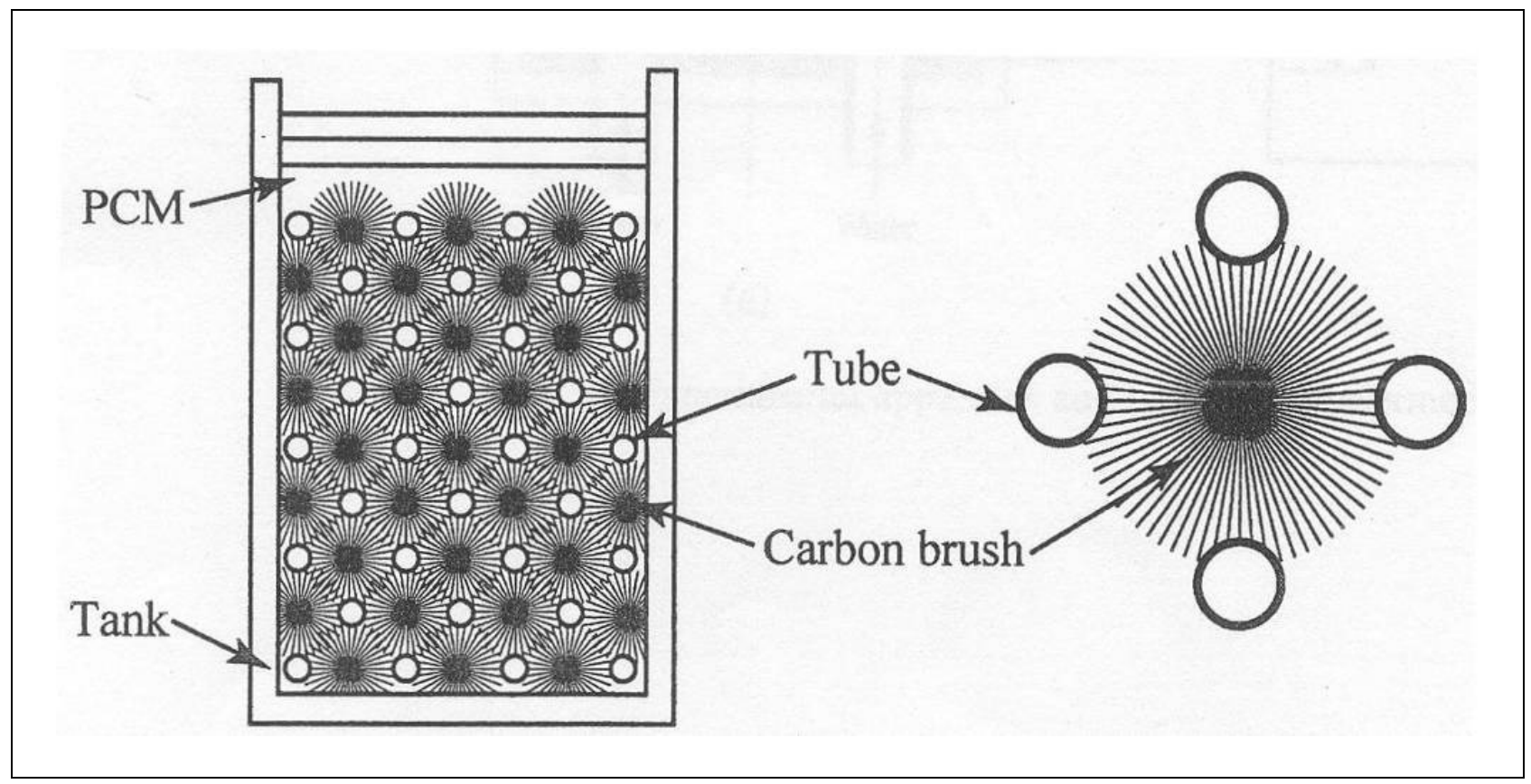

Figure 3.11: Heat Transfer Enhancement by the Use of Carbon Fibre Brushes [82] 
A further possibility of heat transfer enhancement is to disperse high conductivity elements in the PCM. This approach was followed up by Hafner et al [83], investigating several materials for heat transfer enhancement. Figure 3.12 shows the measured effective thermal conductivity of different paraffin/enhancement material fillings. It was found that the highest thermal conductivity was reached by the use of the so-called VSP25 as an enhancement material. These cylindrical elements are made of aluminium

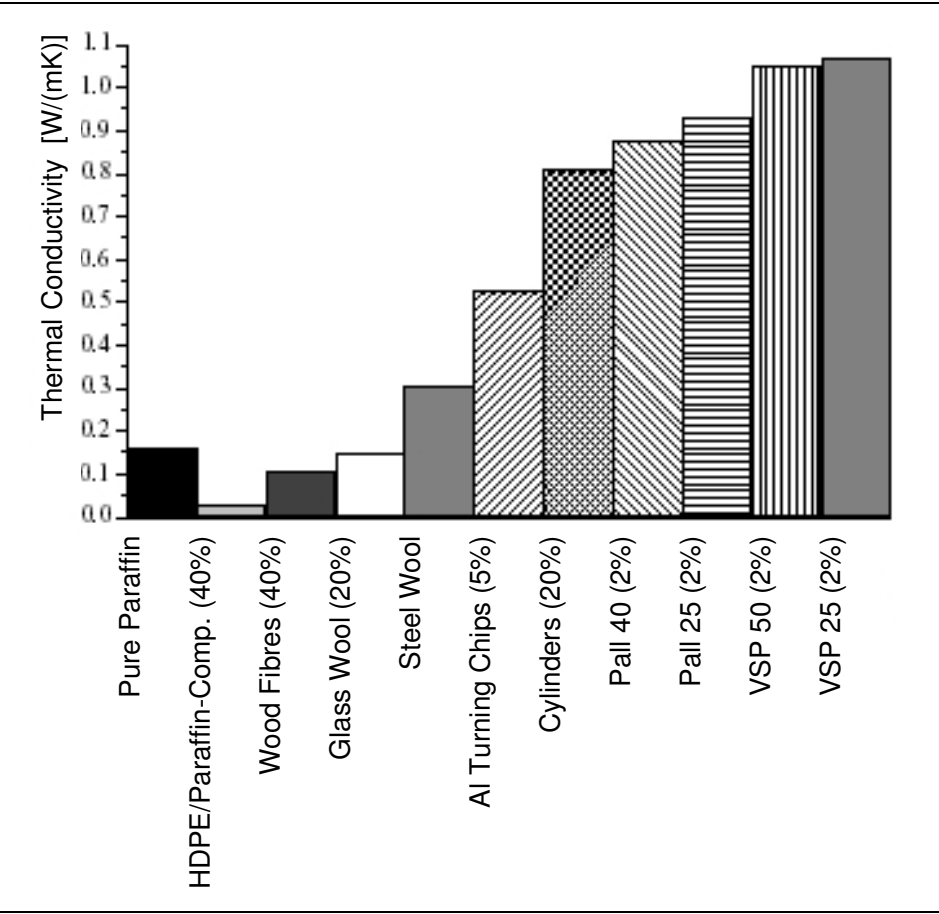

Figure 3.12: Effective Thermal Conductivity of Different Paraffin/Enhancement Material-Composites [83]

and have a displaced surface (Figure 3.13). Their length and diameter is both $25 \mathrm{~mm}$. The elements are filled into the tank with the PCM, paraffin in this case, and occupy a volume of $2 \%$ (Figure 3.14). The major advantage of this approach is its constructive simplicity. However, the heat transfer within the PCM/enhancement element-composite is limited because the aluminium pieces form a loose packaging. The interrupted heat flux paths emerging have a negative influence on the heat transfer in the composite, which was shown by Cabeza et al [84] in an experimental study.

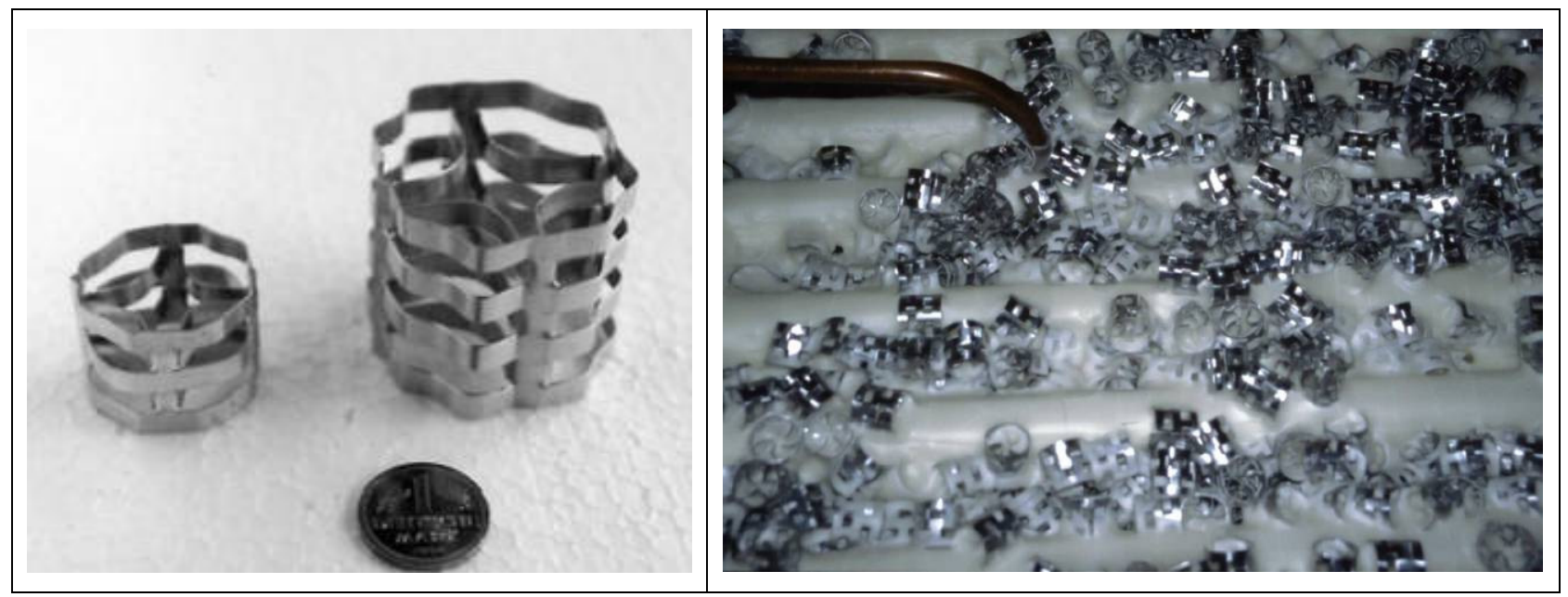

Figure 3.13: VSP25 (left) and VSP50 (right) as Enhancement Material [83]
Figure 3.14: VSP25 dispersed in the Storage Tank, surrounded by solid Paraffin [85] 
A PCM-graphite composite material for enhancement of heat transfer within latent heat stores was developed by Mehling et al [86]. In this concept, the PCM is embedded in a microporous graphite matrix. The matrix is made of expanded graphite, being compressed to $1 \%$ of its original volume and thereby building a highly porous matrix. Filling the PCM into this matrix makes the PCM-graphite composite material. Typically, the graphite has a volume fraction of $10 \%$, the PCM has $80 \%$. The remaining volume is filled with air. Investigations showed an enhancement of the effective thermal conductivity from $0.2 \ldots 0.5 \mathrm{~W} /(\mathrm{mK})$, typical for PCMs, to $20 \ldots 30 \mathrm{~W} /(\mathrm{mK})$ for the composite, depending on the volume fraction of graphite [87].

As illustrated in Figure 3.3, a further conceptual approach for charge and discharge of latent heat stores is guiding the PCM in the tank. This means the PCM is encapsulated in a hermetically closed geometry; the HTF flows through the tank freely.

Depending on the size of the capsules, the encapsulation techniques are divided into microencapsulation and macroencapsulation. Microencapsulation in general means that the capsule size does not exceed 3...20 $\mu \mathrm{m}$. Especially paraffins have been encapsulated in this way by a few companies, e.g. BASF AG, Ludwigshafen (Germany). They are offered as an aqueous solution or in powder form and are mainly applied in buildings as plaster or gypsum plasterboard to increase the buildings' thermal mass.

For macroencapsulation principally all kind of containers can be taken into consideration. Typical products are flat plastic or metal containers, plastic pouches, both offered for example by Climator, Skovde (Sweden), or plastic mats for floor heating systems, e.g. provided by TEAP Energy, Wangara (Australia). Apart from that, different geometries, materials as well as their compatibility to different PCMs have been investigated by Lane [70]. Nevertheless, the most common kind of encapsulation is the spherical nodule (Figure 3.15). These balls are filled with PCM, mainly salt hydrates for cooling applications and are sealed hermetically. Their diameter is usually between $75 \ldots 110 \mathrm{~mm}$, the shell is made of polyolefines. 


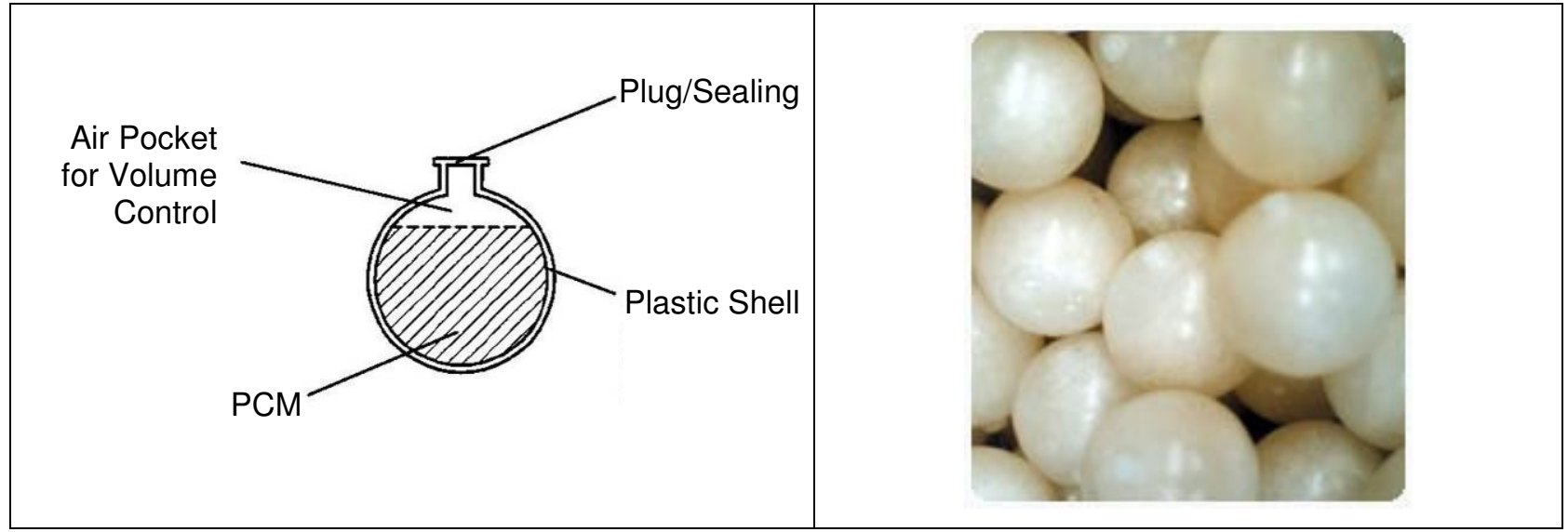

Figure 3.15: Typical Spherical Nodule for Encapsulation of PCM [88]

Figure 3.16: Spherical Nodules containing PCM, poured in a Storage Tank [89]

Depending on the manufacturer, the balls either have a gas pocket for compensation of the PCM's volume change (e.g. BMS-Energieanlagen, Wilderswil (Switzerland), Cristopia Energy Systems, Vence (France), TEAP Energy, Wangara (Australia)), or have preformed dimples on the surface flexing out to allow expansion (Cryogel, San Diego (USA)). The balls are poured into the storage tank. This leads to a homogenous distribution of the nodules in the tank with spacing in between for HTF circulation (Figure 3.16).

The advantage of these encapsulation systems is that the storage capacity solely depends on the number of balls and thereby is highly flexible. However, a clear disadvantage is that the volume fraction of PCM is limited to approximately $60 \%$ due to the spherical form of the balls and the relatively large spacing emerging. Furthermore, investigations showed that the distribution of the two phases within the balls also deteriorate the heat transfer, as is illustrated in Figure 3.17 for an exemplified melting process [90].

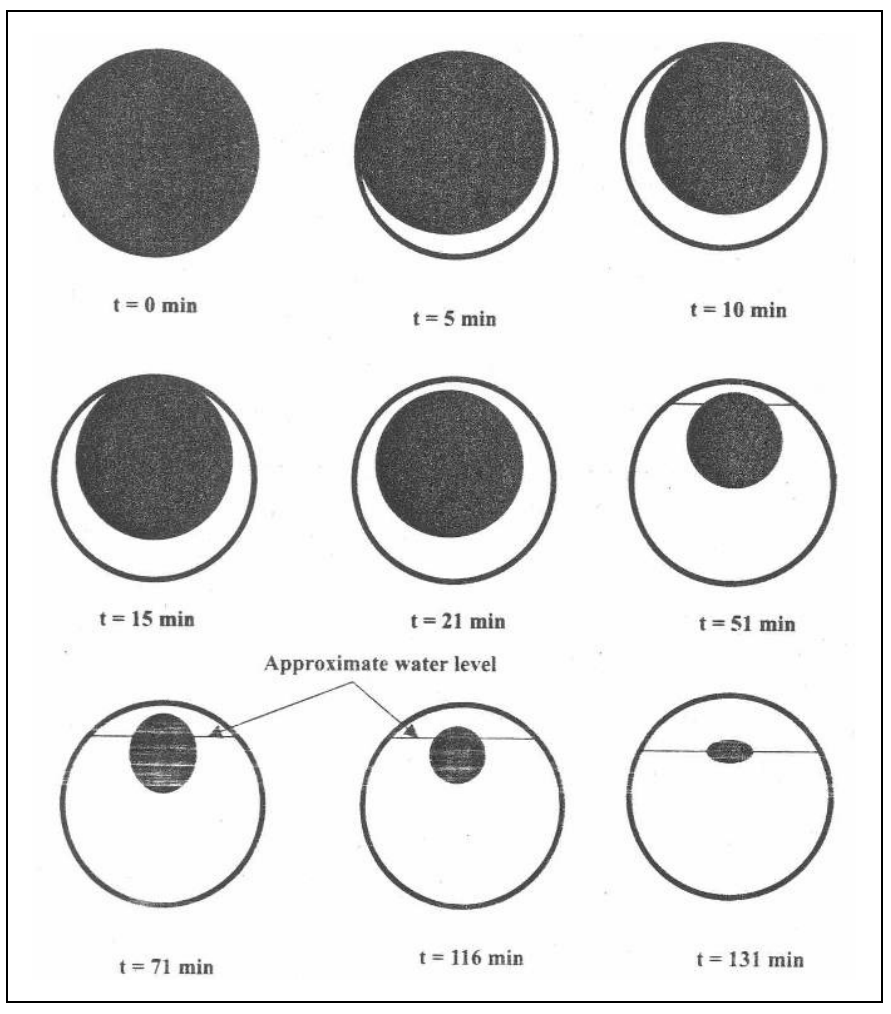

Figure 3.17: Melting Process of Water within a Spherical Nodule [90] 


\subsubsection{Dynamic Heat Exchanger Concepts}

Whereas the storage medium is not in motion in stores with static heat exchangers, dynamic heat exchangers operate with movement of the PCM. Therefore, they are also called active heat exchangers.

A straightforward example of an active latent heat store, a so-called agitated store, was investigated by General Electric, Schenectady (USA). The cylindrical tank rotates; thereby the PCM is agitated in the tank. This leads to an advanced mixing of the salt hydrate used. The problem of self-insulation by solid PCM sticking on the surface of the cylinder has not been observed. Nevertheless, commercial products with this heat exchange technique are not known [91].

In contrary, dynamic stores for refrigeration applications (PCM: mainly water/ice) on an industrial scale are available from several companies. As shown in Figure 3.18 , this process separates ice production and ice storage. Water flows freely over the chilled evaporator plates mounted vertically above the storage tank and freezes on the plates. When a certain thickness $(3 \ldots 10 \mathrm{~mm})$ is reached, the ice is harvested by a hot-gas defrost cycle, lasting usually $20 \ldots 90 \mathrm{~s}$; the ice plates fall into the tank. The PCM is melted either by circulation of warm HTF in

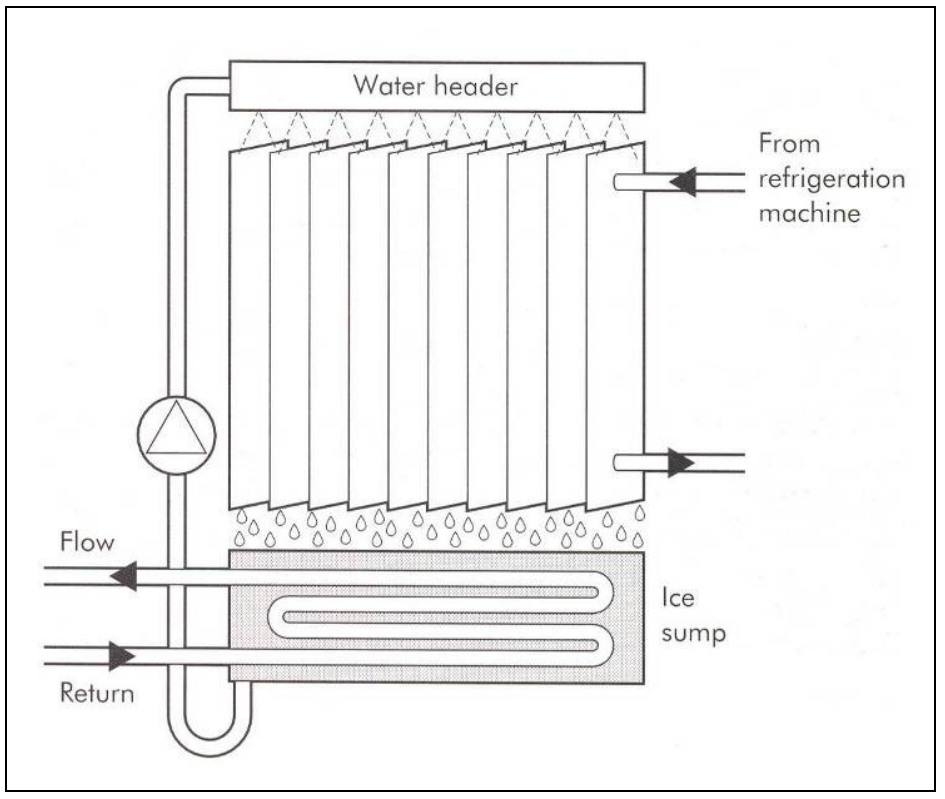

Figure 3.18: Principle of Dynamic Ice Stores for Refrigeration Applications [71]

tube coils in the tank or by direct circulation of chilled water from the tank through the building cooling system [58] [71]. The major advantage of this dynamic latent heat storage system, also known as ice harvester, is that the performance of heat dissipation is consistent over a long period, because the problem of self-insulation does not occur. However, the disadvantage is the system's high space demand for a separated ice gen- 
eration and ice storage device. Apart from that, energy input for harvesting of ice is required, which reduces the overall system performance.

A completely different approach for dynamic latent heat storage has been in the focus of some researchers: the basic proposal is to bypass a heat exchanger between HTF and PCM. Instead, the direct contact between the PCM and a further medium is utilised. The further medium is the so-called additional heat transfer fluid (AHTF) being immiscible with the PCM. The German Aerospace Center, Stuttgart (Germany), for example developed a storage system for Glauber's Salt and Sodium Acetate. The principle is shown in Figure 3.19 and is commonly known as the Lindner-process: For discharging, the AHTF, technical grade oil, is cooled by the HTF in a heat exchanger. The AHTF is sprayed into the bottom of the tank by spray nozzles. Due to its lower density, the oil ascends through the salt hydrate to the surface. The PCM is cooled by the oil drops; it solidifies around them. Whereas the crystals of PCM fall to the bottom of the container (by reason of their higher density in comparison to the liquid PCM) and form a loose and permeable sludge of solidified PCM, the oil accumulates at the salt hydrate surface. It is exhausted from the top of the tank and pumped through the spray nozzle system again. When the storage tank is charged, the heated oil ascends through the permeable sludge of PCM and liquefies it. Thereby the PCM is agitated, which has a positive influence on phase separation. The heat transfer surface hereby is the permanently regenerating surface of the oil drops, in contrast to the boundary surface used in static systems. Crystallisation takes place in the free volume of the PCM.

Several stores were built and investigated on both a laboratory and industrial scale. According to the documentation, the prototypes worked satisfying. An obvious problem is the design of the spray nozzle system for homogenous distribution of the AHTF in the tank as well as the prevention of nozzle plugging and inclusion of oil in solid PCM [92] [93].

The major advantage of this approach is the nearly constant heat transfer performance over the whole cycle, because solid layers of PCM cannot emerge at any heat exchanger surface. A drawback, however, is that several further components (pump, heat exchanger, tubes...) are required for its operation. 
The heat exchange system for salt hydrate and several components of the storage tank are protected by patents [94]. It was manufactured and distributed by Alfred Schneider $\mathrm{GmbH}$, Lahr (Germany) for some years.

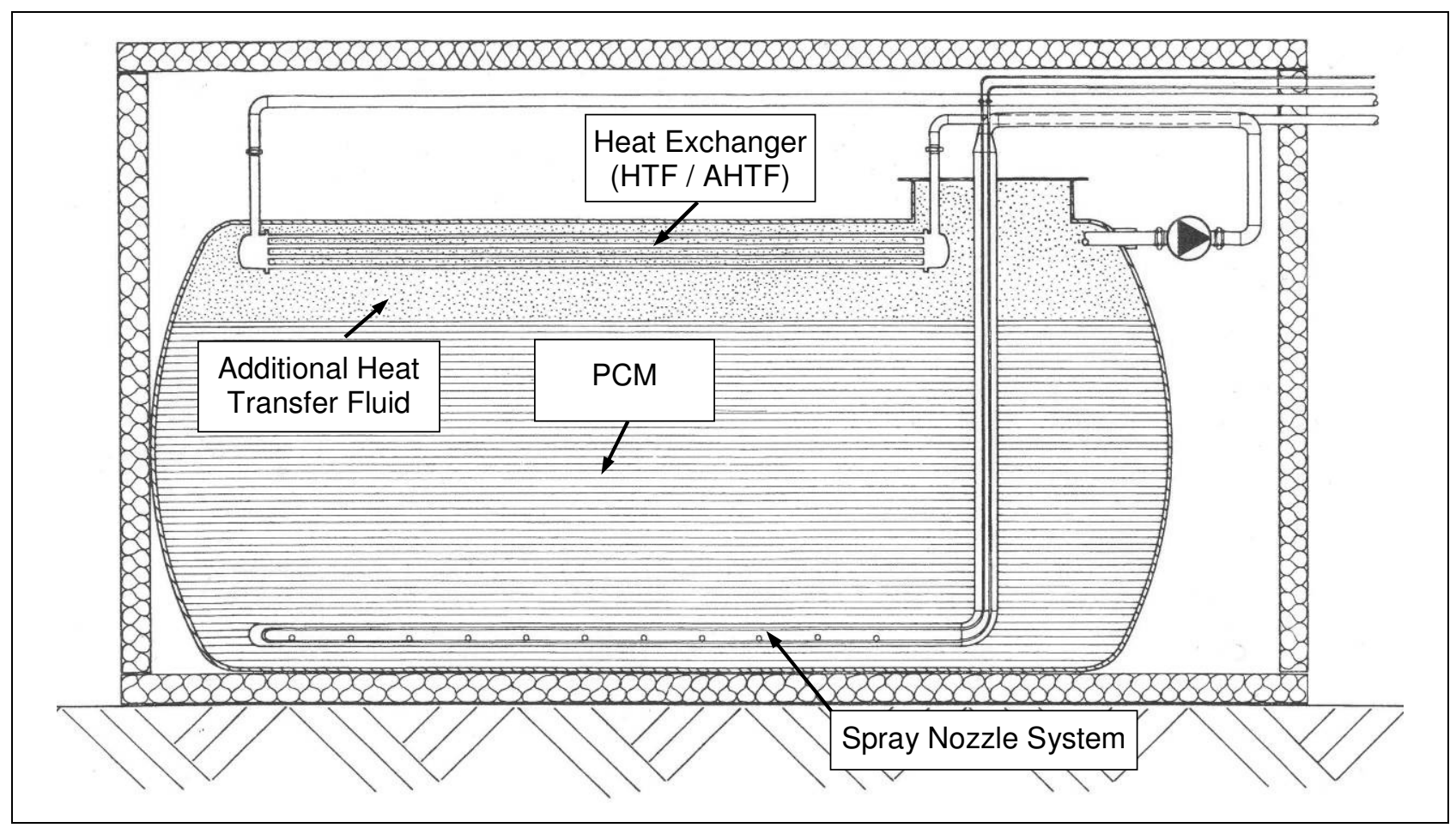

Figure 3.19: Principle of a Latent Heat Store working according to the Lindner-Process [92]

A further development of the Lindner-process is the so-called GALISOL-process. As Lindner's system does, it utilises an additional heat transfer fluid for direct contact heat exchange. To reach the aim of enhancing the charging and discharging performance of latent heat stores, a further phase change was integrated in the process. The GALISOLProcess (GAseous - Llquid - SOLid) uses an AHTF that boils and condenses while charging and discharging, as Figure 3.20 illustrates. For charging the store, heat is transferred to the charging heat exchanger at the bottom of the container. The AHTF boils and ascends through the loose sludge. Thereby it melts the PCM crystals, condenses and falls down to the heat exchanger again. The molten PCM ascends to the PCM surface due to its lower density. For discharging the store, the gaseous AHTF at the top of the store is cooled and thus condensed by the discharging heat exchanger. The liquid AHTF falls down, dissipates heat from the liquid PCM and thereby solidifies it. The PCM crystals fall down to the bottom of the container and form the loose sludge of PCM. The gaseous AHTF ascends to the heat exchanger and again condenses. Due to the phase 
change of the AHTF in the storage tank, this storage concept can be indicated as a heat pipe with integrated PCM [95].

Three different GALISOL-modifications have been developed:

- Auto-Dynamic means that the pressure and temperature required in the store for the phase change of the AHTF are adjusted automatically due to the choice of media.

- Quasi-Dynamic is a modification of the process, which encapsulates the PCM in the storage tank. It is required because otherwise only the environmentally harmful halogenated hydrocarbons come into consideration as AHTF for salt hydrates as PCM.

- The Aqua-SOL-Process simultaneously uses the hydration water of the molten mass as the AHTF [96].

The advantage of the GALISOLprocess is a high charge and dis-

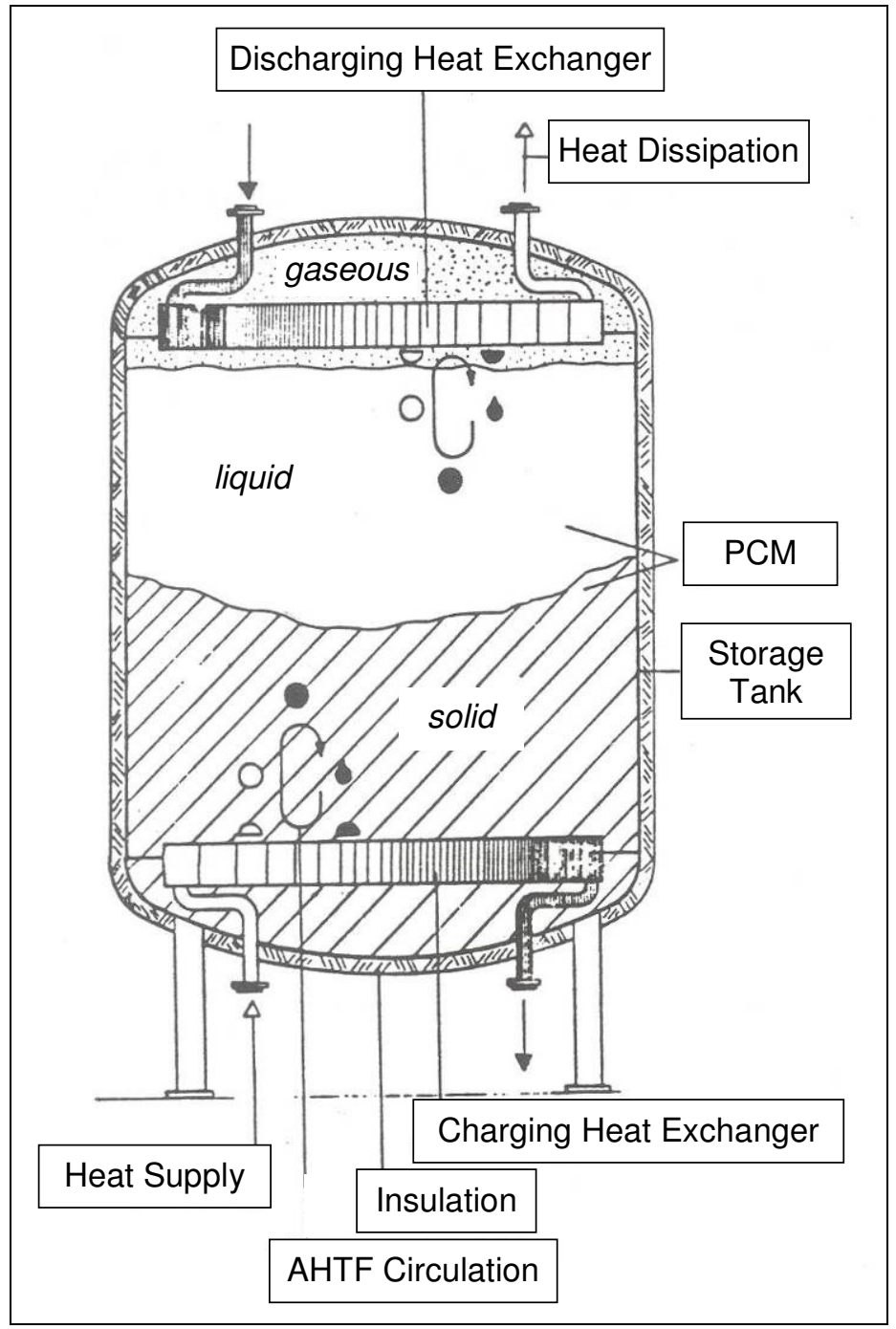

Figure 3.20: Principle of a Dynamic GALISOL-store [95] charge performance in comparison to other latent heat storage concepts. On the other hand, further components (heat exchangers,...) are required and the different media used in a special application have to be chosen properly to ensure satisfactory storage operation. Furthermore, a GALISOL-store is limited to a certain temperature level and works best at constant heat supply (as for example in district heating systems) and therefore appears not to be applicable in solar systems with rapidly changing heat supply at different temperatures.

The GALISOL-process was investigated in laboratory and field tests in widespread research projects by several institutions in the 1980s and early 1990s. Nevertheless, com- 
mercial products working with this process are not known. As for numerous PCMs and their melting point only the environmentally harmful halogenated hydrocarbons come into consideration as AHTF, the ban on chlorofluorocarbons is considered to be the main reason for the termination of all scientific and industrial activities.

\subsubsection{Evaluation}

The literature survey shows that numerous approaches have been taken to realise latent heat stores for different fields of domestic and industrial applications. Apart from that, the examples described prove that on the one hand various theoretical and experimental investigations have been carried out on a scientific level. On the other hand, information on design and construction solutions especially regarding heat exchangers or thermal design guidelines is rare. An evaluation of the different approaches taken is particularly difficult because they are based on different PCMs with varying characteristics. Furthermore, the performance data partly available are based on different testing modes (temperature, volume flow, cycles,...).

Water/ice latent heat stores are mainly designed for refrigeration purposes on an industrial scale (e.g. for breweries or dairies with a volume of $>50 \mathrm{~m}^{3}$ ) and are not optimised with respect to space demand and ease of handling. In contrast, the store for the heating system proposed is applied to a domestic heating system, hence has to be accommodated in a one-family house. Thus, based on the problem analysis of phase change, the literature review and the definition of design specifications to the store, a fundamental development of solutions for this specialised application was carried out. 


\subsection{Conceptual Design}

\subsubsection{Definition of Design Specifications}

The definition of design specifications in the form of the requirements list forms the basis of the latent heat storage tank development. The store has to fulfil particular requirements that are not addressed by the products that are commercially available.

The requirements list is divided into several sections according to functional aspects to maintain clarity of the document. The specifications that have to be fulfilled are defined in detail e.g. for the store's geometry, transport, interfaces and others. Furthermore, the requirements are partially subdivided into requirements for heat exchanger and storage tank, containing the heat exchange system and the storage medium. Apart from that, the requirements are classified as demands being compulsory and wishes being desirable but not essential. The detailed specifications arise from the boundary conditions set by the heating system as well as practical aspects such as installation and maintenance. In the course of development of both the heating system and the latent heat storage tank, the requirements list is updated continuously and supplemented by reasonable topics and values. The latest version of the complete requirements list for the latent heat storage tank and the heat exchangers can be found in Appendix B.

Along with the definition of specifications, the conceptual design of the collector and heat pump circuit has to be defined. Although the hydraulic layout is mainly a task of system development, the definition is required for the completion of the section "Interfaces" in the requirements list and forms a basis for the heat exchanger development.

The conceptual layout of the heating system to be investigated is described in Chapter 1 . The interface of the latent heat storage tank forms an important part of the system. There are two conceptual possibilities to realise the collector and heat pump hydraulic circuit, being the connection of collectors, latent heat storage tank and heat pump:

- Separated hydraulic circuits for collectors and heat pump, with two heat exchangers in the latent heat storage tank (Figure 3.21). 
- Common hydraulic circuit for collectors and heat pump, with one heat exchanger in the latent heat storage tank (Figure 3.22).

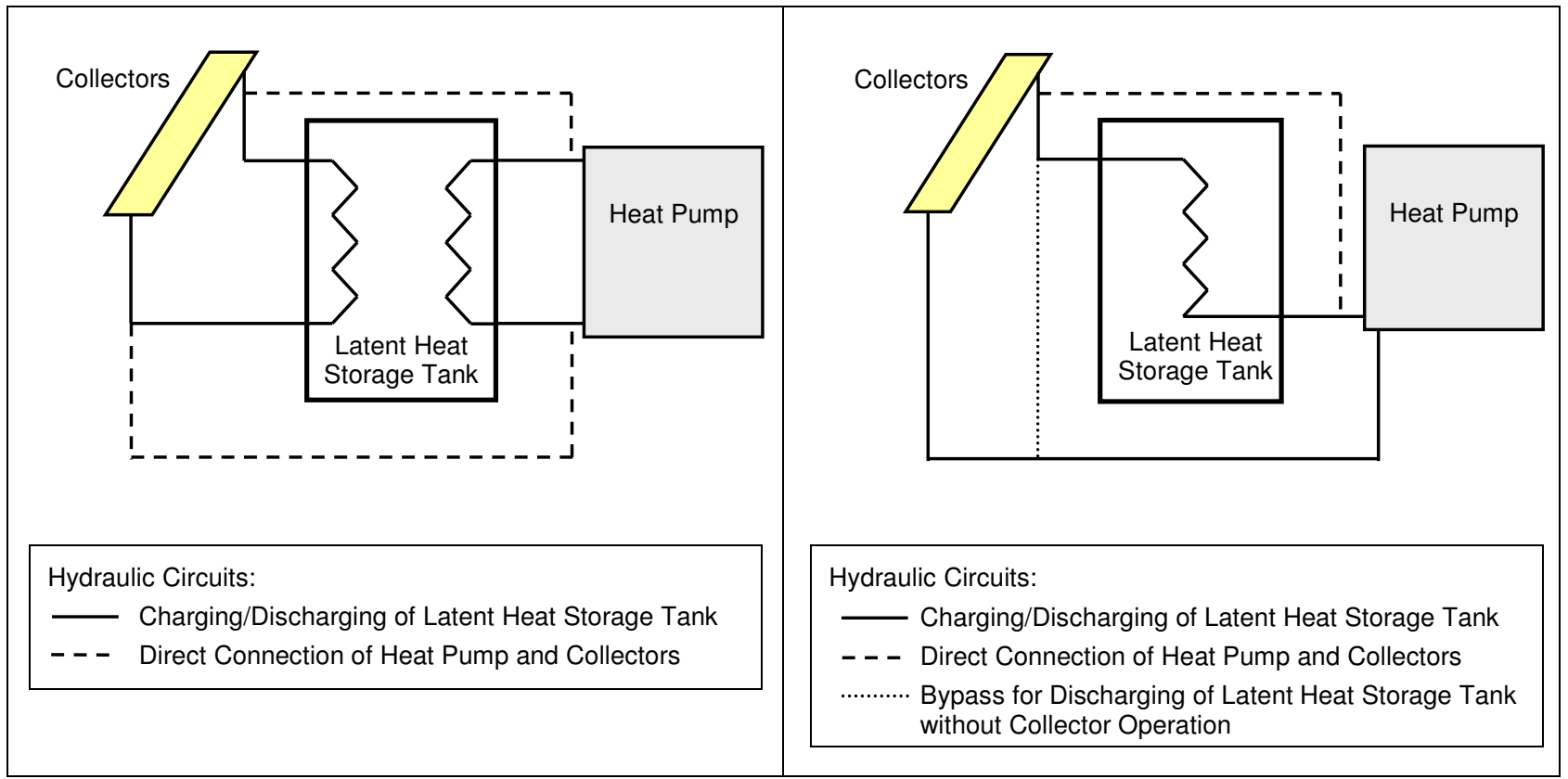

Figure 3.21: Two Hydraulic Circuits with Separated Heat Exchangers
Figure 3.22: One Hydraulic Circuit with a Common Heat Exchanger

As a direct connection between collectors and heat pump without latent heat storage tank operation is necessary, further hydraulic connections are provided which can be activated by the system control. The single hydraulic circuit (Figure 3.22) additionally requires a bypass for the discharging of the storage tank by the heat pump without collector operation.

To decide on the circuit design, an evaluation of the system's operating conditions for both options is necessary. Table 3.2 shows the operating conditions and the anticipated system's behaviour. The direct connection of collectors and heat pump is possible in both options, thus can be neglected in this analysis. The only difference concerning the system's behaviour occurs when the collectors and heat pump work simultaneously. In the circuit with one heat exchanger, the charging or discharging of the storage tank strongly depends on the temperature levels of the collectors and the storage tank. Thus, the one heat exchanger system's behaviour at different temperatures has to be investigated. 
Table 3.2: System Operating Behaviour concerning Different Hydraulic Designs

\begin{tabular}{|c|c|c|c|c|}
\hline \multirow{2}{*}{$\begin{array}{c}\text { Operating Mode } \\
\text { Collectors }\end{array}$} & \multicolumn{2}{c|}{ Latent Heat Storage Tank } & Evaluation concerning \\
off & off & -- & One Heat Exchanger & Influence on the System \\
\hline off & operating & $\begin{array}{c}\text { Discharging by heat } \\
\text { pump, } \\
\text { (use of heat pump-side } \\
\text { heat exchanger). }\end{array}$ & $\begin{array}{c}\text { Discharging by heat } \\
\text { pump, } \\
\text { (use of bypass) }\end{array}$ & congruent behaviour \\
\hline operating & off & $\begin{array}{c}\text { Charging by collectors } \\
\text { (use of collector-side } \\
\text { heat exchanger) }\end{array}$ & $\begin{array}{c}\text { Charging by collectors } \\
\text { (fluid flows through heat } \\
\text { pump without heat ex- } \\
\text { change) }\end{array}$ & congruent behaviour \\
\hline operating & operating & $\begin{array}{c}\text { Simultaneous charging } \\
\text { by collectors and dis- } \\
\text { charging by heat pump. }\end{array}$ & $\begin{array}{c}\text { Fluid flow through collec- } \\
\text { tors, store and heat } \\
\text { pump. }\end{array}$ & $\begin{array}{c}\text { Charging/discharging } \\
\text { depends on temperature } \\
\text { levels of components. }\end{array}$ \\
\hline
\end{tabular}

The anticipated behaviour of the system, shown in Table 3.3, demonstrates that the behaviour is acceptable under all circumstances and no negative influence is anticipated with a common hydraulic circuit and only one heat exchanger in the tank.

Table 3.3: Operating Modes of Components and Evaluation of their Behaviour and Influence on the System

\begin{tabular}{|c|c|c|}
\hline$T_{\text {lhst }}>T_{\text {col }}$ & $T_{\text {lhst }}=T_{\text {col }}$ & $T_{\text {lhst }}<T_{\text {col }}$ \\
\hline $\begin{array}{l}\text { Collectors work as 'preheater', the } \\
\text { storage tank lifts the temperature } \\
\text { to a higher level: } \\
\rightarrow \text { Utilisation of low insolation is } \\
\text { still possible. } \\
\rightarrow \text { Temperature delivered by the } \\
\text { collectors is smoothed out by } \\
\text { the storage tank. }\end{array}$ & $\begin{array}{l}\text { Heat pump utilises energy deliv- } \\
\text { ered from the collectors instead of } \\
\text { discharging the storage tank: } \\
\rightarrow \text { Switch to direct connection } \\
\text { between collectors and heat } \\
\text { pump. }\end{array}$ & $\begin{array}{l}\text { Collectors supply heat pump and } \\
\text { charge storage tank when pass- } \\
\text { ing the tank: } \\
\rightarrow \text { Temperature delivered by the } \\
\text { collectors is smoothed out by } \\
\text { the storage tank. }\end{array}$ \\
\hline acceptable & acceptable & acceptable \\
\hline
\end{tabular}

$T_{\text {col }} \quad$ Average Collector Temperature $\left[{ }^{\circ} \mathrm{C}\right]$

$T_{\text {lhst }} \quad$ Latent Heat Storage Tank Temperature $\left[{ }^{\circ} \mathrm{C}\right]$

Apart from the influence of the hydraulic circuit design, a further important aspect regarding the behaviour of the heat exchanger has to be considered. In many cases, the latent heat storage tank will be driven in a partly charged state especially in winter and spring. This means, an ice layer is built up near the heat exchanger due to heat dissipation by the heat pump even if heat exchanger development is aiming at uniform freezing. During times with sufficient insolation, the collectors charge the tank and melt some medium. If the charge and discharge heat exchangers are locally separated, the warmer liquid me- 
dium cannot be transferred to the discharging heat exchanger if thermal energy is required by the heat pump, as illustrated by Figure 3.23. This would lead to a further cooling of the solid medium and thereby to a lowered heat pump COP.

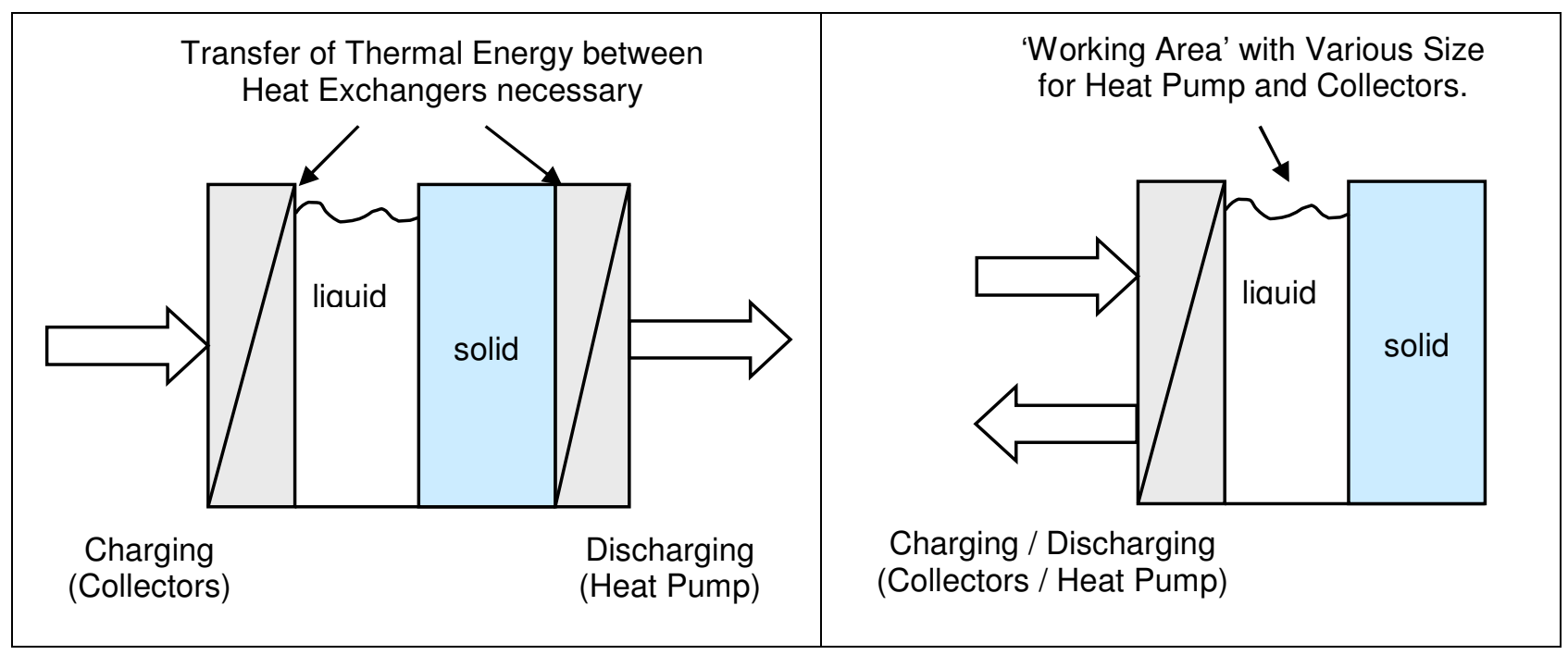

Figure 3.23: Principle Behaviour of a Double Heat Exchanger System

Figure 3.24: Principle Behaviour of a Single Heat Exchanger System

If collectors and heat pump use the same heat exchanger, a working area will be created near the heat exchanger, which is frozen by the heat pump and periodically melted by the solar collectors. The remaining solid medium can be liquefied in times of surplus solar insolation (Figure 3.24).

As the realisation of a single heat exchanger in the latent heat storage tank does not obviously have any appreciable negative effect on the system and can even have a positive influence on the behaviour of the store's efficiency, the implementation of one hydraulic circuit was decided on. 


\subsubsection{Functional Analysis}

After completing the design specification phase, the conceptual design phase starts with the analysis of the product's functions. To identify the essential problems to be solved, the overall function of the latent heat store is broken down into sub-functions and a function structure is derived. Based on the function structure, solutions for the essential tasks are derived and formed to concepts. The proceeding follows a systematic design approach as proposed by Pahl et al [97], aiming at the achievement of the most promising design solutions. As the heat exchanger design obviously is the much more challenging task in this design phase, the detailed functional analysis concentrates on the heat exchanger system.

Figure 3.25 shows the overall function of the latent heat storage tank. It is based on the flow of energy, material and signals. In the block diagram they indicate the relationship between inputs and outputs. The overall function of the store is the storage of thermal energy in water/ice. Thermal energy and heat transfer fluid have to be transferred into and out of the store and the PCM has to be contained in the storage tank. Interactions with the surroundings, e.g. mechanical stress due to volume change, are indicated as effects to / from the environment. The function structure including an overview of main functions and interactions is given in Appendix C [60].

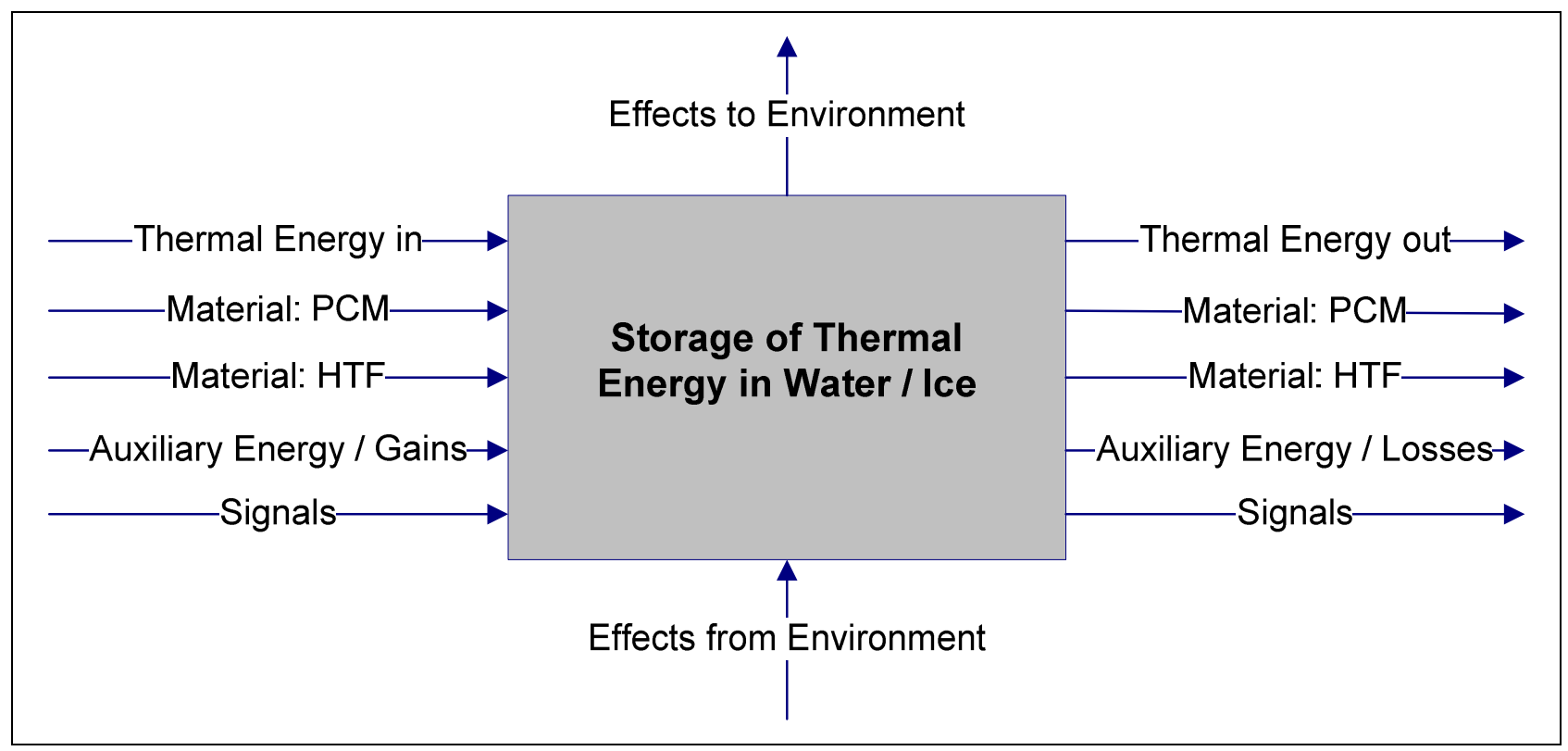

Figure 3.25: Overall Function of the Latent Heat Storage Tank 


\subsubsection{Concept Development}

The objective of the concept development phase is to derive adequate conceptual design solutions, taking into consideration the particular requirements and boundary conditions. The literature survey demonstrates a variety of existing solutions for phase change utilisation that are available or have been proposed and investigated by researchers. However, most of these concepts show clear weaknesses or are appropriate only for very specific applications. Following the systematic design approach, working principles for the sub-functions (cf. Appendix $\mathrm{C}$ ) are derived and combined to working structures which form the basic solution variants. In a preliminary evaluation, the most promising variants are selected for a further examination. These concepts are illustrated below and are subsequently assessed according to their feasibility and technical potential.

The basic idea of Concept $A$ is the encapsulation of PCM in cylindrical polymer containers. The cylindrical containers are arranged in the storage tank and surrounded with brine from the heat pump/solar collector circuit (Figure 3.26). The surface of the polymer containers forms the heat transfer area. The containers' material is polymer, equipped with geometrical details for the compensation of the volume change as well as for simple mounting and fixation in the tank, for example by piling up. Considering a container size of approximately one litre each, different storage volumes can easily be realised. The heat exchange performance promises to be comparably high as the heat exchange surface is rather large. The volume change can be compensated by the material as well as by design measures. On the other hand, water leakages can reduce the storage capacity. A further disadvantage of the concept lies in the necessity of a storage tank withstanding the brine pressure of up to 6 bar in the heat pump/solar collector circuit. 


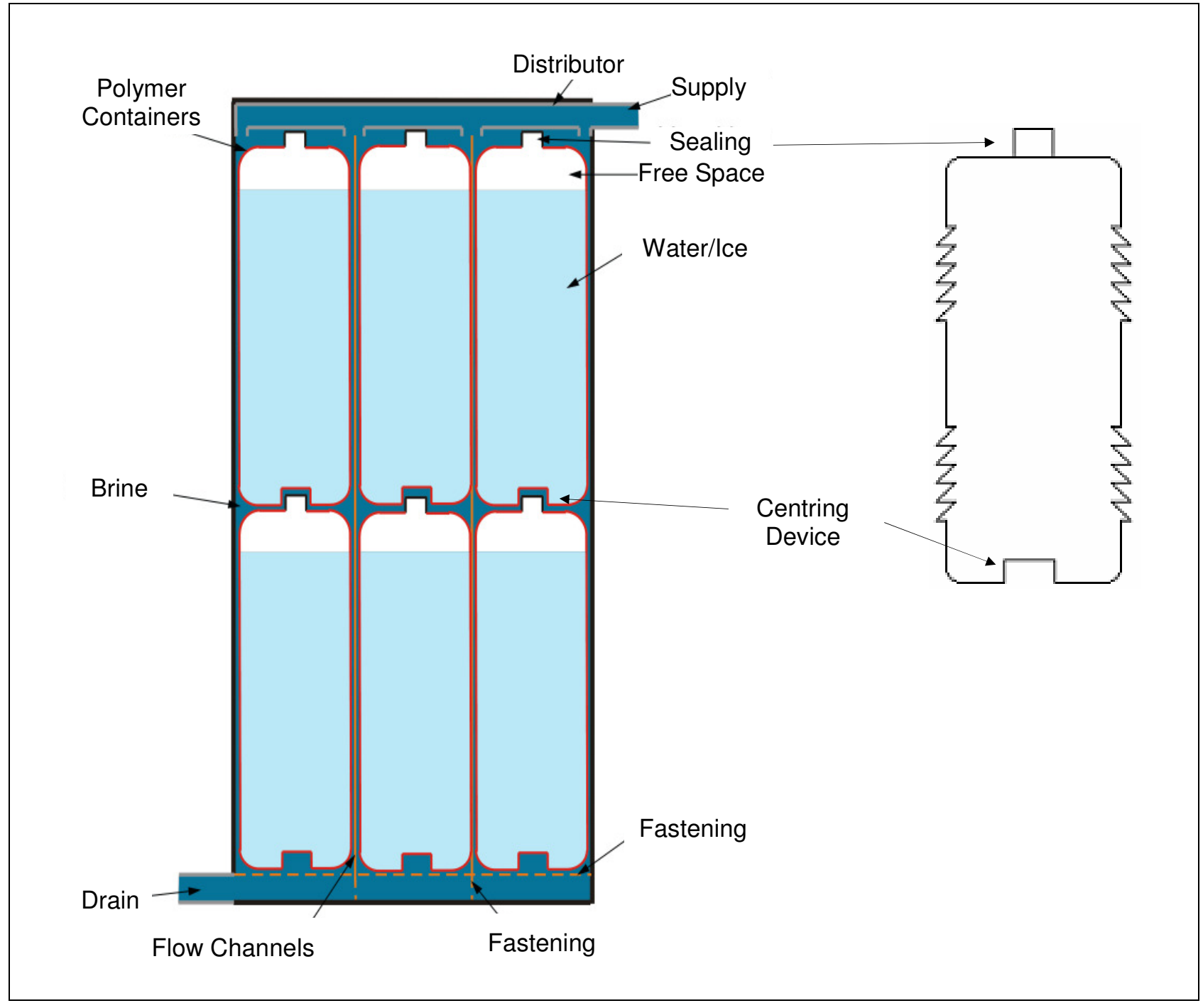

Figure 3.26: Concept A - Encapsulation of PCM in Cylindrical Polymer Containers

Concept $B$ is again based on static charging and discharging. Basically, the heat exchanger is divided into the heat exchanger system, containing the brine, and the heat conduction matrix, filling the storage volume (Figure 3.27):

- The heat exchanger system guides the heat transfer fluid from the heat pump/solar collector circuit through the storage tank. It enables a homogenous distribution of the brine in the tank.

- The heat conduction matrix is linked to the heat exchanger system in a thermally conductive connection. The thermally conductive matrix is thought to form uniformly distributed "heat transfer paths" in the tank. Thus, it serves as a medium for the heat transfer enhancement in the liquid and solid PCM and reduces the influence of poor 
heat conductivity of the PCM, because heat transfer is enabled in an alternative material.

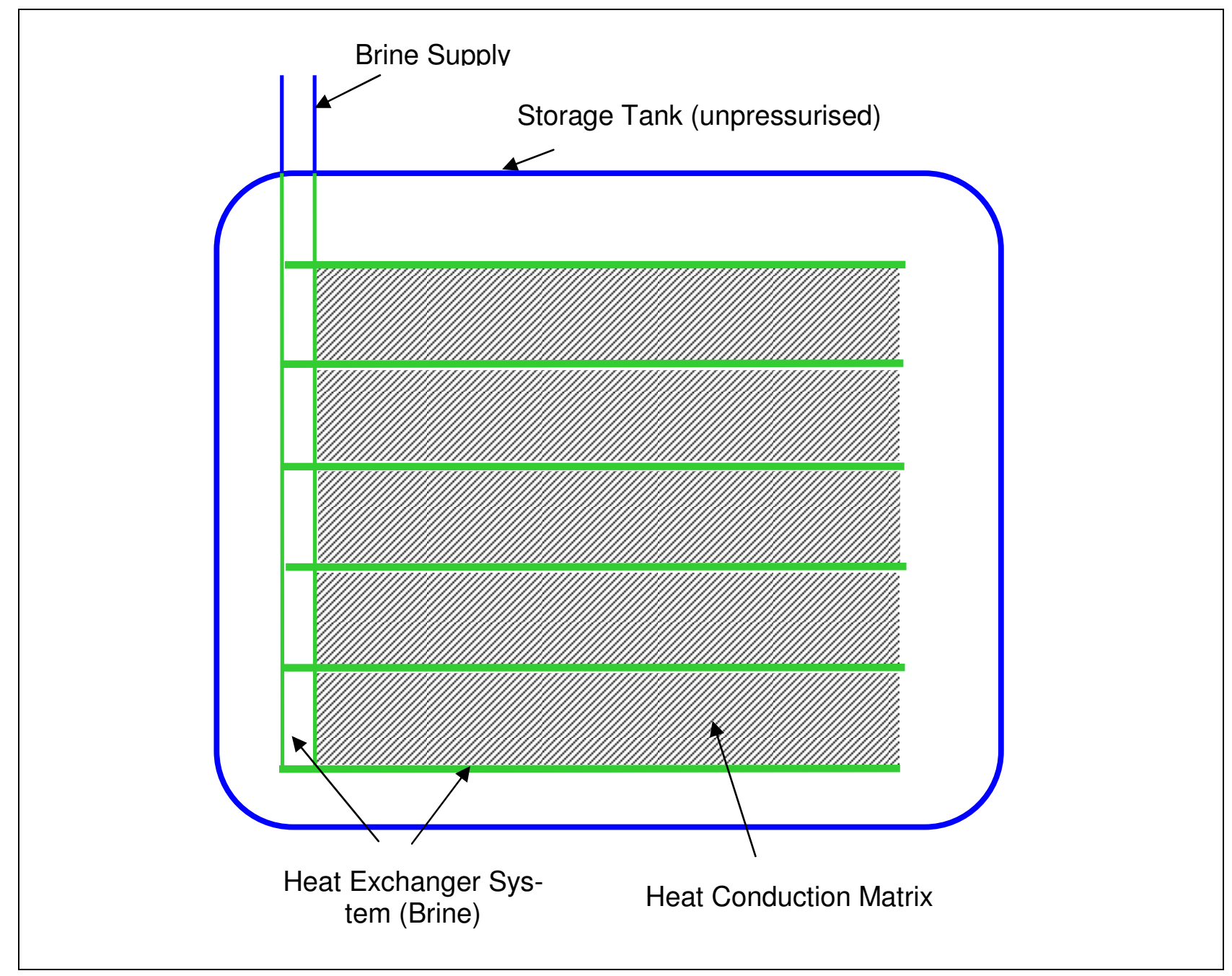

Figure 3.27: Concept B - Heat Exchanger System with Heat Conduction Matrix

The major advantages of this concept are the minimisation of the self-insulation effect and the more uniform freezing process in the storage tank. The reduction of the volume fraction of PCM and the effort for the thermal conductive connection to the heat exchanger system are the concept's disadvantages.

Concept $C$ is based on the dynamic heat exchange principle according to the dynamic Lindner-process, described in its original form in Chapter 3.2.2. The Lindner-process was developed for salt hydrates as PCM, hence cannot be adapted to water without modifications. In contrary to salt hydrates, water reduces its density when freezing (cf. Table 3.1). Thus, ice ascends to the surface of the remaining water, whereas solid material sinks to 
the bottom in a salt hydrate store. In principle, there are two possibilities to adapt the process to water as a storage medium, which were described by Lindner et al [92]:

- Utilisation of an AHTF with higher density than water and change of flow direction: The AHTF is distributed in the top of the tank and falls to the bottom due to its higher density. The drops of AHTF cool down the water. It solidifies around them; the ice crystals ascend to the top of the tank. The AHTF accumulates at the bottom of the container. In case of charging, the AHTF sinks through the permeable sludge of ice crystals and melts it (Figure 3.28).

- Pumping of water instead of the AHTF: Water is pumped to the top of the container and distributed by a spray nozzle system. The water drops fall through the layer of cooled AHTF (a technical grade oil), lying on top of the water/ice. The drops crystallise and accumulate on the layer of water. For charging the tank, the water drops sink through the heated layer of the AHTF and through the permeable sludge of ice crystals and melt them (Figure 3.29).

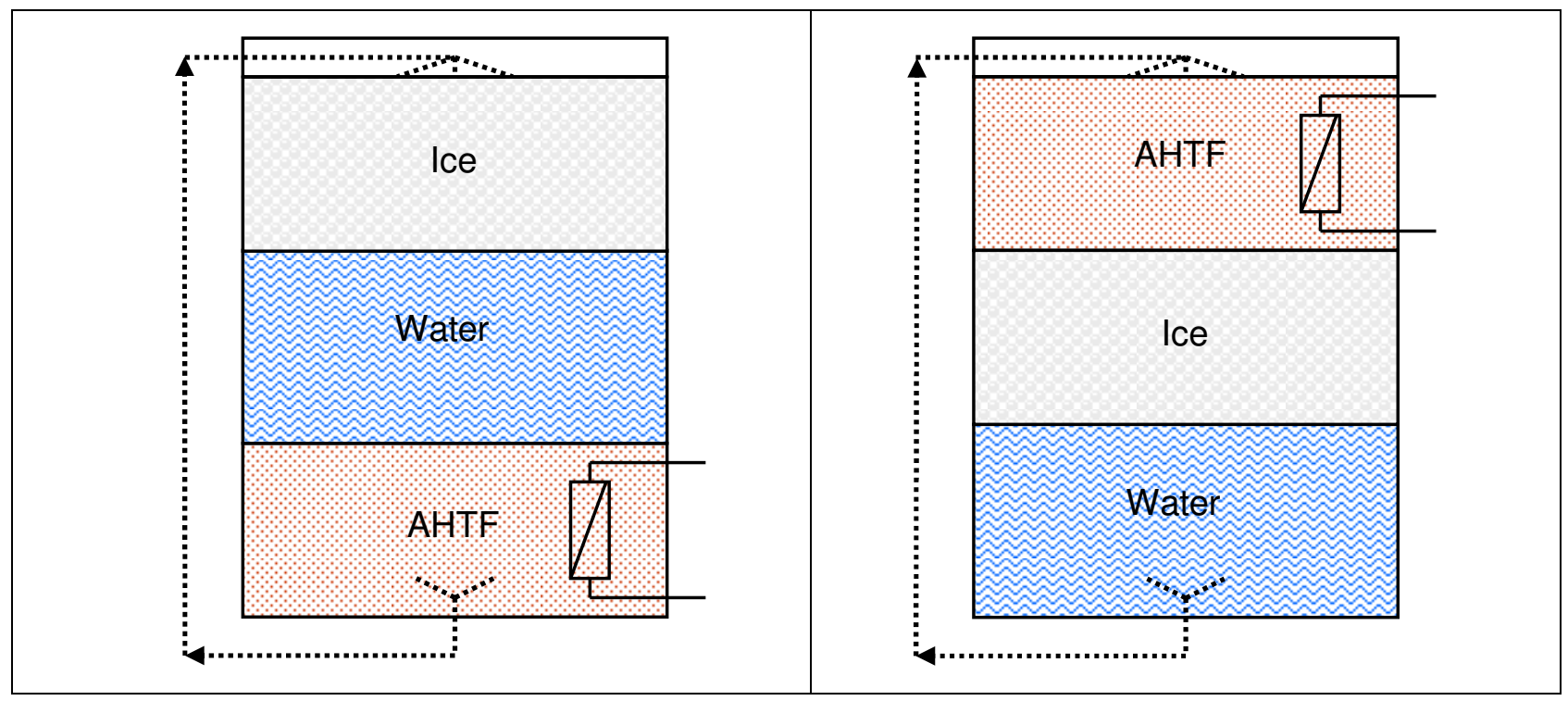

Figure 3.28: Conceptual Layout of the Lindnerprocess with Change of Flow Direction
Figure 3.29: Conceptual Layout of the Lindnerprocess with Pumping of Water

The major advantage of these dynamic approaches lies in the large heat transfer surface of the permanently regenerating drops leading to constant heat transfer performance, as self-insulation of the heat exchangers does not occur. Apart from that, the store forms ice sludge instead of a solid ice block, so that damages by volume change are not expected. The most important disadvantage of the concept is the necessity of several further com- 
ponents in the store, such as pumps, tubes and heat exchangers. Furthermore, an AHTF is required. In case, that water is pumped in the system, technical grade oil can be used. For the system with changed flow direction, a fluid with density higher than water is required: Lindner et al [92] worked with carbon tetrachloride, a chlorofluorocarbon which was subsequently prohibited.

\subsubsection{Concept Evaluation and Selection}

To select a concept for further development, the advantages and disadvantages of the approaches derived are compared considering the concepts' feasibility and technical potential. Table 3.4 summarises the concepts' properties.

Table 3.4: Properties of the Concepts for Heat Exchangers

\begin{tabular}{|c|c|c|}
\hline Concept & Advantages & Disadvantages \\
\hline$A$ & $\begin{array}{l}\text { - Compensation of volume change by } \\
\text { polymer containers } \\
\text { - Simple mounting and adaptation of } \\
\text { store size, high freedom of design } \\
\text { - Comparably large heat transfer area }\end{array}$ & $\begin{array}{l}\text { - Difficult container sealing, reduction of storage } \\
\text { capacity by water leakages } \\
\text { - Poor rate of storage capacity to brine volume } \\
\text { - Uniform distribution of brine in tank } \\
\text { difficult to assure } \\
\text { - Necessity of pressurised tank (<6 bar) }\end{array}$ \\
\hline$B$ & $\begin{array}{l}\text { - Reduction of self-insulation effect } \\
\text { - More uniform freezing process } \\
\text { - Enlarged heat transfer area } \\
\text { - Unpressurised tank }\end{array}$ & $\begin{array}{l}\text { - Reduction of volume fraction of PCM by heat } \\
\text { conduction matrix } \\
\text { - Thermally conductive connection of heat conduc- } \\
\text { tion matrix to heat exchanger system necessary }\end{array}$ \\
\hline $\boldsymbol{C}$ & $\begin{array}{l}\text { - Large heat transfer surface } \\
\text { - No self-insulation effect } \\
\text { - Constant and high heat transfer per- } \\
\text { formance } \\
\text { - Uncritical volume change }\end{array}$ & $\begin{array}{l}\text { - Further components required } \\
\text { (costs, failure probability) } \\
\text { - Further fluid required } \\
\text { - Oil inclusions in ice possible } \\
\text { - Plugging of spray nozzles }\end{array}$ \\
\hline
\end{tabular}

Concept A (encapsulation of PCM in cylindrical polymer containers) has several disadvantages. The most significant is that a pressurised tank is required. According to the specification, up to 6 bar can occur in the collector/heat pump circuit, which the tank has to withstand. The cost-efficient realisation of such a tank (e.g. as a steel tank) seems not to be reasonable with the volume required in the heating system. Therefore, Concept $A$ was not followed up.

The disadvantages of Concept B (heat exchanger system with heat conduction matrix) are considered to be in the reduction of the PCM volume by the heat conduction matrix 
and in the realisation of a thermally conductive connection of heat conduction matrix to the heat exchanger system, which both form a challenge for further development. On the other side, the concept offers several advantages. Compared to an unpressurised tank, a more uniform freezing process and the reduction of the self-insulation effect are to be expected.

Concept $\mathrm{C}$ (dynamic heat exchange) offers the most promising potential for a heat exchange system concerning heat transfer performance, as self-insulation does not occur in this system. Nevertheless, several further components are required, which raise costs and the probability of failure. Further consultation with the original developers showed that inclusions of oil in the solid medium and plugging of the spray nozzles formed major problems especially with water as PCM in the preliminary tests carried out. Thus, Lindner [98] discouraged the author from following up the concept for water/ice because comprehensive practical solutions were not available at the time.

Considering the technical potential and the challenges for further development, in this project Concept B was chosen, as it offered the most promising solution to the specifications derived and had acceptable disadvantages.

However, the dynamic heat exchange concept is still considered to have high potential in latent heat energy storage especially for salt hydrates and paraffins as PCM. The concept avoids self-insulation as the major problem in phase change storage and offers high and constant heat transfer performance over the whole cycle. But, the pre-condition for a successful application of the system is much more fundamental development work in theory and testing, which should be carried out in further projects. 


\subsection{Embodiment Design}

\subsubsection{Design of the Heat Conduction Matrix}

In a first step, the target of the embodiment design phase is to identify an appropriate material and design for the heat conduction matrix and to distribute it homogeneously in the storage volume. Apart from that, the heat conduction matrix has to provide a simple constructive connection to the heat exchanger system with high thermal conductivity and long-term stability in the water bath and during freezing.

Embedding the PCM in a foam structure offers the possibility to realise a homogenously distributed heat transfer enhancement material in the complete storage volume. In this research project, metallic foams and expanded graphite are considered.

Aluminium foams have been in the focus of material researchers for some years. These engineering materials are mostly taken into consideration for lightweight construction in automotive and aviation applications. But also for thermotechnical applications and in particular for latent heat exchanger design, different types of aluminium foam were investigated. For example, Tong et al [99], Calmidi et al [100] and Pinnau [101] dealt with the numerical and experimental investigation of open pore aluminium
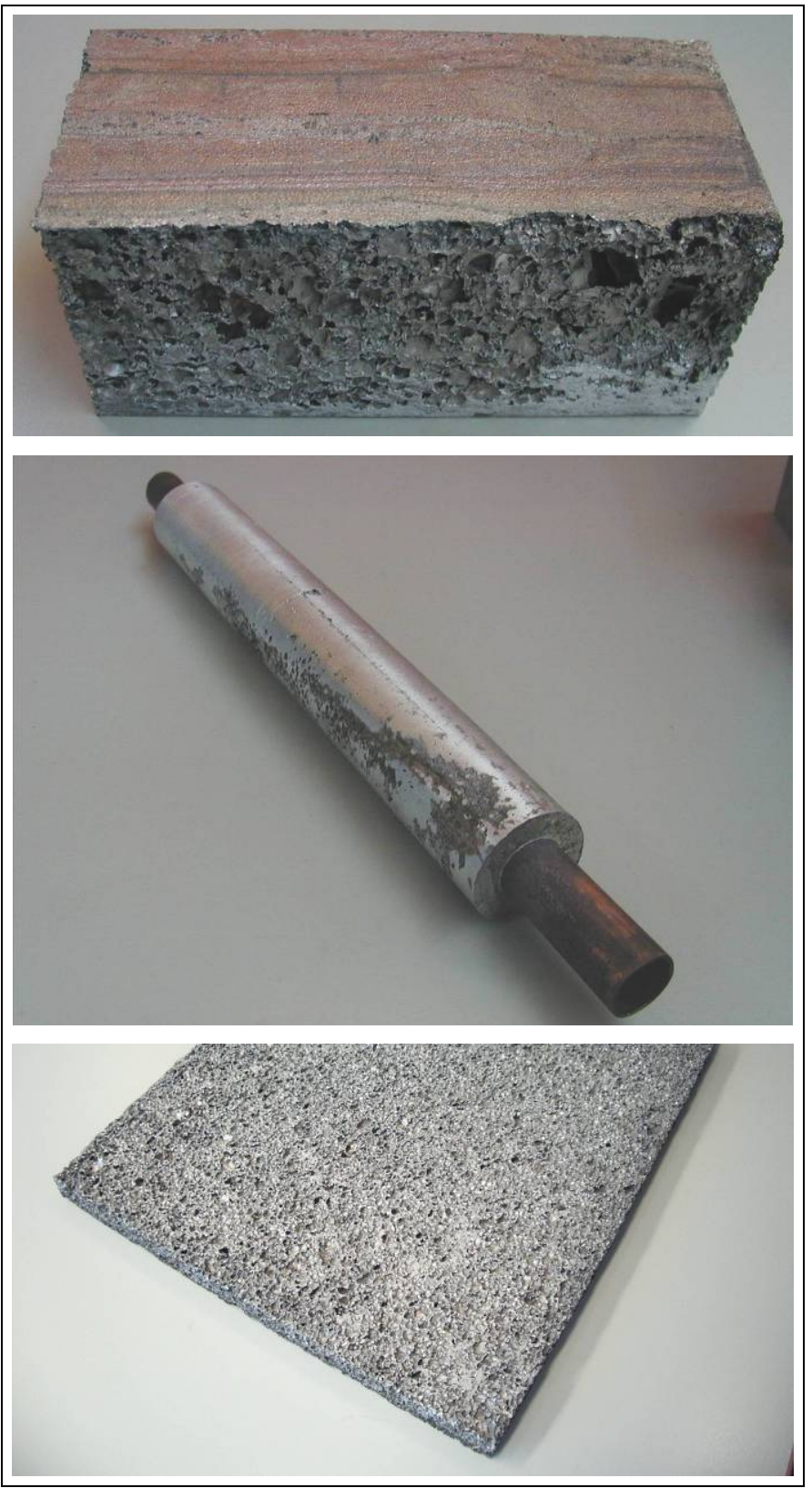
foams. On the one hand, this kind of Figure 3.30: Open Cell Aluminium Foam Samples 
aluminium foam offers low volume fraction of aluminium $(2 \ldots 8 \%)$ and the possibility of connecting the foam to a heat exchanger surface in the production process. On the other hand, the production process is precision casting which means high costs for the foam and limits the size of the products [102]. Thus, in this project open cell aluminium foams are taken into consideration as a further alternative. These aluminium foams, shown in Figure 3.30, are produced in powder metallurgical (top) or melting metallurgical processes (centre and bottom), have a material volume fraction of $10 \ldots 15 \%$ and promise lower production costs and larger units. In the preliminary laboratory tests carried out, however, it was not possible to fill these foam structures with water under ambient conditions even though they are open celled with microporous holes according to the manufacturers. Filling under vacuum seems not to be realistic for the size required on the construction site.

As a further engineering material, steel foam is taken into consideration. Steel foam is produced in a powder metallurgical process from ferrous, steel or nickel powder. The volume fraction of metal is approximately $15 \ldots 50 \%$. In this project, steel foam samples, provided by the Department of Ferrous Metallurgy of Aachen University (Germany) with a metal volume fraction of $25 \%$ is filled with water (Figure 3.31). The foam fills self-acting with water to a degree of $60 \%$. The remaining $15 \%$ is air. Corrosion is a major problem with steel foam in a water bath. Apart from that, parts are to-date only available in a very limited size as the production process is in an early development

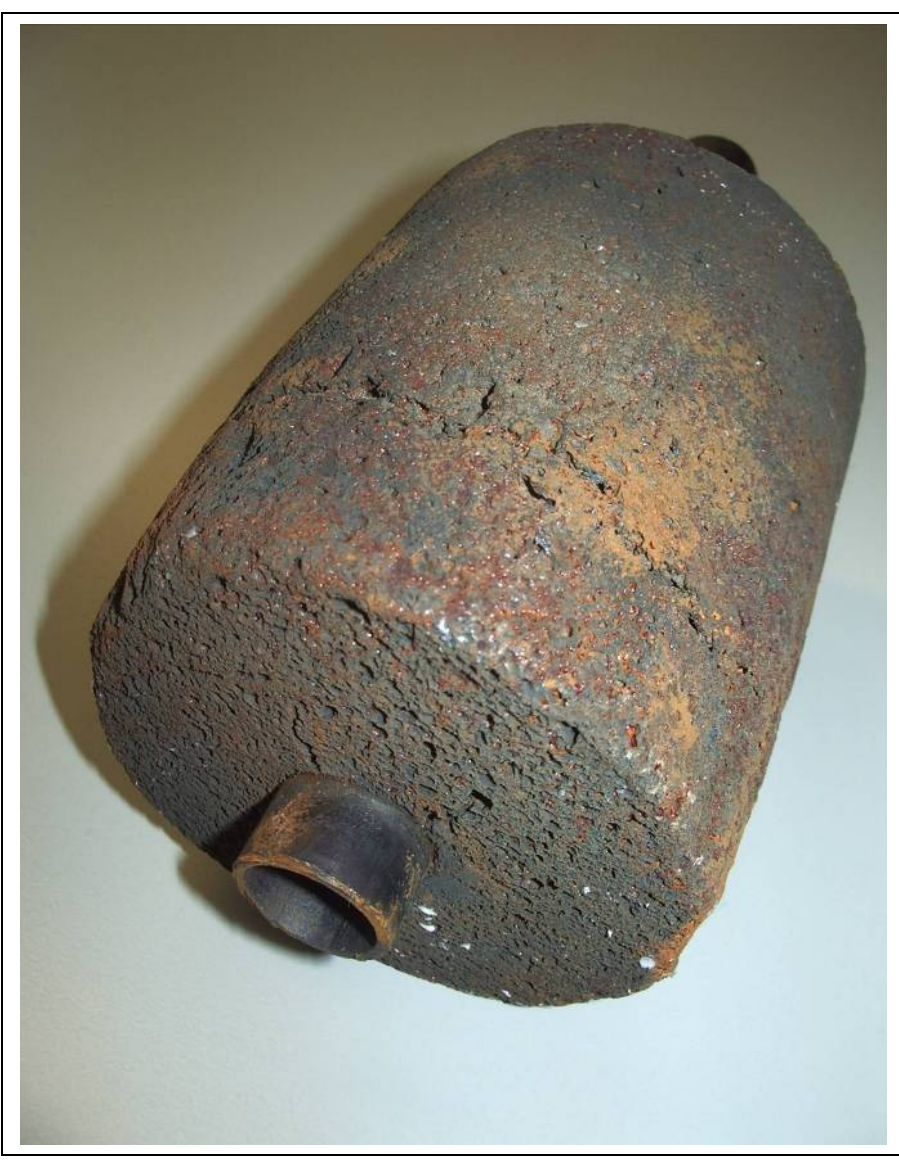

Figure 3.31: Steel Foam Sample (length: 110mm, diameter: $90 \mathrm{~mm}$ ) phase of laboratory scale. Nevertheless, steel foam forms an interesting enhancement material for future applications in latent heat stores, especially because tubes can be 
connected to the foam in the manufacturing process. The manufacturing process as well as the material and heat transfer characteristics of steel foam are investigated by Angel et al [103].

Next to the metal foams, expanded graphite was investigated as a material for the heat conduction matrix. Fundamental research done by Mehling et al [86] showed that the material forms a promising PCM-graphite composite especially when using paraffin (cf. Chapter 3.2.1). For preliminary tests, within this project a heat exchanger using expanded graphite was designed (Figure 3.32, left).

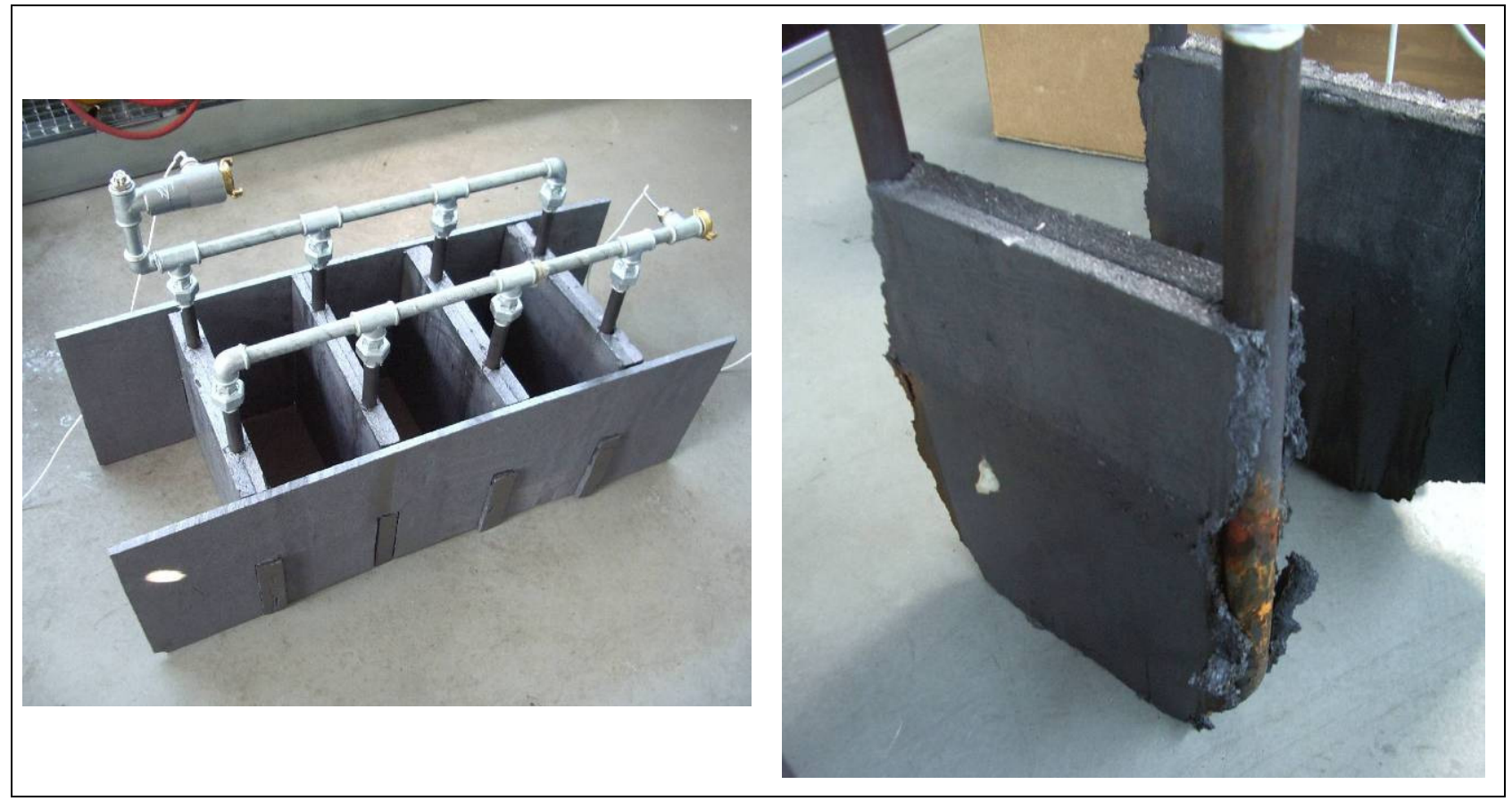

Figure 3.32: Heat Exchanger with Expanded Graphite as Heat Conduction Matrix

As a fundamental practical problem it was found that, in contrast to paraffin, self-acting filling of the graphite material with water takes 2...3 days. Filling under vacuum seems not to be realistic. Apart from that, the thermal conduction of the tube/graphite connection is poor, so that an ice layer grows around the tubes. Furthermore, the mechanical stability of the graphite in the water bath is unsatisfactory (cf. Figure 3.32, right). As a design solution for the problems shown is not available, in particular for the required storage volume, the material was not used in further development.

Embedding a wire netting as heat conduction matrix forms a further possibility of heat transfer enhancement in the PCM. Wire netting is produced in large quantities for filter or 
vibration absorbing applications in automotive, electronic and environmental industry. Several metallic materials (steel, copper, aluminium,...) can be processed. The wire diameter is typically at $0.05 \ldots 1 \mathrm{~mm}$. The mesh size is adjustable in the manufacturing process. The density of the complete part is subsequently adaptable by pressing and forming the wire netting.

In preliminary tests two variants of a wire netting heat exchanger were investigated. Figure 3.33 shows the samples in a tube wrapped variant (left) and flat-plate connected (right). In both cases, the heat exchanger system and the wire netting do not have an intimate material connection. The wire material is steel with a diameter of $0.28 \mathrm{~mm}$. The samples have a density of approximately $0.2 \mathrm{~kg} / \mathrm{m}^{3}$. During freezing in the water bath, the wire netting did not show any significant measurable or visible influence on the freezing process. An ice layer formed around the tubes or at the plate respectively. The reason is considered to be the poor thermal connection between the wire netting and the heat exchanger system. A thermal connection should be created, for instance by soldering or welding, but adequate manufacturing technologies are not available due to the uneven and distributed surface of the wire netting. Hence, the wire netting concept was rejected.
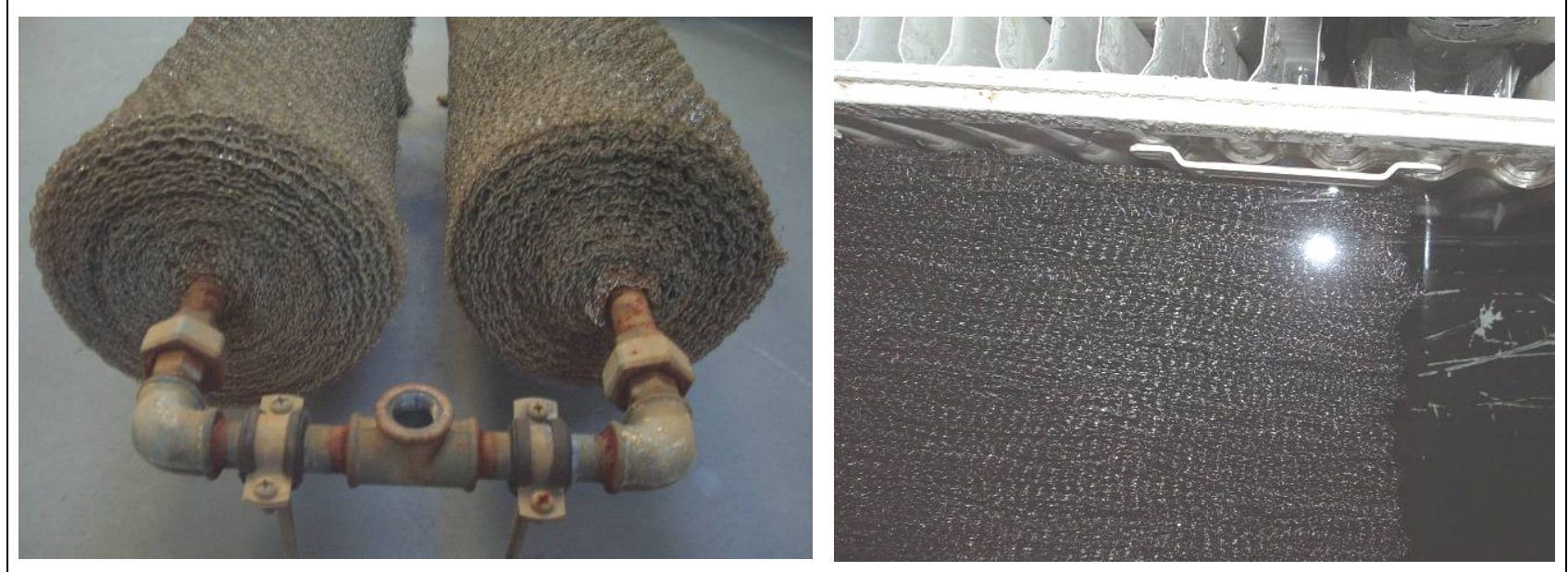

Figure 3.33: Heat Exchangers with Wire Netting as Heat Conduction Matrix

As a further alternative, the heat conduction matrix is formed by a special arrangement of plate heat exchangers and heat conduction fins in the store. This plate and fin arrangement allows the enlargement of the heat exchanger surface in a comparably simple way to freeze a big volume. As the components are commercially available, this approach also promises production at reasonable costs for variable storage volume. Figure 3.34 
shows the conceptual layout of a sheet matrix structure distributed in the storage volume. Fluid is distributed by plate heat exchangers in the tank. Directly attached fins are distributed in the store and enhance heat transfer especially in the solid PCM. For preliminary tests of the freezing behaviour, samples with steel plate heat exchangers and soldered copper fins were utilised (Figure 3.35). The heat exchanger plates are hydraulically connected in parallel, in order that freezing takes places simultaneously from two sides and forms an even ice block. The internal fluid distribution is also arranged in parallel (top to bottom of plate).

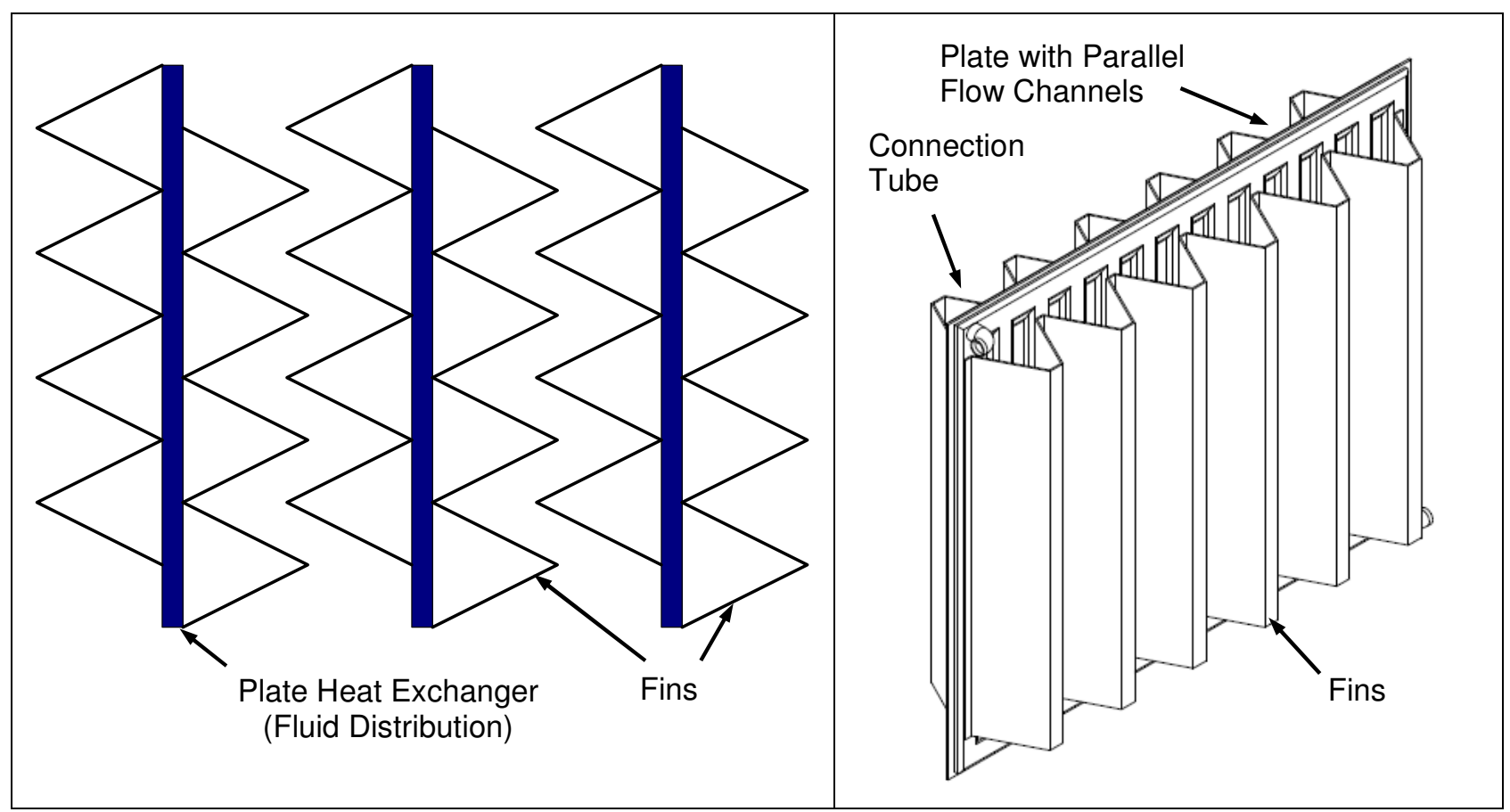

Figure 3.34: Conceptual Layout of a Sheet Matrix Structure Heat Exchanger
Figure 3.35: Design of a Plate Heat Exchanger with Fins

Testing showed that freezing occurred comparatively uniformly in the tank due to the fin structure and that the complete volume can be frozen without damage to the heat exchangers. The major advantage of the concept is that it enables filling of the comparably large storage volume with the heat exchanger. The components are available and a thermal conductive connection between plate and fins can be realised in several manufacturing processes. As this approach combines uniform freezing behaviour with reasonable ease of construction, it was followed up for application in the proposed heating system. 


\subsubsection{Testing of the Sheet Matrix Heat Exchanger}

The target of the testing phase was to study the fundamental behaviour of the proposed sheet matrix heat exchangers during the freezing and melting process in a latent heat store with water as PCM as well as to identify its performance.

For the latent heat exchanger tests a laboratory scale test stand was built up. The heat exchanger sample was mounted in an insulated water tank with a volume of approximately $210 \mathrm{l}$. The heat exchanger was supplied with cold fluid (approx. $-5^{\circ} \mathrm{C}$; water/glycol mixture) from a cooling unit respectively with heated fluid from a test stand already available in the laboratory. Fluid temperatures as well as temperature of PCM and heat exchanger were measured by calibrated resistance thermometers. The volume flow was measured by an electromagnetic flowmeter. Further details on the test stand hydraulics and the measurement equipment are given in Appendix D.

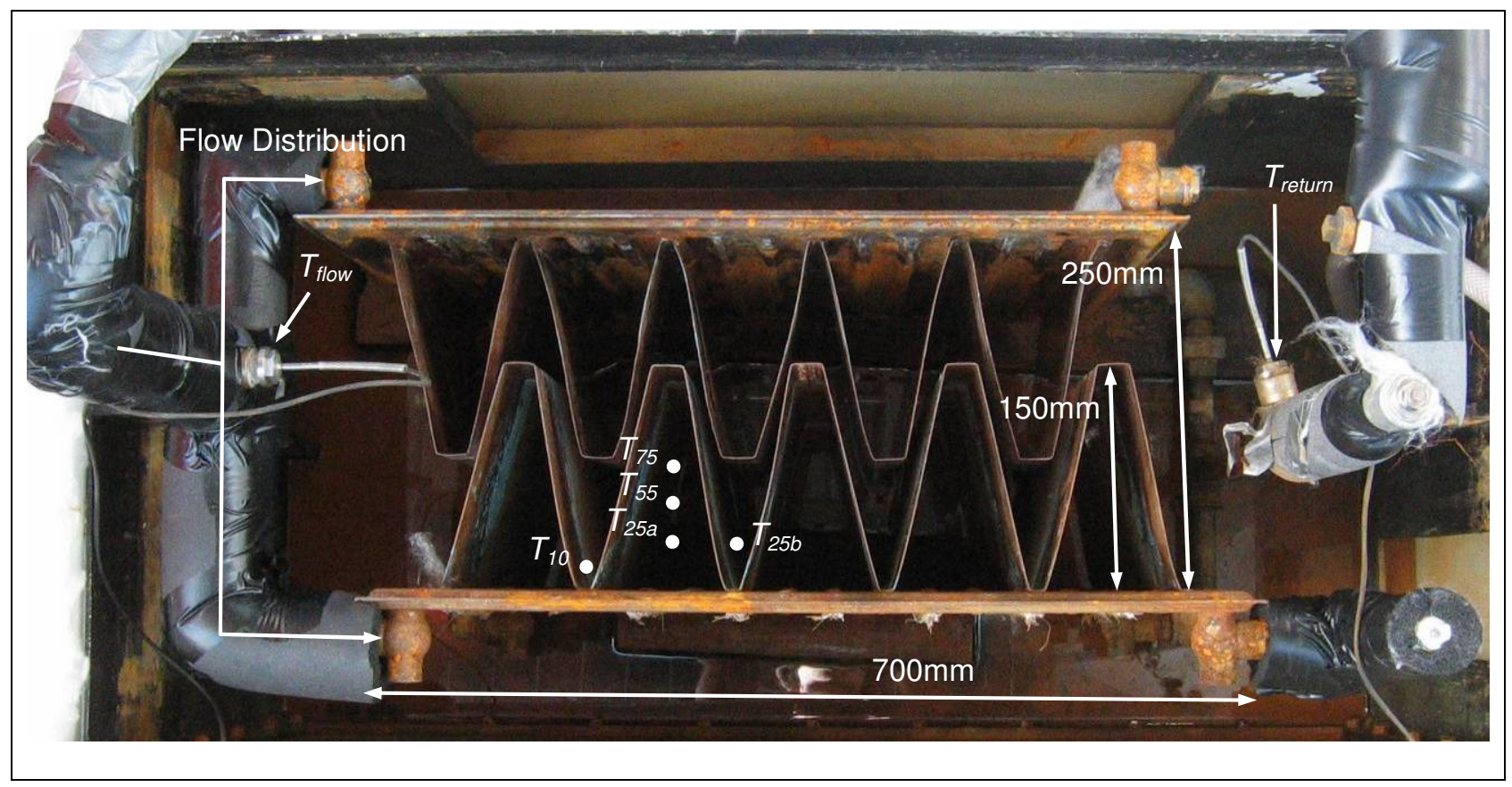

Figure 3.36: Top View of the Heat Exchanger with Positioning of the Temperature Sensors

Figure 3.36 shows the arrangement of the sheet matrix heat exchanger on a steel/copper basis in the tank and the parallel flow distribution of the plates. $T_{\text {flow }}$ and $T_{\text {return }}$ were measured directly inside the tubes close to the plate inlet and outlet. The freezing front was observed visually as well as by temperature sensors placed in the water bath at dif- 
ferent positions and distances from the plates, $90 \mathrm{~mm}$ beneath the water surface. To study the freezing front and the melting process, the water bath was not filled above the fins.

For freezing, the volume flow of cold fluid was set to approximately $\dot{V}=155 \mathrm{l} / \mathrm{h}$. $T_{\text {flow }}$ is at $-6^{\circ} \mathrm{C}$ to $-7^{\circ} \mathrm{C}$, depending on the operating conditions of the cooling unit. Before test start, the cold storage was cooled down by the cooling unit, so that the sample was provided with cold fluid from the beginning. The test procedure started at ambient temperature of the water bath $\left(21.5^{\circ} \mathrm{C}\right)$.

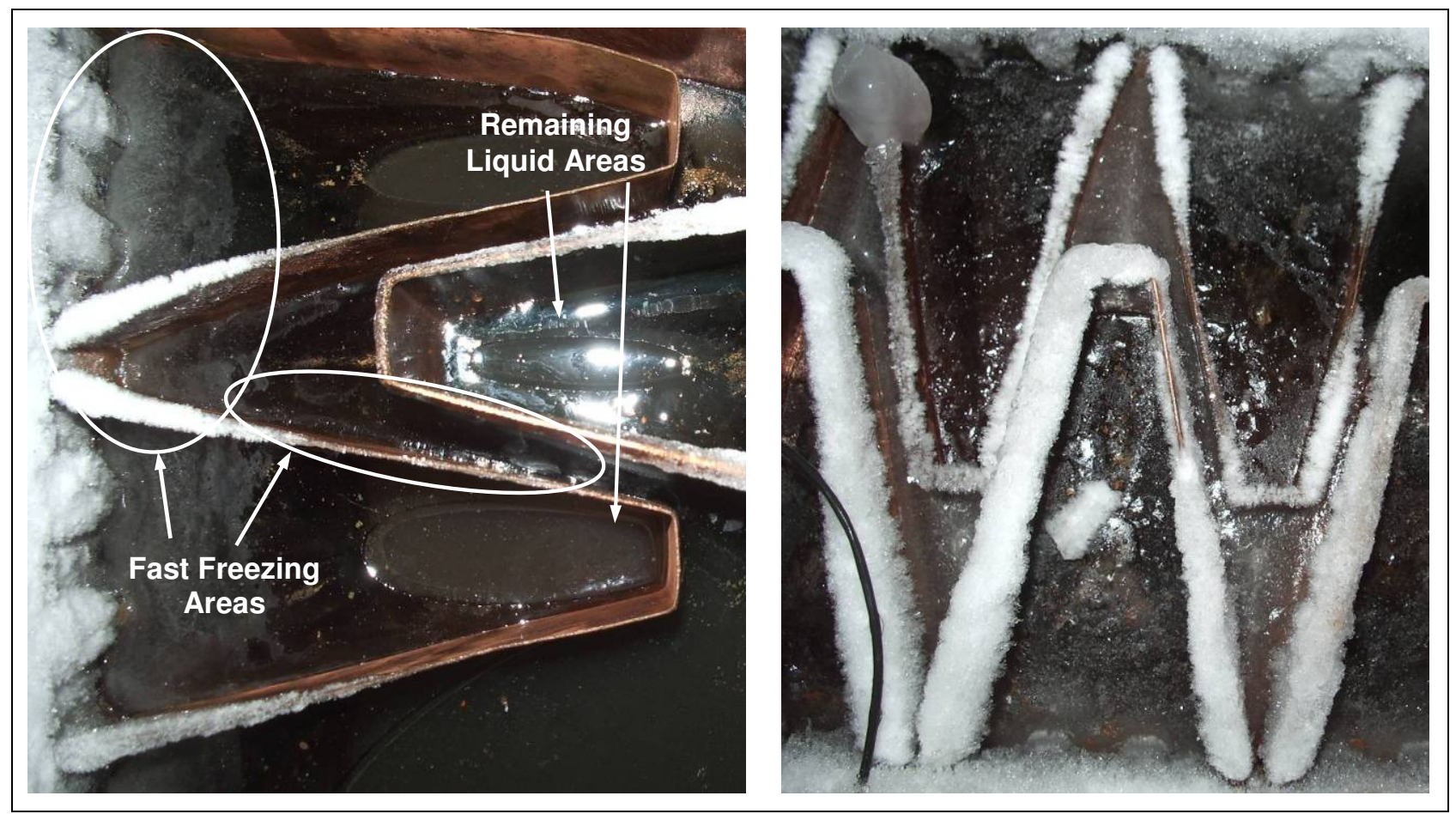

Figure 3.37: Behaviour of Sheet Matrix Heat Exchanger, during freezing (left) and completely frozen (right)

Figure 3.37 illustrates the freezing behaviour of the samples (left, after $41.5 \mathrm{~h}$ from test start). The observation of the freezing front shows its growth from the plate and the fins into the remaining volume. Thus, the areas next to the plates and especially the spaces between the fins are freezing at first (indicated as fast 'freezing areas'), while the more distant areas stay liquid comparatively longer.

All in all, the volume freezes uniformly, except for some areas inside the fins. The freezing behaviour is considered to be satisfactory for the intended application, especially as 
the self-insulating effect of the heat exchanger plate is clearly reduced by the sheet matrix heat exchanger configuration. Furthermore, the test shows that the sheet matrix heat exchanger arrangement can be completely frozen, without damage to the heat exchanger plates, the fins or the fixation (Figure 3.37, right). The volume change is entirely compensated by the displacement of water, which leads to a rise of the water level. Hence, the compensation of the water level may be relied on in this design of the storage tank.

The freezing characteristics of the heat exchanger configuration can also be observed by the temperature sensors placed in the water bath, illustrated in Figure 3.38.

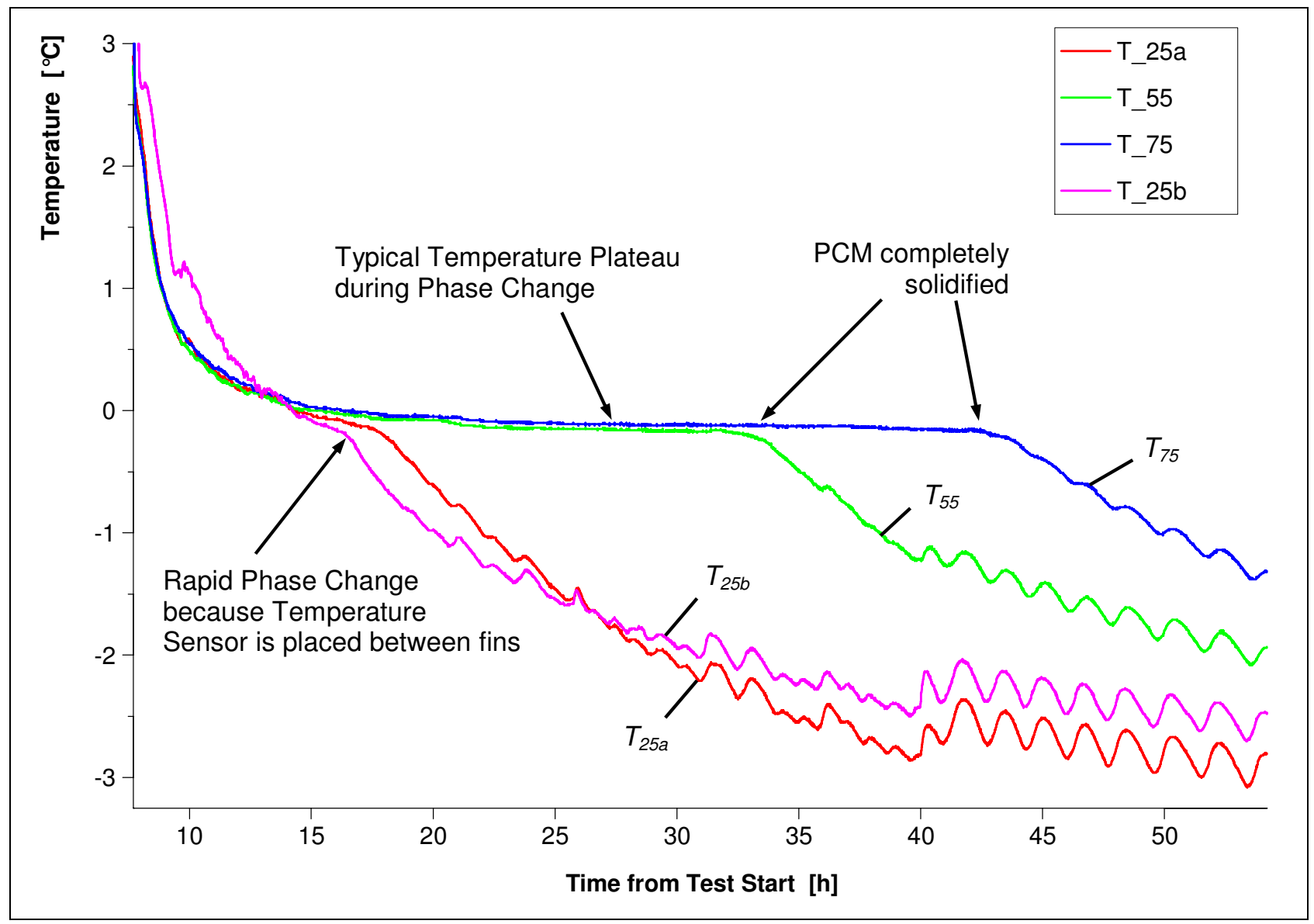

Figure 3.38: Temperature Curves during the Freezing Process

The more distant sensors $T_{55}$ and $T_{75}$ clearly show the typical temperature plateau during phase change. The temperature declines to $0^{\circ} \mathrm{C}$ and stays comparatively long until the latent heat is extracted entirely. The following temperature drop indicates that sensible heat of ice is extracted and the freezing front grows beyond the position of the sensor. 
$T_{25 a}$ and $T_{25 b}$, placed near the plate, pass through phase change faster than the distanced sensors because the freezing front grows away from the plate and fin. $T_{25 b}$ is placed between two fins in a fast freezing area (cf. Figure 3.37); it thus solidifies faster than $T_{25 a}$, which is placed inside a fin.

Under the described conditions with $T_{\text {flow }}=-6 \ldots-7^{\circ} \mathrm{C}$ and $T_{\text {return }}=-4 \ldots-5^{\circ} \mathrm{C}$, a heat exchanger performance of $\dot{Q}=500 \mathrm{~W}$ at beginning of phase change can be reached with the described heat exchanger configuration. However, the heat exchanger performance decreases with proceeding freezing of the store to a minimum value of $\dot{Q}=200 \mathrm{~W}$ when almost the complete volume is frozen.

After the heat exchanger was completely frozen, the melting process was started. The heat exchanger was supplied with warm fluid at a volume flow of approximately $\dot{V}=150 \mathrm{l} / \mathrm{h}$ and a temperature of $T_{\text {flow }}=+8^{\circ} \mathrm{C}$. The flow direction through the heat exchanger plates was equal to the freezing process.

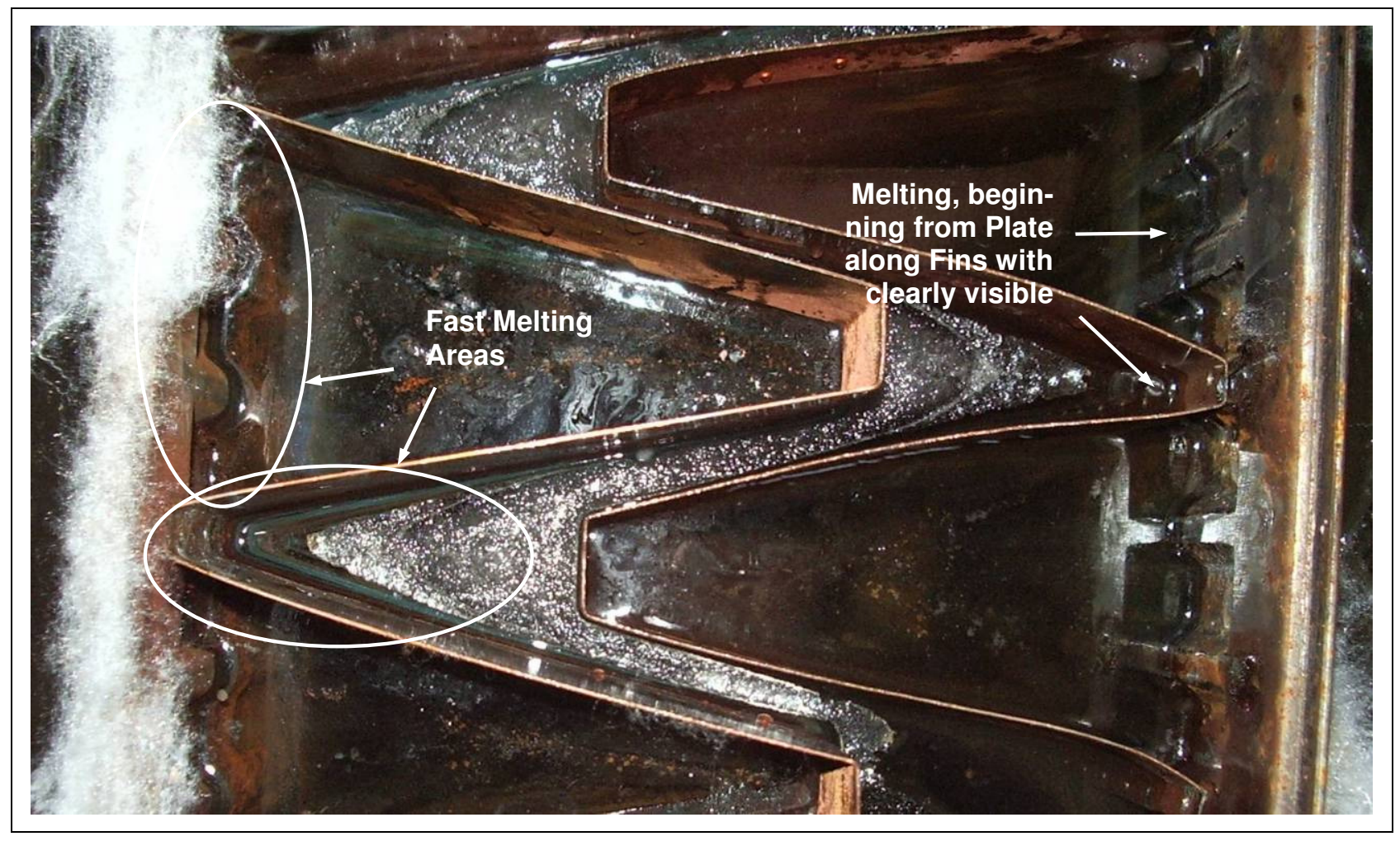

Figure 3.39: Behaviour of Sheet Matrix Heat Exchanger during Melting 
The melting process begins at the plate and along the fins (Figure 3.39). Hence, the fast melting areas are found near the fins. In contrary to the freezing process, convection occurs in the melted areas next to the plates and fins and is clearly visible. This supports the melting process, as warm medium ascends to the heat exchanger surface and cold medium follows from the bottom of the container.

When melting is advanced, remaining ice blocks lie in the water bath without direct connection to the heat exchanger surface and are melted by the surrounding water.

Figure 3.40 shows the typical behaviour of the PCM during phase change. In this case, $T_{10}$ reacts at first as it is located near the plate and two fins followed by $T_{25 b}$. After the start of the heating, sensible heat is extracted from the solid $\mathrm{PCM}$ until $0^{\circ} \mathrm{C}$ is reached and phase change begins. The temperature increases after the PCM is melted completely.

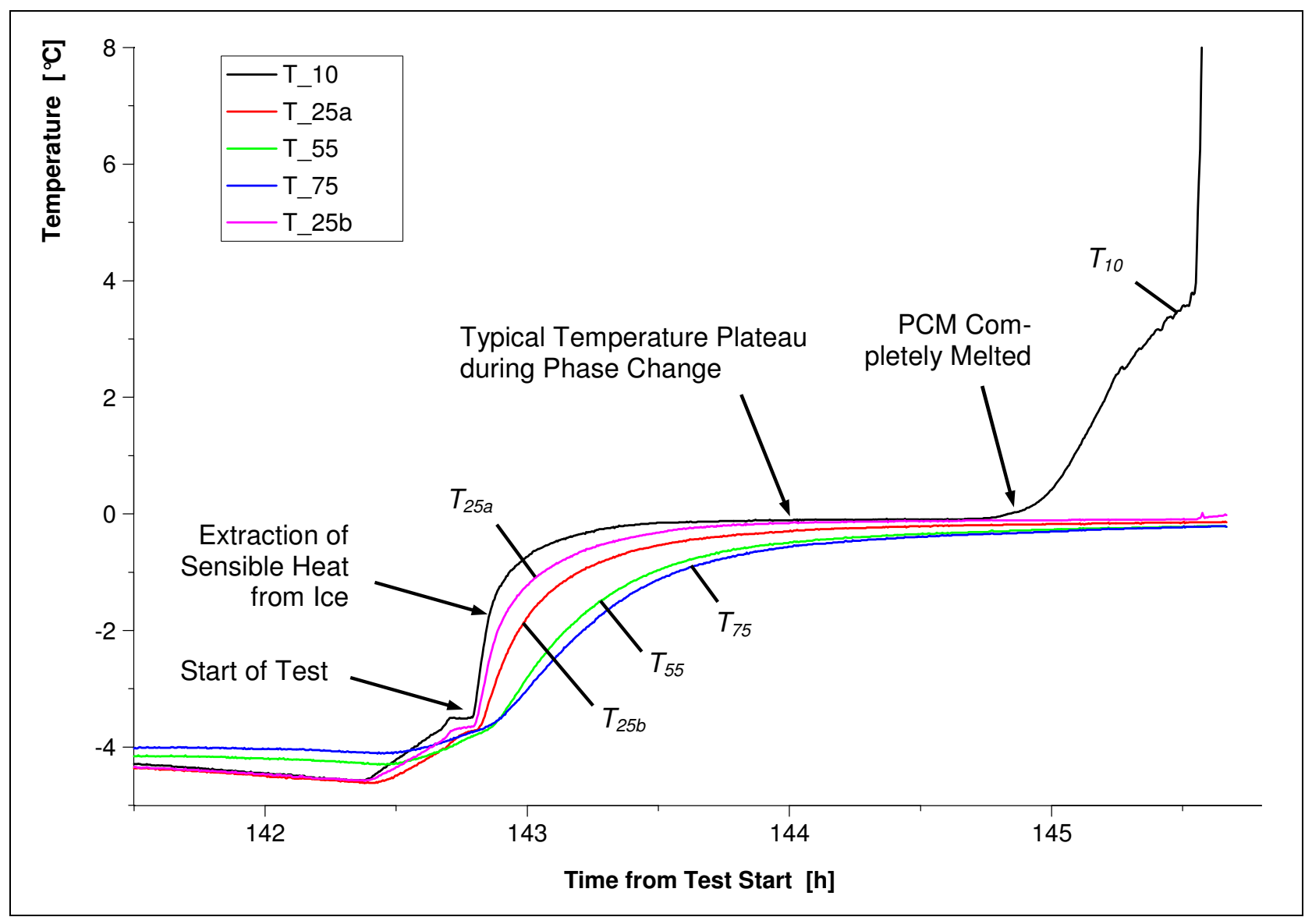

Figure 3.40: Temperature Curves during the Melting Process 
Under the described conditions with $T_{\text {flow }}=8^{\circ} \mathrm{C}$ and $T_{\text {return }}=4^{\circ} \mathrm{C}$, a minimum heat exchanger performance of $\dot{Q}=500 \mathrm{~W}$ can be transferred into the store. Increasing the flow temperature to $T_{\text {flow }}=20^{\circ} \mathrm{C}$ at a volume flow of $\dot{V}=200 \mathrm{l} / \mathrm{h}$ results in $T_{\text {return }}=13^{\circ} \mathrm{C}$ and $\dot{Q}=1,500 \mathrm{~W}$. This indicates that the melting process is the less critical operation mode for the heat exchange system, as the flow temperature of $20^{\circ} \mathrm{C}$ at a temperature spread below $10 \mathrm{~K}$ can frequently be reached by the solar system.

The laboratory tests presented show that the requirements can be fulfilled with the heat exchanger concept proposed. It is possible to freeze a rather big storage volume with a comparatively simple heat exchanger system. The freezing and melting behaviour is uniform in comparison to a conventional tube-type heat exchanger for instance [60]. However, the comparison of the measured heat exchanger performance with concepts described in literature is particularly difficult, as the rarely available measurement data are based on completely different testing modes (regarding temperature, volume flow, cycles,...)

For the proposed heat exchanger design, it is anticipated that an optimal situation can be reached by the change of flow direction for charging and discharging. In the tests, the ice block is formed from top to bottom of the heat exchanger and is melted in the same direction because the flow direction stays the same for melting. This principally leads to a subcooling of the incoming warm medium followed by a slight warming in the remaining liquid areas of the storage tank. Consequently, a change of flow direction for the two operation modes leads to a more even temperature distribution. The freezing should take place beginning in the bottom of the tank to ensure the compensation of the volume change by displacement of remaining water. 


\subsubsection{Latent Heat Store Design and Dimensioning}

The preliminary tests showed that the sheet matrix heat exchanger concept satisfies the requirements defined regarding uniform freezing and melting of the PCM and the achievable heat exchanger performance. Apart from that, appropriate storage tank concepts are developed and an exemplary storage system for the heating system dimensioning defined in Chapter 2.5 is shown.

For the preliminary tests described in Chapter 3.4.2, samples with steel plate heat exchangers and soldered copper fins were utilised. The next step is to adapt the conceptual design approach to an adequate production process with alternative materials. The sheet matrix heat exchangers have to fulfil the following major requirements:

- Plate: Parallel flow channels and connection tubes

- Heat transfer medium: Water/glycol-mixture (60\% / 40\%)

- Temperature range: $-10^{\circ} \mathrm{C} \ldots+130^{\circ} \mathrm{C}$

- Pressure: 3...6bar

- Volume flow: $50 \ldots 150 \mathrm{l} / \mathrm{h}$ per plate

- Thermal conductive connection between plate and fins

- Lifetime: $\geq 20$ years

Considering the corrosion problem at a required lifetime of 20 years in the water bath, aluminium -offering advantages concerning corrosion, weight and thermal conductivityis pre-selected as a material for plate and fins. The obvious production process for aluminium heat exchanger plates is aluminium rollbonding. This manufacturing technique connects two aluminium sheets in a roll-forming process. One sheet is pre-treated with mostly graphite-based compounds along the intended flow channels so that the two sheets are not connected in these areas during the succeeding roll-forming. Afterwards, the double plate is inflated with compressed air, which then forms the fluid channels. Aluminium rollbonding is established as a continuous and automated process on an industrial scale (e.g. for refrigerating evaporators). Plate heat exchangers can be produced in high numbers at favourable quality and cost. 
In order to adapt the heat exchanger design to the production process, the further steps in production related design are discussed in collaboration with aluminium rollbonding manufacturers. Despite the favourable material characteristics of aluminium, corrosion is identified as a major task. According to manufacturers, the problem can be solved by adequate inhibitors in the water/glycol brine and by varnishing the outer side of the heat exchangers. The thermal conductive connection between plate and fins can be realised by soldering. Regarding the size and the positioning of the flow channels, the aluminium rollbonding process offers high freedom of design [104].

The proposed heating system requires a comparably large latent heat storage volume $\left(>11 \mathrm{~m}^{3}\right)$ exceeding the storage tank volume of typical products. Thus, two alternative approaches for the unpressurised storage tank are developed within this project:

- The first concept is a rectangular polymer container as for example applied for rainwater utilisation (Figure 3.41, left). The tank consists of a bottom part and a cover, offering openings for tubes and measurement equipment. The tank is in principal designed for building installation and construction site assembly. Its dimensions are $2,000 \mathrm{~mm} \times 2,000 \mathrm{~mm} \times 825 \mathrm{~mm}$ (with a volume of $3.3 \mathrm{~m}^{3}$ ). The volume of the single tank is fixed, but the storage size is modular when combining more than one tank to a storage system as required by the heating system. Insulation can be applied to the storage tank on the construction site, so that this concept forms a favourable solution for the heating system variant investigated in the system simulations (cf. Chapter 2.3).

- The second concept is a cylindrical concrete tank (Figure 3.41, right). It is assembled on the construction site using commercially available concrete rings. The concept offers the realisation of a highly flexible storage volume. It is designed for ground installation in particular, as this variant is especially interesting for the application of the heating system in new and existing buildings. Although the arrangement of the sheet matrix heat exchangers is more complicated in this cylindrical tank, it provides a robust and cost effective solution. As insulating the tank is difficult in the ground, this concept will only be applicable in the low-temperature heating system variant to be investigated (cf. Chapter 2.6). 


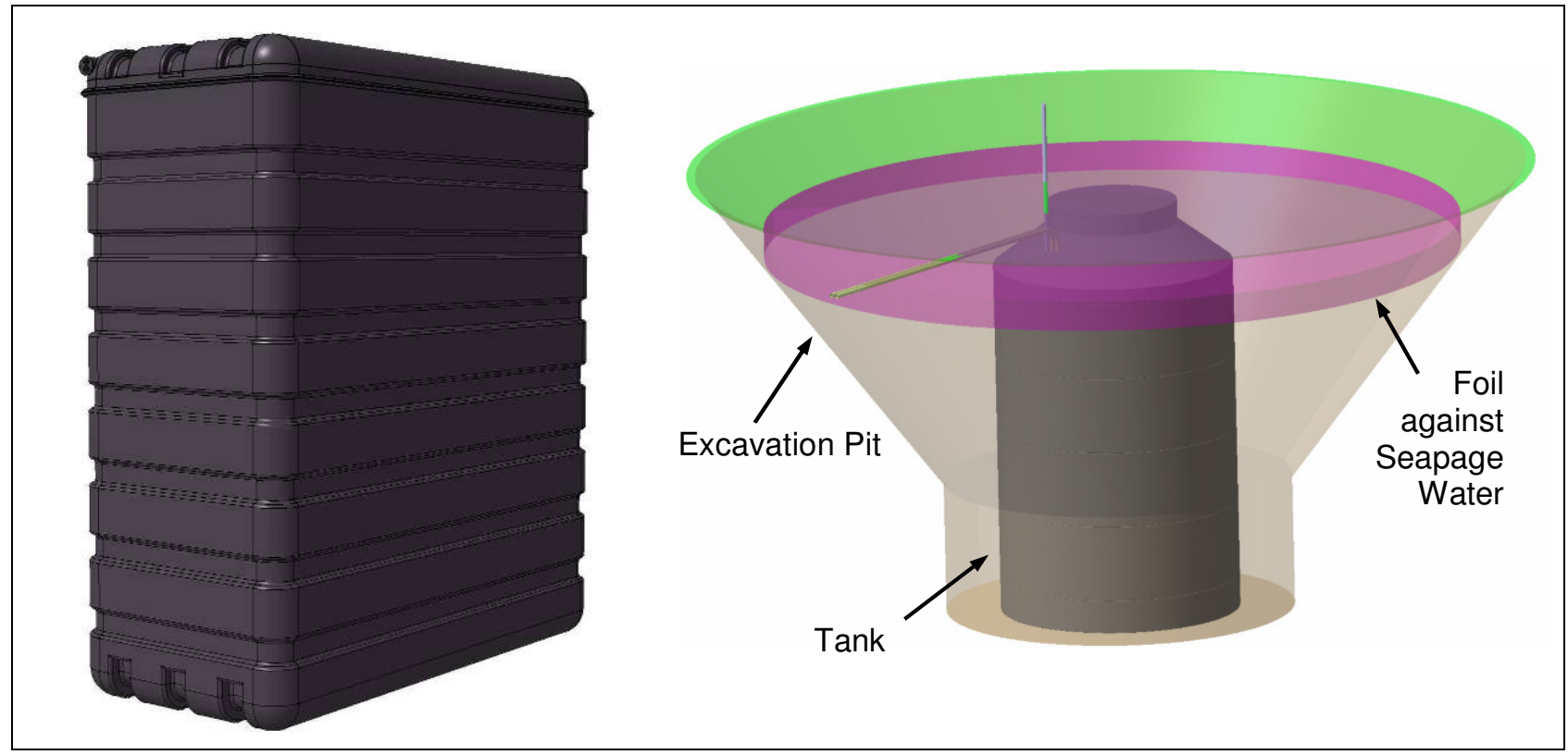

Figure 3.41: Storage Tank Concepts: Rectangular Polymer Tank (left) Cylindrical Concrete Tank (right)

For the recommended heating system dimensioning with $A_{c o l}=30.56 \mathrm{~m}^{2}$ and $V_{\text {lhst }}=12.5 \mathrm{~m}^{3}$, which was derived by parameter variations in the system simulations (cf4. Chapter 2.5), a latent heat store is dimensioned. While in the system simulation the latent heat storage tank is considered as a mass of PCM in a simplified approach, in this step the latent heat store is preliminarily dimensioned on the basis of the rectangular polymer tank concept. Table 3.5 illustrates the dimensioning in comparison to the requirements to the latent heat store from the system simulation. The required nominal latent heat store volume is $12.5 \mathrm{~m}^{3}$ and the active latent heat store volume is $10 \mathrm{~m}^{3}$ in the simulation $\left(D o S_{\text {lhst_max }}=80 \%\right)$. For a nominal storage volume of $16.5 \mathrm{~m}^{3}$, five rectangular polymer tanks are required, which have an effective water volume of $14 \mathrm{~m}^{3}$ assuming that only $85 \%$ of the storage volume is filled with water considering the volume change. According to the results from heat exchanger testing, 70 heat exchanger configurations as shown in Figure 3.36 (double plate, spaced $250 \mathrm{~mm}, 14$ per store) are necessary to freeze and melt a volume of $10.4 \mathrm{~m}^{3}$ (representing the active latent heat volume). The considerable difference between the effective water volume and the active latent heat volume results from the comparably poor space utilisation of the heat exchangers in the storage tanks due to tube connections, fixation devices, etc. Figure 3.42 and Figure 3.43 show the five storage tanks as well as an interior view on the heat exchanger arrangement inside the tanks. 
Table 3.5: Preliminary Latent Heat Store Dimensioning

\begin{tabular}{|c|c|c|}
\hline & $\begin{array}{c}\text { Requirements, derived } \\
\text { from System Simulation } \\
\left(A_{c o l}=30.56 \mathrm{~m}^{2} \text { and } V_{\text {lhst }}=12.5 \mathrm{~m}^{3}\right)\end{array}$ & $\begin{array}{l}\text { Preliminary Storage } \\
\text { Dimensioning }\end{array}$ \\
\hline \multicolumn{3}{|c|}{ Storage Volume and Heat Exchanger Configuration } \\
\hline Nominal Volume $\quad\left[\mathrm{m}^{3}\right]$ & 12.5 & $\begin{array}{c}16.5 \\
\text { (5 stores a } 3.3)\end{array}$ \\
\hline $\begin{array}{l}\text { Effective Water } \quad\left[\mathrm{m}^{3}\right] \\
\text { Volume }\end{array}$ & & $\begin{array}{c}14.0 \\
(\approx 85 \% ; \text { reduced for } \\
\text { compensation of volume change })\end{array}$ \\
\hline Heat Exchangers & & $\begin{array}{c}70 \\
\text { (14 per store) }\end{array}$ \\
\hline $\begin{array}{l}\text { Active Latent } \\
\text { Heat Volume }\end{array}$ & $\begin{array}{c}10 \\
(=80 \% ; \text { actually frozen) }\end{array}$ & $\begin{array}{l}10.4 \\
\text { (calculated on basis of } \\
\text { laboratory test results) }\end{array}$ \\
\hline \multicolumn{3}{|c|}{ Heat Exchanger Performance in Case of Phase Change } \\
\hline Discharging & $\max .3 .5$ & $\begin{array}{c}\text { approx. } 10 \\
\text { (extrapolated from measured values, } \\
\text { safety factor } 2 \text { ) }\end{array}$ \\
\hline Charging & $\max .25$ & $\begin{array}{c}\text { approx. } 74 \\
\text { (extrapolated from measured values, } \\
\text { safety factor } 2 \text { ) }\end{array}$ \\
\hline \multicolumn{3}{|l|}{ Volume Flow } \\
\hline Discharging & $\begin{array}{c}1,400 \\
\text { (heat pump) }\end{array}$ & $\begin{array}{c}3,000 \ldots 4,000 \\
\text { (based on testing conditions) }\end{array}$ \\
\hline Charging & $\begin{array}{c}1,200 \\
\text { (solar collectors) }\end{array}$ & $\begin{array}{c}3,000 \ldots 4,000 \\
\text { (based on testing conditions) }\end{array}$ \\
\hline
\end{tabular}

Next to the determination of the required active latent heat volume, the heat exchanger performance in case of phase change (representing the worst case for the heat exchangers) has to be considered for a dimensioning. Hence, the results from heat exchanger testing are extrapolated for the intended number of heat exchangers. Despite the consideration of a safety factor of 2 , the results show that the heat exchanger performance is quite sufficient during both freezing and melting in comparison to the maximum values derived from the simulation. 
Christoph Trinkl

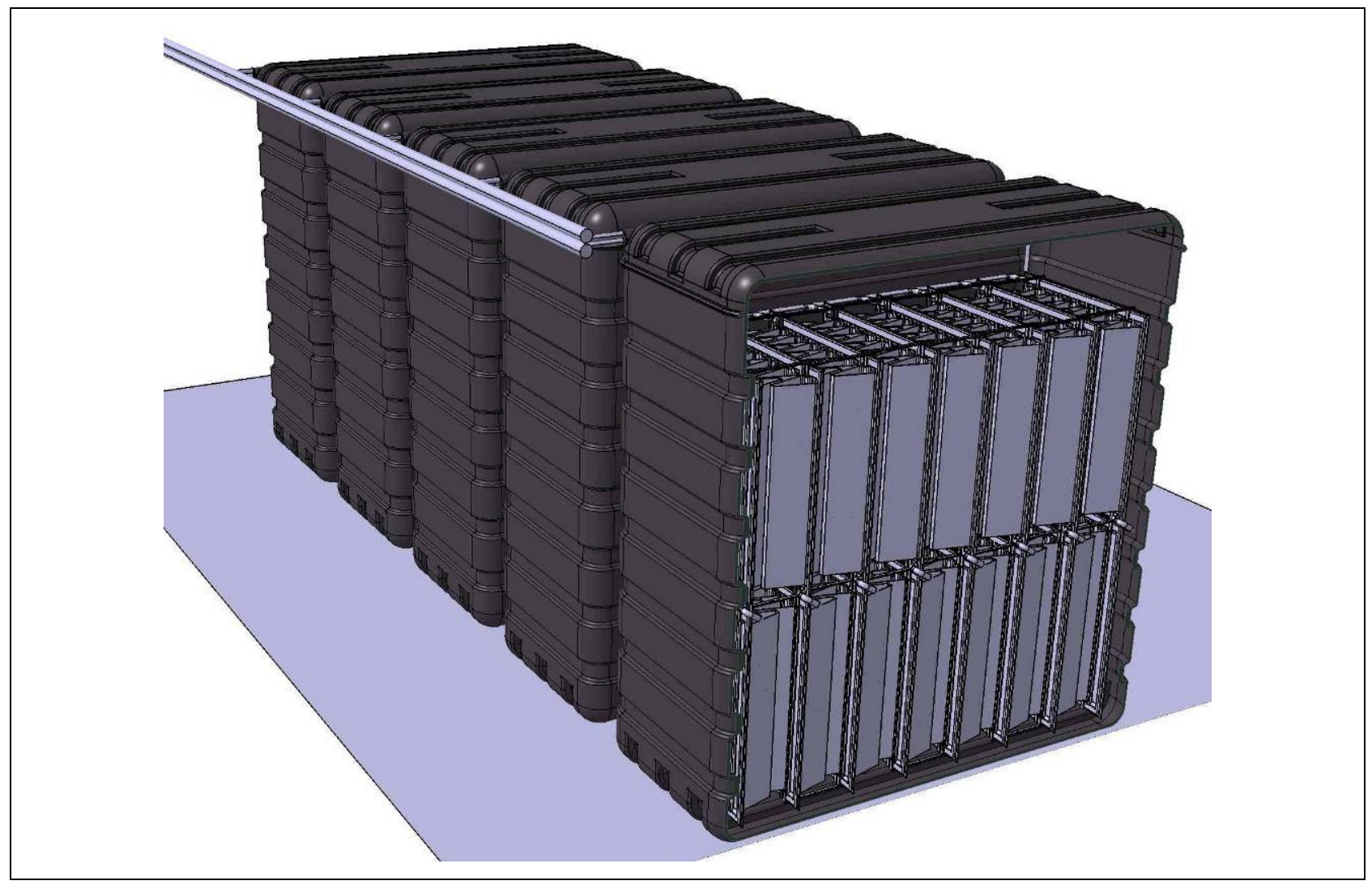

Figure 3.42: Latent Heat Store for the Recommended Heating System

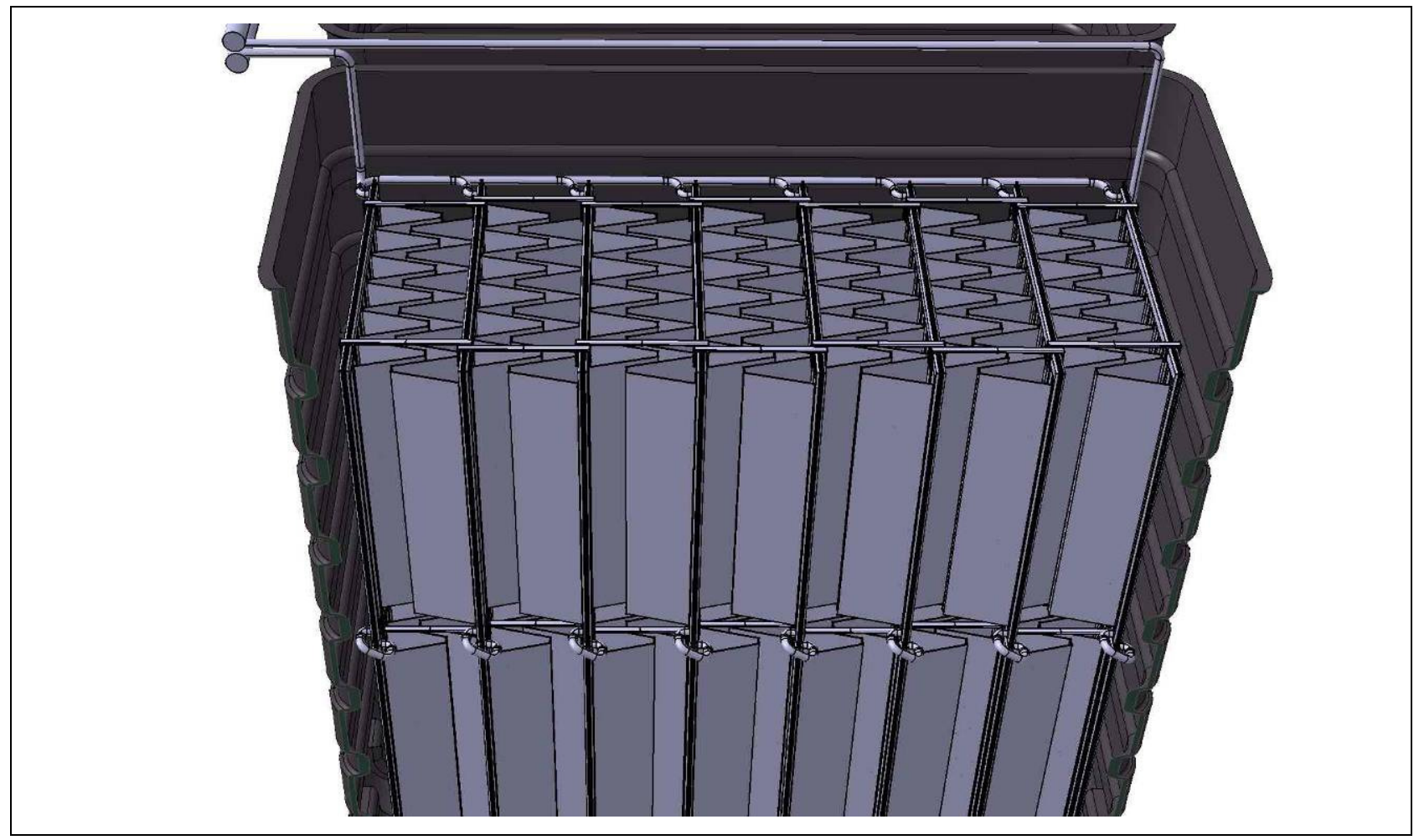

Figure 3.43: Interior View on the Heat Exchanger Arrangement inside the Storage Tanks 
The volume flow for the five storage tanks and 70 heat exchanger configurations is calculated on the basis of the volume flow per heat exchanger plate used in the tests. It is assumed that the heat exchanger plates in each row are connected in parallel. The rows are connected in series while the tanks are also arranged in parallel. The comparison of the volume flow used in the system simulation and the extrapolated volume flow from heat exchanger testing shows that the values used for testing are above the simulation parameters. As the heat exchanger performance is sufficient by far, the volume flow in the described storage arrangement is recommended to be reduced to the values required by the heat pump and solar collectors in a real system to keep the pressure drop in the system at an acceptable level. 


\subsection{Conclusions}

The investigations into latent heat storage technology showed that on the one hand several conceptual approaches for latent heat storage heat exchangers as well as phase change materials have been investigated and some products have been developed in the past. On the other hand, the development of a latent heat store suitable for the heating system proposed based on the water/ice transition has proved to be a challenging task due to the specialised requirements of the system and the numerous problems linked with phase change systems in general.

Aiming at an optimised design solution via a systematic procedure, the requirements of the store are defined in detail and concepts and alternative engineering materials investigated. Although they are not applicable in this project, the foam structures studied based on aluminium, steel or graphite were considered interesting solutions for future applications with phase change energy storage, especially when aiming at smaller storage units and other PCMs without corrosion potential. Also the Lindner-Process for dynamic phase change was thought to have useful potential for high-performance latent heat stores in heating and cooling applications and thus should be taken into consideration for further research. The sheet matrix heat exchanger concept was chosen for the proposed heating system because the specialised requirements of the system can be met by a simple, hence potentially low-cost solution. This has been backed up by laboratory tests and the preliminary storage dimensioning:

- Uniform freezing and melting of the storage volume is possible at an acceptable level.

- Satisfactory heat exchange power for the requirements derived from system simulation can be provided in a preliminary design of the storage system.

- The comparatively large storage volume required for domestic applications can be realised with sheet matrix heat exchangers in transportable, modular tanks.

With the heat exchanger and storage tank developed within this research project, promising solutions for the low-temperature latent heat storage tank, one of the most important components in the proposed heating system, is available. However, the following steps 
are recommended to further investigate and develop the storage system with the heat exchangers:

- As a production prospect for the heat exchangers, aluminium plates with soldered fins are proposed, offering high freedom of design and a favourable material. Together with aluminium rollbonding manufacturers the concept should be refined and the design challenges regarding corrosion in the tube system as well as in the water bath should be investigated on laboratory scale.

- Based on the laboratory testing already carried out and the preliminary storage dimensioning derived in this work, a prototype of the storage tank with heat exchangers as proposed should be built up and investigated in detail regarding its thermodynamic characteristics and the freezing and melting behaviour in the tank. In the course of the development of a more precise storage tank model for the system simulation, such experimental investigations form the basis for its validation. Hence, optimisation in simulation and testing can be carried out, for instance aiming at the three-dimensional distribution of liquid and solid areas in the storage tank.

- After a detailed laboratory investigation and optimisation, the latent heat storage tank should be applied in a field test system to gather experience with the special conditions in such a heating system and in a real building.

Next to further development of the polymer tank approach, the concrete tank concept forms a promising solution especially when considering investigations of a lowtemperature heating system with a ground-coupled uninsulated latent heat store. 


\section{Conclusions and Further Work}

The research has demonstrated the feasibility of a fuel-free domestic heating system consisting of solar thermal collectors, heat pump, stratified thermal storage and water/ice latent heat storage. This novel system was investigated by a combination of system simulation coupled with a programme of experimental work related to the latent heat store. For the heating system, fundamental components have been developed such as, for example, the system control approach. The feasibility of the heating system has been demonstrated by the system simulations, leading to advanced optimisation approaches. For the latent heat store, promising solutions for the heat exchanger design as well as for the tank design have been shown, with clear prospects for further development, beginning with laboratory-scale prototypes and aiming eventually at a design suitable for higher production numbers.

In the course of heating system development, performance data with innovative heating system configurations were collected in the simulation study. They clearly show that the system can work satisfactorily with up-to-date components in a state-of-the-art building as a target application. The collector area and the latent heat store volume were found to be the decisive parameters for system dimensioning, and reasonable values for the application in a one-family house were established, so that the main target of the system development was achieved. The promising annual simulation results of the heating system offer very good prospects for a further application of both heat pump and solar thermal systems in Central Europe. With the solar/heat pump heating system proposed, horizontal or vertical ground heat exchangers for the heat pump can be avoided. Due to their disadvantages (high space required, subject to authorisation, cost intensive, problematic application in existing buildings) they presently constrict the heat pump market to a significant extent.

The simulation model provides relevant calculation results and thereby forms the basis for further investigation of the heating system. As a fundamental and comprehensive concept for the control of such systems was not available, a control strategy was developed, so that a solution to the problem of the two storage tanks (the major task in the system control) has been achieved. The realisation of the system control has proved to be a challenging task, which was not solvable by known and common approaches from 
conventional heating systems. On the one hand, the system combines numerous components with various system operational modes. On the other hand, control decisions often cannot be based on the current system state but also have to be made considering the annual context. As particularly in the field of system control further development offers a considerable potential for the optimisation of the system, the control strategy should be extended by a more seasonal strategy to enhance the system performance and allow a further optimisation of the components' dimensioning.

Although the system investigation presented shows promising results, it is limited to a single system configuration and to the reference building defined. While the results are transferable to similar buildings with varying heat demand they allow only limited conclusions for conceptually different system configurations. Therefore, a broadening of the investigation with an analysis of further system configurations, for example using a groundcoupled uninsulated latent heat store, waste-air-utilisation or additional space cooling, requiring different control strategies and dimensioning is recommended.

The investigations into latent heat storage technology showed that on the one hand several conceptual approaches for latent heat storage heat exchangers as well as phase change materials have been investigated and some products have been developed in the past. On the other hand, adequate design solutions were not available. Furthermore, the development of a latent heat store suitable for the heating system proposed based on the water/ice transition has proved to be a challenging task due to the specialised requirements of the system and the numerous problems linked with phase change systems in general. Aiming at an optimised design solution via a systematic procedure, the requirements of the store were defined in detail and concepts and alternative engineering materials investigated. A sheet matrix heat exchanger concept was chosen for the proposed heating system because the specialised requirements of the system can be met by simple, hence potentially low-cost solution. This has been backed up by laboratory tests and the preliminary storage dimensioning:

- Uniform freezing and melting of the storage volume is possible at an acceptable level.

- Satisfactory heat exchange power for the requirements derived from system simulation can be provided in a preliminary design of the storage system.

- The comparatively large storage volume required for domestic applications can be realised with sheet matrix heat exchangers in transportable, modular tanks. 
With the heat exchanger and storage tank developed within this research project, promising solutions for the low-temperature latent heat store, one of the most important components in the proposed heating system, is now available. Based on the heat exchanger concept developed, a refinement should be carried out aiming at design solutions for higher numbers of production. Aluminium rollbonding plates with soldered fins are recommended, offering high freedom of design and favourable material properties. Apart from that, further prototypes of the storage tank with heat exchangers should be built up and investigated in detail. Next to further development of the polymer tank approach presented here, the concrete tank concept forms a promising solution especially when considering investigations of a low-temperature heating system with a ground-coupled uninsulated latent heat store.

In comparison to the research work available, this work has contributed a fundamental and comprehensive concept for the control of such systems, so that a solution to the problem of the two storage tanks is available. With regard to the latent heat store, a solution for the heat exchanger and tank design was achieved, while an appropriate solution was not available.

For both parts of the research work several further tasks and widespread optimisation potential are highlighted. Considering the prospects shown for the solar / heat pump heating system, further research work was defined and integrated in a succeeding project, so that this work forms the basis for further research, containing the following major topics:

- Design and construction of the proposed latent heat store and detailed experimental laboratory investigation of its thermodynamic characteristics, aimed at the derivation of a set of measurement data for simulation purposes.

- Development of a detailed simulation model for the latent heat store and validation with the measurement data derived in the laboratory tests.

- Planning, building up and detailed monitoring of a field test with the proposed heating system on a scientific level.

- Further development of the system simulation model and validation with measurement data derived from the monitored field test. 
- Simulation study of the heating system aiming at system optimisation and at the investigation of further applications regarding different building types, climates and system configurations.

This succeeding research project will be carried out with the collaboration of three scientific and two industrial partners, with the financial support of the German Ministry for Education and Research in a two-year research programme. 


\section{References}

[1] Duffie J.A., Beckman W.A.: Solar Engineering of Thermal Processes, $3^{\text {rd }}$ edition, John Wiley \& Sons, Inc., Hoboken (USA), 2006

[2] Rebhan, E. (ed.): Energiehandbuch - Gewinnung, Wandlung und Nutzung von Energie, Springer Verlag, Berlin (Germany), 2002

[3] Trinkl, C.; Zörner, W.; Hanby, V.: Solar Heating with Heat Pump - An Overview on Solar-Assisted Heat Pump Systems for Domestic Heating, 15. Symposium Thermische Solarenergie, Bad Staffelstein (Germany), 27.-29.04.2005 (in German)

[4] Trinkl, C.; Zörner, W.; Fellner, A.; Kruck, A.; Weidinger, A.: New Technology for Solar Heating: Concept and Application of a Fuel-Free, Solar-Based Heating System for Family Houses, European Solar Thermal Energy Conference 2003 (estec2003), Freiburg (Germany), 26.-27.06.2003

[5] N.N.: Verordnung über energiesparenden Wärmeschutz und energiesparende Anlagentechnik bei Gebäuden (Energieeinsparverordnung - EnEV), Bundesgesetzblatt 2004/Part 1/No. 64, pp. 3146-3162, 2004

[6] Schulze-Darup, B.: Gleicher Gebäudetyp - variierender Energiestandard. 16 Gebäude in Erlangen und Nürnberg zwischen 15 und $45 \mathrm{kWh} /\left(\mathrm{m}^{2} \mathrm{a}\right), 11$. Symposium Thermische Solarenergie, Bad Staffelstein (Germany), pp. 504-508, 2001

[7] N.N.: DIN V 4701-10:2001-02: Energy Efficiency of Heating and Ventilation Systems in Buildings - Part 10: Heating, Domestic Hot Water Supply, Ventilation, Deutsches Institut für Normung e.V. (ed.), Beuth Verlag GmbH, Berlin (Germany), 2001 (in German)

[8] Schwickert, S.: Energetische Sanierung des Baubestandes. Möglichkeiten der Umsetzung, dargestellt an Wohngebäuden der Gemeinde Riedstadt/Leeheim, Dissertation, University of Darmstadt (Germany), 2001

[9] N.N.: Energie sparen, Heizkosten senken, $\mathrm{CO}_{2}$-Ausstoß mindern. Ratgeber zur energetischen Gebäudemodernisierung, Hessian Ministry of Economics, Transportation, Urban and Regional Development (ed.), Wiesbaden (Germany), 2001

[10] Hoffmann, L., Beck, A., Ziegler, F.: Energetische Gebäudesanierung. Teil 1, Wärmetechnik-Versorgungstechnik 10, pp. 40-46, 1998

[11] Trinkl, C.; Zörner, W.; Hanby, V.: A Review on Solar-Assisted Heat Pump Systems for Domestic Heating, $5^{\text {th }}$ ISES Europe Solar Conference (EuroSun2004), Freiburg (Germany), 20.-23.06.2004

[12] Dietrich, B.; Jacobs, U.: Stand und Trend der Entwicklung von EnergieabsorberSystemen, Elektrowärme im Technischen Ausbau 42 A4, pp. A114-A128, 1983

[13] Kaufmann, K.-D.: Energiedächer, Energiefassaden, Energiezäune, Energiestapel und andere Energieabsorber, Idea Verlag GmbH, Puchheim (Germany), 1981 
[14] Paulisch, A.; Reichel, B.: Heizen mit Umgebungsenergie. Sonnenkollektor, Energiedach und -fassade, Wärmepumpe, Deutscher Consulting Verlag, Essen (Germany), 1980

[15] Shinobu, Y.; Matsuki, K.: Recent Technical Trends in Direct Expansion Heat Pump Systems, $3^{\text {rd }}$ Int. Energy Agency Heat Pump Conference, pp. 487-496, Tokyo, 1990

[16] N.N.: QUICK STEP - SolarThermie. Produkteigenschaften, Wärmenutzung, Technical Documentation of Rheinzink GmbH\&Co.KG, Datteln (Germany), 2003

[17] Ito, S.; Miura, N.; Wang, K.: Performance of a Heat Pump using Direct Expansion Solar Collectors, Solar Energy 65 (3), pp. 189-196, 1999

[18] Ito, S.; Miura, N.; Wang, J.I.; Nishikawa, M.: Heat Pump using Solar Collectors with Photovoltaic Modules on its Surfaces, ASME Joint Solar Engineering Conference 1994, pp. 53-57

[19] Broschk, J.; Speidel, K.: Solar House Essen, Final Report of Research Project BMFT-FB-T-81-120, German Ministry of Research and Technology, EggensteinLeopoldshafen (Germany), 1981 (in German)

[20] Bruno, R.; Brombach, U.; Hermann, W.; Klinkenberg, K.; Knabben, H.: Wärmepumpe zur Sonnenenergienutzung, in: VDI-Report 289: Wärmepumpen in Betrieb. Heute und in Zukunft, pp. 197-202, VDI-Verlag GmbH, Düsseldorf (Germany), 1977

[21] Ziegenbein, B.; Liemert, K.: The BBC-Solar House - Design of a solar heating installation for a one family house, Ki Klima + Kälte-Ingenieur 4 (3), pp. 175-178, 1976 (in German)

[22] Ziegenbein, B.: Experimental and Computer Simulation Results from a Heat Pump assisted Solar Heating System with Latent Heat Storage, IEA-Workshop on Latent Heat Stores - Technology and Application, International Energy Agency (IEA), Stuttgart (Germany), 1984

[23] Kaygusuz, K.: Calculation of Required Collector Area of a Solar-Assisted Series Heat Pump for Domestic Heating, Energy Sources 22, pp. 247-256, 2000

[24] Kaygusuz, K.; Comakli, O.; Ayhan, T.; Arslan, F.: Experimental Investigation and a Dynamic Simulation of the Solar-Assisted Energy-Storaged Heat Pump System, Solar Energy 51 (2), pp. 147-158, 1993

[25] van der Ree, H.: Heat Pumps with Thermal Storage, in: Beghi, G. (ed.): Thermal Energy Storage. Lectures of a Course held at the Joint Research Centre, Ispra (Italy), June 1-5 1981, pp. 387-414, D. Reidel Publishing Company, Dordrecht (Holland), 1982

[26] Fischer, H.C.: The Annual Cycle Energy System, $10^{\text {th }}$ Intersociety Energy Conversion Engineering Conference, Newark/Delaware (USA), pp. 251-259, 1975

[27] Holman, A.S.; Brantley, V.R.: ACES Demonstration: Construction, Startup and Performance Report, ORNL/CON-26, Oak Ridge National Laboratory, 1978

[28] Weik, H.: Das Solarhaus-Experiment der Fachhochschule Lübeck, Publication of Lübeck University of Applied Sciences, Lübeck (Germany), 1988 
[29] Kreußler, S.: Doppelspeichersolarsystem mit Wärmepumpe, http://193.175.120.23/an/pt/solar/slangz/index.html, Lübeck University of Applied Sciences, 04.06.2003

[30] Plagge, J.: Das Solarhaus der Fachhochschule Lübeck. Erfahrungen aus der ersten Heizperiode, Sonnenenergie 8 (5), pp.21-25, 1983

[31] Hesse, W.: Heizen mit der Sonne, http://home.t-online.de/home/winfried.hesse, 04.06.2003

[32] Hesse, W.: Personal Communication, 02.08.2003

[33] Hüneburg, B.: Personal Communication, HitSolar21, 28.06.2003

[34] Hinrichs, K.-H., http://www.hitsolar21.com/, 27.01.2004

[35] Schaap, A.B.; Warmerdam, J.M.; Gramsbergen, E.E.: Solar Heating with Heat Pump and Ice Storage, ISES Solar World Congress 1999, Jerusalem (IL)

[36] Gordon, J. (ed.): Solar Energy. The State of the Art, ISES Position Papers, James\&James Ltd., London (UK), 2001

[37] Tiwari, G.N.: Solar Energy, Alpha Science International Ltd., Pangbourne (UK), 2002

[38] Kaygusuz, K.: Performance of Solar-Assisted Heat Pump Systems, Applied Energy 51, pp. 93-109, 1995

[39] Kaygusuz, K.; Comakli, Ö.; Ayhan, T: Solar-assisted Heat Pump Systems and Energy Storage, Solar Energy 47 (5), pp. 383-391, 1991

[40] Freeman, T.L.; Mitchell, J.W.; Audit, T.E.: Performance of Combined Solar-Heat Pump Systems, Solar Energy 22, pp. 125-135, 1979

[41] O'Dell, M.P.; Mitchell, J.W.; Beckman, W.A.: Design Method and Performance of Heat Pumps With Refrigerant Filled Solar Collectors, Journal of Solar Energy Engineering 106, pp. 159-164, 1984

[42] Posorski, R.: Thermisches Verhalten von Energieabsorbern als Wärmequellenanlage in Wärmepumpen-Heizungsanlagen, Research Report Jül-1864, Kernforschungsanlage Jülich GmbH, Institut für Kernphysik, Jülich (Germany), 1983

[43] Peuser, F.A.; Remmers, K.-H.; Schnauss, M.: Solar Thermal Systems. Successful Planning and Construction, Solarpraxis Supernova AG, Berlin (Germany) / James\&James Ltd., London (UK), 2002

[44] Trinkl, C.; Zörner, W.; Hanby, V.: Solar-Assisted Domestic Heating with Heat Pump and Latent Heat Storage, $2^{\text {nd }}$ European Solar Thermal Energy Conference 2005 (estec2005), Freiburg (Germany), 21.-22.06.2005

[45] Trinkl, C.; Zörner, W.; Hanby, V.: Solares Heizen mit Wärmepumpe und Latentwärmespeicher, 3. Forum Wärmepumpe, Berlin (Germany), 13.-14.10.2005

[46] Kreußler, S.: Personal Communication, Head of Solar Laboratory, Lübeck University of Applied Sciences, 27.06.2003 
[47] N.N.: Matlab/Simulink user manuals, The Mathworks Inc., http://www.mathworks.com, Natick (USA), 2002

[48] Hafner, B.; Plettner, J.; Wemhöner, C.: CARNOT Blockset: Conventional And Renewable eNergy systems OpTimization Blockset - User's Guide, Solar-Institut Jülich, Aachen University of Applied Sciences (Germany), 1999

[49] Isakson, P.: Matched Flow Solar Collector Model for TRNSYS, TRNSYS Users and Programmers Manual, November 1991

[50] Hafner, B.; Schwarzer, K.; Plettner-Marliani, J.; Wemhöner, C.; Faber, C.; Wenzel, T.: Entwicklung einer Heizungs-/Solarthermie "Toolbox" für die Simulationsumgebung MATLAB/SIMULINK, Final Report of Research Project BMBF 1700698, Solar-Institut Jülich, Aachen University of Applied Sciences (Germany), 2000

[51] Bachmann, S.; Drück, H.: Prüfbericht Speicher zur Trinkwassererwärmung und Raumheizung incl. externe Wärmeübertrager, Test Report 03ST091 for Storage Ratiotherm Oskar 1000/1.5, University of Stuttgart (Germany), 2003

[52] Feist, W.: Thermische Gebäudesimulation - Kritische Prüfung unterschiedlicher Modellansätze, Verlag C.F. Müller, Heidelberg (Germany), 1994

[53] Balters, E.; Lehmann, H.; Schaub, A.: SOPASIM - Test weit verbreiteter SolarPassiv-Simulationssysteme für Architekten, Final Report, Arbeitsgemeinschaft Solar Nordrhein-Westfalen, UHL Data, Herzogstr. 27, Aachen (Germany), 1995

[54] Meteonorm 4.0: Global Meteorological Database for Engineers, Planers and Education, Meteotest, Bern (Switzerland)

[55] Schwamberger, K.: Modellbildung und Regelung von Gebäudeheizungsanlagen mit Wärmepumpen, VDI-Report 263, VDI-Verlag GmbH, Düsseldorf (Germany), 1991

[56] N.N.: DIN 8900: Heat Pumps; Heat Pump Units with Electric Driven Compressors, Deutsches Institut für Normung e.V. (ed.), Beuth Verlag GmbH, Berlin (Germany), 1980 (in German)

[57] N.N.: Wärmepumpen-Systeme: Planung und Installation, Technical Documentation of Stiebel Eltron GmbH\&Co. KG, Holzminden, November 2002

[58] Dincer, I.; Rosen, M.A.: Thermal Energy Storage, John Wiley \& Sons, Chichester (UK), 2002

[59] Zalba, B.; Marin, J.M.; Cabeza, L.F.; Mehling, H.: Review on Thermal Energy Storage with Phase Change: Materials, Heat Transfer Analysis and Applications, Applied Thermal Engineering 23, pp.251-283, 2003

[60] Trinkl, C.; Zörner, W.; Hanby, V.: A Domestic Solar/Heat Pump Heating System: System Investigation and Latent Heat Store Development, 17. Symposium Thermische Solarenergie, Bad Staffelstein (Germany), 09.-11.05.2007 (in German), to be published

[61] Köln, H.: Test Report 39-04/D for Collector Conergy F6000, Institut für Solarenergieforschung $\mathrm{GmbH}$, Hameln/Emmerthal (Germany),2004 
[62] N.N.: Test Report 2.04.00274.1.0-1 for Collector Conergy F4000, arsenal research, Vienna (Austria), 2004

[63] Rommel, M.; Schäfer, A.: Prüfung eines Sonnenkollektors nach EN 12975-1,2, Test Report KTB Nr. 3003-17-a for Collector Thermosolar 300N, Fraunhofer Institut für Solare Energiesysteme ISE, Freiburg (Germany), 2003

[64] Abhat, A.: Low Temperature Latent Heat Thermal Energy Storage Materials, Solar Energy 30 (4), pp. 313-332, 1983

[65] Kakiuchi, H.; Yamazaki, M.; Yabe, M; Chihara, S.; Terunuma, Y.; Sakata, Y.; Usami, T.: A Study of Erythritol as Phase Change Material, $2^{\text {nd }}$ Workshop of IEA Annex 10, Final Proceedings, International Energy Agency (IEA), Sofia (Bulgaria), 11-13.11.1998

[66] Rubitherm GmbH, Hamburg (Germany): www.rubitherm.com, 12.09.2003

[67] Lane, G.A.: Low Temperature Heat Storage With Phase Change Materials, The International Journal of Ambient Energy 1 (3), pp. 155-168, 1980

[68] Fieback, K.; Gutberlet, H.: The Use of Paraffin Waxes in Thermal Energy Storage Applications, $1^{\text {st }}$ Workshop of IEA Annex 10, Final Proceedings, International Energy Agency (IEA), Adana (Turkey), 16-17.04.1998

[69] Lane, G.A. (ed.): Solar Heat Storage: Latent Heat Materials. Volume I: Background and Scientific Principles, CRC Press Inc., Boca Raton (USA), 1983

[70] Lane, G.A. (ed.): Solar Heat Storage: Latent Heat Materials. Volume II: Technology, CRC Press Inc., Boca Raton (USA), 1986

[71] Yarham, R. (ed.): Ice Storage. A Guide to the Use and Application of Ice for Cool Thermal Storage, Yale Press Ltd., London (UK), 1994

[72] de Jong, A.G.; Hoogendoorn, C.J.: Improvement of Heat Transport in Paraffines for Latent Heat Storage Systems, in: den Ouden, C.: Thermal Storage of Solar Energy, pp. 123-133, TNO and Martinus Nijhoff Publishers, The Hague, 1981

[73] Abhat, A.: Low Temperature Latent Heat Thermal Energy Storage, in: Beghi, G. (ed.): Thermal Energy Storage. Lectures of a Course held at the Joint Research Centre, Ispra (Italy), June 1-5 1981, pp. 33-91, D. Reidel Publishing Company, Dordrecht (Holland), 1982

[74] Bostel, R.: Experimentelle und rechnergestützte Untersuchung eines bivalenten Wärmepumpensystems mit Latentwärmespeicher, Dissertation, University of Stuttgart (Germany), 1989

[75] Schneider, A.: Latent Heat Storage, European Patent EP 1098157 B1, 2003

[76] Meyer, J.-P.: Es muss nicht immer Wasser sein, Sonne Wind\&Wärme 12, pp. 2729, 2002

[77] Bednarek, H.; Freymann, R: Anforderungen, Konzeption und Entwicklung eines Latentwärmespeichers für den Kraftfahrzeugeinsatz, in: VDI-Report 1168: Energie- 
speicher für Strom, Wärme und Kälte, pp. 419-435, VDI-Verlag GmbH, Düsseldorf (Germany), 1994

[78] Blüher, P.: Heat Accumulator Increases the Comfort in the Passenger-Compartment and the Driving-Safety, ATZ Automobiltechnische Zeitschrift 93 (10), pp. 620-625, 1991 (in German)

[79] Hörz, S.; Hughes, G.G.: Heat Accumulator, especially a PCM Device, World Patent WO 99/53258, Modine Manufacturing Co., Racine (USA), 1999

[80] Hoogendoorn, C.J.; Bart, G.C.J.: Performance and Modelling of Latent Heat Stores, Solar Energy 48 (1), pp. 53-58, 1992

[81] Fukai, J.; Kanou, M.; Kodama, Y.; Miyatake, O.: Thermal Conductivity Enhancement of Energy Storage Media using Carbon Fibers, Energy Conversion and Management 41, pp. 1543-1556, 2000

[82] Fukai, J.; Hamada, Y.; Morozumi, Y; Miyatake, O.: Effect of Carbon-Fiber Brushes on Conductive Heat Transfer in Phase Change Materials, International Journal of Heat and Mass Transfer 45, pp. 4781-4792, 2002

[83] Hafner, B.; Schwarzer, K.: Improvement of the Heat Transfer in a Phase-ChangeMaterial Storage, $4^{\text {th }}$ Workshop of IEA Annex 10, International Energy Agency (IEA), Benediktbeuern (Germany), 28-29.10.1999

[84] Cabeza, L.F.; Mehling, H.; Hiebler, S.; Ziegler, F.: Heat Transfer Enhancement in Water when used as PCM in Thermal Energy Storage, Applied Thermal Engineering 22, pp. 1141-1151, 2002

[85] Gramlich, K.; Safarik, M.; Schammler, G.: Latentwärmespeicherung in einer solarthermisch angetriebenen Absorptionskältemaschine, Final Report of Research Project BMBF-1706899 (German Ministry of Education and Research), Fachhochschule Anhalt (Germany), 2001

[86] Mehling, H.; Hiebler, S.; Ziegler, F.: Latent Heat Storage using a PCM-graphite Composite Material: Advantages and Potential Applications, $4^{\text {th }}$ Workshop of IEA Annex 10, International Energy Agency (IEA), Benediktbeuern (Germany), 2829.10.1999

[87] Mehling, H.; Hiebler, S.; Ziegler, F.: Latent Heat Storage using a PCM-graphite Composite Material, Terrastock 2000: $8^{\text {th }}$ International Conference on Thermal Energy Storage, Stuttgart (Germany), pp. 375-380, 28.08.-01.09.2000

[88] N.N.: DB/1.20 Latentspeichersysteme. Technischer Beschrieb, Technical Documentation of BMS-Energieanlagen AG, Wilderswil (Switzerland), 2000

[89] TEAP Energy, Wangara (Australia): http://www.teappcm.com/encapsulation.html, 08.09.2003

[90] Eames, I.W.; Adref, K.T.: Freezing and Melting of Water in Spherical Enclosures of the type used in Thermal (Ice) Storage Systems, Applied Thermal Engineering 22, pp. 733-745, 2002 
[91] Comly, J.B.; Golibersuch, D.C.; Herrick, C.S.; Vakil, H.B.; Vosburgh, K.G.: Ergebnisse von Forschungs- und Entwicklungsarbeiten auf dem Gebiete der thermischen Energiespeicherung bei General Electric, in: VDI-Report 288: Rationelle Energienutzung durch Wärmespeicher, pp. 73-78, VDI-Verlag GmbH, Düsseldorf (Germany), 1977

[92] Lindner, F.; Scheunemann, K.: The Development of a Dynamic Working LatentHeat Storage with Glauber's Salt up to Production Stage, Research Report DFVLR - FB 81-32, German Aerospace Center (ed.), Stuttgart, 1981 (in German)

[93] Lindner, F.: Heat Storage using Salts and Salt Hydrates, Ki Luft- und Kältetechnik 32 (10), pp. 462-467, 1996 (in German)

[94] Lindner, F.; Tattermusch, P.: Heat Storage of Latent Heat Type, European Patent EP 0789215 B1, 2003

[95] Steiner, D.; Erdelitsch, G.: Labortest 'Galisol-Speicher', in: Thermische Energiespeicherung. Statusbericht 1989, BMFT-Workshop 1989, pp. 211-226, German Ministry of Research and Technology, Stuttgart (Germany)

[96] Oswald, J.; Meyer, F.: Latentwärmespeicher. Entwicklung neuartiger Verfahren, BINE Project-Information 6/96, Fachinformationszentrum Karlsruhe, Ges. f. wissenschaftlich-technische Informationen $\mathrm{mbH}$ (ed.), Eggenstein-Leopoldshafen (Germany), 1996

[97] Pahl, G.; Beitz, W.: Engineering Design. A Systematic Approach, $2^{\text {nd }}$ edition, Springer-Verlag, London (UK), 1996

[98] Lindner, F.: Personal Communication, German Aerospace Center Stuttgart (Germany), 28.10.2004

[99] Tong, X.; Khan, J.A.; Amin, M.R.: Enhancement of Heat Transfer by inserting a Metal Matrix into Phase Change Material, Numerical Heat Transfer, Part A 30, pp. 125-141, 1996

[100] Calimidi, V.V.; Mahajan, R.L.: The Effective Thermal Conductivity of High Porosity Fibrous Metal Foams, Transactions of the ASME, Journal of Heat Transfer 121 (2), pp. 466-471, 1999

[101] Pinnau, S.: Untersuchungen an Modellen für Metallschaum-Latentspeicher, Diploma Thesis, University of Applied Sciences Mittweida (Germany), 2004

[102] Wagner, I.; Hintz, C.; Sahm, P.R.: Precision Cast Near Net Shape Components Based on Cellular Metal Materials, in: Clyne, T.W.; Simancik, F. (ed.): Metal Matrix Composites and Metallic Foams, EUROMAT 99 - Volume 5, Wiley-VCH Verlag GmbH, Weinheim (Germany), pp. 40-45, 2000

[103] Angel, S.; Bleck, W.; Scholz, P.-F.; Fend, T.: Influence of Powder Morphology and Chemical Composition on Metallic Foams produced by SlipReactionFoamSintering (SRFS)-Process, Steel Research International 75 (7), pp. 483-488, 2004

[104]Burin, P.: Personal Communication, CGA Compagnia Generalle Alluminio spA, Cividale del Friuli (Italy), 28.06.2006 
Appendix A:

Simulation Parameters 
Flat Plate Collector

\begin{tabular}{|c|c|c|c|}
\hline collector type & CONERGY F6000 [61] & CONERGY F4000 [62] & Thermosolar 300N [63] \\
\hline collector surface (aperture) $A_{\text {col }}\left[\mathrm{m}^{2}\right]$ & variable & variable & variable \\
\hline linear heat loss coefficient $U_{1}\left[\mathrm{~W} /\left(\mathrm{m}^{2} \mathrm{~K}\right)\right]$ & 3.430 & 3.125 & 4.843 \\
\hline quadratic heat loss coefficient $U_{2}\left[\mathrm{~W} /\left(\mathrm{m}^{*} \mathrm{~K}\right)^{2}\right]$ & 0.019 & 0.021 & 0.019 \\
\hline height between inlet and outlet [m] & 2 & 2 & 2 \\
\hline effective heat capacity $c_{c o l}\left[J /\left(m^{2} K\right)\right]$ & 23,800 & 23,800 & 23,800 \\
\hline collector optics & $\begin{array}{l}\text { single glazing, } \\
\text { extra white glass }\end{array}$ & $\begin{array}{l}\text { single glazing, } \\
\text { extra white glass }\end{array}$ & $\begin{array}{r}\text { single glazing, } \\
\text { extra white glass }\end{array}$ \\
\hline optical efficiency [-] & 0.841 & 0.806 & 0.796 \\
\hline glass thickness [mm] & 4 & 4 & 4 \\
\hline refraction index [-] & 1.526 & 1.526 & 1.526 \\
\hline extinction coefficient $[1 / \mathrm{m}]$ & 4 & 4 & 4 \\
\hline mass flow rate $m_{\text {dot }}[\mathrm{kg} / \mathrm{s}]$ & $A_{c o l}^{*} 40 / 3,600$ & $A_{c o l}^{*} 40 / 3,600$ & $A_{\text {col }}{ }^{*} 40 / 3,600$ \\
\hline hysteresis $\mathrm{dT}_{\text {on }}[\mathrm{K}]$ & 6 & 6 & 6 \\
\hline hysteresis $\mathrm{dT}_{\text {off }}[\mathrm{K}]$ & 2 & 2 & 2 \\
\hline heat transfer fluid & $60 \%$ water $/ 40 \%$ glycol & $60 \%$ water $/ 40 \%$ glycol & $60 \%$ water $/ 40 \%$ glycol \\
\hline system pressure [Pa] & 300,000 & 300,000 & 300,000 \\
\hline
\end{tabular}

Stratification Tank

\begin{tabular}{|c|c|}
\hline storage type & Ratiotherm OSKAR [51] \\
\hline volume $\mathrm{V}_{\text {strat }}[\mathrm{l}]$ & variable \\
\hline diameter $[\mathrm{m}]$ & variable \\
\hline position & standing cylinder \\
\hline heat loss coefficient wall $\left[\mathrm{W} /\left(\mathrm{m}^{2 \star} \mathrm{K}\right)\right]$ & 0.54 \\
\hline heat loss coefficient bottom $\left[\mathrm{W} /\left(\mathrm{m}^{2 *} \mathrm{~K}\right)\right]$ & 1.89 \\
\hline effective axial conductivity $\left[\mathrm{W} /\left(\mathrm{m}^{\star} \mathrm{K}\right)\right]$ & 0.90 \\
\hline ambient temperature $\left[{ }^{\circ} \mathrm{C}\right]$ & 20 \\
\hline numer of nodes & 4 \\
\hline heat exchanger for solar collectors & $\begin{array}{r}\text { stratified charging } \\
\text { smooth tube }\end{array}$ \\
\hline relative height of inlet & 1.0 \\
\hline relative height of outlet & 0.1 \\
\hline heat exchanger surface $\left[\mathrm{m}^{2}\right]$ & 7 \\
\hline conductivity of material $\left[\mathrm{W} /\left(\mathrm{m}^{*} \mathrm{~K}\right)\right]$ & 384 \\
\hline wall thickness [m] & 0.002 \\
\hline inner diameter [m] & 0.025 \\
\hline diameter of heat exchanger [m] & 0.5 \\
\hline $\begin{array}{l}\text { heat exchanger for energy transfer } \\
\text { from latent heat store } \\
\text { relative height of inlet }\end{array}$ & $\begin{array}{r}\text { stratified charging } \\
\text { smooth tube } \\
1.0\end{array}$ \\
\hline relative height of outlet & 0.0 \\
\hline heat exchanger surface $\left[\mathrm{m}^{2}\right]$ & 7 \\
\hline conductivity of material $\left[\mathrm{W} /\left(\mathrm{m}^{*} \mathrm{~K}\right)\right]$ & 384 \\
\hline wall thickness [m] & 0.002 \\
\hline inner diameter [m] & 0.025 \\
\hline diameter of heat exchanger [m] & 0.4 \\
\hline heat exchanger for heat pump $\left(45^{\circ} \mathrm{C}\right)$ & stratified charging \\
\hline $\begin{array}{l}\text { relative height of inlet } \\
\text { relative height of outlet }\end{array}$ & $\begin{array}{r}1.0 \\
0.66\end{array}$ \\
\hline heat exchanger for heat pump $\left(35^{\circ} \mathrm{C}\right)$ & stratified charging \\
\hline $\begin{array}{l}\text { relative height of inlet } \\
\text { relative height of outlet }\end{array}$ & $\begin{array}{l}0.5 \\
0.3\end{array}$ \\
\hline heat exchanger for floor heating & stratified charging \\
\hline $\begin{array}{l}\text { relative height of inlet } \\
\text { relative height of outlet }\end{array}$ & $\begin{array}{l}0.25 \\
0.55\end{array}$ \\
\hline heat exchanger for hot water & stratified charging \\
\hline $\begin{array}{l}\text { relative height of inlet } \\
\text { relative height of outlet }\end{array}$ & $\begin{array}{l}0.0 \\
1.0\end{array}$ \\
\hline
\end{tabular}


Hot Water Consumption

mass flow rate [kg/s]

$600 / 3,600$

time values

7.00am - 7.03am

12.00am - 12.03am

$7.00 \mathrm{pm}-7.06 \mathrm{pm}$

consumption [l/day]

Heating Load

floor size [m²]

wall height $[\mathrm{m}]$

windows $\left[\mathrm{m}^{2}\right]$

time constant for room node [s]

2.5

$1.5 * 2.5$ on southern and western side

heat transfer coefficient walls $\left[\mathrm{W} /\left(\mathrm{m}^{2 *} \mathrm{~K}\right)\right]$

100

0.34

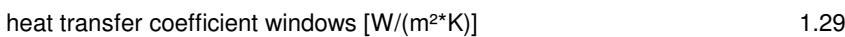

heat transfer coefficient ceiling $\left[\mathrm{W} /\left(\mathrm{m}^{2 *} \mathrm{~K}\right)\right] \quad 0.36$

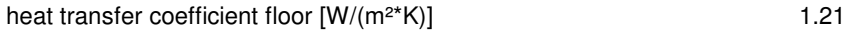

desired room temperature $\left[{ }^{\circ} \mathrm{C}\right] \quad 20$

flow temperature for floor heating $\left[{ }^{\circ} \mathrm{C}\right]$

mass flow rate floor heating $[\mathrm{kg} / \mathrm{s}] \quad 1,000 / 3,600$

specific annual heat demand $\left[\mathrm{kWh} /\left(\mathrm{m}^{2 *} \mathrm{a}\right)\right]$

Latent Heat Storage Tank

volume $V_{\text {lhst }}\left[\mathrm{m}^{3}\right]$

variable

diameter [m]

position

$\operatorname{sqrt}\left(\left(\mathrm{V}_{\text {lnst }} / 3\right) / \mathrm{pi}\right){ }^{*} 2$

standing cylinder

heat loss coefficient wall $\left[\mathrm{W} /\left(\mathrm{m}^{2 *} \mathrm{~K}\right)\right]$

heat loss coefficient bottom $\left[\mathrm{W} /\left(\mathrm{m}^{2 *} \mathrm{~K}\right)\right]$

0.8

effective axial conductivity $\left[\mathrm{W} /\left(\mathrm{m}^{*} \mathrm{~K}\right)\right]$

ambient temperature $\left[{ }^{\circ} \mathrm{C}\right]$

numer of nodes

heat exchanger for solar collectors

relative height of inlet

smooth tube

relative height of outlet

heat exchanger surface $\left[\mathrm{m}^{2}\right]$

conductivity of material $\left[\mathrm{W} /\left(\mathrm{m}^{*} \mathrm{~K}\right)\right]$

wall thickness $[\mathrm{m}] \quad 0.002$

inner diameter $[\mathrm{m}] \quad 0.035$

diameter of heat exchanger [m] $\quad 0.4$

heat exchanger for heat pump evaporator smooth tube

relative height of inlet $\quad 0.0$

relative height of outlet $\quad 1.0$

heat exchanger surface $\left[\mathrm{m}^{2}\right]$

conductivity of material $\left[\mathrm{W} /\left(\mathrm{m}^{*} \mathrm{~K}\right)\right]$

wall thickness [m] $\quad 0.002$

inner diameter $[\mathrm{m}] \quad 0.035$

diameter of heat exchanger $[\mathrm{m}] \quad 0.4$

\section{Heat Pump}

\begin{tabular}{lr}
\hline heat pump type & Stiebel Eltron WPF 5 [57] \\
coefficient primary inlet temp. $\mathrm{K}_{1}[\mathrm{~W} / \mathrm{K}]$ & 140.3 \\
coefficient secondary outlet temp. $\mathrm{K}_{2}[\mathrm{~W} / \mathrm{K}]$ & 23.5 \\
temperature independent heating power $\mathrm{K}_{3}[\mathrm{~W}]$ & $4,295.3$ \\
fluid mass hot loop [kg] & 1.5 \\
time constant hot loop [s] & 120 \\
mass flow rate cold loop [kg/s] & $500 / 3,600$ \\
fluid mass cold loop [kg] & 1.5 \\
time constant cold loop [s] & 120 \\
mass flow rate cold loop [kg/s] & $1,400 / 3,600$ \\
total electrical power (desired temp. $\left.35^{\circ} \mathrm{C}\right)[\mathrm{W}]$ & 1,250 \\
total electrical power (desired temp. $\left.50^{\circ} \mathrm{C}\right)[\mathrm{W}]$ & 2,000 \\
hysteresis $\mathrm{dT}_{\text {on }}[\mathrm{K}]$ & 3 \\
hysteresis $\mathrm{dT}_{\text {off }}[\mathrm{K}]$ & 0
\end{tabular}




\section{Efficiency Curve of Simulated Collectors}

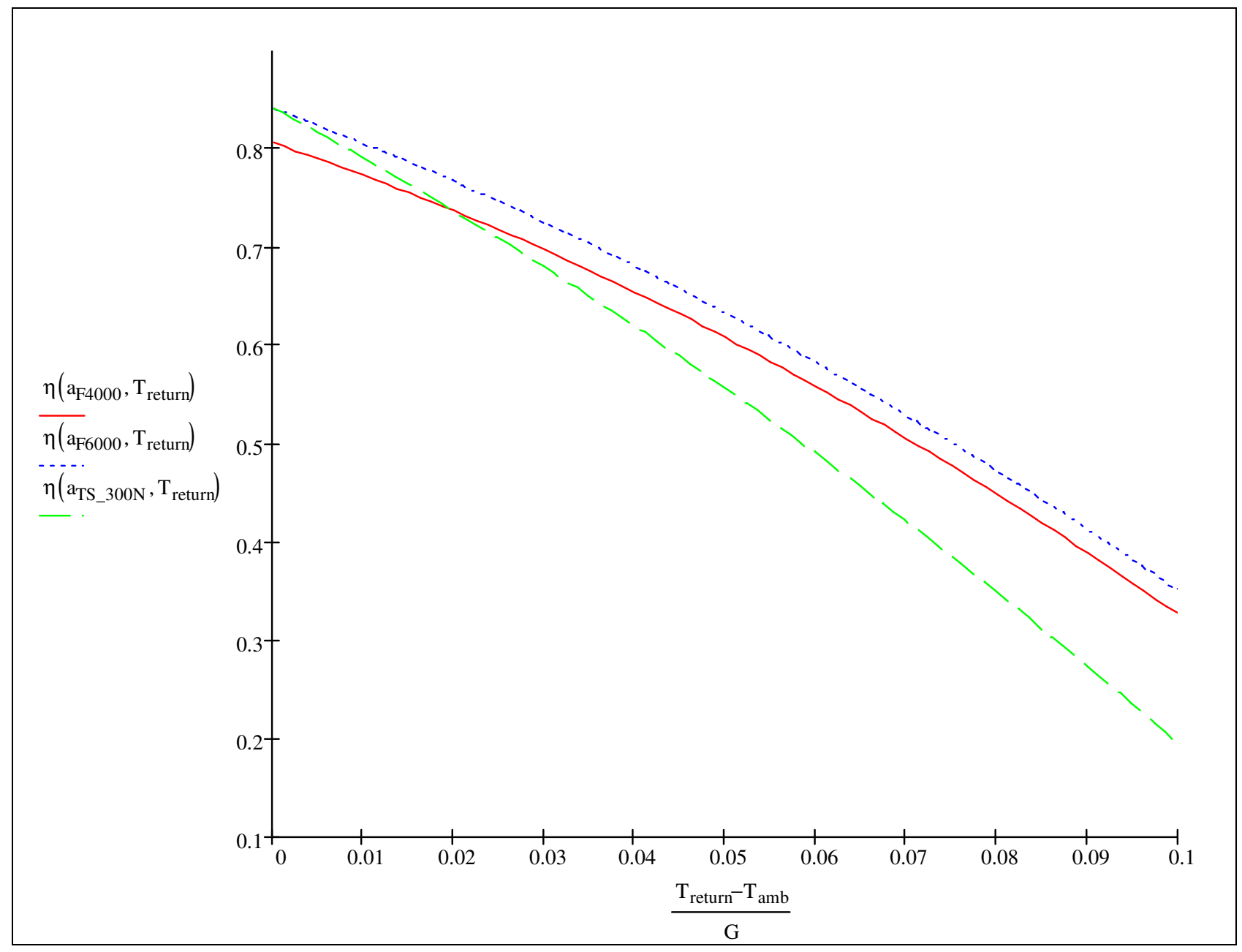


Appendix B:

Requirements List 


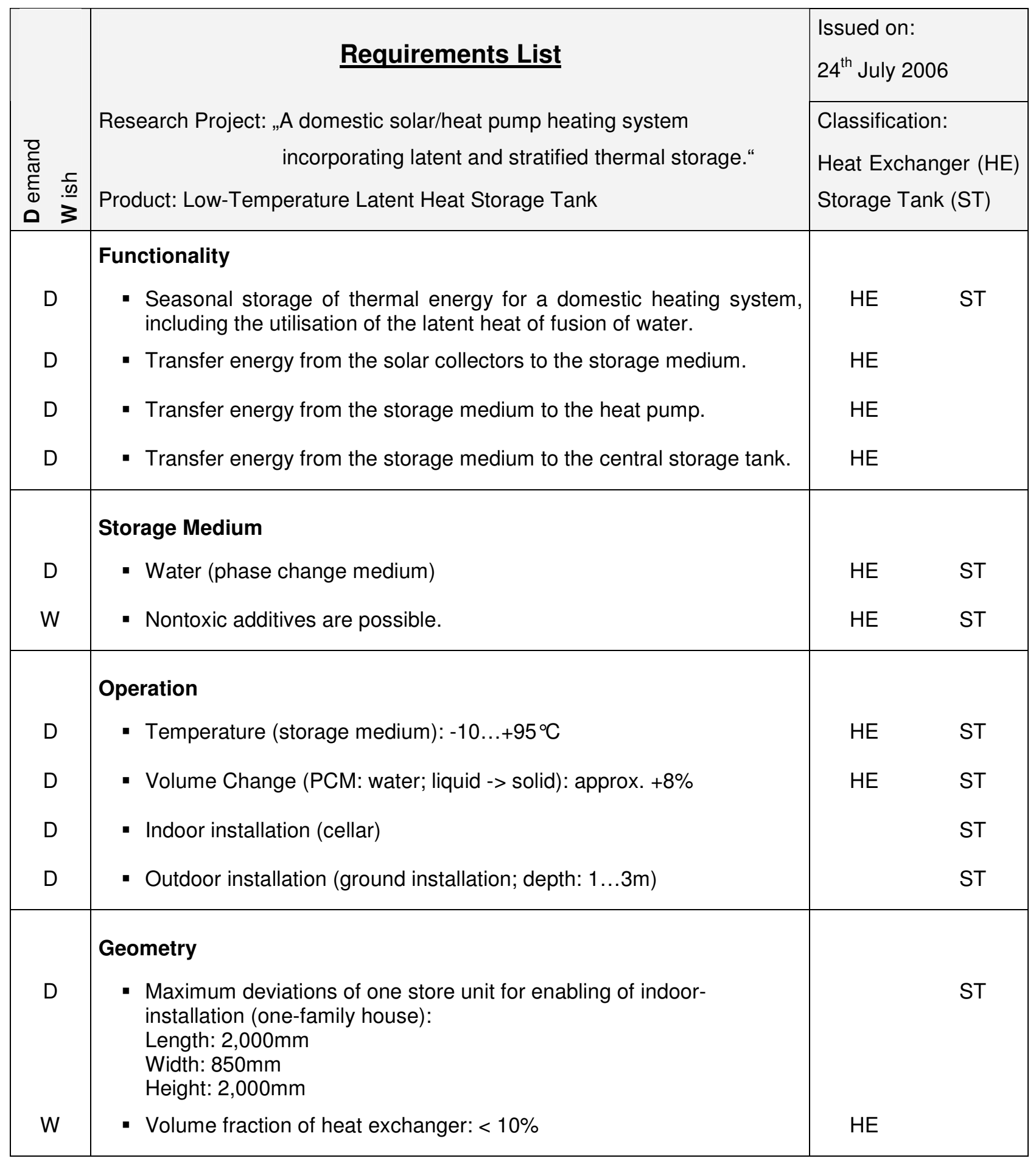




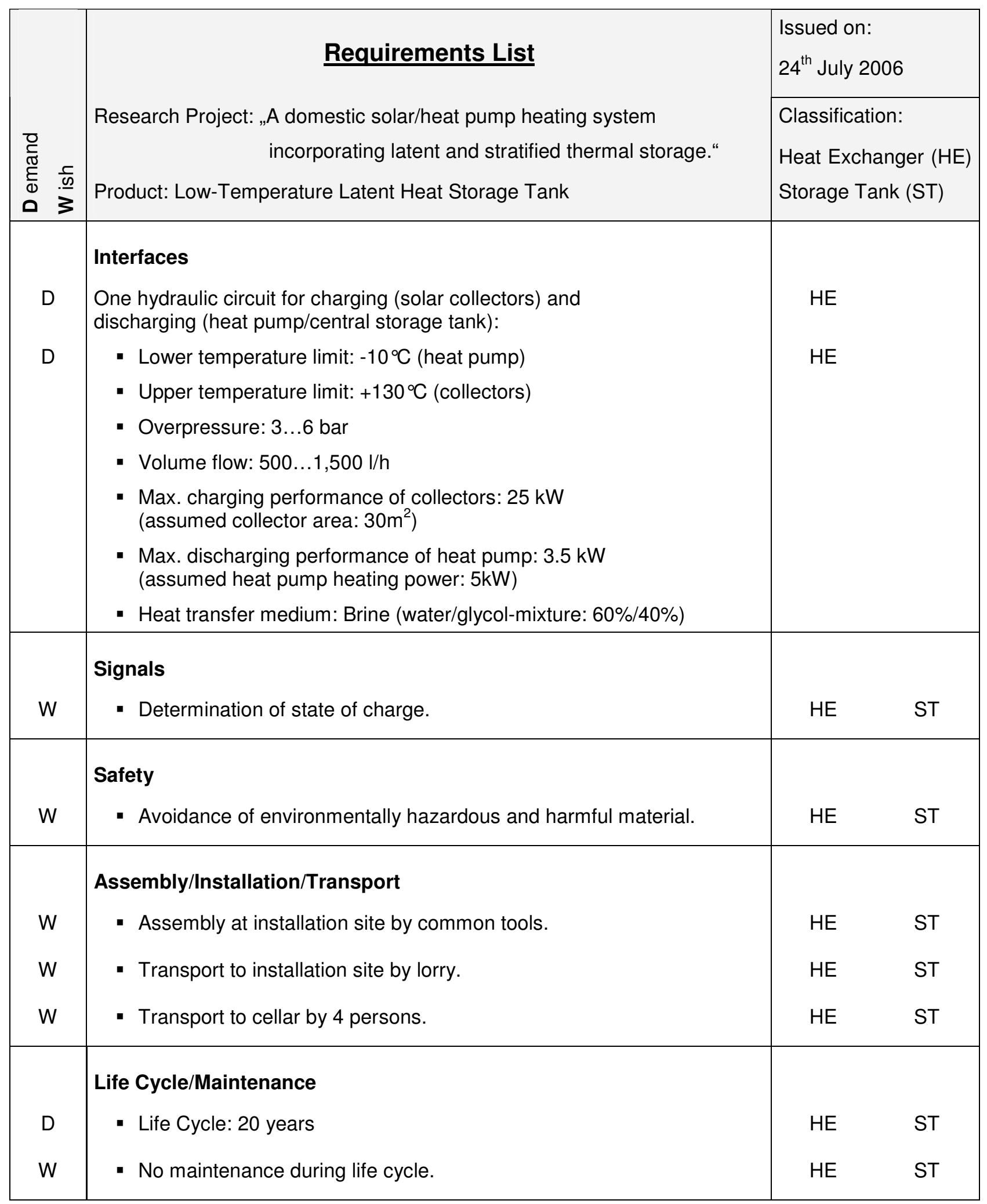


Appendix C:

Function Structure

(Main Functions) 


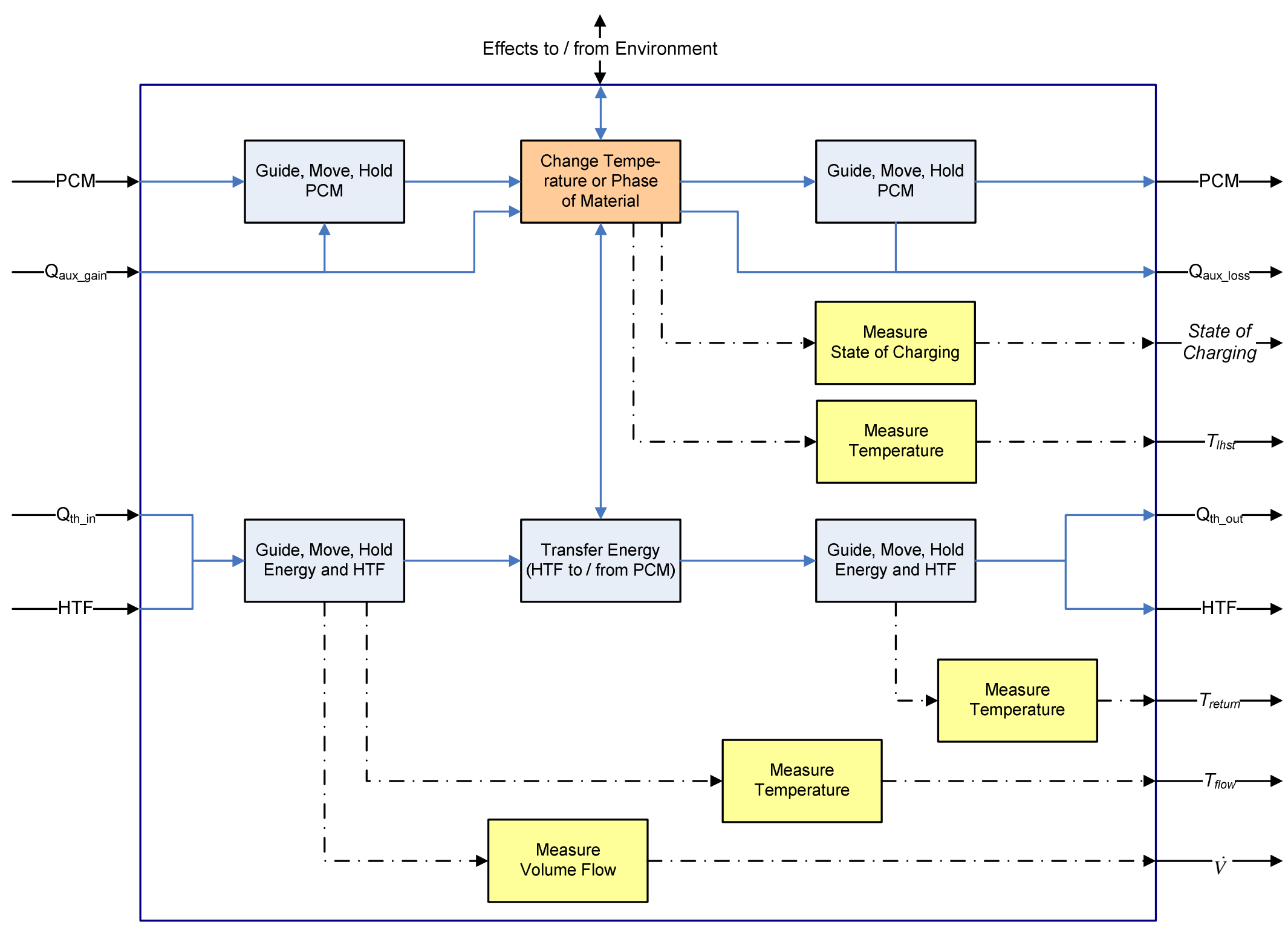


Appendix D:

Test Stand 


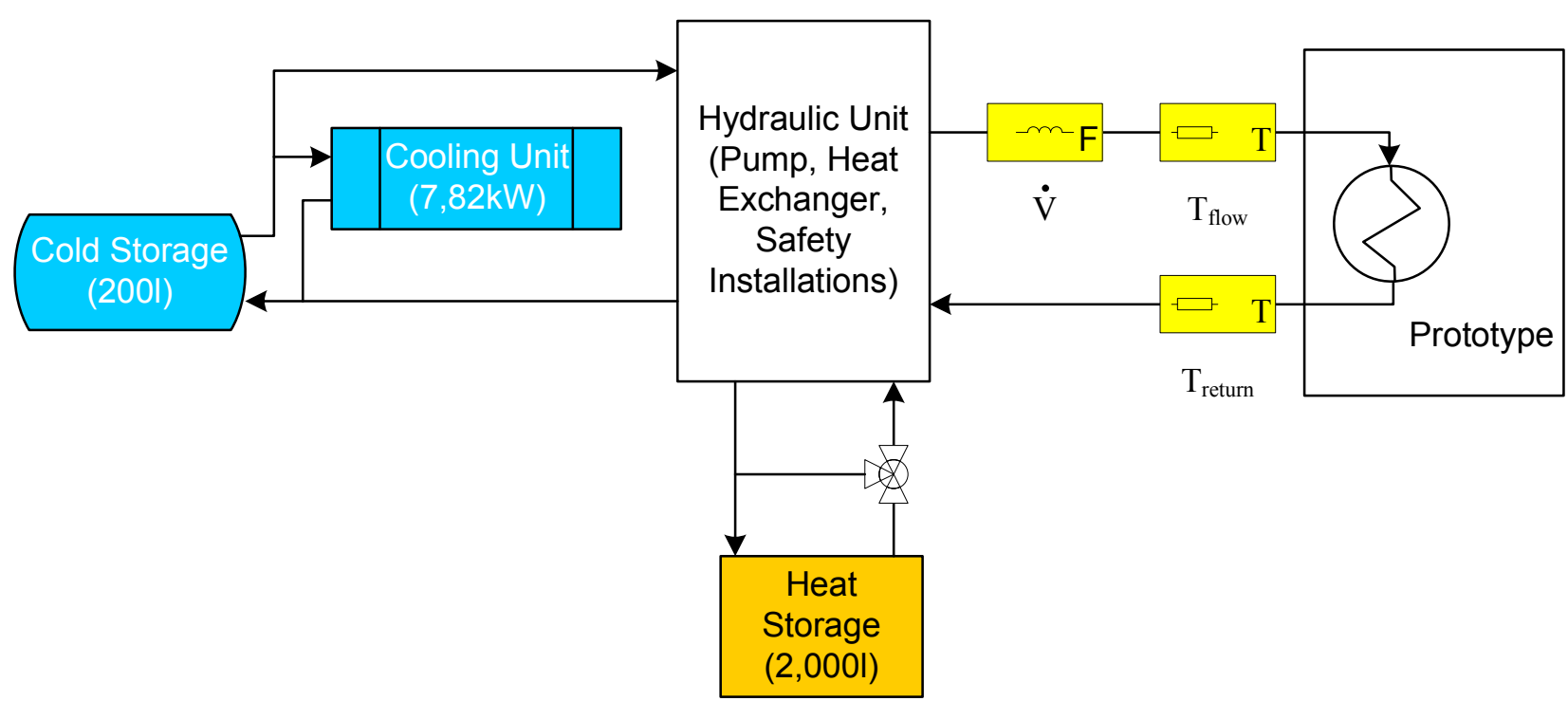

\section{Hydraulics (Prototype)}

\begin{tabular}{|c|c|c|}
\hline Volume Flow & \multicolumn{2}{|l|}{$150 \ldots 2001 / h$} \\
\hline $\begin{array}{l}\text { Flow Temperature Range } \\
\text { (Freezing) }\end{array}$ & \multicolumn{2}{|l|}{$-6 \ldots-7^{\circ} \mathrm{C}$} \\
\hline $\begin{array}{l}\text { Flow Temperature Range } \\
\text { (Melting) }\end{array}$ & \multicolumn{2}{|l|}{$+8 \ldots+20^{\circ} \mathrm{C}$} \\
\hline Measurement & \multicolumn{2}{|r|}{ Range and Accuracy } \\
\hline Volume Flow $(\dot{V})$ & Electromagnetic Flowmeter & $\begin{array}{l}100 \ldots 2,000 \mathrm{l} / \mathrm{h} \\
\pm 0.5 \%\end{array}$ \\
\hline $\begin{array}{l}\text { Temperature Difference } \\
\left(T_{\text {flow }}, T_{\text {return }}\right)\end{array}$ & $\begin{array}{l}\text { PT100 Resistance Thermometers, } \\
\text { calibrated by pairs }\end{array}$ & $\begin{array}{l}-10 \ldots 100^{\circ} \mathrm{C} \\
\pm 0.02 \mathrm{~K}\left(\text { at } 0^{\circ} \mathrm{C}\right)\end{array}$ \\
\hline $\begin{array}{l}\text { Temperature } \\
\text { (Prototype, Water Bath,...) }\end{array}$ & $\begin{array}{l}\text { PT100 Resistance Thermometers, } \\
\text { calibrated }\end{array}$ & $\begin{array}{l}-10 \ldots 100^{\circ} \mathrm{C} \\
\pm 0.1 \mathrm{~K}\left(\text { at } 0^{\circ} \mathrm{C}\right)\end{array}$ \\
\hline $\begin{array}{l}\text { Accuracy of } \dot{Q} \text {-Calculation } \\
\text { assuming temperature differ } \\
\text { accuracy of density determin } \\
\text { accuracy of heat capacity de }\end{array}$ & $\begin{array}{l}3 \% \\
2 \mathrm{~K} \\
1 \% \\
\text { ination: } 1 \%\end{array}$ & \\
\hline
\end{tabular}



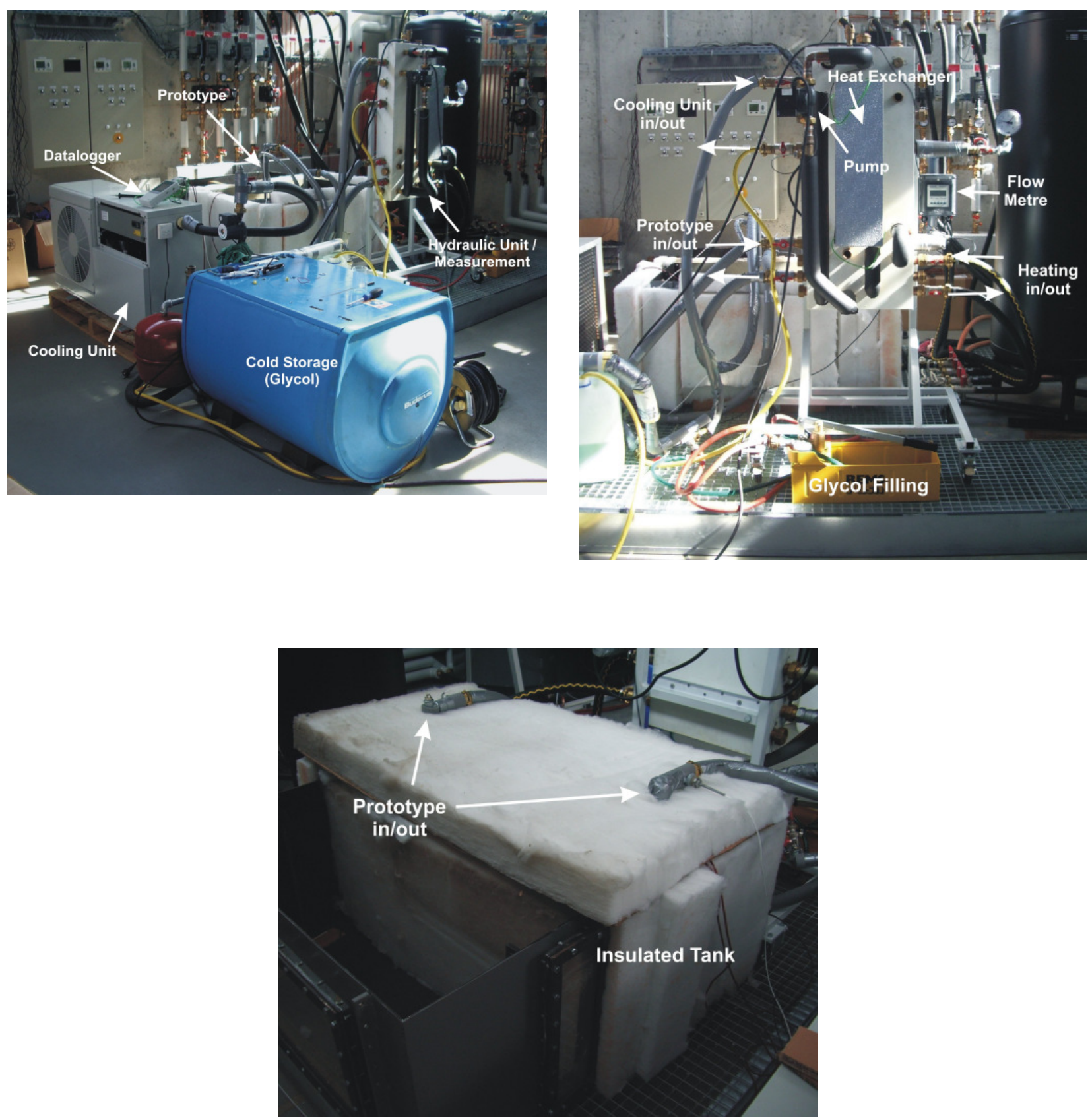
Appendix E:

Publications 
Trinkl, C.; Zörner, W.; Fellner, A.; Kruck, A.; Weidinger, A.

New Technology for Solar Heating: Concept and Application of a Fuel-Free, Solar-Based Heating System for Family Houses

European Solar Thermal Energy Conference 2003 (estec2003), Freiburg (Germany), 26.-27.06.2003

Trinkl, C.; Zörner, W.; Hanby, V.

A Review on Solar-Assisted Heat Pump Systems for Domestic Heating

$5^{\text {th }}$ ISES Europe Solar Conference (EuroSun2004), Freiburg (Germany), 20.-23.06.2004

Trinkl, C.; Zörner, W.; Hanby, V.

Solar Heating with Heat Pump - An Overview on Solar-Assisted Heat Pump Systems for Domestic Heating

15. Symposium Thermische Solarenergie, Bad Staffelstein (Germany), 27.-29.04.2005 (in German)

Trinkl, C.; Zörner, W.; Hanby, V.

Solar-Assisted Domestic Heating with Heat Pump and Latent Heat Storage $2^{\text {nd }}$ European Solar Thermal Energy Conference 2005 (estec2005), Freiburg (Germany), 21.-22.06.2005

Trinkl, C.; Zörner, W.; Hanby, V.

Solares Heizen mit Wärmepumpe und Latentwärmespeicher

3. Forum Wärmepumpe, Berlin (Germany), 13.-14.10.2005 (in German)

Trinkl, C.; Zörner, W.; Hanby, V.

A Domestic Solar/Heat Pump Heating System: System Investigation and Latent Heat Store Development

17. Symposium Thermische Solarenergie, Bad Staffelstein (Germany), 09.-11.05.2007 (in German) 